\title{
AVALIAÇÃO DA LOCALIZAÇÃO DE PACKING- HOUSES NO ESTADO DE SÃO PAULO: O CASO DA LARANJA DE MESA
}

\section{SIMONE YURI RAMOS}

Engenheiro Agrônomo

Orientador: Prof. Dr. JOSÉ VICENTE CAIXETA FILHO

\begin{abstract}
Dissertação apresentada à Escola Superior de Agricultura "Luiz de Queiroz", Universidade de São Paulo, para a obtenção do título de Mestre em Ciências, Área de Concentração: Economia Aplicada.
\end{abstract}

PIRACICABA

Estado de São Paulo - Brasil

Outubro-2001 


\title{
Dados Internacionais de Catalogação na Publicação (CIP) DIVISÃO DE BIBLIOTECA E DOCUMENTAÇÃO - ESALQ/USP
}

\author{
Ramos, Simone Yuri \\ Avaliação da localização de Packing-houses no Estado de São Paulo : o caso da \\ laranja de mesa / Simone Yuri Ramos. - - Piracicaba, 2001. \\ 132 p. : il. \\ Dissertação (mestrado) - - Escola Superior de Agricultura Luiz de Queiroz, 2001. \\ Bibliografia. \\ 1. Beneficiamento 2. Laranja 3. Modelo matemático 4. Produção agrícola 5. \\ Programação linear 6. Sistema agroindustrial I. Título
}

CDD 338.17431 
"O sonho é ver as formas invisiveis Da distância imprecisa, e, com sensiveis Movimentos da esp'rança e da vontade, Buscar na linha fria do horizonte A árvore, a praia, a flor, a ave, a fonte Os beijos merecidos da Verdade". (Fernando Pessoa)

“O esforço é grande e o homem é pequeno.

A alma é divina e a obra é imperfeita.

Que, da obra ousada, é minha a parte feita:

o por-fazer é só com Deus".

(Fernando Pessoa) 
Aos meus pais,

Yoshiko Ramos e Álvaro Antônio Ramos, Aos meus avós,

Ângelo Ramos e Maria Cândida Abrunhosa E à minha irmã,

Milena Yumi Ramos.

Pelo apoio e presença constante em minha vida. 


\section{AgRadecImentos}

A Luiz de Queiroz, fundador da ESALQ, que, graças ao seu espírito idealista, pioneiro e inovador, ten proporcionado, em seus 100 anos de existência, uma sólida formação àqueles que decidem dedicar a sua vida às Ciências Agrárias.

À gloriosa Escola Superior de Agricultura "Luiz de Queiroz", minha escola querida, que me proporcionou ótima formação profissional e, acima de tudo, ajudou-me a ser uma cidadã consciente dos meus deveres e direitos.

Aos meus pais, pelo amor irrestrito, carinho, companheirismo, confiança, apoio, dedicação, esmero na minha formação...enfim, pela vida.

À minha família, em especial à minha irmã Milena e à minha tia Kayoko, que sempre torcem pelo meu sucesso.

Aos professores do Departamento de Economia, Sociologia e Administração, principalmente aqueles que estimularam e incentivaram o meu interesse pela Economia Agrícola.

Ao Prof. José Vicente Caixeta Filho pela paciência, compreensão, presença constante e orientação sempre segura.

Aos Professores Marcos Fava Neves e Evaristo Marzabal Neves pelas preciosas colaborações.

À Profa Heloísa Lee Burnquist pelo suporte dado durante o Programa de Aperfeiçoamento do Ensino Superior (PAE).

Aos colegas de turma, em especial às minhas amigas Sílvia Pizzol e Raquel Caruso, que sempre estiveram comigo, compartilhando tanto as alegrias quanto os momentos mais dificeis do curso.

Aos amigos do Curso de Pós-graduação em Economia Aplicada, Marcos Hasegawa, Casimiro, Clayton Nunes, Cristiane, Dilson, Patrick Whole e Ricardo Lopes pelo constante auxilio e incentivo.

Aos funcionários do Departamento de Economia, Sociologia e Administração, especialmente Pedro Scardua, Maielli, Helena e Ligiana, pela amizade 
e dedicação. A Vinícius, André e Fernando, do Laboratório de Informática, pela dedicação e prontidão na resolução de problemas operacionais.

Aos demais professores da ESALQ, em especial João Alexio e Zilmar Ziler Marcos, pela amizade e formação profissional.

Ao Dr. Eduardo Luis Leão de Sousa pela paciência, compreensão, pelas contribuições dadas à conclusão da dissertação, pela oportunidade de trabalho e por estar sempre apresentando novos desafios e possibilitando meu crescimento profissional.

A Secretaria de Acompanhamento Econômico e aos amigos que nela fiz: Letícia, Gustavo Prado, Gustavo Bracale, Mandai, Nilma, Carlos, Dr. Horta, Zuleide, Lourdes, Janete, Verônica, Dulce, Aurilene, Valois, Eugênio, Mazinho, Romilda, Lana, Ernani, Léia e Maria de Lourdes.

Aos amigos de sempre, que me ajudaram, de alguma forma, na realização de mais esta etapa da minha vida: Daniele Takahashi, Denise, Beatriz, Juliano, Bete, Simão e Leandra Scarpari (Scargô), do Laboratório de Biologia Molecular/ESALQ, Silvia Pizzol (Pizô), Raquel Caruso (Kxassa), Simone Farahte, Letícia Watanabe, Alini Pomponio (Brisa), Ana Maria de Meira (Pequi), Janaína Braga do Carmo (Bronquinha), Vânia Saintive (Paetê), Maria Cecília da Silva (Içá), Míriam Gomes da Costa, Gisele e Luciane.

Aos meus vizinhos Ugo Leandro Belini (Fuk), Marco Antônio Querol (Boiadeiro), Wladmir Pena Camargo (Kvera), Anderson (Kramunhão), Marcelo Castro Pereira (Ksamurro), Adail (Felino), Maurício Pahor (Anelídio), Evandro (Mók) e Cristiano Ribeiro Moreira (Oligator) pela amizade e pelos momentos de descontração.

Aos amigos Gabriel Bittencourt de Almeida, Hélio Watanabe, Cláudio e Anita de Sousa Dias Gutierrez do Centro de Qualidade em Horticultura da CEAGESP, pelo apoio e auxilio na elaboração e coleta de informações.

Ao Centro de Estudos Avançados em Economia Aplicada (CEPEAVESALQ), na pessoa de Margarete Boteon, pelas informações. e trabalho.

Aos futuros leitores deste estudo, por recompensarem todo o meu esforço

A CAPES e CNPQ, pelas bolsas de estudo que permitiram minha dedicação total aos estudos.

Por fim, agradeço a Deus, pela vida por ter colocado essas pessoas e oportunidades no meu caminho.

A todos,

o meu mais sincero muito obrigada. 


\section{SUMÁRIO}

Página

LISTA DE FIGURAS ...........................................................................

LISTA DE QUADROS ..................................................................

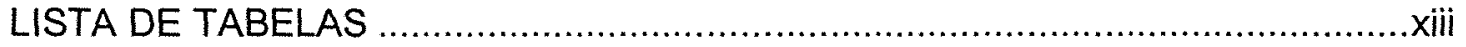

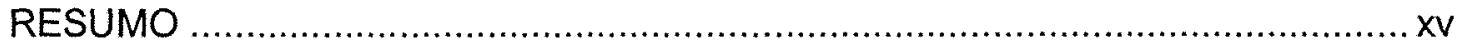

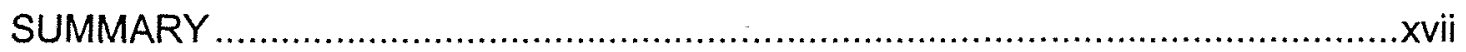

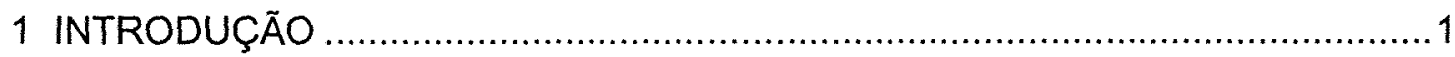

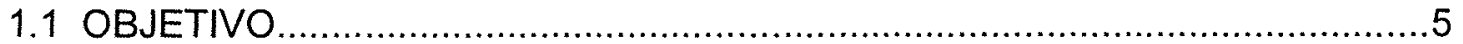

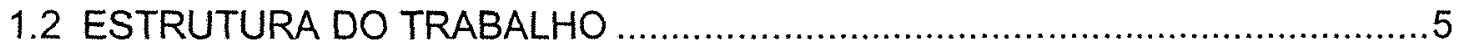

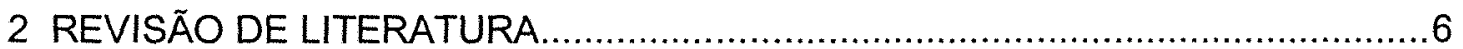

2.1 Caracterização do mercado e da logística de transporte e distribuição da laranja in natura no estado de São Paulo. ........................................6

2.1.1 Caracterização dos canais de distribuição da laranja . .............................9

2.1.2 Dimensão econômica do sistema agroindustrial citrícola ..........................11

2.1.3 Caracterização dos agentes envolvidos.......................................... 14

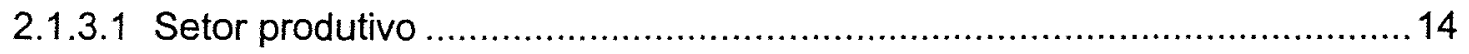

2.1.3.2 Packing-houses .................................................................... 18

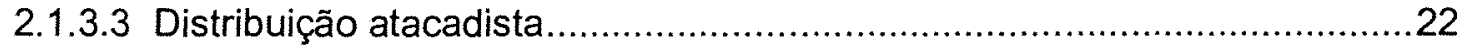

2.1.3.3.1 Comercialização de laranja na CEAGESP ........................................26

2.1.3.3.1.1 Embalagens e movimentação de carga no entreposto........................26

2.1.3.3.1.2 Volume comercializado e preços ..............................................27

2.1.3.3.1.3 Procedência da laranja comercializada no ETSP............................30

2.1.3.4 Distribuição varejista......................................................... 35

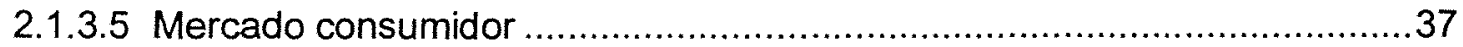

2.1.4 Atividades logisticas do sistema agroindustrial da laranja in natura............39 


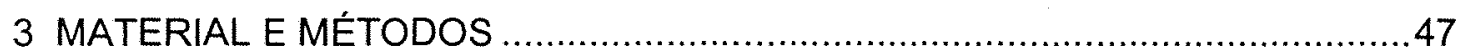

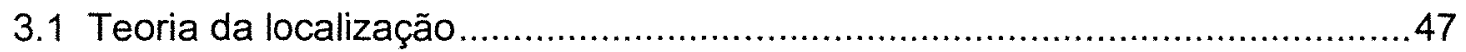

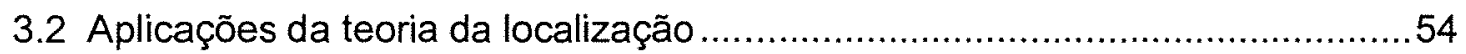

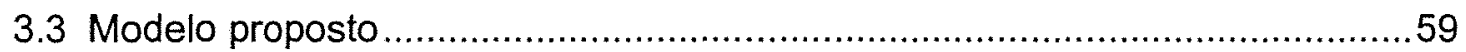

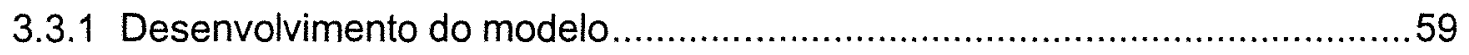

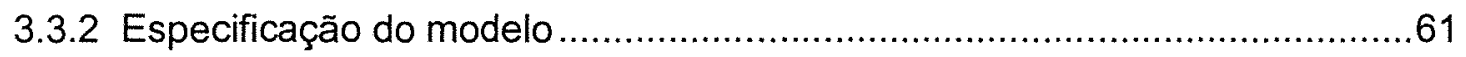

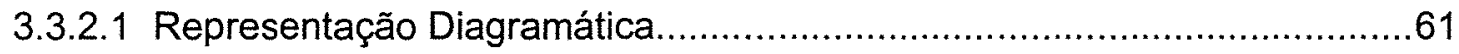

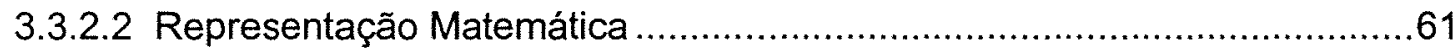

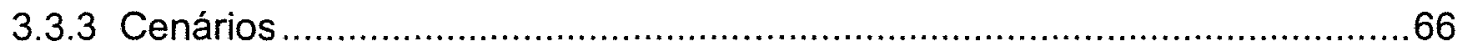

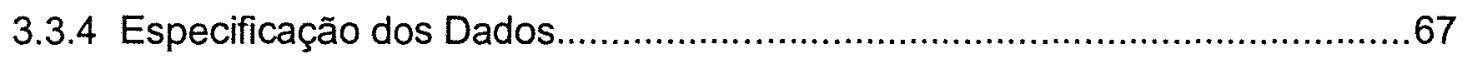

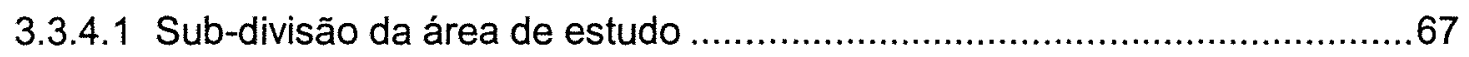

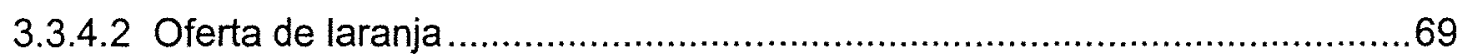

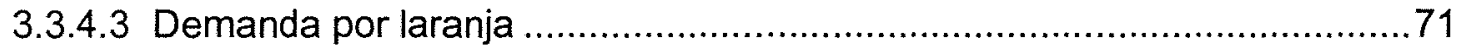

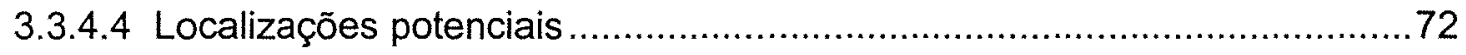

3.3.4.5 Capacidade de processamento dos packing-houses ..............................73

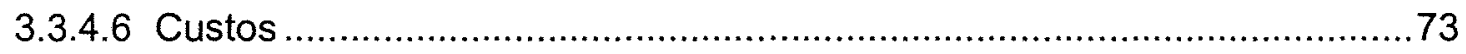

3.3.4.6.1 Custos de processamento e de implantação. ……….............................73

3.3.4.6.2 Custos transporte ...........................................................................

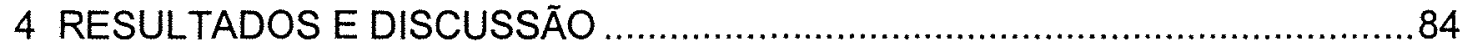

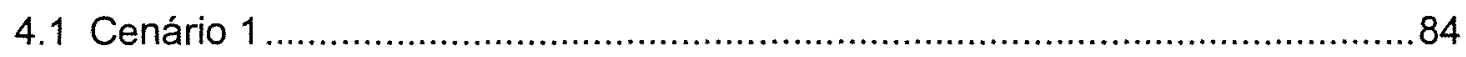

4.2 Cenário 2

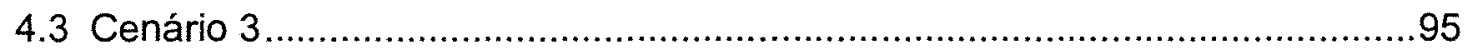

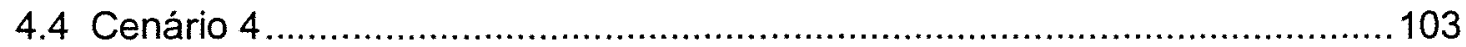

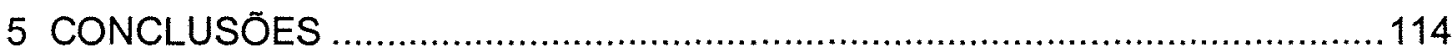

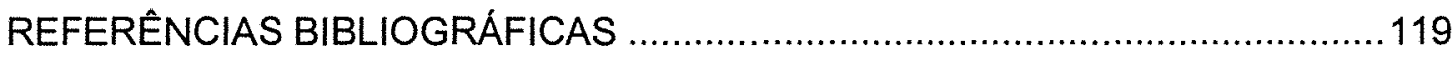

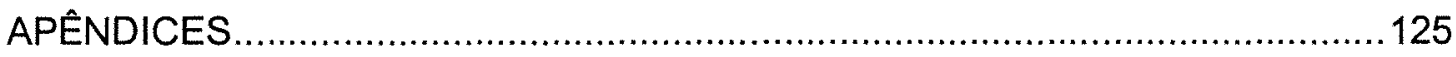

Apêndice 1: Questionário aplicado junto a atacadistas da CEAGESP ..................126

Apêndice 2: Comandos utilizados no software GAMS

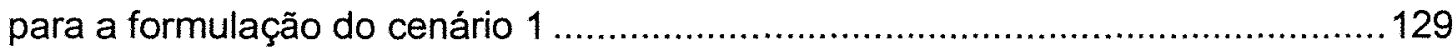




\section{LISTA DE FIGURAS}

Página

1 Evolução dos preços recebidos pelo produtor de laranja e pela indústria de suco concentrado no Brasil entre agosto de 1998 e maio de 2001. 3

2 Canais de distribuição da laranja no Estado de São Paulo ........................................... 10

3 Dimensão econômica do sistema agroindustrial da laranja, 1999................................. 13

4 Principais regiões produtoras de frutas cítricas, São Paulo. ....................................... 17

5 Número de packing-houses, por região, São Paulo, 1998 .......................................... 19

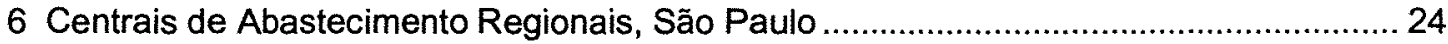

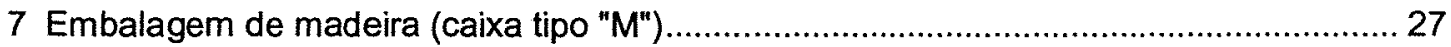

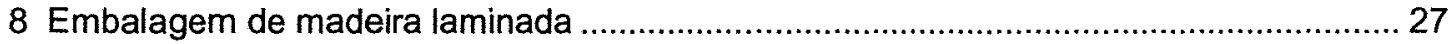

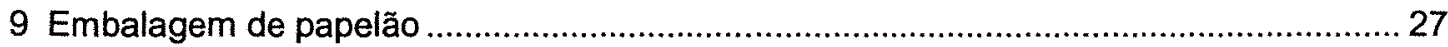

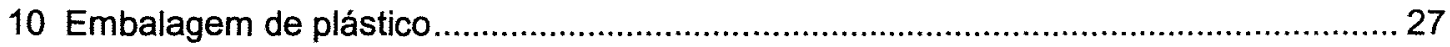

11 Produção total do Estado de São Paulo, parcela da produção destinada ao mercado interno e volume de laranja comercializado no ETSP, em milhões de toneladas.......... 28

12 Participação dos cultivares de laranja na comercialização do ETSP,

1994 a 1998 30

13 Participação das regiões produtoras no volume total de laranja comercializado no ETSP

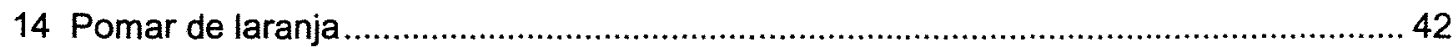

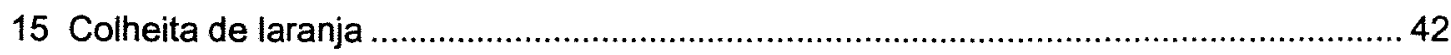

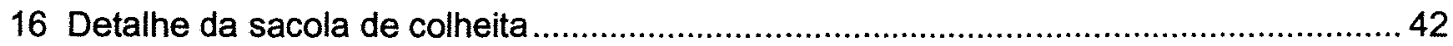




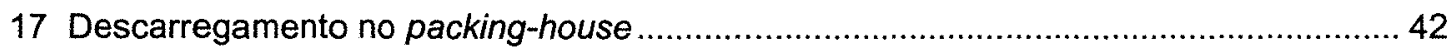

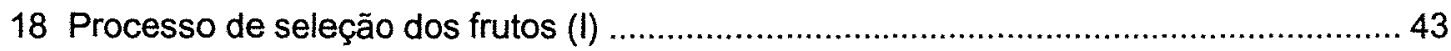

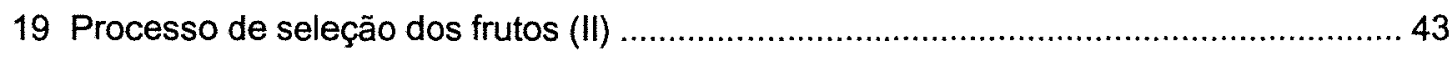

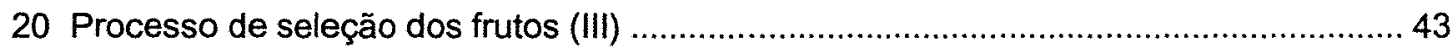

21 Máquina classificadora com princípio eletrônico de classificação................................. 44

22 Máquina classificadora com princípio mecânico de classificação................................. 44

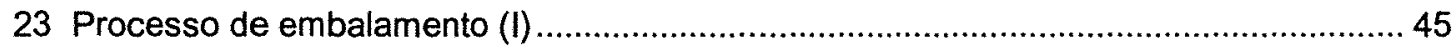

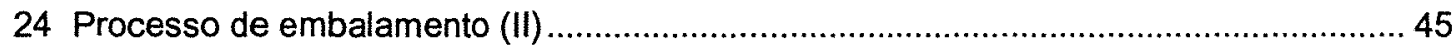

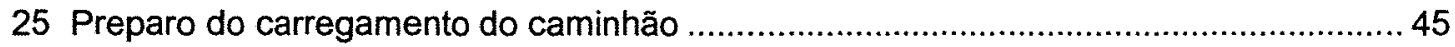

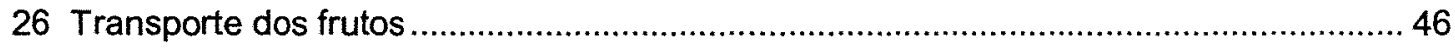

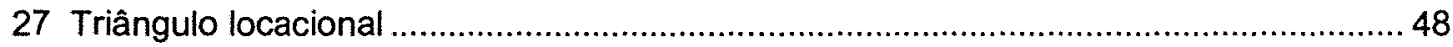

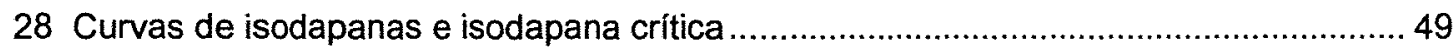

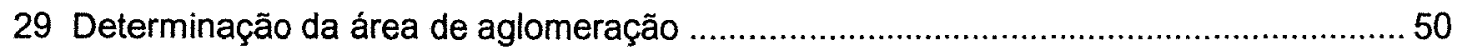

30 Representação diagramática do modelo de localização ótima ..................................... 61 


\section{LISTA DE QUADROS}

Página

1 Volume transportado de laranja dos centros de produção para os centros de

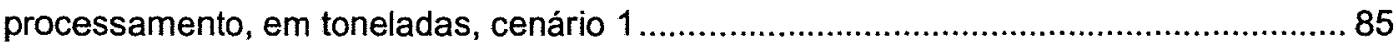

2 Número de packing-houses instalados, por EDR, cenário 1 .......................................86

3 Volume transportado de laranja dos centros de processamento para os centros de

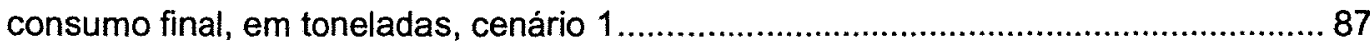

4 Custos marginais de tranporte, em Reais por tonelada transportada, cenário 1 ............. 89

5 Volume transportado de laranja dos centros de produção para os centros de

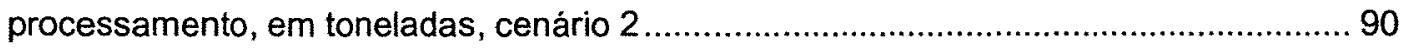

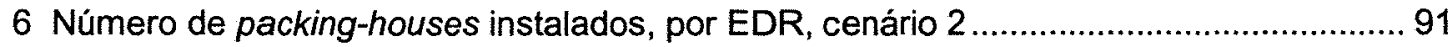

7 Volume transportado de laranja dos centros de processamento para os centros de

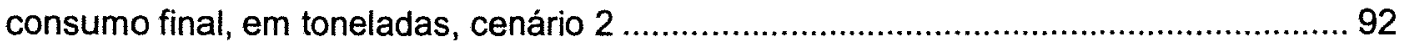

8 Custos marginais de tranporte, em Reais por tonelada transportada, cenário 2 ............. 94

9 Volume transportado de laranja dos centros de produção para os centros de

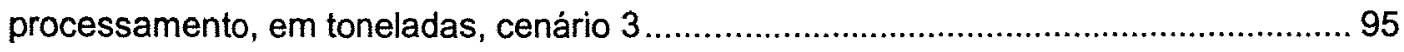

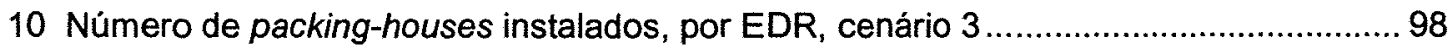

11 Volume transportado de laranja dos centros de processamento para os centros de

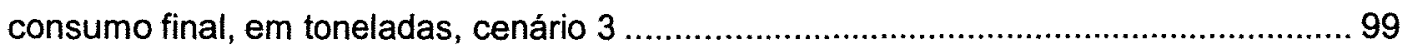

12 Custos marginais de tranporte, em Reais por tonelada transportada, cenário 3 ......... 101

13 Volume transportado de laranja dos centros de produção para os centros de processamento, em toneladas, cenário 4 
14 Número de packing-houses instalados, por EDR, cenário 4.

15 Volume transportado de laranja dos centros de processamento para os centros de consumo final, em toneladas, cenário 4 108

16 Custos marginais de transporte, em Reais por tonelada transportada, cenário 4 110 


\section{LISTA DE TABELAS}

Página

1 Estimativa do destino da produção de laranja, São Paulo, 1990 a 2001 ........................... 2

2 Estimativa dos principais destinos da produção de laranja no

Estade de São Paulo, 1980/81 a 1999/00

8

3 Valor dos serviços prestados ao sistema agroindustrial citrícola, 1999. .......................... 12

4 Participação dos segmentos no total do faturamento do sistema citrícola, 1999.............. 14

5 Produção total e principais produtores de laranja, 2000............................................. 15

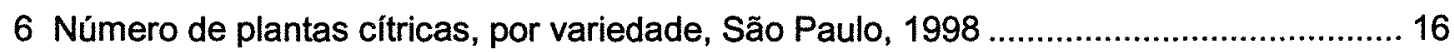

7 Principais regiōes produtoras de laranja, São Paulo, 1999 ............................................ 16

8 Volume de comercialização dos packing-houses, São Paulo, 1995 ................................. 20

9 Participação da CEAGESP no volume de laranja destinado ao mercado interno,

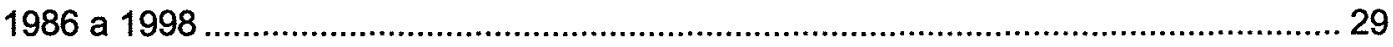

10 Participação do município no total de laranja enviado para o ETSP, 1998...................... 32

11 Participação das variedades no volume comercializado no ETSP, 1998 ...................... 33

12 Participação dos estados no fornecimento de laranja ao ETSP, 1998 .......................... 34

13 Participação dos equipamentos varejistas na comercialização de laranja,

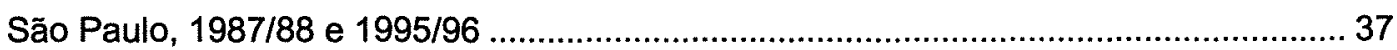

14 Consumo per capita de laranja, São paulo, $1987 / 88$ e 1995/96 ................................... 38

15 Participação da laranja nos gastos com frutas, por faixa salarial,

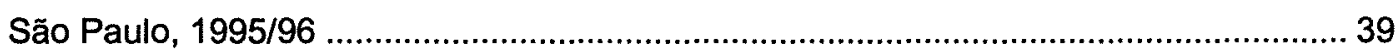

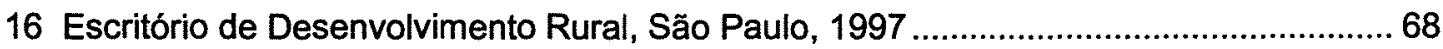


17 Produção e oferta de laranja para o mercado de frutas frescas,

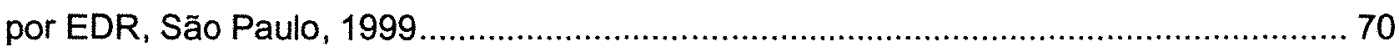

18 População e demanda por laranja de mesa, por EDR, São Paulo, 1999 ..................... 71

19 Custos de implantação e de processamento de packing-houses, São Paulo, 2001 ...... 74

20 Valor do frete para a laranja, por faixas de distância, São Paulo, $2001 \ldots \ldots \ldots \ldots \ldots \ldots \ldots \ldots . . . . . . . . . . .75$

21 Distâncias entre origens e destinos, São Paulo ...................................................... 76

22 Custo de transporte entre origens e destinos, Estado de São Paulo, 2001 .................. 80 


\section{AVALIAÇÃO DA LOCALIZAÇÃO DE PACKING-HOUSES NO ESTADO DE SÃO PAULO: O CASO DA LARANJA DE MESA}

Autora: Simone Yuri Ramos

Orientador: Prof. Dr. José Vicente Caixeta Filho

\section{RESUMO}

O objetivo do presente estudo foi analisar a forma mais eficiente de se organizar o complexo de laranja in natura no Estado de São Paulo, de modo a minimizar os custos de transporte, tanto da matéria-prima quanto do produto processado, bem como os custos de processamento e implantação de packing-houses, de acordo com determinadas capacidades de processamento destas plantas. $\mathrm{O}$ modelo matemático proposto foi baseado na teoria da localização, desenvolvida por Weber, e em seus refinamentos mais recentes, utilizando uma estrutura de programação inteira-mista. Para os fins da presente análise, adotou-se, como centros de oferta, de consumo e como potenciais centros de processamento, os 40 Escritórios de Desenvolvimento Rural (EDRs) existentes no Estado de São Paulo. As variáveis selecionadas para este estudo foram as relacionadas aos custos de transporte da laranja, dos centros de produção aos centros de processamento e, destes, aos centros de consumo. Além destas, considerou-se, ainda, os custos de implantação de packinghouses de diferentes capacidades, seus custos de processamento, assim como a oferta e a demanda de cada EDR. A avaliação da localização de packing-houses baseou-se na definição de quatro cenários distintos, os quais consideraram a possibilidade de instalação de apenas uma planta processadora por região, a igualdade entre a oferta e a demanda por laranja em São Paulo e a inexistência de plantas processadoras neste Estado. Conforme os resultados obtidos, verificou-se que 
prevaleceu, dentre os portes propostos, plantas com maiores capacidades de processamento (entre 250 mil a 1 milhão de caixas por ano), refletindo a necessidade de economia de escala no processamento. Os resultados mostraram, também, que o transporte inter-regional ocorre, principalmente, em centros de processamento que se localizam em áreas que não são consideradas como grandes centros de produção. Por fim, verificou-se a existência de uma tendência à instalação de plantas em áreas intermediárias, ou seja, aquelas que apresentam proximidade tanto em relação aos centros de produção quanto em relação aos centros de consumo. Outro resultado importante foi a identificação de áreas potenciais para a implantação de packinghouses, as quais ainda não estão sendo exploradas, o que pode orientar os agentes do setor em relação à instalação de futuras unidades de beneficiamento, de modo que os custos de transporte, processamento e implantação sejam mínimos, conferindo maior competitividade às empresas, um custo menor ao produto $e$, portanto, um maior consumo de laranja in natura, como é o desejo do setor. 


\title{
EVALUATION OF THE LOCATION OF PACKING-HOUSES IN THE STATE OF SÃO PAULO: THE FRESH CITRUS CASE
}

\author{
Author: Simone Yuri Ramos \\ Adviser: Prof. Dr. José Vicente Caixeta Filho
}

\section{SUMMARY}

The goal of this study was to analyze the most efficient method to organize the agroindustrial system of fresh citrus in São Paulo State so as to minimize transportation costs of both raw material and processed product and the costs of processing and setting up of packing-houses according to particular processing capacities of these plants. The mathematical model proposed was based on the location theory developed by Weber and its recent refinements, using a mixed-integer programming structure. For the purpose of this study, 40 Rural Development Agencies (RDA) in São Paulo were adopted as supplying and consumption centers and as potential processing centers. The variables selected for the study were those related to the costs of orange transportation, from the production centers to the processing centers, and from the latter to the consumption centers. In addition, the costs of setting up different-capacity packing-houses and respective processing costs as well as supply balance of each RDA were considered. The evaluation of the locations of the packinghouses was based on the definition of four distinct scenarios. According to the results, proposition indicating higher processing capacity plants (between 250 thousand and one million boxes per year) prevailed, reflecting the need of an economy of scale in the processing. Also, inter-regional transportation was observed, especially in processing centers located in areas not considered as large production centers. Finally, it was verified a trend in setting up plants in intermediary areas, that is, close to both 
production and consumption centers. Another important resul was the identification of potential areas to set up the packing-houses, still unexplored, which can be of help for agents of the sector towards setting up future processing units, so that the costs of transportation, processing and setting up be minimum, thus allowing more competition between the companies, lower product costs and, accordingly, an increase in fresh citrus consumption, as desired by the sector. 


\section{INTRODUÇÃo}

A citricultura, em especial a cultura da laranja, é uma atividade de suma importância para a economia brasileira, o que é demonstrado pelo fato do pais figurar entre os principais produtores mundiais da fruta. Conforme estatísticas da FAO, citadas por Neves (2000), no ano de 1999, o Brasil se manteve como o maior produtor de laranja, respondendo por cerca de $34 \%$ da produção mundial, enquanto os Estados Unidos, segundo maior produtor, responderam por $15 \%$.

No Brasil, a produção de laranja é fortemente concentrada na região Sudeste, onde destaca-se, como maior produtor, o Estado de São Paulo que, segundo Neves (2000), respondeu por $76,1 \%$ da área colhida e $82,9 \%$ da produção brasileira no ano de 1999. Neste Estado, a implantação e o desenvolvimento da indústria de suco concentrado, ocorrida a partir da década de 60 , fizeram com que a comercialização de frutas cítricas destinadas ao mercado interno, especialmente o grupo das laranjas, ficasse em segundo plano e dependente do mercado internacional de suco concentrado, de modo que a oferta apresentava oscilações em função do comportamento dos preços pagos pela indústria. Ou seja, em anos de redução na oferta internacional de laranja, causada principalmente por geadas na Flórida, os produtores e agentes que atuavam no mercado interno destinavam sua produção à indústria, devido aos melhores preços.

No entanto, na década de 90 , o cenário citrícola passou por profundas alterações. A recuperação dos pomares da Flórida tornaram os Estados Unidos menos dependentes do suco brasileiro, levando à queda nas cotações internacionais do produto. Como conseqüência, verificou-se uma forte redução nos preços pagos aos produtores de laranja em relação aos elevados valores observados no final da década de 80. Paralelamente, o plantio acelerado, realizado naquela década, gerou excedentes de oferta de matéria-prima no mercado interno. 
A partir da análise dos dados contidos na Tabela 1, pode-se concluir que um dos principais problemas dos citricultores paulistas, na década de 90 , passou a ser o excesso de oferta de laranja para o processamento, uma vez que a produção tem crescido a uma taxa anual de $2,62 \%$, enquanto o processamento tem apresentado um crescimento da ordem de $2,14 \%$ ao ano.

Tabela 1. Estimativa do destino da produção de laranja São Paulo, 1990 a 2001.

\begin{tabular}{ccccc}
\hline Safra & Processamento & Mercado interno & Exportação in natura & Total \\
\hline $1990 / 91$ & 210,00 & 56,80 & 1,90 & 268,70 \\
$1991 / 92$ & 225,00 & 57,80 & 2,70 & 285,50 \\
$1992 / 93$ & 265,00 & 33,00 & 2,00 & 300,00 \\
$1993 / 94$ & 240,00 & 65,20 & 1,80 & 307,00 \\
$1994 / 95$ & 245,00 & 37,00 & 3,00 & 285,00 \\
$1995 / 96$ & 247,00 & 72,50 & 2,80 & 322,30 \\
$1996 / 97$ & 260,00 & 92,60 & 2,40 & 355,00 \\
$1997 / 98$ & 278,00 & 102,80 & 2,20 & 383,00 \\
$1998 / 99$ & 268,00 & 71,10 & 1,60 & 340,70 \\
$1999 / 00$ & 275,00 & 122,70 & 2,40 & 400,10 \\
$2000 / 01$ & 265,00 & 90,0 & 2,20 & 357,20 \\
\hline
\end{tabular}

Fonte: Associação Brasileira dos Exportadores de Citros (2001).

${ }^{1}$ Valores expressos em milhões de caixas de 40,8 kg.

O crescimento da oferta de laranja em niveis superiores aos da capacidade de processamento da indústria, levou a uma redução no preço pago ao produtor pela caixa de laranja, como pode ser observado na Figura 1. Nota-se, também, que tanto o preço da caixa de laranja quanto o preço do suco concentrado de laranja no mercado internacional sofreram uma redução. No entanto, o preço recebido pelo produtor apresentou uma redução muito mais significativa do que o recebido pela indústria. Cabe destacar que, a partir de outubro de 2000 , a tendência de queda nos preços ao produtor começaram a sofrer uma inversão devido à redução da oferta mundial de laranja, ocasionada pela diminuição das produções de São Paulo e Flórida. Apesar da redução da oferta mundial de laranja, as cotações do suco concentrado no mercado internacional continuam estáveis, em função dos níveis de estoques permanecerem elevados. 


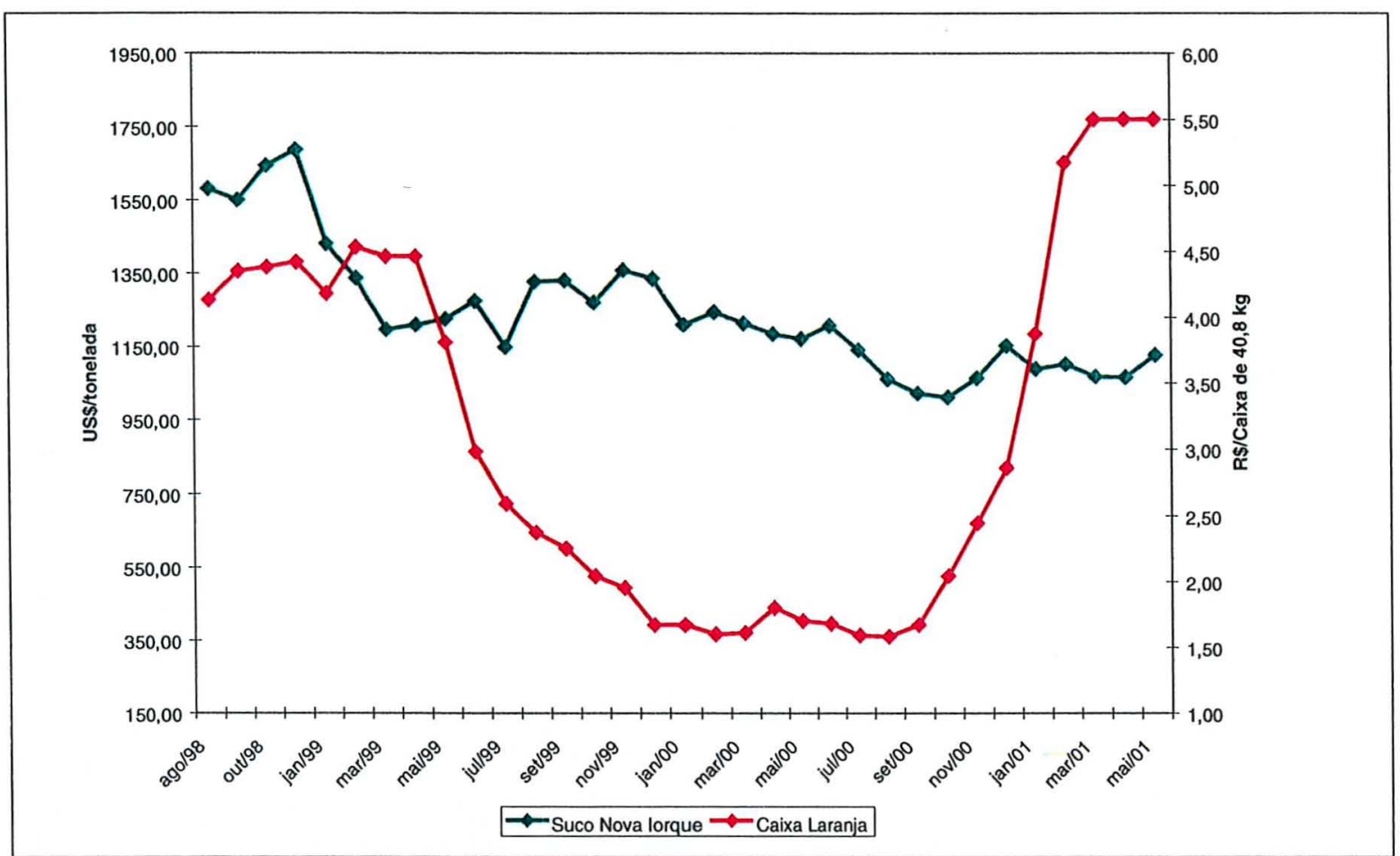

Figura 1 - Evolução dos preços recebidos pelo produtor de laranja e pela indústria de suco concentrado no Brasil entre agosto de 1998 e maio de 2001.

Fonte: Instituto de Economia Agrícola, 2001.

As possíveis soluções para o problema relacionado ao excesso de oferta e conseqüente redução no preço pago ao produtor passam pela redução da taxa de crescimento da produção de laranjas, pelo desenvolvimento e fortalecimento do mercado interno de laranjas, bem como pelo aumento das exportações de suco concentrado. Dentro deste contexto, o governo do Estado de São Paulo, juntamente com a Câmara Setorial do Agronegócio de Citros, vem delineando, desde 1997, uma série de políticas para minimizar esta situação problemática na qual a citricultura paulista está inserida.

Para Neves et al. (2001), a grande oportunidade para que o sistema agroindustrial citrícola consiga superar a crise em que se encontra é o crescimento e fortalecimento do mercado interno de laranja. Os autores salientam, ainda, que este segmento apresenta uma série de deficiências, relacionadas, principalmente, à padronização da fruta, à logística de distribuição, à falta de união e profissionalismo dos produtores, à ausência de marketing e à falta de foco nas vendas para o mercado interno. 
Nesse sentido, o governo do Estado de São Paulo criou, em 1997, o "Programa Paulista para a Melhoria dos Padrões Comerciais e Embalagens de Hortigranjeiros", que passou a ter abrangência nacional desde o ano de 2000. O objetivo deste programa é desenvolver padrões mais atuais de classificação para produtos hortícolas, bem como embalagens mais apropriadas para estes produtos, além de capacitar os produtores, promover a melhoria da qualidade dos produtos ofertados e desenvolver práticas mais modernas e eficientes de comercialização, tais como leilões, utilização e código de barras e de paletes.

No que se refere à logística de distribuição, a política do governo tem sido a de reduzir o custo São Paulo, por meio da melhoria da infra-estutura de transporte e do apoio logístico necessário a toda cadeia produtiva.

Dessa forma, a avaliação da localização de packing-houses de laranja torna-se um instrumento de política pública muito importante, na medida em que busca a minimização dos custos de transporte da fruta, que constitui-se, atualmente, num dos principais gargalos do setor, já que representa cerca de $4 \%$ do seu faturamento total e 8 a $16 \%$ do valor do produto final. 


\subsection{OBJetivos}

O objetivo geral do presente estudo é analisar a forma mais eficiente de se organizar o sistema agroindustrial da laranja in natura no Estado de São Paulo, de modo a minimizar os custos de coleta, processamento e distribuição da fruta. Especificamente, pretende-se:

- caracterizar o mercado paulista de laranja in natura.

- apresentar e descrever as principais atividades logísticas observadas na produção de laranja in natura.

- descrever o segmento que processa a fruta fresca (packing-houses).

- propor e aplicar um modelo matemático de otimização para a localização de packing-houses para regiões representativas do Estado de São Paulo, considerando as diferentes capacidades de processamento das empresas. A estratégia a ser incorporada no modelo proposto será baseada na minimização dos custos de implantação, processamento e transporte da laranja.

\subsection{ESTRUTURA DO TRABALHO}

O presente estudo está estruturado da seguinte forma: após este capítulo introdutório, um panorama referente à cultura da laranja no Estado de São Paulo, bem como os aspectos logísticos envolvidos, são descritos no capítulo 2. O capítulo 3 trata do material e métodos a serem utilizados neste estudo. No capitulo 4 são apresentados os resultados e, finalmente, no capítulo 5 , as conclusões e recomendações para trabalhos futuros. 


\section{REVISÃo de LITERATURA}

\subsection{CaracterizaÇão do MERCado E DA logística de transporte E} distribuição da laranja IN NATURa No ESTAdo de São PaUlo.

Conforme Vieira (1976)', citado por Maia (1996), nos primórdios da citricultura brasileira, da qual se tem notícia desde o início da colonização do país, a produção destinava-se quase que totalmente ao consumo de subsistência, sendo o excedente comercializado em mercados e feiras-livres. Posteriormente, o aumento da área cultivada fez com que tal excedente passasse a ser significativo, o que permitiu ao país realizar sua primeira exportação de laranja em 1911, tendo como destino a Argentina.

A história da citricultura nacional confunde-se com a da citricultura paulista, a mais expressiva do país, cujo início, segundo Maia (1996), ocorreu em meados do século XX na região do Vale do Paraíba. Martinelli Júnior (1987) destaca que, no Estado de São Paulo, a cultura de citrus encontrou condições favoráveis ao seu desenvolvimento, uma vez que pôde aproveitar a infra-estrutura operacional e econômico-financeira propiciada pela cafeicultura. Além disso, nas décadas de 20 e 30, o governo estadual já mostrava preocupação com a cultura, levando-o a criar órgãos de pesquisa em citrus, iniciativa fundamental para 0 desenvolvimento da atividade.

Maia (1996) salienta que, nesta época, as boas perspectivas econômicas da citricultura paulista passaram a atrair as principais firmas exportadoras de laranja, que se deslocaram do Rio de Janeiro e se instalaram no interior de São Paulo, mais

\footnotetext{
${ }^{1}$ VIEIRA, L.F. A citricultura no Estado de São Paulo e a contribuição da pesquisa à bibliografia citricola nacional. São Paulo: ITAL, 1976. 91p. (Instruçōes Técnicas, 21).
} 
precisamente nos municipios de Limeira, Sorocaba e Araraquara. No entanto, em fins da década de 30 , a citricultura paulista passou por uma séria crise, em função do aparecimento da "tristeza" dos citrus, doença que eliminou a maior parte dos laranjais do Estado. Aliado a isso, a eclosão da Segunda Guerra Mundial causou a paralisação de quase todo o tráfego marítimo, afetando as exportações brasileiras de laranja.

Conforme Maia (1996), a citricultura continuou a se desenvolver, devido à recuperação dos mercados externos, alcançada com o final do conflito mundial, e aos resultados obtidos pelas pesquisas desenvolvidas por instituições governamentais. A "tristeza" foi controlada e as variedades de laranja foram substituídas, com o intuito de ajustar a oferta nacional às exigências do mercado internacional e tornar os pomares mais resistentes às doenças. Com isso, a atividade citrícola paulista ressurgiu a partir de meados da década de 50 e se expandiu em direção ao norte do Estado, atingindo os municípios de São José do Rio Preto, Bebedouro, Araraquara, Taquaritinga e Matão.

Para Maia (1996), a instalação de unidades processadoras de suco de laranja concentrado e congelado, de larga aceitação no exterior, foi o fator primordial para a cultura continuar se expandindo durante a década de 60 e, ainda, marcou uma nova etapa no desenvolvimento da citricultura paulista que, até então, restringia-se ao comércio de laranja in natura para os mercados interno e externo. A partir deste momento, as processadoras de suco passaram a demandar volumes crescentes de laranja a tal ponto que, no período compreendido entre 1980 e 2000 , absorveram, em média, $81 \%$ da produção total do Estado (vide Tabela 2).

De acordo com Boteon (1999), a implantação e o desenvolvimento da indústria de suco concentrado fizeram com que a comercialização de frutas cítricas destinadas ao mercado interno, especialmente o grupo das laranjas, ficasse em segundo plano e dependente do mercado internacional de suco concentrado. lannini (1989), ressalta que essa dependência fez com que a oferta doméstica de laranja apresentasse oscilações, decorrentes do comportamento dos preços pagos pela indústria.

Segundo a mesma autora, os estados de São Paulo (Brasil) e Flórida (Estados Unidos) são os maiores produtores de frutas e sucos cítricos, respondendo pela produção de, aproximadamente, $85 \%$ do suco de laranja comercializado no mundo. Contudo, o autora destaca que as geadas sempre afetaram significativamente 
o desempenho da produção norte-americana de laranja. Conseqüentemente, em anos de fortes geadas na Flórida e, portanto, de redução na oferta mundial da fruta, os produtores e agentes que atuavam no mercado interno brasileiro destinavam sua produção à indústria, devido aos melhores preços. Este comportamento pôde ser observado nas safras de 1984/85 e 1985/86 (vide Tabela 2).

Além disso, como salienta lannini (1989), as oscilações na oferta interna, aliadas ao baixo consumo de laranja in natura no país, não estimulavam os produtores a adotar, em seus pomares, novas técnicas que permitissem a melhoria da qualidade dos frutos, bem como os comerciantes e proprietários de packing-houses a aprimorar suas técnicas de trabalho. Desta forma, o mercado interno passou a ser considerado um "mercado residual, que praticamente não mudou sua estrutura, tanto na parte de comercialização como de consumo e qualidade da matéria-prima" (lannini, 1989, p.71).

Tabela 2. Estimativa dos principais destinos da produção de laranja no Estado de São Paulo, $1980 / 81$ a $1999 / 00$.

\begin{tabular}{cccc}
\hline Safra & $\begin{array}{c}\text { Produção } \\
\text { (milhões de toneladas) }\end{array}$ & $\begin{array}{c}\text { Processamento } \\
(\%)\end{array}$ & $\begin{array}{c}\text { Mercado interno } \\
(\%)\end{array}$ \\
\hline $80 / 81$ & 6,9 & 81,2 & 18,8 \\
$81 / 82$ & 7,3 & 86,1 & 13,9 \\
$82 / 83$ & 8,0 & 82,6 & 17,4 \\
$83 / 84$ & 8,2 & 82,5 & 17,5 \\
$84 / 85$ & 8,4 & 90,2 & 9,8 \\
$85 / 86$ & 8,9 & 89,4 & 10,6 \\
$86 / 87$ & 7,8 & 78,9 & 21,1 \\
$87 / 88$ & 9,5 & 79,5 & 20,5 \\
$88 / 89$ & 9,0 & 81,4 & 18,6 \\
$89 / 90$ & 12,1 & 85,1 & 14,9 \\
$90 / 91$ & 10,7 & 79,9 & 19,3 \\
$91 / 92$ & 11,6 & 78,8 & 20,2 \\
$92 / 93$ & 12,2 & 88,3 & 11,0 \\
$93 / 94$ & 12,5 & 78,2 & 21,2 \\
$94 / 95$ & 12,7 & 78,0 & 20,9 \\
$95 / 96$ & 14,6 & 72,5 & 26,6 \\
$96 / 97$ & 14,8 & 73,9 & 25,6 \\
$97 / 98$ & 17,5 & 74,3 & 25,7 \\
$98 / 99$ & 13,5 & 84,5 & 15,5 \\
$99 / 00$ & 15,8 & 72,2 & 27,8 \\
$2000 / 01$ & 14,6 & 74,9 & 25,1 \\
\hline
\end{tabular}

Fonte: Associação Brasileira dos Exportadores de Cítricos (2001).

$\mathrm{Na}$ década de 90 , o cenário citrícola passou por profundas alterações. Amaro \& Maia (1997) enfatizam que houve uma forte redução nos preços pagos aos 
produtores de laranja em relação aos elevados valores observados no final da década de 80. Para Boteon (1999), esta queda de preços pode ser explicada pelo excesso de oferta, ocasionada pelo deslocamento e recuperação dos pomares da Flórida, o que tornaram os Estados Unidos menos dependentes do produto brasileiro. Além disso, o crescimento da produção nacional de laranja, causada pelos novos plantios realizados na década de 80 , fez com que os excedentes de oferta gerados pela produção paulista passassem a ser absorvidos pelo mercado interno. Isto pode ser confirmado por meio das informações contidas na Tabela 2 , as quais mostram que, na década de 80,0 mercado interno, absorvia, em média, cerca de $16,6 \%$ da produção de laranja do Estado de São Paulo. Já na década de 90, este valor passou para, aproximadamente, $20,9 \%$ da produção, o que representa um acréscimo de $26,3 \%$.

\subsubsection{CaRACTERIZAÇÃo dOS CANAIS de DISTRIBUIÇÃo da laRANJA}

De acordo com Stern \& El Ansary $(1992)^{2}$, citados por Kotler (1996), canais de distribuição são um conjunto de organizações independentes, tais como atacadistas e varejistas, que estão envolvidas no processo de tornar o produto ou serviço disponível para o uso ou consumo. Esquematicamente, os canais de distribuição da laranja no Estado de São Paulo podem ser representados conforme ilustrado na Figura 2.

No que tange ao mercado interno, os canais de comercialização do setor citrícola apresentam-se divididos entre fruta in natura e suco de laranja, sendo os packing-houses considerados como "divisores de águas", já que comercializam as frutas que thes são destinadas em ambos os mercados. No caso das frutas frescas, a passagem pelos packing-houses é obrigatória devido à necessidade de beneficiamento, sendo este processo facultativo para as indústrias de suco pasteurizado. Entretanto, algumas indústrias compram boa parte de sua matéria-prima nos packing-houses em função de exigências em relação ao tamanho e à limpeza.

${ }^{2}$ STERN, L. W.; EL-ANSARY A. I. Marketing channels. 4 ed. Englewood Cliffs: Prentice-Hall, 1992. p.1. 

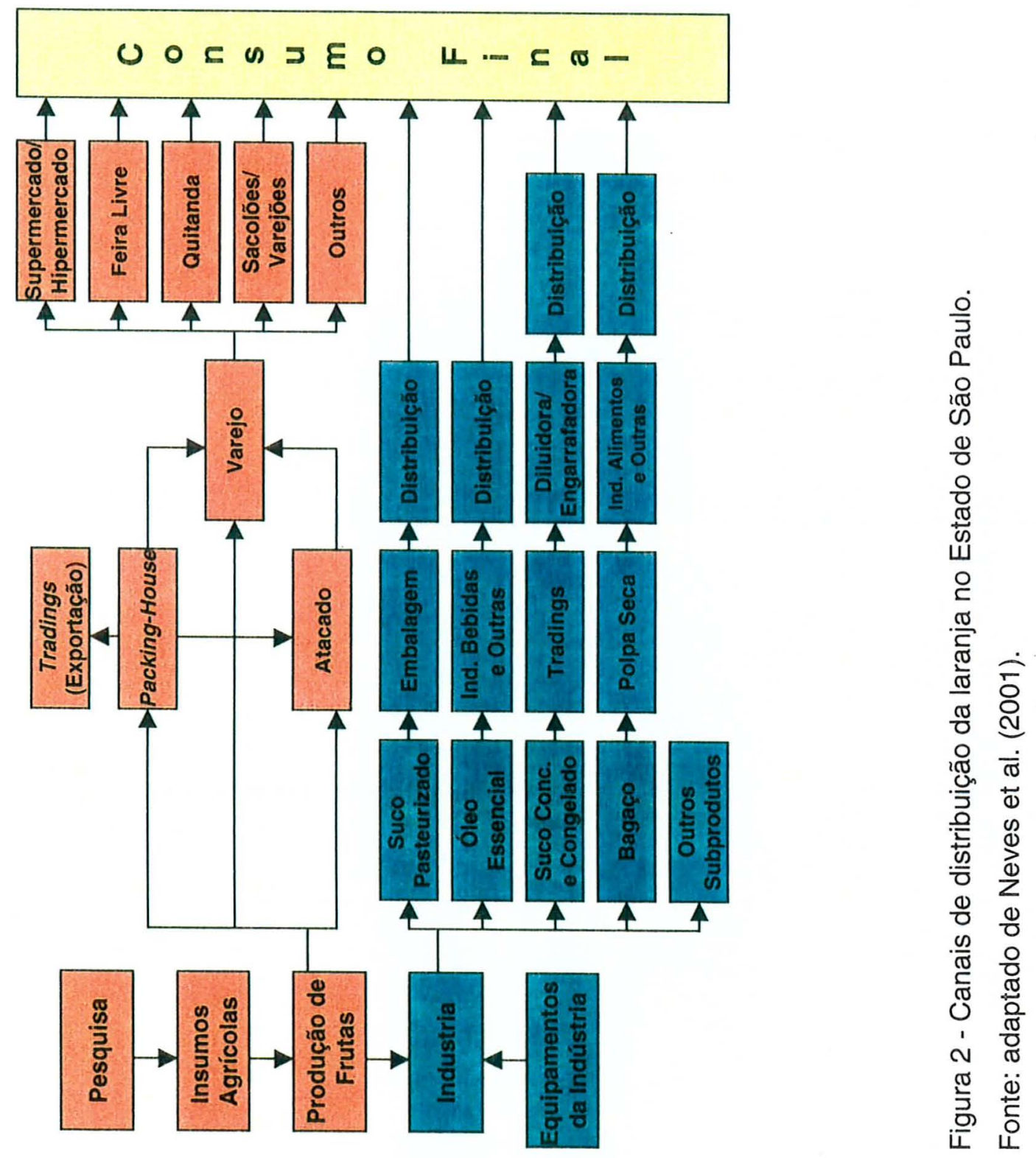
O canal de comercialização da laranja in natura envolve todos os agentes ligados a seu comércio, desde a produção até o consumidor final. A estrutura tradicional consiste na condução das laranjas dos pomares aos packing-houses, onde são classificadas, beneficiadas e embaladas. Posteriormente, seguem para os centros de consumo, onde são entregues aos atacadistas, que as vendem aos equipamentos varejistas (supermercados, quitandas, varejões, sacolões, feiras-livres, restaurantes etc.) e estes aos consumidores finais. $O$ refugo do beneficiamento, estimado em 20 a $30 \%$, é normalmente enviado às fábricas para ser processado. Amaro (1991) salienta que no mercado de fruta fresca, os agentes comerciais (atacadistas e varejistas) também podem adquirir a fruta diretamente de produtores, sendo muito comuns casos em que atacadistas são também produtores e compradores de terceiros. Observa-se, ainda, a venda da laranja beneficiada pelos packing-houses diretamente aos equipamentos varejistas, em especial aos supermercados, que têm procurado evitar os agentes atacadistas.

\subsubsection{DIMENSÃo ECONÔMICA DO SISTEMA AGROINDUSTRIAL CITRÍCOLA}

Neste estudo, adotar-se-á o conceito de Sistema Agroindustrial (SAG), estabelecido por Goldberg em 1968. Conforme este conceito, um SAG "engloba todos os atores envolvidos com a produção, processamento e distribuição de um produto. Tal sistema inclui o mercado de insumos agrícolas, a produção agrícola, operações de estocagem, processamento, atacado e varejo, demarcando um fluxo que vai dos insumos até o consumidor final. $O$ conceito engloba todas as instituições que afetam a coordenação dos estágios sucessivos do fluxo de produtos, tais como as instituiçães governamentais, mercados futuros e associações de comércio" (Zylbersztajn, 1995, p.118).

O sistema agroindustrial citrícola é, indiscutivelmente, um dos principais do país. De acordo com Neves et al. (2001), no ano de 2000, este SAG respondeu pela décima terceira colocação na pauta de exportações brasileiras, com uma participação de $2 \%$ no total de produtos exportados e $7 \%$ nas exportações nacionais relativas aos produtos do agribusiness. O suco concentrado e congelado de laranja foi o principal gerador de divisas do sistema, respondendo por $94 \%$ do valor de suas exportações. 
No Estado de São Paulo, o sistema agroindustrial citrícola não é importante somente em termos de geração de divisas. De acordo com Neves et al (2001), este SAG é, também, um grande mercado para insumos e serviços, respondendo por $15 \%$ do total de fertilizantes consumidos e $85 \%$ das vendas de tratores de $75 \mathrm{CV}$ no Estado. No que tange aos agentes facilitadores (serviços), no caso do mercado interno de frutas frescas, a citricultura também é bastante relevante, conforme pode ser visto na Tabela 3.

Tabela 3. Valor dos serviços prestados ao sistema agroindustrial citrícola, 1999.

\begin{tabular}{lc}
\multicolumn{1}{c}{ Agente } & $\begin{array}{c}\text { Valor anual } \\
\text { (milhões de US\$) }\end{array}$ \\
\hline Transportadoras de frutos & 106,00 \\
Mão de obra na colheita & 106,00 \\
Combustíveis & 48,50 \\
Embalagens de frutos & 44,00 \\
Transporte do fruto empacotado & 40,00 \\
Empresas extratoras & 30,00 \\
Serviços portuários & 20,00 \\
Pedágio & 17,00 \\
Transporte de suco concentrado & 16,50 \\
Embalagens de suco & 10,00 \\
Total & 438,00 \\
\hline
\end{tabular}

Fonte: Neves et al (2001).

A partir das informações contidas na Figura 3, pode-se verificar que, em 1999, o valor do faturamento do mercado de laranja foi estimado em torno de US\$2 bilhões. Desse total, a fatia mais significativa pertenceu à indústria (US\$1,3 bilhão), cabendo ao segmento de fruta fresca (mercado interno e exportações) um faturamento próximo a US\$ 686 milhões. 


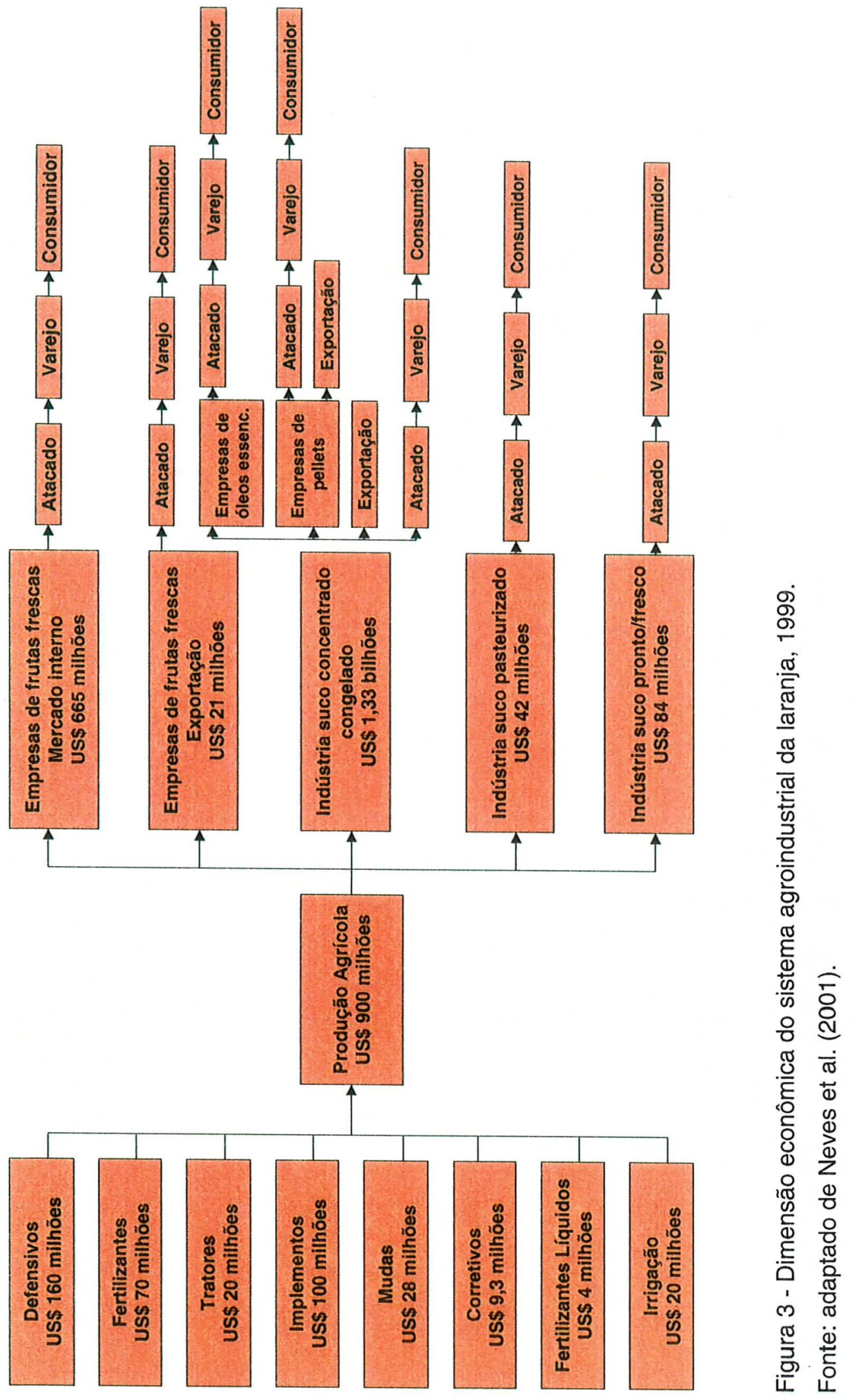


A Tabela 4 mostra o faturamento total do tema agroindustrial citrícola, bem como a participação de cada segmento neste montante.

Tabela 4. Participação dos segmentos no total do faturamento do sistema agroindustrial citrícola, 1999.

\begin{tabular}{lcc}
\hline \multicolumn{1}{c}{ Segmento } & $\begin{array}{c}\text { Faturamento } \\
\text { (milhões de dólares) }\end{array}$ & Participação (\%) \\
\hline Insumos & 411 & 10,56 \\
Produção agrícola & 900 & 23,13 \\
Indústria & 1330 & 34,18 \\
Consumo interno & 665 & 17,09 \\
Suco pronto fresco & 84 & 2,16 \\
Suco pasteurizado & 42 & 1,08 \\
Fruta fresca exportada & 21 & 0,54 \\
Serviços & 438 & 11,26 \\
Total & 3.891 & 100 \\
\hline
\end{tabular}

Fonte: Neves et al. (2001).

\subsubsection{CARACTERIZAÇÃo DOS AGENTES ENVOLVIDOS}

\subsubsection{Setor Produtivo}

A laranja é a uma das principais espécies frutícolas cultivadas e consumidas mundialmente. Segundo estatísticas da FAO, no ano de 2000, a laranja foi a fruta mais cultivada no mundo, respondendo por $22,5 \%$ do total produzido. A produção tem como destino três segmentos: a) consumo como fruta fresca na forma direta; b) comercialização in natura para o preparo de sucos e c) produção de sucos cítricos concentrados.

Conforme Boteon (1999), os principais destinos da laranja no mundo são o consumo interno $(48 \%)$ e a produção de suco $(42 \%)$. O restante é destinado ao comércio externo in natura. Entretanto, São Paulo e Flórida, os dois maiores produtores mundiais de laranja, destinam as maiores proporções de sua produção para o processamento de suco.

No que se refere à oferta mundial de laranja, a análise das informações contidas na Tabela 5 permite constatar a extrema concentração observada, sendo que somente o Brasil e os Estados Unidos responderam por, aproximadamente, $52 \%$ da produção total da fruta no ano de 2000. 
Tabela 5. Produção total e principais paises produtores de laranja, 2000.

\begin{tabular}{lcc}
\hline \multicolumn{1}{c}{ Região } & $\begin{array}{c}\text { Produção } \\
\text { (em mil toneladas) }\end{array}$ & $\begin{array}{c}\text { Participação } \\
(\%)\end{array}$ \\
\hline Brasil & 22.744 & 34,40 \\
Estados Unidos & 11.896 & 18,00 \\
México & 3.390 & 5,10 \\
Espanha & 2.500 & 3,80 \\
China & 3.507 & 5,30 \\
Itália & 2.268 & 3,40 \\
Outros & 19.749 & 30,00 \\
Total & 66.054 & 100 \\
\hline
\end{tabular}

Fonte: Neves et al. (2001), a partir de informações da Food and Agriculture Organization (FAO).

No Brasil, a produção de citrus encontra-se disseminada por todo o território nacional, concentrando-se, porém, no Estado de São Paulo (84\%), onde é uma das principais explorações agrícolas.

A cultura da laranja apresenta grande relevância sócio-econômica para São Paulo, o que pode ser claramente confirmado por meio da observação de algumas estatísticas referentes ao sistema agroindustrial citrícola:

- o suco de laranja respondeu por, aproximadamente, 4,9\% das exportações paulistas e por $7 \%$ das exportações brasileiras de produtos do agribusiness no ano de 2000 (Neves et al., 2001);

- em 2000, a participação do Estado de São Paulo nas exportações brasileiras de suco de laranja foi de $96,19 \%$ (Neves et al., 2001);

- o valor da produção agrícola de laranja, no ano de 2000, foi de $\mathrm{R} \$ 796$ milhões, $5 \%$ do valor total gerado pelas dez principais culturas do Estado (Neves et al., 2001);

- empregou, na safra 1998/99, 12,7\% do total estadual de força de trabalho disponivel para a agricultura (Neves, 2000);

- ocupou, em 1998, $86 \%$ da área estadual destinada à fruticultura (Neves, 2000).

Conforme Neves et al. (2001), o parque citricola paulista, conta com cerca de 223 milhões de árvores, sendo a colheita de laranja realizada o ano todo, devido aos diversos cultivares de laranja utilizados, tais como Seleta, Baía, Lima, Westin, Pera, Hamlin, Natal e Valência, sendo os quatro últimos os mais indicados para a produção de suco. 
No tocante às variedades comerciais de laranja cultivadas no Estado, observa-se a preferência pela laranja Pera, seguida pelas laranjas Natal, Valência, Hamlim e Lima (vide Tabela 6).

Tabela 6. Número de plantas cítricas, por variedade, São Paulo, 1998.

\begin{tabular}{lcc}
\hline Variedade & $\begin{array}{c}\text { Número de Plantas } \\
\text { (milhões de pés) }\end{array}$ & $\begin{array}{c}\text { Participação } \\
(\%)\end{array}$ \\
\hline Hamlim & 14,30 & 6,79 \\
Natal & 53,90 & 25,58 \\
Pera & 80,10 & 38,02 \\
Valência & 36,50 & 17,32 \\
Lima & 6,10 & 2,90 \\
Tangerina & 11,60 & 5,50 \\
Outras & 8,20 & 3,89 \\
Total & 210,7 & 100 \\
\hline
\end{tabular}

Fonte: Agroanalysis (1999), a partir de informaçōes do FUNDECITRUS.

Em São Paulo, a cultura da laranja está disseminada, praticamente, por quase todo Estado e é cultivada em 330 municipios dos 624 existentes. A produção paulista, como ocorre no Brasil e no mundo, é fortemente concentrada no denominado "cinturão citrícola" (vide Figura 4), onde apenas 8 EDRs (Escritórios de Desenvolvimento Rural), dos 40 existentes, responderam por cerca de $78 \%$ da produção paulista no ano de 1999 (vide Tabela 7) e por $84 \%$ da área total de citrus do Estado (Boteon, 1999).

Tabela 7. Principais regiões produtoras de laranja, São Paulo, 1999.

\begin{tabular}{lcc}
\hline \multicolumn{1}{c}{ EDR } & $\begin{array}{c}\text { Produção } \\
\text { (caixas de 40,8 kg) }\end{array}$ & $\begin{array}{c}\text { Participação } \\
(\%)\end{array}$ \\
\hline Barretos & 65.135 .601 & 16,28 \\
Jaboticabal & 49.506 .364 & 12,37 \\
Araraquara & 42.841 .796 & 10,71 \\
Limeira & 36.394 .878 & 9,10 \\
São José do Rio Preto & 32.287 .977 & 8,07 \\
Mogi Mirim & 30.657 .692 & 7,66 \\
Catanduva & 28.567 .421 & 7,14 \\
São João da Boa Vista & 25.472 .690 & 6,37 \\
Total do Estado & 400.061 .598 & 100 \\
\hline
\end{tabular}

Fonte: Instituto de Economia Agrícola (2000). 
Boteon (1999) afirma que nas regiōes de Barretos, São José do Rio Preto, Catanduva, Jaboticabal e Araraquara está instalada a maior parte das indústrias processadoras de suco de laranja concentrado, o que faz com que a produção dessa área seja destinada principalmente à indústria, enquanto a produção das regiões de Mogi-Mirim, Limeira e São João da Boa Vista destina-se, tradicionalmente, para o mercado de fruta fresca.

A análise do volume de laranja comercializado no Entreposto Terminal de São Paulo (E.T.S.P) no ano de 1998, confirma esta "especialização" das áreas produtoras de laranja. As regiões tradicionais na produção para mercado interno responderam por, aproximadamente, $50 \%$ do total de laranja comercializada no entreposto, cabendo às regiões voltadas para as indústrias uma participação de $32 \%$.

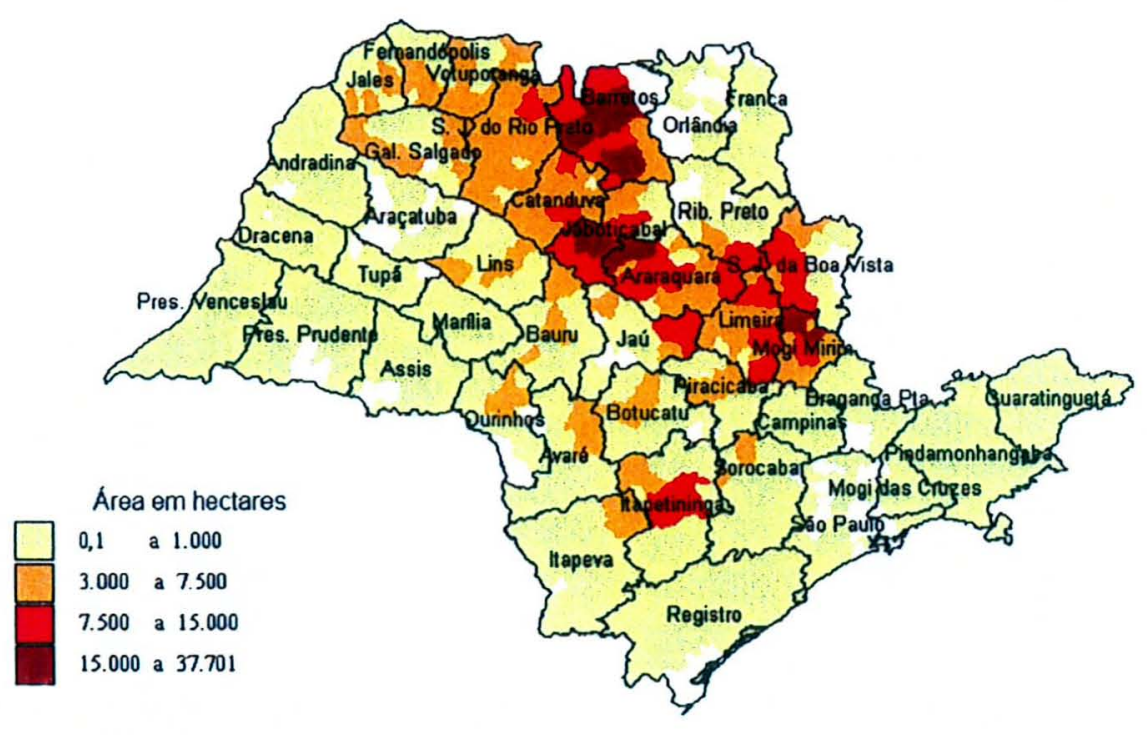

Figura 4 - Principais regiões produtoras de frutas cítricas, São Paulo.

Fonte: Coordenadoria de Assistência Técnica Integral (CATI, 2000).

Segundo levantamentos realizados pelo FUNDECITRUS ${ }^{1}$, citados por Amaro \& Maia (1997), em 1995 havia, no Estado de São Paulo, 27.867 propriedades comerciais que se dedicavam à citricultura. Destas, $92 \%$ foram consideradas como pomares de pequeno porte (até 80 hectares). Em 1998, de acordo com Neves (2000),

\footnotetext{
${ }^{1}$ REVISTA DO FUNDECITRUS. Araraquara, v.12, n. 78, set./out. 1996.
} 
existiam cerca de 49.866 propriedades que se dedicam ao cultivo de citrus, o que significa um incremento de $79 \%$ em relação ao ano de 1995 . Vale ressaltar que o levantamento constatou, ainda, que $58 \%$ das propriedades dedicavam-se exclusivamente à citricultura e que em $32 \%$ do total de propriedades amostradas o plantio de citrus concentrava-se apenas na laranja.

Finalmente, no que tange ao destino da produção paulista de laranja, verifica-se que a indústria absorveu, em média, $77,6 \%$ da produção de laranja no período compreendido entre as safras $1990 / 91$ e 2000/01. Ao mercado interno coube um papel secundário $(21,7 \%)$ e às exportações um papel inexpressivo, $0,7 \%$ (vide Tabela 1).

\subsubsection{Packing-Houses}

Os packing-houses são as unidades responsáveis pela seleção, classificação, beneficiamento e acondicionamento da laranja. Estas unidades também realizam a comercialização das frutas cítricas, seja nos mercados atacadistas e varejistas ou no mercado de sucos (integral ou natural pronto para beber). Para Amaro et al. (1997), o segmento dos packing-houses é essencial, pois pode contribuir para a melhoria da aparência do produto, para o controle da oferta, bem como para a redução dos custos de transporte, retendo produtos inferiores.

De acordo com levantamentos realizados pelo FUNDECITRUS, no ano de 1995 estavam em funcionamento cerca de 500 packing-houses nas regiões citrícolas do Estado de São Paulo, sendo que a maior parte deles destinava-se ao processamento de frutas para o mercado interno e apenas uma pequena parte $(1 \%)$, destinava-se ao beneficiamento voltado para o mercado externo. O levantamento constatou que muitas destas casas de embalagem beneficiavam outras frutas além da laranja, com destaque para manga, maracujá e abacate. No ano de 1998, novas estimativas mostravam que havia no Estado cerca de 400 unidades beneficiadoras de laranja, o que representa uma redução de 20\% em relação ao ano de 1995.

Os packing-houses localizam-se nas principais regiões produtoras de frutas cítricas do Estado, onde destacam-se os EDRs de Jaboticabal, Limeira e Mogi Mirim (vide Figura 5). 


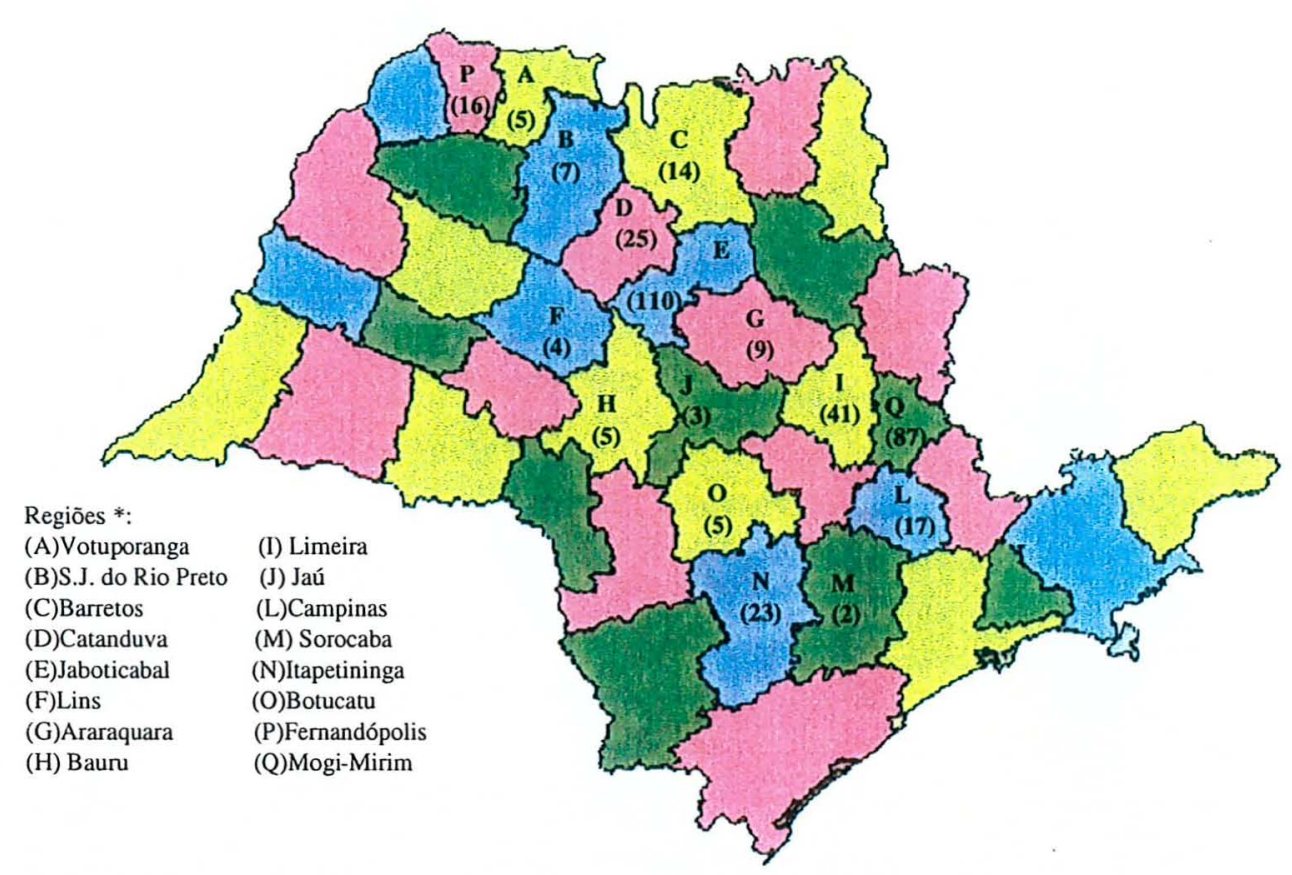

Figura 5 - Número de packing-houses, por região, São Paulo, 1998.

Fonte: adaptado de Boteon (1999) a partir de informações do FUNDECITRUS (1998).

${ }^{*}$ o número entre parênteses representa a quantidade de packing-houses existentes em cada região.

O FUNDECITRUS estimou, também, o tamanho dos packing-houses, baseado no volume de comercialização realizado no ano de 1995 . Segundo o levantamento, a maior parte dos packing-houses era de porte pequeno a médio, sendo que $80 \%$ do total de barracões apresentavam movimento abaixo de 250 mil caixas por ano (vide Tabela 8). 
Tabela 8. Volume de comercialização dos packing-houses, São Paulo, 1995

\begin{tabular}{lcc}
\hline $\begin{array}{c}\text { Classe } \\
\text { (mil caixas/ano) }\end{array}$ & Número de Packing-houses & $\begin{array}{c}\text { Participação } \\
(\%)\end{array}$ \\
\hline Até 50 & 169 & 33,8 \\
De 50 a 100 & 99 & 19,8 \\
De 100 a 250 & 126 & 25,2 \\
De 250 a 500 & 63 & 12,6 \\
De 500 a 1.000 & 27 & 5,4 \\
De 1.000 a 2.000 & 9 & 1,8 \\
De 2.000 a 3.000 & 3 & 0.6 \\
De 3.000 a 4.000 & 2 & 0,4 \\
De 4.000 a 5.000 & 2 & 0,4 \\
Total & 500 & 100 \\
\hline
\end{tabular}

Fonte: Boteon (1999), a partir de dados básicos do FUNDECITRUS (1998).

Durante o desenvolvimento deste estudo, realizou-se, no período de 12 a 24 de fevereiro de 2001, um trabalho de campo, com o intuito de melhor caracterizar o segmento processador de laranja para mercado interno (packing-houses). 0 levantamento foi realizado junto a 25 proprietários de packing-houses de diversas regiões do Estado de São Paulo. A pesquisa constatou que a capacidade de processamento mais comum $(71 \%)$, dentre os packing-houses que destinam sua produção para o mercado interno, gira em torno de 100 a 500 mil caixas por ano. Já as unidades de beneficiamento que processam volumes superiores a este valor, além de atenderem ao mercado interno, atuam, também, no mercado externo. Na maior parte dos casos (77\%), verificou-se que os packing-houses localizam-se dentro da própria fazenda ou na mesma cidade em que se situa a área de produção, devido à maior proximidade. Quando isso não ocorre, razões relativas à origem e expansão da empresa, bem como questões logísticas, foram apontadas como motivos da opção de localização adotada.

O processamento de laranja ocorre praticamente $O$ ano todo, o que é possivel graças à diversificação dos cultivares utilizados nos pomares. Ainda assim, $83 \%$ dos entrevistados afirmaram processar outras frutas, especialmente as demais espécies cítricas e, em menor escala, a manga e o abacate. No que tange às perdas (10\%, em média), observou-se que são bem variáveis (de 3 a $25 \%$ ) e dependentes do grau de tecnologia e tratamento dispensados à fruta, desde o plantio até o pós colheita. 
Um ponto que merece destaque é a dinâmica de produção e processamento, que é bastante diferenciada em função do mercado que o produtor deseja atingir. Observou-se, basicamente, duas situações: mercado interno e exportação (exterior e região Nordeste). No primeiro caso, o produtor, além de possuir packing-houses, atua no mercado atacadista e se encarrega do transporte da fruta, além de vender o produto diretamente ao setor varejista, em especial aos supermercados. Neste segmento, praticamente não se nota uma grande diferenciação do produto. A maior parte dos produtores $(61 \%)$ busca a diferenciação por meio da melhoria da aparência da fruta, o que se dá via aplicação de ceras, fungicidas e acondicionamento em embalagens de madeira com bom acabamento.

Quando o objetivo é a exportação, a diferenciação se dá desde a seleção das mudas, passando pelo tratamento pré-colheita, a colheita propriamente dita e 0 tratamento pós-colheita. Ou seja, todas as etapas de produção são mais rigorosas, assim como a classificação e o acondicionamento da fruta. Além disso, existem empresas que estão adotando certificados de não utilização de defensivos agrícolas em seu produto.

A maior parte dos entrevistados (56\%), compra laranja de terceiros para satisfazer suas necessidades operacionais, sendo a negociação informal. A escolha dos fornecedores, que podem ou não ser fixos, se dá em função da qualidade da matéria-prima e, em menor grau, pelo preço. Verificou-se, também, na pesquisa, que $72 \%$ dos produtores/atacadistas vendem laranja para feiras-livres, $72 \%$ para supermercados, $39 \%$ para varejões, $50 \%$ para sacolões e $11 \%$ para quitandas e redes de distribuição. Além de atender ao mercado paulista, grande parte dos atacadistas negocia com agentes de outros estados, destacando-se os do Sul do país $(50 \%)$.

$O$ acondicionamento da laranja pode ser realizado em embalagens de papelão, no caso de exportação, e em embalagens de madeira (caixa $M$ ) ou de plástico, quando se trata do mercado interno. As embalagens de madeira são as mais utilizadas e têm um custo que varia de $R \$ 0,60$ a $R \$ 2,70$, dependendo de sua qualidade. $O$ fato das caixas tipo $M$ serem retornáveis constitui um grande problema para os atacadistas, pois a devolução nem sempre ocorre, apesar de ser cobrado um depósito dos compradores. Dessa forma, observam-se altos índices de perda de embalagens, que podem chegar até a $50 \%$ ao mês. 
Quanto ao maquinário utilizado para a classificação da laranja, estão disponíveis no mercado vários tipos de classificadoras, as quais são adquiridas em função do segmento em que o produtor deseja atuar. No caso do mercado interno, as máquinas utilizadas selecionam a fruta conforme seu diâmetro. Quando se trata de classificação de produtos voltados para o mercado externo, costuma-se utilizar máquinas que selecionam a fruta de acordo com seu peso e coloração da epiderme. Estas últimas máquinas apresentam um valor de compra muito elevado, o que dificulta sua aquisição por parte dos produtores de menor porte. Apesar disso, segundo os entrevistados, os supermercados estão adotando a classificação proposta pelo Programa Brasileiro para a Melhoria do Padrões Comerciais e Embalagens de Hortigranjeiros, elaborada no ano 2000 pela Secretaria da Agricultura e do Abastecimento do Estado de São Paulo, que considera a cor como um parâmetro de classificação. Futuramente, acredita-se que isso possa se transformar num fator de redução de mercado de laranja in natura para os pequenos produtores.

\subsubsection{Distribuição Atacadista}

Stern et al. (1996) ${ }^{4}$ e Berman (1996) ${ }^{5}$, citados por Neves (1999), definem as atividades atacadistas como as exercidas por estabelecimentos que vendem a varejistas, compradores industriais, institucionais e comerciais, mas não em quantias significativas aos consumidores finais.

Segundo Neves (1999), no caso de sistemas agroindustriais, diversas empresas podem exercer atividades atacadistas, seja nas etapas iniciais (distribuição de insumos aos produtores), na distribuição de suprimentos para as indústrias, atuando na venda da produção agropecuária até sua chegada às indústrias ou ao consumidor, no caso de produtos in natura. No entanto, a principal posição do atacado é como fornecedor de serviços de alimentação (fora do lar) ao varejo e à indústria.

Para Neves (1999), uma das principais funções do atacado é a de melhorar a coordenação entre a produção e o consumo, suprindo lacunas e tentando reduzir

\footnotetext{
${ }^{4}$ STERN, L. W; EL-ANSARY A. I; Coughlan, A. Marketing channels. $5^{\text {th }}$ ed. Englewood Cliffs: Prentice-Hall, 1996. 576p.

${ }^{5}$ BERMAN, B. Marketing channels. John Willey \& Sons, 1996. 663p.
} 
irregularidades de oferta e demanda, e prover o diferencial dos serviços esperados pelos consumidores e os oferecidos pelos fabricantes, diretamente.

Neves (1999) destaca, ainda, que se tem observado uma crescente especialização neste setor, em resposta às demandas mais especificas de serviços por parte de seus consumidores (o varejo) e fornecedores (a indústria). Dentre os serviços prestados aos fornecedores, Stern et al. (1996) e Berman (1996), citados por Neves (1999), destacam a cobertura de mercado, o contato de vendas, a estocagem, o processamento de pedidos, a informação de mercado e o apoio aos consumidores. Quanto aos serviços prestados aos seus clientes (varejistas), os autores salientam as funções de disponibilização de produtos, de conveniência no suprimento, de fracionamento, de crédito e de suporte técnico.

No Brasil, o mercado atacadista de produtos in natura é constituído pelas Centrais de Abastecimento (CEASAs), as quais encontram-se instaladas nas capitais e nos principais municípios de todos os estados brasileiros. Dentre elas, destaca-se o Entreposto Terminal de São Paulo (E.T.S.P), considerado o segundo maior centro de comercialização atacadista de hortigranjeiros e pescado do mundo. De acordo com Amaro et al. (1997), o entreposto é responsável por pouco mais de $25 \%$ de toda a comercialização verificada nos entrepostos oficiais do país, abastecendo a população da cidade de São Paulo, interior do Estado e muitas das principais capitais nacionais.

No Estado de São Paulo, o mercado atacadista de frutas é constituído pela rede de entrepostos da Companhia de Armazéns Gerais de São Paulo (CEAGESP), que inclui, além do Entreposto Terminal de São Paulo (E.T.S.P), mais 9 CEASAs regionais. Segundo Amaro et al., (1997), as funções da CEAGESP são complementadas, no âmbito da região metropolitana de São Paulo, pelo mercado atacadista da zona central da cidade (Mercado Central, Mercado da Cantareira e Zona Cerealista da Santa Rosa) e pelas Centrais de Abastecimento de Santo André (CRAISA). No interior, destacam-se, ainda, as Centrais de Abastecimento de Campinas e de Jundiai (vide Figura 6). 


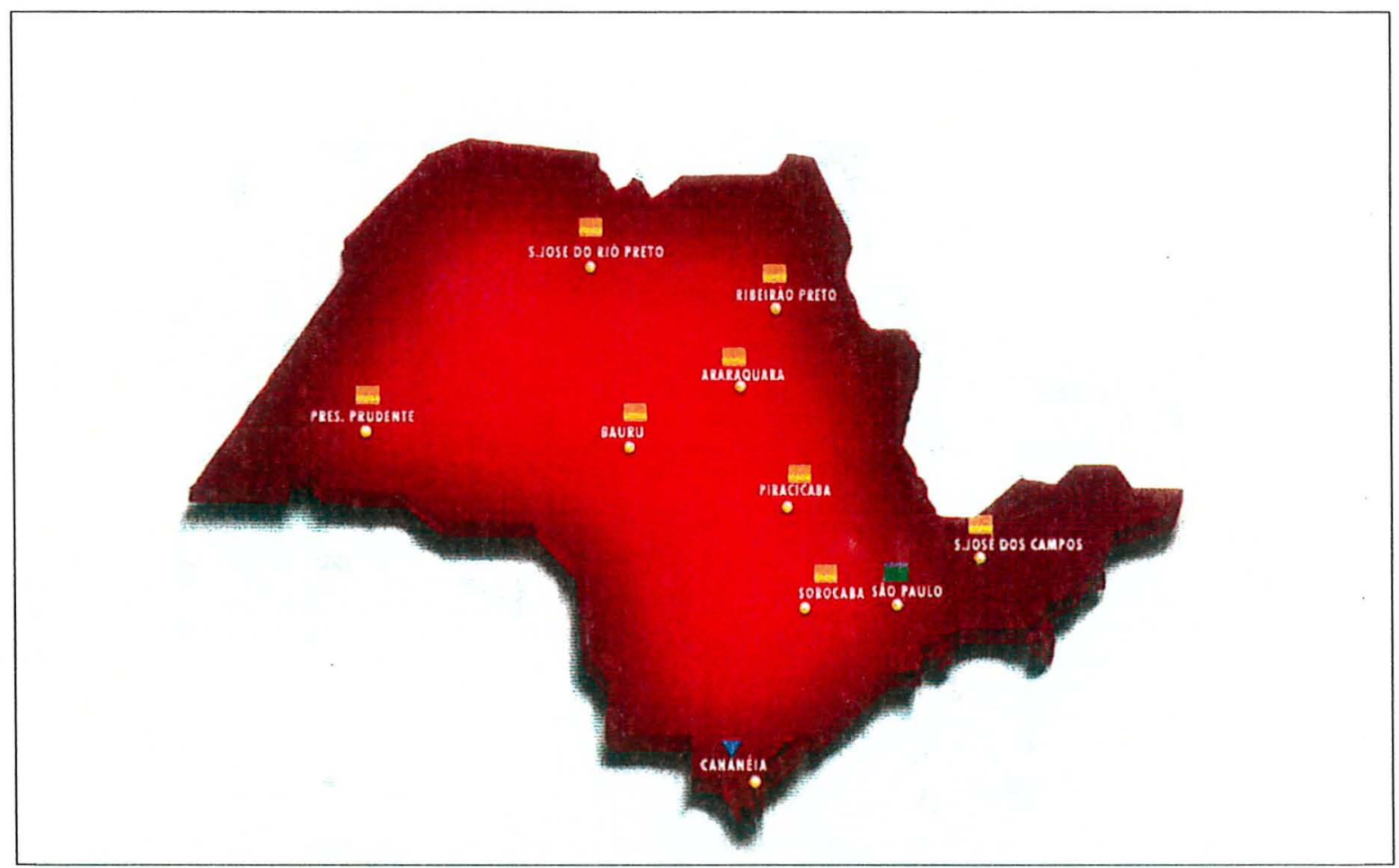

Figura 6 - Centrais de Abastecimento Regionais, São Paulo.

Fonte: Companhia de Entrepostos e Armazéns Gerais do Estado de São Paulo (2000).

Para Stern et al. (1996) e Berman (1996), mencionados por Neves (1999), as funções do atacado estão sendo repensadas, em função das mudanças no ambiente de negócios, tais como compras diretas entre varejo e indústria de alimentos, e todas as outras observadas no macroambiente. Segundo Neves (1999), as principais tendências do mercado atacadista são as seguintes:

- estratégia de foco: as empresas estão se focando em determinados mercados e oferecendo linhas de produtos mais completas, no sentido de satisfazer totalmente às necessidades de suprimentos do comprador. Esta estratégia é cada vez mais necessária, devido à crescente competição por parte dos grandes varejistas, que têm elevada lealdade dos consumidores e oferecem completa linha de produtos;

- uso da tecnologia: o atacado deve ser um importante agente difusor da tecnologia de informação e distribuição nos sistemas. Nesse sentido, a adoção de código de barras, depósitos automatizados, troca eletrônica de dados e informações, entre outras ações, possibilitam corte de custos, aumento de produtividade, melhora do fluxo de informações e melhora dos serviços aos consumidores. A tecnologia pode se constituir 
num problema para o atacado, pois, com estas ferramentas disponiveis também ao varejo e à indústria, algumas de suas funções poderão ser substituídas de maneira mais fácil;

- qualidade total na distribuição: implementação de programas de qualidade, atividades de pesquisa de mercado, entre outras;

- investimentos no varejo: visando a garantir a sobrevivência do pequeno varejo, foco da atuação do atacadista distribuidor, alguns grupos estão investindo no varejo.

Segundo Barrizzelli (1998) ${ }^{6}$, citado por Neves (1999), só sobreviverão no segmento atacadista os agentes que:

- não focam apenas preço, e sim, o serviço e o cliente;

- os especializados;

- os que se preocupam com custos, modemização da gestão, planejamento e controle financeiro;

- os que fidelizam o varejo e trabalham com poucos itens;

- os operadores logísticos;

- os que têm raio limitado de atuação;

- os que têm compromisso com os fabricantes.

Amaro et al. (1997) afirmam que em relação ao comércio atacadista de hortigranjeiros, espera-se que, no Brasil, ocorra uma crescente perda de importância dos entrepostos oficiais, já que os modernos equipamentos de distribuição, principalmente supermercados, estão otimizando as funções ligadas ao abastecimento de suas lojas, por meio da redução de intermediários comerciais e da utilização de sistemas mais eficientes de padronização de produtos, formas de acondicionamento e de sistemas logísticos de distribuição.

\footnotetext{
${ }^{6}$ Revista Distribuição, dez. 1998. p. 21
} 


\subsection{Comercialização de laranja na CEAGESP}

\subsection{Embalagens e movimentação de carga no entreposto}

De um modo geral, a movimentação de carga na CEAGESP pode ser considerada bastante defasada. Nos boxes, o descarregamento do produto, assim como o carregamento do caminhão com embalagens vazias, é feito manualmente. A movimentação da laranja dentro do entreposto também é realizada com o auxílio de "tração humana", ou seja, é feita por carregadores credenciados, que utilizam carrinhos para transportar o produto. Estas práticas, além de causarem danos mecânicos, consomem muito tempo, impondo altos custos de comercialização à laranja.

No que se refere à embalagem, a mais utilizada pelos atacadistas é a caixa de madeira tipo " $M$ ", que tem capacidade para acondicionar $25 \mathrm{~kg}$ de fruta e possui dimensões não paletizáveis: $54 \times 29 \times 29 \mathrm{~cm}$ (vide Figura 7). Embora apresente baixo custo de aquisição, fato que explica sua permanência no mercado há mais de 30 anos, a caixa tipo " $M$ " exibe inúmeras desvantagens, sendo as principais relacionadas às condições de higiene, ergonomia do trabalho, apresentação do produto, limitação no aproveitamento da capacidade de carga líquida do caminhão, além de onerar as atividades de carga e descarga do produto.

Apesar da hegemonia da caixa " $M$ ", verifica-se, também, a existência de embalagens de papelão e de plástico (retornáveis). As primeiras podem acondicionar de 18 a $20 \mathrm{~kg}$ de laranja, apresentando grande variedade no que diz respeito às dimensões, as quais podem ou não ser paletizáveis. De acordo com Harder (1998), a utilização do papelão vem aumentando devido às exigências do setor supermercadista. As embalagens de plástico, que possuem capacidade de 14 a $18 \mathrm{~kg}$, apresentam uma característica importante: facilitam o processo de desinfecção. A despeito de possuírem alto custo de aquisição, espera-se que a utilização das embalagens plásticas, de forma generalizada, tenha sucesso, pois os atacadistas estão familiarizados com o sistema de embalagens retornáveis, o que não ocorre com as embalagens de papelão (vide Figuras 8, 9 e 10). 


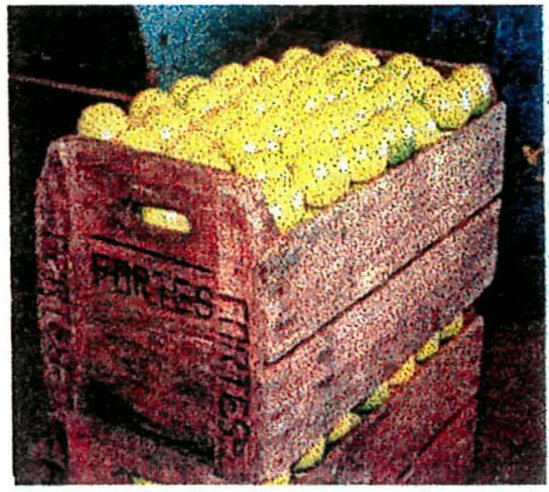

Figura 7 - Embalagem de madeira.

Fonte: CQH/CEAGESP.

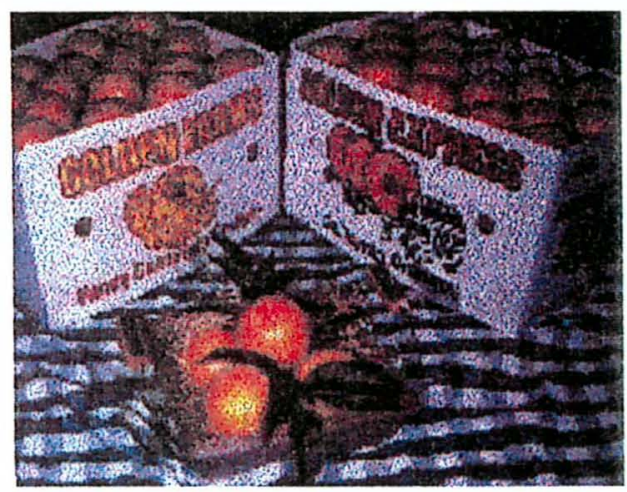

Figura 9 - Embalagem de papelão.

Fonte: CQH/CEAGESP.

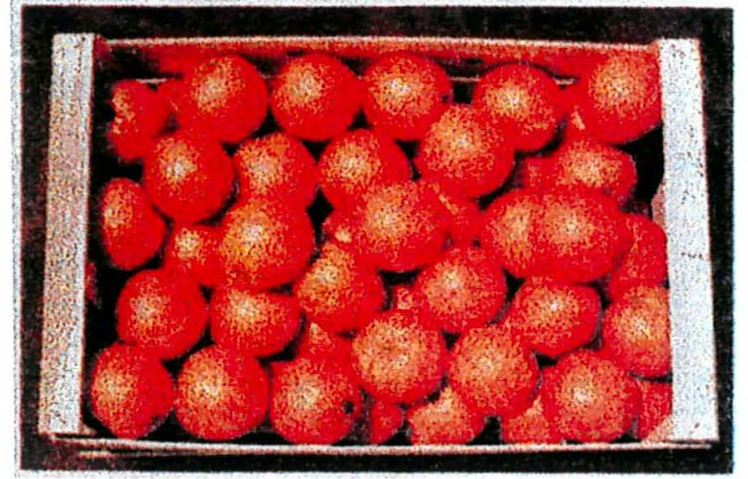

Figura 8 - Embalagem de madeira laminada. Fonte: CQH/CEAGESP.

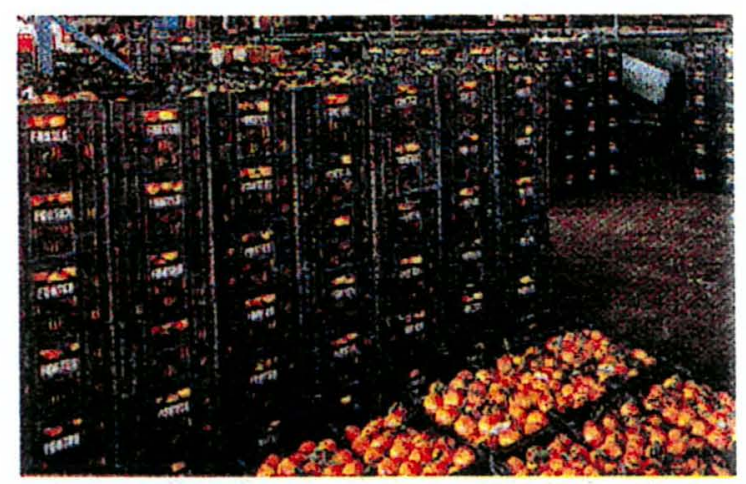

Figura 10 - Embalagem de madeira laminada. Fonte: CQH/CEAGESP.

\subsection{Volume comercializado e preços}

Analisando o período compreendido entre 1994 e 1998, nota-se que, em média, foram comercializadas na CEAGESP cerca de 14,63 milhões de caixas de laranja por ano, o que representa aproximadamente $3 \%$ da produção do Estado e $11 \%$ do total de frutas destinadas ao mercado interno (vide Figura 11). 


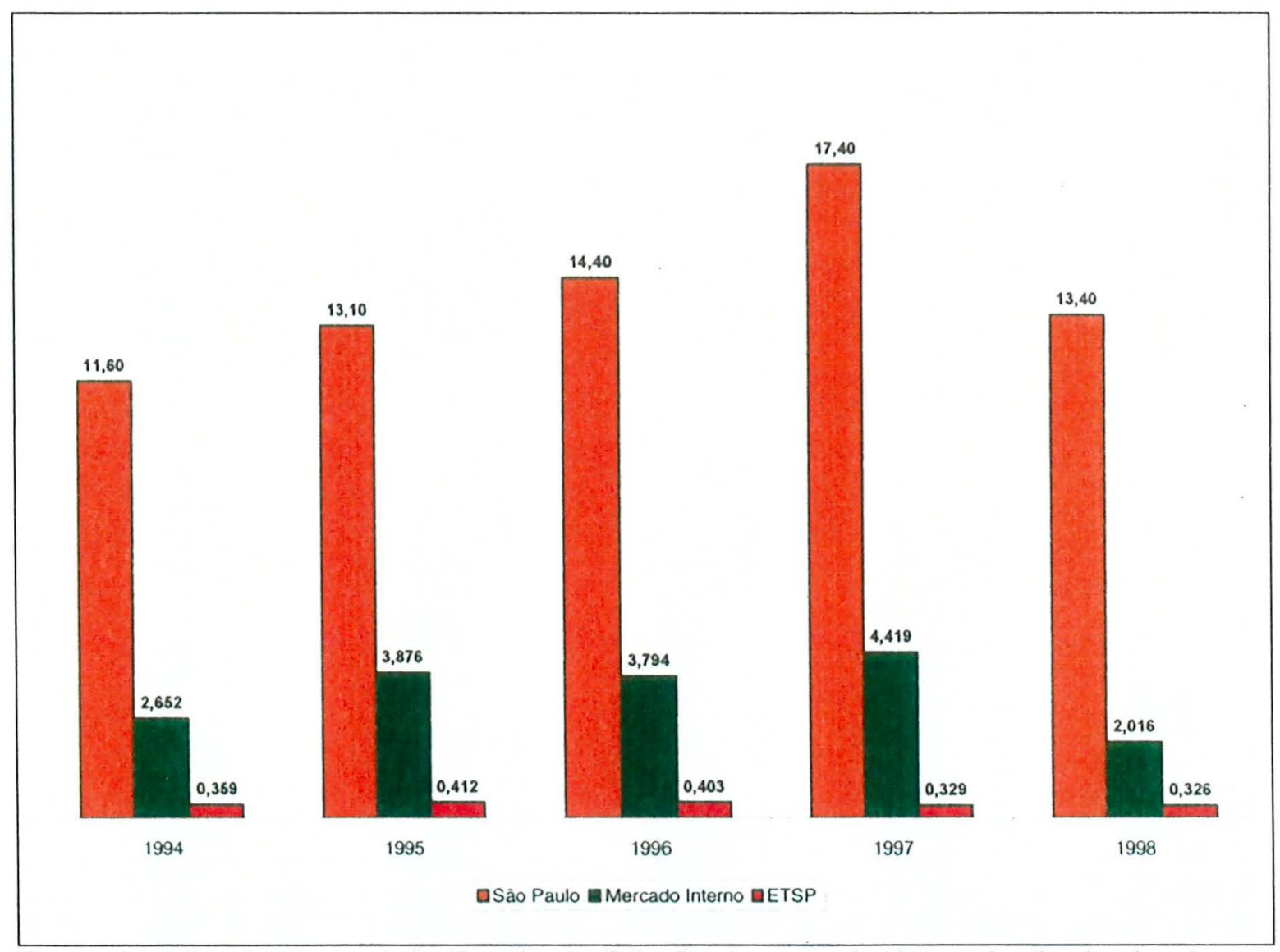

Figura 11 - Produção total do Estado de São Paulo, parcela da produção destinada ao mercado interno e volume de laranja comercializado no ETSP, em milhões de toneladas.

Fonte: Centro de Qualidade em Horticultura - CQH/CEAGESP (2000).

A CEAGESP vem perdendo importância como centralizadora do escoamento da produção para o mercado varejista. Esta tendência pode ser verificada comparando-se a produção de laranja destinada ao mercado interno com o volume comercializado no entreposto. A partir dos dados contidos na Tabela 9, observa-se que, em fins da década de 80, a CEAGESP era responsável, em média, por $18 \%$ da comercialização de laranja destinada ao mercado interno. Na década de 90, esta participação foi reduzida para 13\%, em média. Boteon (1999) aponta a comercialização direta dos packing-houses nos mercados atacadistas e varejistas como causa principal desta queda de participação. 
Tabela 9. Participação da CEAGESP no volume de laranja* destinado ao mercado interno**, 1986 a 1998.

\begin{tabular}{ccc}
\hline Ano & $\begin{array}{c}\text { Volume comercializado } \\
\text { (mil toneladas) }\end{array}$ & $\begin{array}{c}\text { Participação no volume destinado } \\
\text { ao mercado interno (\%) }\end{array}$ \\
\hline 1986 & 567 & 19 \\
1987 & 581 & 21 \\
1988 & 400 & 16 \\
1989 & 526 & 18 \\
1990 & 552 & 16 \\
1991 & 513 & 14 \\
1992 & 436 & 17 \\
1993 & 512 & 13 \\
1994 & 359 & 14 \\
1995 & 412 & 11 \\
1996 & 403 & 11 \\
1997 & 329 & 7 \\
1998 & 325 & 16 \\
\hline Fonte: adaptado de Boteon (1999), a partir de informações do boletim Mensal CEAGESP (1980-1998) e \\
Centro de Qualidade em Horticultura (CQH)/CEAGESP (2000). \\
*considera somente os cultivares Baia, Lima, Pera, Seleta e Valência. \\
**considera somente a produção do Estado de São Paulo.
\end{tabular}

No que se refere às variedades de laranja comercializadas no entreposto, apenas a Lima, a Pera, a Baía, a Seleta e a Valência apresentam volumes de comercialização significativos. Dentre elas, destaca-se a Pera que, durante o período de 1994 a 1998, respondeu por mais de $80 \%$ do volume total de laranja comercializado (vide Figura 12). Neste mesmo período, o cultivar que atingiu cotações mais elevadas foi a laranja Baía, $R \$ 10,80$ /caixa, em média, seguida pelas laranjas Lima (R\$ 8,94/caixa), Seleta (R\$ 6,89/caixa), Pera (R\$6,30/caixa) e Valência ( $R$ \$ 5,18/caixa). 


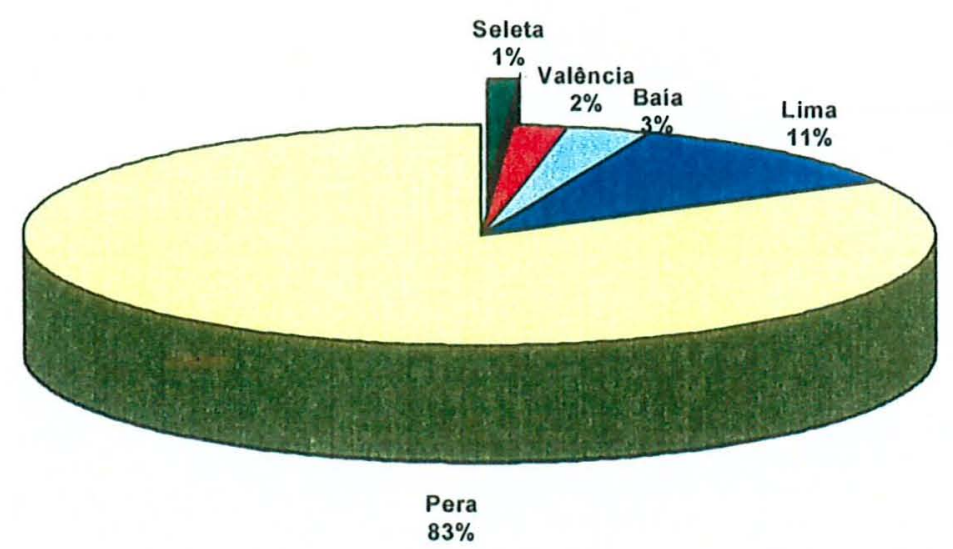

Figura 12 - Participação dos cultivares de laranja na comercialização do ETSP, 1994 a 1998.

Fonte: Centro de Qualidade em Horticultura/CEAGESP (2000).

\subsection{Procedência da laranja comercializada no ETSP}

Em relação à procedência do produto, constata-se que a laranja comercializada no entreposto é oriunda de diversas regiões produtoras, tanto do Estado de São Paulo quanto de outros estados e, até mesmo, de outros países. A título de ilustração, pode-se considerar o ano de 1998, quando foram comercializadas mais de 12 milhões de caixas de laranja, distribuídas da seguinte forma: 95,87\% provenientes de regiões produtoras do Estado de São Paulo, 3\% de origem desconhecida, $0,72 \%$ de outros estados e $0,41 \%$ de outros países.

Das 40 regiões agrícolas existentes no Estado de São Paulo, apenas Guaratinguetá não contribuiu no volume total de laranja comercializado no entreposto, o que demonstra que a cultura está distribuída, praticamente, por todo o Estado. Dentre as principais regiões fornecedoras destacaram-se, em 1998: Limeira, Mogi Mirim, Jaboticabal, São João da Boa Vista e Barretos que, juntas, responderam por quase $70 \%$ do volume total comercializado (vide Figura 13). Neste ano, a variedade mais vendida foi a laranja Pera $(81,08 \%)$, sendo seguida pelas variedades Lima $(12,09 \%)$, Baía $(4,01 \%)$, Valência $(2,22 \%)$ e Seleta $(0,60 \%)$. 


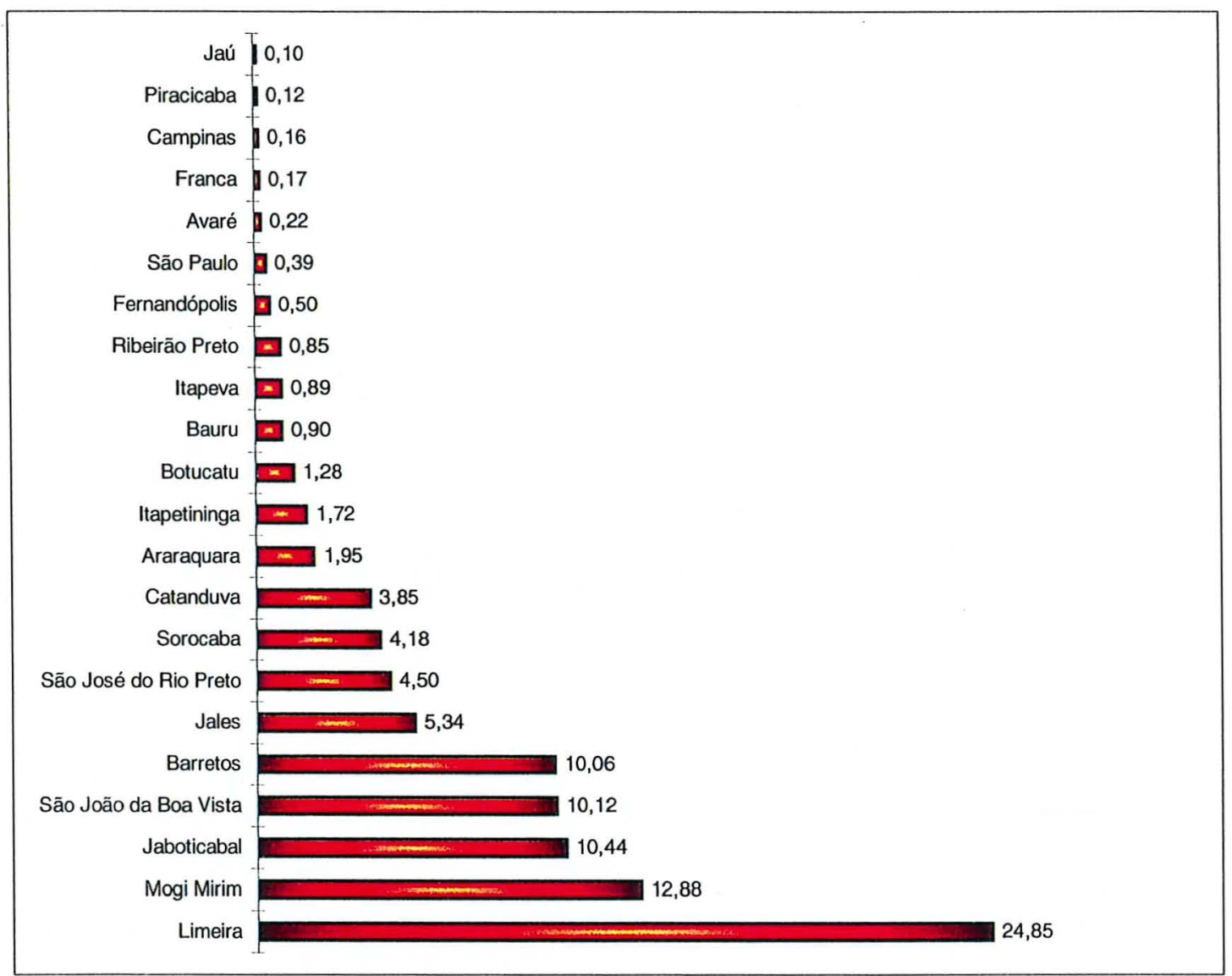

Figura 13 - Participação das regiões produtoras no volume total de laranja comercializada no $\mathrm{ETSP}^{7}$.

Fonte: Centro de Qualidade em Horticultura/ CEAGESP.

Para uma análise mais detalhada sobre a procedência da laranja, a Tabela 10 lista os municípios produtores e suas respectivas participações no total de laranja enviado pela região agrícola ao entreposto. Na Tabela 11, lista-se a participação de cada variedade no volume total fornecido pela região.

${ }^{7} \mathrm{O}$ gráfico considera somente as regiões com participação superior a $0,10 \%$, de forma que as regiões mencionadas na figura perfazem um total de $95,49 \%$, sendo os $4,51 \%$ restantes divididos entre as demais regiões agrícolas do Estado de São Paulo. 
Tabela 10. Participação do município no total de laranja enviado para o ETSP, 1998.

\begin{tabular}{|c|c|c|}
\hline EDR $^{*}$ & Município & $\begin{array}{l}\text { \% do Município no total do } \\
\text { EDR }\end{array}$ \\
\hline \multirow{11}{*}{ Limeira } & Limeira & 84,55 \\
\hline & Cordeirópolis & 8,17 \\
\hline & Araras & 3,65 \\
\hline & Porto Ferreira & 1,96 \\
\hline & Corumbataí & 0,77 \\
\hline & Itirapina & 0,39 \\
\hline & Pirassununga & 0,39 \\
\hline & Leme & 0,06 \\
\hline & Analândia & 0,03 \\
\hline & Cosmópolis & 0,01 \\
\hline & Santa Gertrudes & 0,01 \\
\hline \multirow[t]{4}{*}{ Total fornecido pelo EDR } & 3.128 .277 caixas de $25 \mathrm{~kg}$ & 100,00 \\
\hline & Mogi Mirim & 30,85 \\
\hline & Artur Nogueira & 23,90 \\
\hline & Jaguariúna & 18,89 \\
\hline \multirow[t]{4}{*}{ Mogi Mirim } & Conchal & 12,77 \\
\hline & Mogi Guaçu & 8,55 \\
\hline & Espirito Santo do Pinhal & 5,02 \\
\hline & Santo Antônio de Posse & 0,02 \\
\hline \multirow[t]{4}{*}{ Total fornecido pelo EDR } & 1.622 .205 caixas de $25 \mathrm{~kg}$ & 100,00 \\
\hline & Taquaritinga & 32,33 \\
\hline & Vista Alegre do Alto & 28,07 \\
\hline & Taiaçu & 22,66 \\
\hline \multirow{6}{*}{ Jaboticabal } & Taiúva & 6,68 \\
\hline & Monte Alto & 5,11 \\
\hline & Itápolis & 2,27 \\
\hline & Fernando Prestes & 1,79 \\
\hline & Cândido Rodrigues & 0,67 \\
\hline & Borborema & 0,43 \\
\hline \multirow[t]{4}{*}{ Total fornecido pelo EDR } & 1.314 .349 caixas de $25 \mathrm{~kg}$ & 100,00 \\
\hline & Aguai & 30,81 \\
\hline & Santa Cruz das Palmeiras & 28,12 \\
\hline & Casa Branca & 23,72 \\
\hline \multirow{4}{*}{ São João da Boa Vista } & Mococa & 9,48 \\
\hline & Tambaú & 7,75 \\
\hline & São José do Rio Pardo & 0,11 \\
\hline & Vargem Grande do Sul & 0,01 \\
\hline Total fornecido pelo EDR & 1.273.726 caixas de $25 \mathrm{~kg}$ & 100,00 \\
\hline
\end{tabular}


Tabela 10. Participação do município no total de laranja enviado para o ETSP, 1998 .

\begin{tabular}{clc}
\hline \multicolumn{1}{c}{ EDR $^{*}$} & \multicolumn{1}{c}{ Município } & $\begin{array}{c}\text { \% do Município no total do } \\
\text { EDR }\end{array}$ \\
\hline \multirow{4}{*}{ Barretos } & Bebedouro & 46,77 \\
& Pirangi & 38,23 \\
& Barretos & 13,60 \\
& Monte Azul Paulista & 0,49 \\
& Colina & 0,36 \\
& Pitangueiras & 0,24 \\
& Cajobi & 0,15 \\
& Altair & 0,09 \\
Total fornecido pelo EDR & Olímpia & 0,08 \\
\hline
\end{tabular}

Fonte: Centro de Qualidade em Horticultura/CEAGESP.

*Escritório de Desenvolvimento Rural

Tabela 11. Participação das variedades no volume comercializado no ETSP, 1998.

\begin{tabular}{|c|c|c|}
\hline EDR & Variedade & $\begin{array}{l}\% \text { da variedade no total fornecido } \\
\text { pelo EDR }\end{array}$ \\
\hline \multirow{4}{*}{ Limeira } & Pera & 69,91 \\
\hline & Lima & 20,31 \\
\hline & Valência & 5,17 \\
\hline & Baía & 3,34 \\
\hline \multirow{3}{*}{ Total fornecido pelo EDR } & Seleta & 1,27 \\
\hline & 3.128 .277 caixas de $25 \mathrm{~kg}$ & 100,00 \\
\hline & Pera & 84,03 \\
\hline \multirow{4}{*}{ Mogi Mirim } & Lima & 7,76 \\
\hline & Valência & 5,95 \\
\hline & Baía & 1,70 \\
\hline & Seleta & 0,56 \\
\hline \multirow[t]{2}{*}{ Total fornecido pelo EDR } & 1.622 .205 caixas de $25 \mathrm{~kg}$ & 100,00 \\
\hline & Pera & 94,88 \\
\hline \multirow{4}{*}{ Jaboticabal } & Lima & 4,75 \\
\hline & Valência & 0,19 \\
\hline & Baía & 0,18 \\
\hline & Seleta & 0,01 \\
\hline \multirow[t]{2}{*}{ Total fornecido pelo EDR } & 1.314 .349 caixas de $25 \mathrm{~kg}$ & 100,00 \\
\hline & Pera & 83,47 \\
\hline \multirow{4}{*}{ São João da Boa Vista } & Lima & 10,17 \\
\hline & Baía & 3,85 \\
\hline & Valência & 1,69 \\
\hline & Seleta & 0,83 \\
\hline Total fornecido pelo EDR & 1.273 .726 caixas de $25 \mathrm{~kg}$ & 100,00 \\
\hline
\end{tabular}


Tabela 11. Participação das variedades no volume comercializado no ETSP, 1998.

\begin{tabular}{|c|c|c|}
\hline EDR & Variedade & $\begin{array}{c}\% \text { da variedade no total fornecido } \\
\text { pelo EDR }\end{array}$ \\
\hline \multirow{5}{*}{ Barretos } & Pera & 83,47 \\
\hline & Lima & 10,17 \\
\hline & Baía & 3,85 \\
\hline & Valência & 1,69 \\
\hline & Seleta & 0,83 \\
\hline Total fornecido pelo EDR & 1.273 .726 caixas de $25 \mathrm{~kg}$ & 100,00 \\
\hline
\end{tabular}

Fonte: Centro de Qualidade em Horticultura/CEAGESP.

No que se refere às laranjas procedentes de outros estados, o de maior destaque foi Minas Gerais, que respondeu por, aproximadamente, $60 \%$ do total fornecido pelos demais estados (vide Tabela 12). Quanto às variedades, a laranja Pera é a que apresentou maior participação $(90,94 \%)$ no total fornecido, seguida pelas variedades Baia $(4,13 \%)$, Lima $(3,77 \%)$, Valência $(0,97 \%)$ e Seleta $(0,18 \%)$

Tabela 12. Participação dos estados no fornecimento de laranja ao ETSP, 1998.

\begin{tabular}{lccc}
\hline \multicolumn{1}{c}{ Estado } & Volume (cx. de 25 kg). & \% na CEAGESP & $\begin{array}{c}\% \text { no Total dos } \\
\text { Estados }\end{array}$ \\
\hline Minas Gerais & 54.162 & 0,43 & 59,83 \\
Bahia & 12.652 & 0,10 & 13,98 \\
Goiás & 5.316 & 0,04 & 5,87 \\
Rio Grande do Sul & 5.019 & 0,04 & 5,54 \\
Paraná & 3.720 & 0,03 & 4,11 \\
Santa Catarina & 3.108 & 0,02 & 3,43 \\
Rio de Janeiro & 2.018 & 0,02 & 2,23 \\
Pernambuco & 1.764 & 0,01 & 1,95 \\
Espírito Santo & 1.132 & 0,01 & 1,25 \\
Mato Grosso & 609 & 0,00 & 0,67 \\
Alagoas & 470 & 0,00 & 0,52 \\
Tocantins & 382 & 0,00 & 0,42 \\
Mato Grosso do Sul & 168 & 0,00 & 0,19 \\
Total dos Estados & 90.520 & 0,72 & 100,00 \\
\hline
\end{tabular}

Fonte: Centro de Qualidade em Horticultura/CEAGESP.

No tocante à comercialização de laranja importada, verifica-se que sua participação é marginal, representando apenas $0,41 \%$ do volume total comercializado no entreposto. Em termos absolutos, este valor significa a entrada de 51.470 caixas, oriundas do Uruguai, da Espanha e da Argentina. Do total de laranjas importadas e 
comercializadas no entreposto no ano de $1998,90,44 \%$ pertenciam à variedade Baía, $8,24 \%$ à variedade Pera, $0,78 \%$ à variedade Lima e $0,54 \%$ à Seleta.

Quanto à procedência de cada variedade, vale destacar que o Uruguai respondeu por $50,48 \%$ da laranja Baía importada, sendo seguido por Espanha $(36,77 \%)$ e Argentina $(12,75 \%)$. Em relação à variedade Pera, o país que apresentou maior participação em seu fornecimento foi a Espanha (74,53\%), seguida da Argentina (20,75\%), e do Uruguai $(4,72 \%)$. As variedades Lima e Seleta foram envidas somente por Argentina e Uruguai, respectivamente.

O Uruguai foi responsável por $46,58 \%$ (23.976 caixas) do total de laranja importada comercializada no entreposto. Destas, $98 \%$ pertenciam à variedade Baía, $1,17 \%$ à Seleta e $0,83 \%$ à Pera. A Espanha enviou ao entreposto 20.280 caixas $(39,40 \%)$ de laranja, as quais se distribuíram do seguinte modo: $84,41 \%$ de laranja Baía e 15,59\% de laranja Pera. Finalmente, a Argentina respondeu por 14,02\% (7.214 caixas) da laranja importada e comercializada no ETSP, sendo que destas, $82,26 \%$ eram da variedade Baía, $12,20 \%$ da variedade Pera e 5,54\% da variedade Lima.

\subsubsection{Distribuição Varejista}

Stern et al. (1996), Berman (1996) e Rosembloon (1999) ${ }^{8}$, citados por Neves (1999), definem varejo como sendo um composto de atividades ligadas à venda de produtos e serviços aos consumidores para uso pessoal, familiar ou da casa. De acordo com o autor, existe um grande número de formatos diferentes de lojas varejistas, dependendo do foco, tamanho, número de produtos, especialização e outros fatores. No Brasil, os tipos mais importantes para distribuição são os hipermercados, supermercados, lojas de conveniência e lojas de especialidades (açougues, varejões, padarias, mercearias entre outros).

Segundo Neves (1999), o setor supermercadista é o principal equipamento varejista, sendo responsável por cerca de $80 \%$ das vendas globais do varejo. Este setor apresenta um grande potencial de desenvolvimento no pais, o que tem trazido investimentos externos de grandes redes mundiais, tais como Ahold, Sonae, Wal Mart e Carrefour. Tais investimentos, apesar de consolidarem fortemente o setor, estão

\footnotetext{
${ }^{8}$ ROSEMBLOON, B. Marketing channels. $6^{\text {th }}$ ed. The Dyden Press, 1999. 688p.
} 
gerando uma grande concentração neste mercado, uma vez que, nos últimos anos, as grandes redes têm adquirido um grande número de lojas.

No caso da distribuição de produtos frescos, os produtores têm como opção a venda para exportadores, compradores da própria região e, principalmente, para atacadistas que atuam nas centrais de abastecimento. Dos mercados atacadistas até os consumidores, os produtos são distribuídos por meio de variada rede de equipamentos varejistas, dentre os quais destacam-se, pela importância, as feiraslivres, supermercados, sacolões e varejões, além de ambulantes, quitandas e frutarias, com menores participações.

Comparando-se a Pesquisa de Orçamentos Familiares, realizada pelo Instituto Brasileiro de Geografia e Estatística (IBGE) nos anos de 1987/88 e 1995/96, constata-se que as feiras-livres são os equipamentos mais importantes na distribuição da laranja, especialmente nas áreas de periferia e nas classes sociais de menor poder aquisitivo. No entanto, estão perdendo espaço para os mercados, sacolões e supermercados (vide Tabela 13).

De acordo com Amaro et al. (1997), outros estabelecimentos que estão perdendo importância na comercialização de laranja, em nível de varejo, são as frutarias, as quitandas e os mercados municipais, principalmente nos grandes centros. A perda de participação de mercado de formatos tradicionais, tais como feiras livres e quitandas, deve-se ao fato dos consumidores estarem buscando maior conveniência, comodidade e variedade, de modo que possam realizar suas compras num mesmo local, que thes seja atrativo e apresente soluções prontas.

Tabela 13. Participação dos equipamentos varejistas na comercialização de laranja, São Paulo, 1987/88 e 1995/96.

\begin{tabular}{lccc}
\hline $\begin{array}{c}\text { Equipamento } \\
\text { Varejista }\end{array}$ & $\begin{array}{c}\text { (I) Participação } \\
\text { em 1987/88 (\%) }\end{array}$ & $\begin{array}{c}\text { (II) Participação } \\
\text { em 1995/96 (\%) }\end{array}$ & $\begin{array}{c}\text { Variação } \\
\text { Percentual } \\
\text { (II/I) }\end{array}$ \\
\hline Armazém & 6,36 & 11,32 & 77,98 \\
Estabelecimento especializado & 0,91 & 1,89 & 107,69 \\
Feira-livre & 72,73 & 54,72 & $-24,76$ \\
Mercado e sacolões & 7,27 & 13,84 & 90,37 \\
Supermercado & 10,91 & 11,95 & 9,53 \\
Ambulante & 1,82 & 6,28 & 245,05 \\
\hline
\end{tabular}

Fonte: Pesquisa de Orçamentos Familiares (POF)/ Fundação Instituto Brasileiro de Geografia e Estatística (FIBGE). 
No que se refere aos supermercados, embora não detenham participação dominante, a venda de produtos hortícolas representa um potencial estratégico de negócios, na medida em que possibilitam a atração de um maior número de consumidores. Em vista disso, o setor tem investido na venda de frutas e hortaliças, o que tem contribuído para a melhoria da qualidade do produto ofertado. Já o crescimento da participação dos sacolões é explicado em função de algumas parcelas da população estarem buscando alternativas mais populares de suprimento, com preços mais acessíveis.

Por fim, como principais tendências do varejo, Neves (1999) aponta o crescimento do comércio eletrônico e das associações de compra, principalmente por parte dos pequenos varejistas; a automação e utilização da tecnologia como fator dominante; o aumento da participação das "marcas próprias" no mix de produtos ofertados e o foco no consumidor (melhoria na disposição dos produtos, no lay-out das lojas, na qualidade e no tipo de produto e segmentação dos consumidores).

\subsubsection{Mercado Consumidor}

Boteon (1999) afirma que o brasileiro consome laranja tanto in natura quanto na forma de sucos (caseiro, fresco, reconstituído e integral) ou, ainda, na forma cristalizada ou em compotas, sendo que a proporção de cada uma dessas formas de consumo ainda não está bem quantificada na literatura.

De acordo com a autora anteriormente citada, o mercado interno de laranja apresenta uma característica muito peculiar, quando comparado aos demais países tradicionais na comercialização da fruta fresca. $O$ consumidor brasileiro adquire tanto os cultivares de mesa (Baía, Lima) quanto os específicos para a indústria (Pera, Natal e Valência) para o consumo in natura, uma vez que a disponibilidade desses últimos no mercado interno é muito maior. Isso se deve ao fato das indústrias de suco terem exercido forte influência no parque citrícola paulista. Contudo, espera-se que haja uma especialização no consumo, ou seja, o grupo de laranjas próprias para a indústria deve ser mais consumido na forma de sucos, enquanto os cultivares típicos para consumo in natura devem ser consumidos como tal.

De acordo com a Pesquisa de Orçamentos Familiares (POF), realizada pelo Instituto Brasileiro de Geografia e Estatística (IBGE), com a finalidade de avaliar o 
consumo alimentar no Brasil, nos anos de $1987 / 88$ e 1995/96, a laranja Pera destacase como a fruta mais consumida nos domicílios da maior parte das regiões metropolitanas do país. Entretanto, analisando os dois períodos avaliados nos estudos mencionados acima, observa-se que o consumo per capita de laranja em São Paulo apresentou uma redução de, aproximadamente, $37 \%$, considerando-se os cultivares Pera e Lima (vide Tabela 14).

Tabela 14. Consumo per capita de laranja, São Paulo, 1987/88 e 1995/96

\begin{tabular}{lccc}
\hline Cultivar & $\begin{array}{c}\text { (I) } 1987 / 88 \\
\text { (kg/habitante/ano) }\end{array}$ & $\begin{array}{c}\text { (II) 1995/96 } \\
\text { (kg/habitante/ano) }\end{array}$ & $\begin{array}{c}\text { Variação percentual } \\
\text { (II/I) }\end{array}$ \\
\hline Baía & 2,70 & - & - \\
Lima & 1,70 & 0,80 & $-52,94$ \\
Pera & 18,50 & 12,0 & $-35,13$ \\
Seleta & 0,30 & - & - \\
Total & 23,20 & 12,80 & \\
\hline Fonte: Pesquisa de Orçamentos Familiares/ Fundação Instituto Brasileiro de Geografia e Estatística.
\end{tabular}

Este decréscimo pode ser atribuído à maior sofisticação do consumo, ocasionada pela estabilização da moeda na primeira metade da década de 90 . Além disso, um outro fator, salientado por Boteon (1999), é a concorrência dos sucos, principalmente o de laranja.

Analisando o consumo per capita nos domicilios, por classe de recebimento, o levantamento realizado em 1995/96 constatou que o dispêndio das familias com laranja representa, em média, $0,61 \%$ do gasto com alimentação e 12,30\% do gasto com frutas. Constatou-se, também, que a participação do dispêndio com laranja no gasto total com frutas é função da renda, com o consumo tendendo a aumentar conforme sua elevação. Todavia, apesar do maior dispêndio com laranja, verifica-se que, relativamente, a participação deste gasto tende a diminuir conforme o aumento da renda (vide Tabela 15), o que se explica pelo fato da camada de maior poder aquisitivo ter acesso a uma maior gama de espécies frutíferas. 
Tabela 15. Participação da laranja nos gastos com frutas, por faixa salarial, São Paulo, 1995/96.

\begin{tabular}{lccc}
\hline $\begin{array}{c}\text { Faixa Salarial } \\
\text { (salário mínimo) }\end{array}$ & $\begin{array}{c}\text { Despesa com Frutas } \\
(R \$)\end{array}$ & $\begin{array}{c}\text { Despesa com Laranja } \\
(R \$)\end{array}$ & $\begin{array}{c}\text { Participação da } \\
\text { laranja (\%) }\end{array}$ \\
\hline até 2 & 2,55 & 0,64 & 25,10 \\
de 2 a 3 & 3,78 & 0,79 & 20,90 \\
de 3 a 5 & 4,31 & 0,97 & 22,50 \\
de 5 a 6 & 7,16 & 1,52 & 21,23 \\
de 6 a 8 & 9,26 & 1,38 & 14,90 \\
de 8 a 10 & 6,41 & 1,05 & 16,38 \\
de 10 a 15 & 10,91 & 1,53 & 14,02 \\
de 15 a 20 & 9,38 & 1,68 & 17,91 \\
de 20 a 30 & 44,65 & 2,81 & 6,29 \\
mais de 30 & 20,65 & 2,50 & 12,11 \\
\hline Fonte: Pesquisa de Orçamentos Familiares/Fundação Instituto Brasileiro de Geografia e Estatística.
\end{tabular}

\subsubsection{Atividades Logísticas do Sistema Agroindustrial Da LaRanja in NATURA.}

No caso da laranja in natura, considera-se como atividades logísticas as operações realizadas desde a colheita da fruta até seu destino final. Portanto, essas atividades englobam as operações de colheita, beneficiamento e transporte da fruta até o mercado consumidor.

A colheita apresenta como principais objetivos a retirada de produtos do campo em níveis adequados de maturidade, com um mínimo de dano ou perda, com a maior rapidez possivel e a um custo mínimo. Conforme Petto Netto \& Pompeu Júnior (1991), o início da colheita das laranjas destinadas ao consumo in natura é determinado pela coloração externa da casca e por uma relação acidez/sólidossolúveis mínima, ao redor de 1:7 (vide Figuras 14 e 15).

De acordo com esses autores, após colhidas, as frutas são colocadas em sacolas (vide Figura 16) e, em seguida, transferidas para caixas plásticas (27 kg), containers $(400 \mathrm{~kg})$ ou carretas apropriadas, sendo então transportadas para os packing-houses, locais que têm por finalidade selecionar (consumo/indústria), classificar (qualidade), embalar e proporcionar melhores condições de conservação às frutas. O transporte das frutas do local de produção até o packing-house é realizado por meio de caminhões abertos, sendo as frutas cobertas por uma lona (vide Figura 17). 
Petto Netto \& Pompeu Júnior (1991) destacam que, dentro do packinghouse, as laranjas são colocadas numa esteira e têm seus ramos e folhas retirados, sendo também eliminadas as frutas que apresentam algum tipo de dano (vide Figuras $18,19,20)$. Após esta seleção inicial, as laranjas passam por um calibrador, que elimina as frutas de diâmetro inadequado à comercialização. Em seguida, são levadas para um tanque com água clorada e para um lavador, onde são escovadas sob jatos de água, cuja finalidade é remover impurezas e resíduos de pulverização presentes na epiderme da fruta. Uma vez limpas, as laranjas passam por um processo de secagem e recebem um tratamento à base de fungicidas, seguindo para um secador em forma de túnel (circulação de ar quente). A seguir, são colocadas em "containers" de $400 \mathrm{~kg} e$ passam por um descanso de 48 horas.

Completado o período de descanso, as frutas retornam ao processamento, onde os frutos indesejáveis (que manifestaram sintomas de danos) são retirados, havendo nova aplicação de fungicidas, a qual é seguida por outra secagem com ar quente. Realizada a secagem, as frutas são polidas com escovas que utilizam a cera natural da casca para thes proporcionar brilho (que dura de 2 a 3 dias). Continuando o processo, elas recebem a aplicação de cera, destinada a manter e a realçar o brilho da epiderme, bem como reduzir a perda de água, sendo a secagem da cera realizada com fluxo de ar a temperatura ambiente.

Após este tratamento, as frutas são classificadas conforme o diâmetro, passando, a seguir, para mesas de embalagem ou para máquinas embaladoras (vide Figuras $21,22,23,24$ e 25). As frutas destinadas ao mercado externo são envolvidas com um papel especial, impregnado com produtos fungistáticos, sendo posteriormente acondicionadas em embalagens de papelão com capacidade para 10 ou $20 \mathrm{~kg}$ de frutas em disposições pré-estabelecidas, que variam com o tamanho, o número de frutas por camada e o número de camadas. Já as frutas destinadas ao mercado interno são acondicionadas em embalagens de madeira, com capacidade ao redor de $27 \mathrm{~kg}$ ou em sacos de material sintético, com 5 ou $20 \mathrm{~kg}$ de frutas. Vale salientar que este procedimento é o comumente utilizado para as laranjas destinadas ao mercado externo, sendo que no beneficiamento para as frutas destinadas ao mercado interno são suprimidas algumas dessas etapas, tais como as aplicações de fungicidas, 0 descanso e, em alguns casos, a aplicação de cera. 
Finalmente, o transporte das frutas dos packing-houses até os centros de comercialização, no caso do consumo interno, é realizado, em sua maior parte, por caminhões abertos, sendo as embalagens cobertas por uma lona (vide Figura 26). De acordo com Harder (1998), esta prática acaba por afetar a respiração da fruta, acelerando o processo de senescência dos frutos, além de provocar maior aquecimento da carga. Segundo a autora, tecnicamente, o ideal seria armazenar e transportar as frutas a uma temperatura de $7-10^{\circ} \mathrm{C}$ e umidade relativa ao redor de 85 a $95 \%$, o que preservaria suas características organolépticas e, portanto, sua vida de prateleira por mais tempo. Como a realidade observada no Estado de São Paulo está muito longe de ser ideal, algumas medidas simples poderiam ser tomadas com a finalidade de reduzir a exposição da fruta ao calor, tais como a utilização de materiais que o reflitam ou que gerem sombra (como, por exemplo, sombrites e lonas térmicas) ou, ainda, evitar horários que apresentem temperaturas elevadas.

Conforme levantamentos realizados junto a atacadistas da CEAGESP, o custo de transporte, da produção ao mercado atacadista, representa cerca de 15 a $20 \%$ dos custos de comercialização e algo em torno de 8 a $16 \%$ do custo do produto no atacado, considerando a média de preços praticados para a laranja Pera no ano de 1998.

No caso de exportações via rodovia, o transporte é efetuado por caminhões frigorificados. Quando se utiliza transporte marítimo para a exportação, as frutas são transferidas para os porões frigoríficos dos navios, cuja temperatura é mantida entre 0 e $6^{\circ} \mathrm{C}$ e umidade relativa ao redor de $85 \%$ (Harder, 1998). Neste caso, o uso de paletes é imprescindível. 


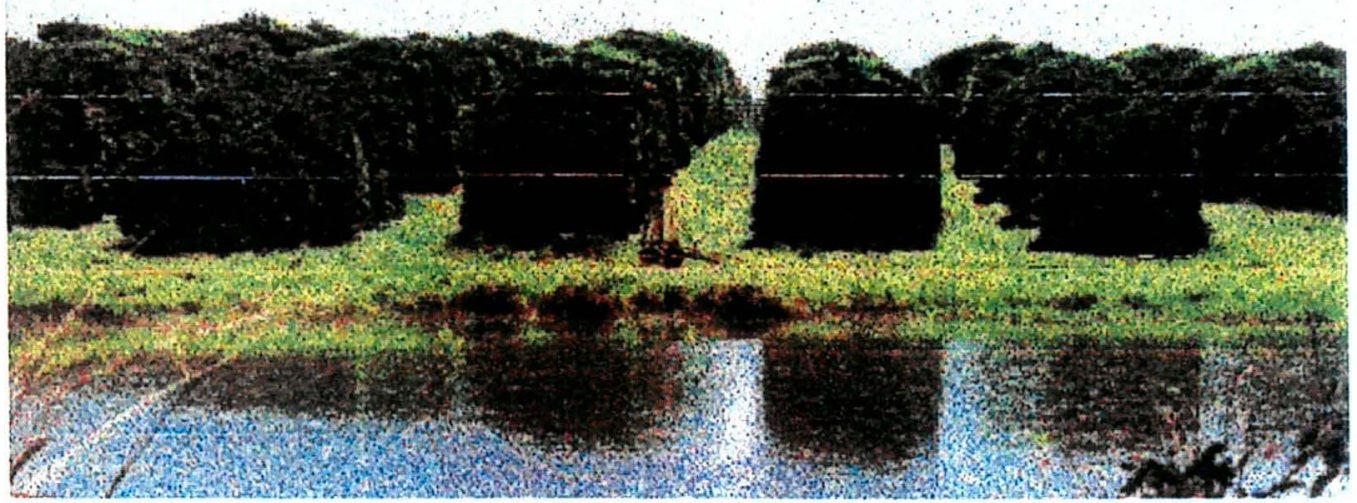

Figura 14 - Pomar de laranja.

Fonte: CQH/CEAGESP.

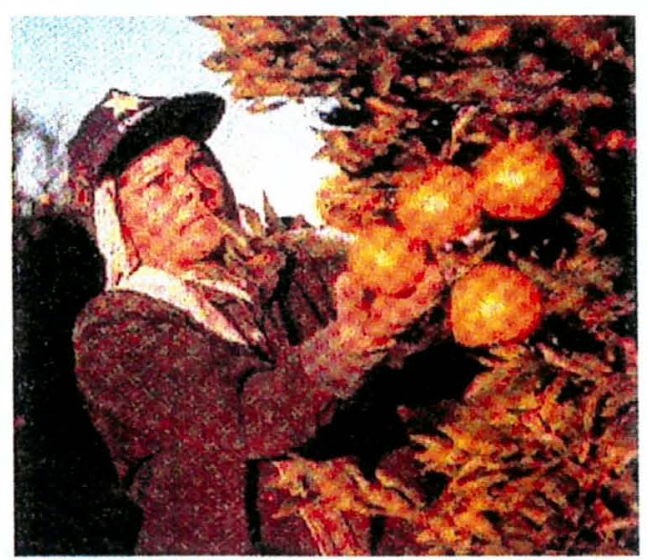

Figura 15 - Colheita de laranja.

Fonte: CQH/CEAGESP

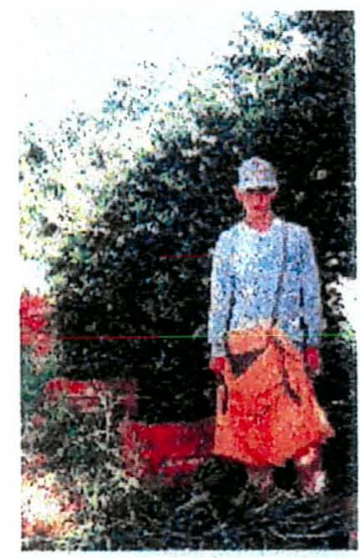

Figura 16 - Detalhe da sacola de colheita. Fonte: CQH/CEAGESP.

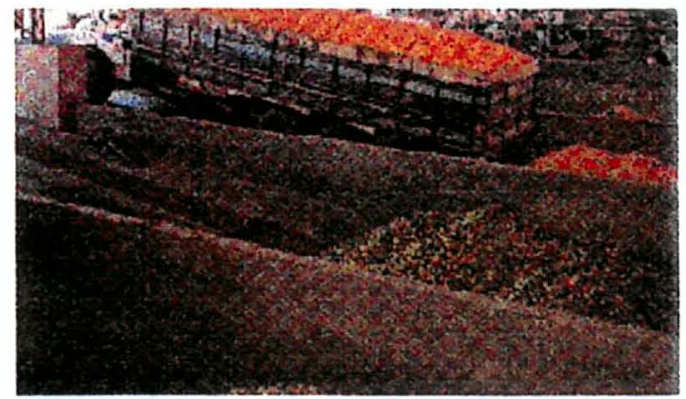

Figura 17- Descarregamento no packing-house.

Fonte: CQH/CEAGESP. 


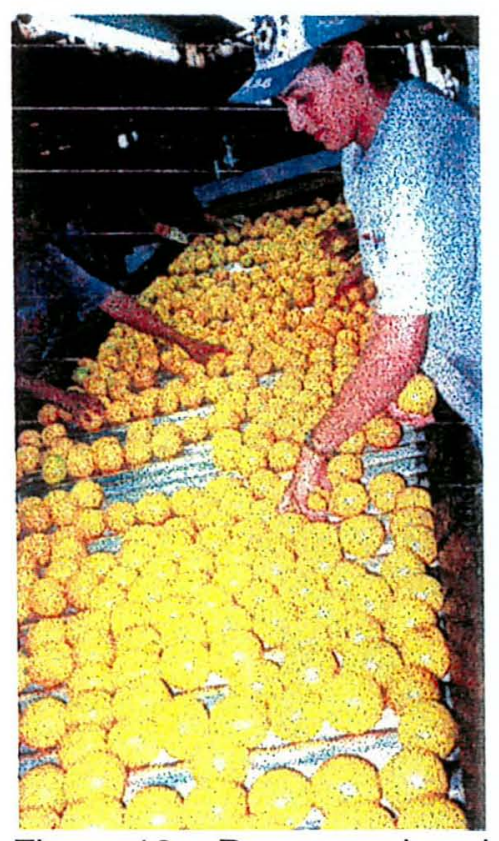

Figura 18 - Processo de seleção dos frutos (I).

Fonte: CQH/CEAGESP.

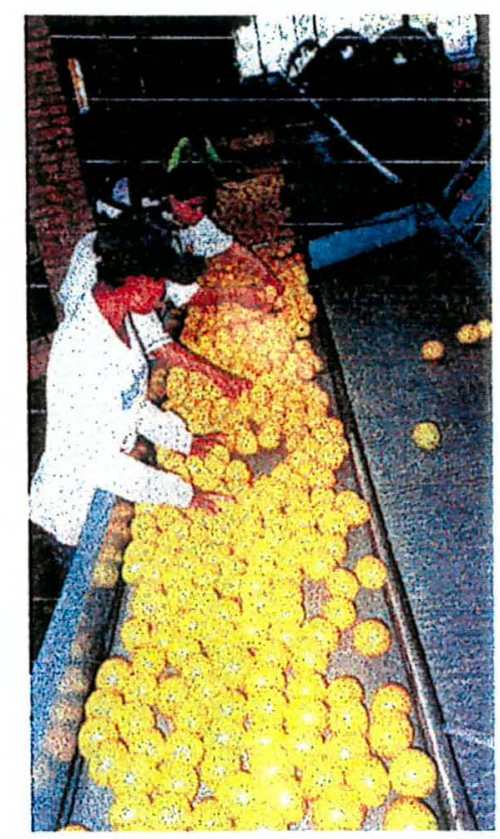

Figura 19 - Processo de seleção

dos frutos (II).

Fonte: CQH/CEAGESP.

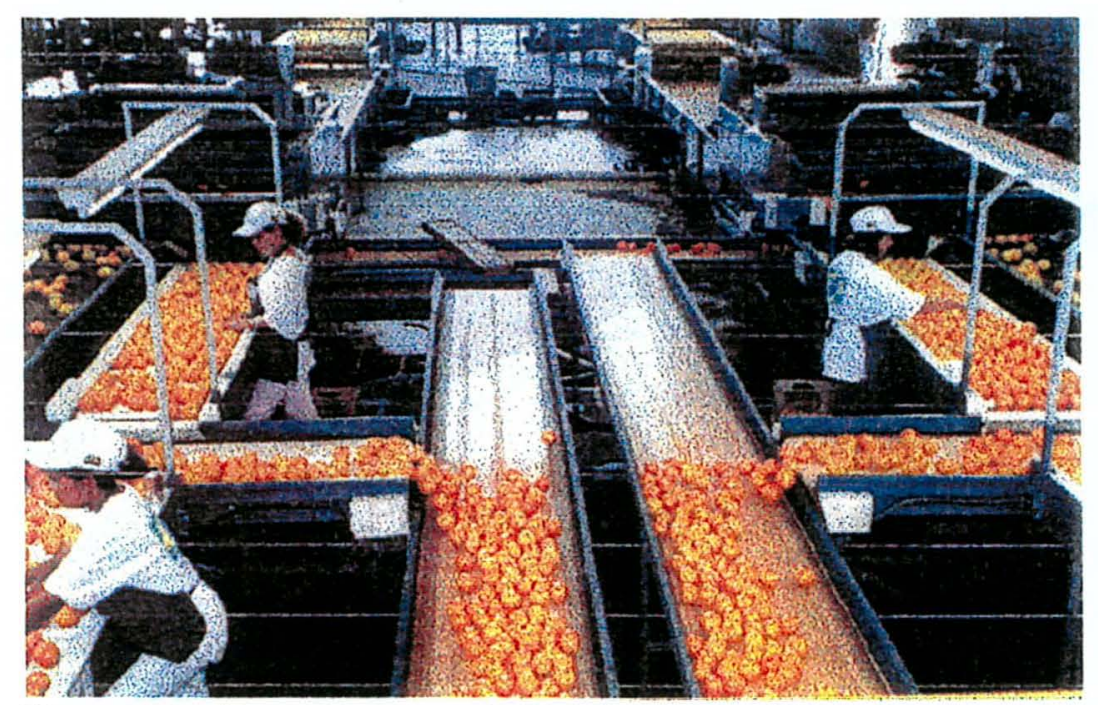

Figura 20 - Processo de seleção dos frutos (III).

Fonte: CQH/CEAGESP. 


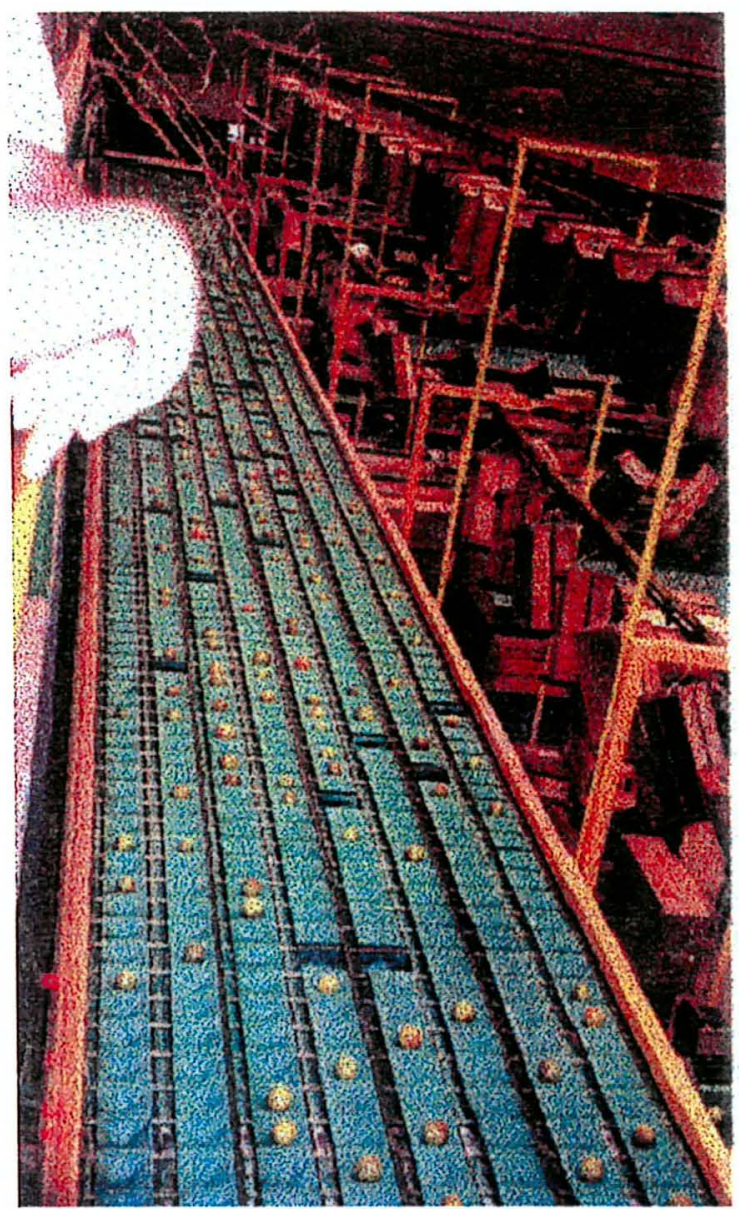

Figura 21 - Máquina classificadora com princípio eletrônico de classificação.

Fonte: CQH/CEAGESP.

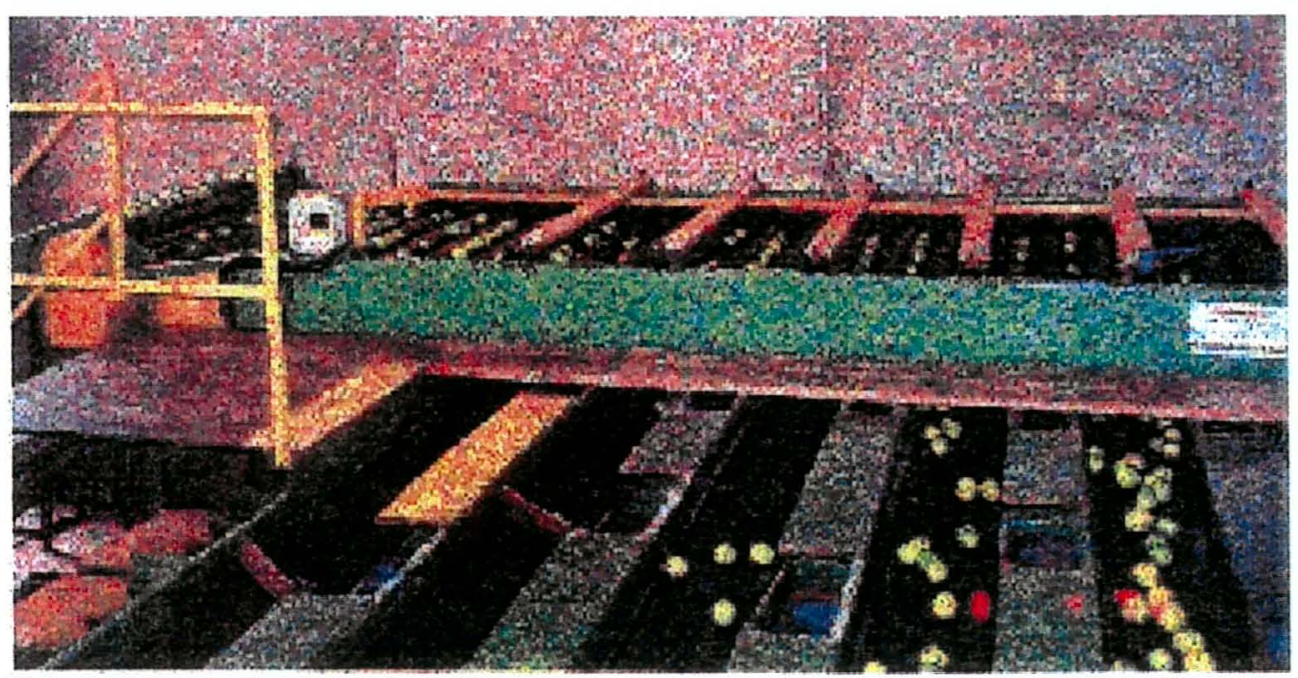

Figura 22 - Máquina classificadora com princípio mecânico de classificação. 


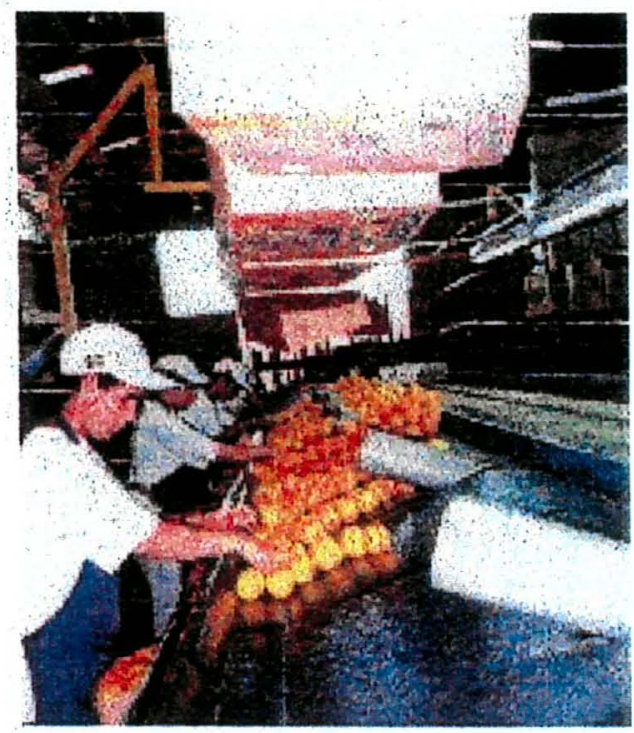

Figura 23 - Processo de embalamento (I).

Fonte: $\mathrm{CQH} / \mathrm{CEAGESP}$.

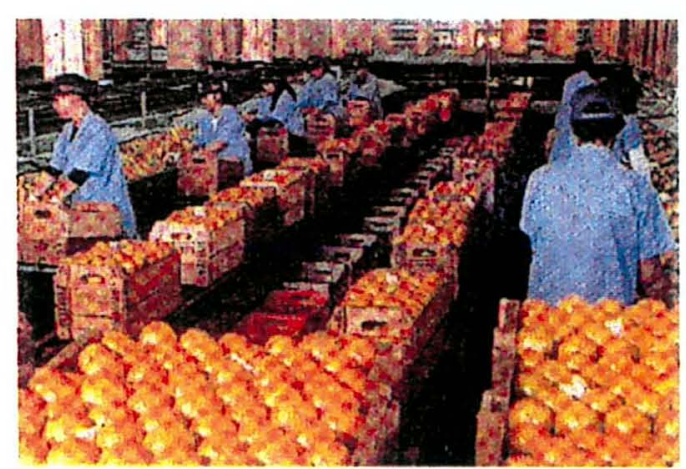

Figura 24 - Processo de embalamento (II).

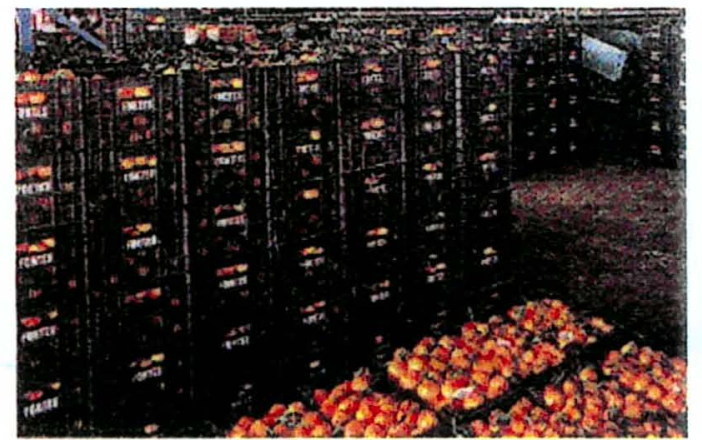

Figura 25 - Preparo para o carregamento do caminhão.

Fonte: CQH/CEAGESP. 


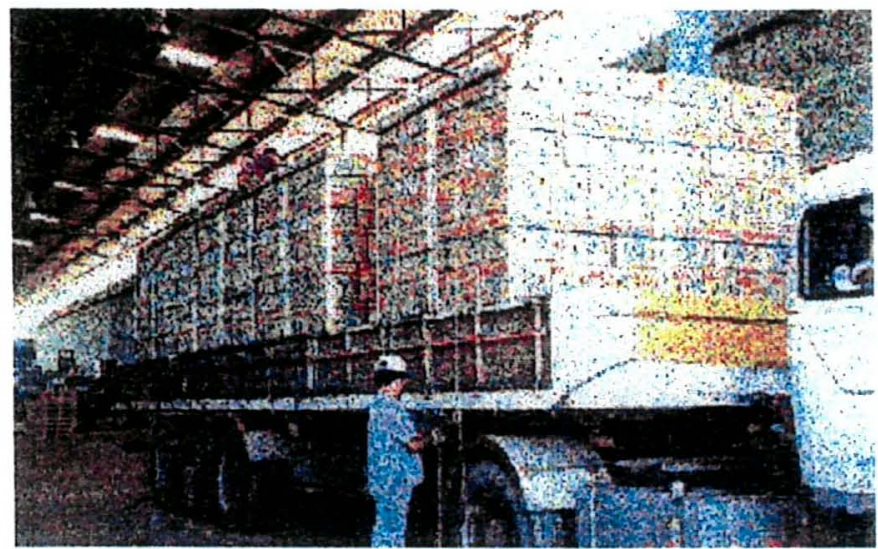

Figura 26 - Transporte dos frutos.

Fonte: CQH/CEAGESP.

A partir da discussão da teoria da localização e suas aplicações, será proposto, no capítulo seguinte, um modelo matemático de otimização para a localização de packing-houses no Estado de São Paulo. Para tanto, a descrição do sistema agroindustrial citrícola e de seus aspectos logísticos, realizada no presente capítulo, foram fundamentais para o entendimento das relações existentes neste sistema, destacando-se as questões relacionadas ao processamento e transporte da laranja. 


\section{Material e MÉtodos}

Neste capítulo será descrito, de forma sucinta, o referencial teórico relativo à Teoria da Localização, bem como suas aplicações, tanto em nivel nacional quanto internacional. Posteriormente, apresentar-se-á o processo de modelagem do problema em questão, destacando-se sua representação diagramática e matemática. Finalmente, descreve-se o procedimento aplicado aos dados utilizados no estudo.

\subsection{TeOria da localizaÇão}

De acordo com Azzoni (1982), a determinação do local de produção de um bem sempre representou uma preocupação para os economistas, mesmo que de uma forma superficial. Entretanto, a clássica pergunta "onde e o que produzir" só começou a ser respondida, cientificamente, há cerca de dois séculos. O primeiro autor a se preocupar com esta questão foi o alemão Von Thünen, em 1826. Em seu trabalho, intitulado "Isoliert Staat", procurou determinar a influência das cidades na localização e na distribuição das atividades agrícolas. $O$ procedimento criado por ele ficou conhecido como "anéis de Von Thünen", pois originava circunferências ao redor da cidade, sendo que cada uma dessas envoltórias (anéis) delimitava a área de cultivo de um produto, em função de seu valor.

Para Kellerman (1989), a teoria da localização agrícola, desenvolvida durante os séculos XVIII e XIX, foi o primeiro passo para a formulação da teoria da localização de plantas industriais (Weber) e de serviços (Christaller \& Lösch), ambas propostas somente no século $\mathrm{XX}$.

Dado que a abordagem do presente estudo refere-se à localização de plantas industriais (packing-houses), descreve-se, sucintamente, a teoria desenvolvida 
por Alfred Weber, que buscou determinar a localização de atividades industriais por meio de forças de atração, apresentando uma teoria geral para a localização de uma firma individual.

Segundo Saboya (2001), no modelo weberiano, a decisão locacional é função de três forças atrativas: o custo de transporte, o custo de mão-de-obra e as forças de aglomeração e de desaglomeração, as quais serão brevemente comentadas a seguir.

No trabalho de Weber, a força de atração relacionada aos custos de transporte assume papel central na determinação da localização das atividades industriais. A obtenção do ponto de mínimo custo de transporte $(P)$ se dá por meio do triângulo locacional, constituído, apenas, por três forças atrativas: um mercado consumidor $(C)$ e duas fontes de matéria-prima $\left(M_{1}\right.$ e $\left.M_{2}\right)$. Neste caso, o equilíbrio das forças de atração $\left(d_{i}\right)$ determina a localização da atividade industrial, ou seja, o ponto de mínimo custo de transporte (vide Figura 27).

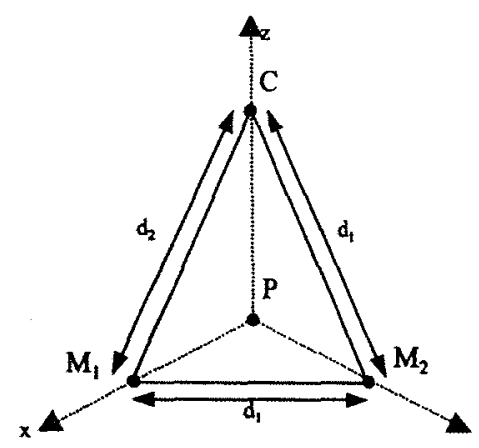

Figura 27 - Triângulo locacional (adaptado de Saboya, 2001).

De acordo com Saboya (2001), a determinação da localização, em função do custo mínimo de transporte, fornece uma primeira aproximação para a obtenção da localização ótima da firma. A partir desta primeira aproximação, são consideradas as possiveis vantagens que outros locais podem oferecer, tanto em temos de mão-deobra mais barata quanto em economias de aglomeração, fatores que podem promover o deslocamento da firma para uma nova região. 
O efeito das outras forças de atração (mão-de-obra e aglomeração) sobre a localização da firma é analisado por meio das curvas isodapanas ${ }^{9}$ que, como o próprio nome diz, são um conjunto de pontos que têm igual acréscimo de custo de transporte em relação àquele local em que esse custo é mínimo (vide Figura 28).

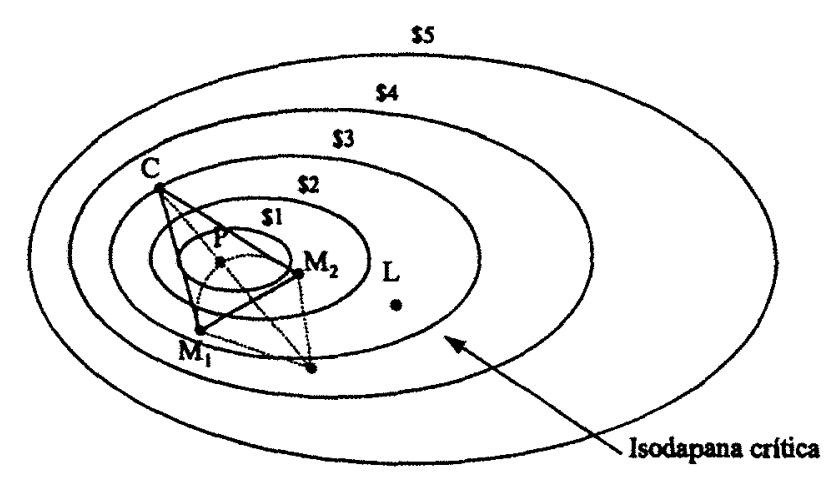

Figura 28 - Curvas de isodapanas e isodapana crítica (adaptado de Saboya, 2001).

Para a análise da influência da mão-de-obra, Weber utilizou o conceito de isodapana crítica, a qual é obtida quando o acréscimo do custo de transporte se iguala à redução de custo proporcionada pela mão-de-obra mais barata. Assim, na Figura 28, os valores monetários sobre cada isodapana simbolizam os acréscimos no custo de transporte a partir do ponto $P$. Se no ponto $L$ a economia de custos devido à mão-deobra mais barata for igual a $\$ 3$, valor igual ao acréscimo nos custos de transporte do ponto $P$ ao ponto $L$, a isodapana crítica está determinada. Lopes (1997) destaca que se localização inicial estiver contida no interior da isodapana crítica, a mudança de localização não é interessante. Por outro lado, se a localização inicial estiver situada externamente à isodapana crítica ${ }^{10}$, a mudança torna-se vantajosa.

Por fim, Weber considerou os fatores aglomerativos, uma vez que surgem economias resultantes da concentração de firmas num dado local. Para esta análise, o conceito de isodapanas foi, mais uma vez, utilizado. Na Figura 29, a interseção das três isodapanas críticas seria a única área de aglomeração. Segundo Saboya (2001), nessa região, as economias de custo, devidas à aglomeração, são capazes de

$\overline{9}$ Iso, igual e dapane, despesa ou custo. 
contrabalançar os custos adicionais devidos ao afastamento das firmas em relação ao ponto de custo mínimo de transporte.

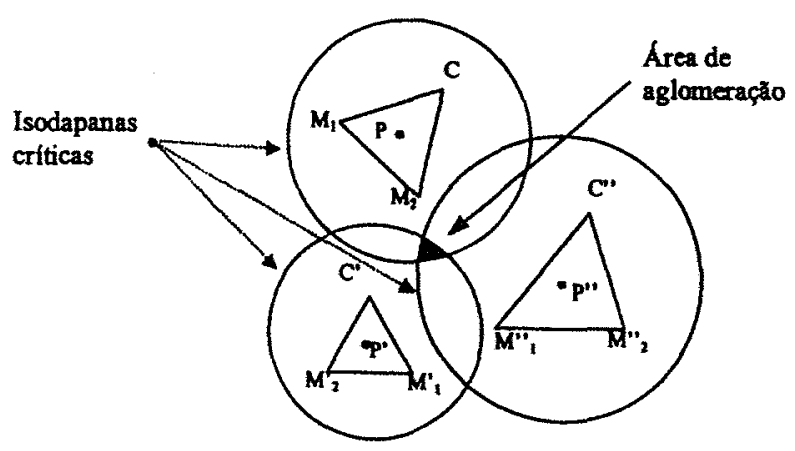

Figura 29 - Determinação da área de aglomeração (adaptado de Saboya, 2001).

O surgimento da programação linear, em meados da década de 40 , em especial o modelo de transporte, proporcionou a introdução de situações mais complexas do que a inicialmente considerada por Weber. A partir de então, como destaca Lopes (1997), tornou-se possível adicionar ao modelo weberiano várias regiōes de demanda, bem como de oferta de matéria-prima. Segundo Bressler \& King $(1970)^{11}$, mencionados por Lopes (1997), uma das vantagens do modelo de transporte consiste na possibilidade de se determinar o fluxo de produtos e os preços relativos de mercado.

Conforme Amaro et al. (1973), o modelo de transporte apresenta grande interesse devido à sua simplicidade e à sua aplicação econômica. Originalmente, este modelo visava a minimização do custo de transporte de diferentes origens $\left(\mathrm{O}_{i}\right)$ para vários destinos $\left(\mathrm{D}_{\mathrm{j}}\right)$, sendo expresso, matematicamente, da seguinte forma:

\footnotetext{
${ }^{10}$ Para maiores detalhes, consultar Azzoni (1982).

${ }^{11}$ BRESSLER, R. G.; KING, R. A. Markets, prices and interregional trade. New York: Jonh Wiley, 1970. 426p.
} 
Função objetivo:

$$
\operatorname{Min} C=\sum_{i=1}^{m} \sum_{j=1}^{n} C_{i j} X_{i j}
$$

onde:

$\mathrm{C}_{i j}=$ custo unitário para transportar uma unidade da mercadoria em questão da origem i para o destino j;

$X_{\mathrm{ij}}=$ quantidade a ser transportada de Oi para $D_{\mathrm{j}}$;

$\mathrm{C}=$ custo total de transporte do produto, da origem $\mathrm{i}$ ao destino $\mathrm{j}$;

$\mathrm{m}=$ número total de regiões de origem do produto;

$n=$ número total de regiões de destino para o produto produto.

Para a obtenção do custo total mínimo, os valores de $X_{\mathbb{1}}$ devem satisfazer a quatro diferentes restrições, a saber:

- A soma das quantidades $X_{i j}$ a serem transportadas a partir da região de origem $i$ não pode exceder à sua capacidade de oferta (Si):

$$
\sum_{j=1}^{n} x_{i j} \leq S_{i} \text {, para todo } i
$$

onde:

$S_{i}=$ oferta do produto na região $i$.

- A soma das quantidades $X_{i j}$ a serem transportadas para um destino $\mathrm{j}$ não pode ser menor que a demanda desta região:

$$
\sum_{i=1}^{m} x_{i j} \geq P_{j} \text {, para todo } j .
$$

onde:

$P_{j}=$ demanda do produto na região $j$. 
- A demanda total pelo produto deve ser igual à sua oferta total:

$$
\sum_{j=1}^{n} P_{j}=\sum_{i=1}^{m} s_{i}
$$

onde:

$$
\begin{aligned}
& \sum_{j=1}^{n} P_{j}=\text { demanda total pelo produto. } \\
& \sum_{i=1}^{m} S_{i}=\text { oferta total do produto. }
\end{aligned}
$$

- Os valores de $X_{i j}$ não podem ser negativos.

$$
x_{i j} \geq 0
$$

Amaro et al. (1973), salientam que a condição (4) é considerada para fins de simplificação, uma vez que elimina o valor das desigualdades (2) e (3).

Conforme os mesmos autores, o modelo de transporte, embora aprimorasse o modelo weberiano, apresentava algumas limitações, resultantes de suas pressuposições teóricas, listadas a seguir:

- admite um mercado em concorrência perfeita;

- não considera economias de escala no transporte;

- não se computam os custos de transporte até o mercado de reunião, nos casos de produção espacialmente dispersa;

- a tecnologia é considerada constante dentro de uma mesma região produtora ou consumidora;

- as demandas e ofertas de cada região são conhecidas;

- as variáveis possuem relações lineares;

- não se considera economias de escala no processamento.

Devido a essas limitações, uma série de outros modelos, extensões do modelo básico de transporte, foram desenvolvidos com a finalidade de eliminar uma ou 
a incluir, além de relações no espaço, relações no tempo e na forma, assim como informações complementares ao custo de transporte, tais como vantagens comparativas, custos de produção e diferenças de preço pago pelos consumidores e as recebidas pelos produtores.

Lopes (1997) salienta que um grande avanço na modelagem de localização foi alcançado a partir da utilização da programação inteira-mista, mais especificamente com a utilização de variáveis binárias no modelo. De acordo com essa concepção, tornou-se possivel testar, para cada região, as diversas capacidades de processamento, procurando-se, assim, não só a localização que minimiza os custos de transporte, como também a melhor capacidade de processamento para a região. Conforme o autor, a teoria da localização, em termos de programação, pode ser entendida como uma variação do modelo de transporte que, em conjunto com a programação inteira, constitui um ferramental bastante poderoso para a determinação do melhor local para a instalação de uma indústria.

No entanto, a despeito de suas vantagens, para Lopes (1997) a programação inteira-mista apresenta algumas limitações relativas ao fato de:

- a solução ótima ser obtida para um equilíbrio de longo-prazo, tratando-se, portanto, de um modelo que apresenta características estáticas;

- não considerar alterações na oferta e na demanda, sendo estas perfeitamente inelásticas em relação às variações nos preços;

- não considerar a importância de fatores exógenos, sendo que a localização ótima é obtida para o local de mínimo custo ou de máximo lucro.

Para Lopes (1997), os modelos de localização são aperfeiçoamentos do modelo desenvolvido por Weber. Listam-se, a seguir, as principais considerações e hipóteses destes modelos. 
a) Considerações

- existência de uma série de mercados demandantes $i$, os quais deverão ser atendidos por uma firma, sendo que suas demandas serão função de sua localização em relação à firma;

- os preços dos bens nesses mercados são determinados em função da localização relativa dos mesmos em relação à firma;

- a capacidade de produção da firma é tal que atende à soma das demandas dos mercados.

- as quantidades requeridas de insumos para um dado nível de produção, fornecida pelas diversas fontes, é função da localização da firma, devido, principalmente, aos custos de transporte;

- o custo de transformação da matéria-prima em bens é, também, função da localização.

b) Hipóteses

- define-se que as demandas dos mercados atendidos pelas firmas sejam fixas e determinadas a priori; portanto, a capacidade de produção da firma será constante;

- os preços dos bens vendidos nos mercados atendidos são constantes;

- as quantidades de insumos fornecidas por região são constantes, sendo que podem ser de dois tipos: a) localizadas, quando se considera apenas uma fonte de insumo dentro da área de estudo e b) ubiqüidades, quando as fontes de insumo são encontradas em todas as partes e, dessa forma, não exercem qualquer força de atração.

\subsection{ApliCaÇões da teoria da localizaÇão}

Como comentado anteriormente, a questão da localização sempre se constituiu numa preocupação para os economistas, uma vez que, independentemente de sua natureza, as empresas possuem três etapas em comum no que se refere à produção de um determinado bem, as quais consistem na aquisição da matéria-prima, no seu processamento e na distribuição do produto final. A primeira e a terceira etapas 
são diretamente influenciadas pelos custos de transporte, sendo, portanto, relevante a determinação do local em que os custos associados a ele sejam minimizados. Isso significa que, uma vez definida a localização ótima, os custos, tanto a curto quanto a longo prazos, serão minimizados. Esta minimização advém do fato de a localização exercer grande influência sobre os custos operacionais, os quais serão reduzidos já que os custos de transporte da matéria-prima e de distribuição do produto final serão mínimos.

No que tange à aplicação da teoria da localização na Agricultura, Kellerman (1989) destaca que este assunto tem recebido pouca atenção na literatura, em decorrência da perda de importância relativa desta atividade, especialmente nas sociedades mais industrializadas, o que justifica o fato de maiores esforços estarem concentrados em aplicações da teoria em questões urbanas. A despeito disso, observa-se a existência de alguns estudos, relativos à teoria da localização em termos agrícolas, que enfocam o problema da minimização dos custos de transporte. Inicialmente, este problema era tratado por meio do modelo de transporte que, posteriormente, foi aprimorado até se constituir num poderoso ferramental para a determinação do local ótimo para a instalação de uma indústria.

A teoria da localização apresenta outras aplicações, além daquela relativa à obtenção do local ótimo para a instalação de plantas industriais. A seguir, descrevese, em ordem cronológica, algumas das aplicações desta teoria.

Amaro et al. (1973) destacam que, apesar das limitações, o modelo de transporte foi bastante utilizado, após a Segunda Guerra, para fins de pesquisa. Nesta linha, cabe destacar os trabalhos desenvolvidos por Stemberger (1959), que o aplicou para avaliar a posição competitiva de ovos produzidos na Carolina do Norte, Estados Unidos, e por West \& Brandow (1964) que utilizaram o modelo para a indústria de laticínios do Nordeste e região Centro-Norte dos Estados Unidos.

Em termos nacionais, o modelo de transporte foi utilizado por Amaro et al. (1973), para tratar do problema da organização eficiente do complexo das indústrias processadoras de laranja no Estado de São Paulo, em relação ao suprimento de matéria-prima, visando à minimização dos custos de transporte. Berger (1975) estudou a maneira mais eficiente de organizar o complexo das fábricas celulósico-papeleiras e de chapas de fibra de madeira no Estado de São Paulo. O autor também se apoiou no modelo de transporte, determinando as quantidades de madeira de eucalipto a serem 
transportadas das regiões produtoras até os centros consumidores, visando a minimização do custo individual e total de transporte da madeira de eucalipto.

Como ressaltado anteriormente, uma série de outros modelos foram desenvolvidos com a finalidade de quebrar a simplicidade do modelo de transporte, por meio da eliminação de uma ou mais pressuposições do modelo inicial. Dentro dessa concepção, pode-se mencionar os estudos realizados por Stollsteimer (1963) e por King \& Logan (1964).

Para Stollsteimer (1963), o problema de localização deveria fornecer não só a melhor localização, mas também o número de firmas e seu tamanho. Sendo assim, o autor desenvolveu um modelo para determinar o número, o tamanho e a localização de packing-houses para pera na região noroeste da Califórnia, de modo a minimizar o custo de reunião e processamento de qualquer quantidade de matériaprima. Neste estudo, foram incluídas as possibilidades de se trabalhar com economias de escala, bem como com os custos da firma variando conforme sua localização.

King \& Logan (1964) consideraram, simultaneamente, os custos de transporte da matéria-prima, processamento e distribuição do produto final. O modelo foi aplicado para se determinar a localização, o número e o tamanho ótimos de abatedouros de bovinos para o estado da Califórnia, Estados Unidos, em função da localização, da quantidade de animais abatidos e da demanda pelo produto final. Os autores incorporaram, também, a possibilidade de se trabalhar com economias de escala no processamento.

A partir do advento da programação inteira-mista, surgiram alguns trabalhos cujo objetivo era a determinação de localizações ótimas. Dentre eles, podese mencionar, em termos nacionais, os realizados por Almeida (1981), Canziani (1991) e Lopes (1997).

Almeida (1981) analisou a viabilidade econômica e a localização mais eficiente para a implantação de unidades produtoras de farinha de milho integral e desengordurada no Estado de São Paulo. A autora utilizou programação linear mista e a criação de cenários, considerando cinco unidades fabris, com diferentes capacidades de processamento de milho. Para o estudo da localização ótima, a autora procurou minimizar os custos de coleta, processamento e distribuição da farinha de milho aos moinhos de trigo, dadas as restrições de capacidade e de localização das fábricas, de disponibilidade de matéria-prima, de demanda dos moinhos e da equação de 
conservação da fábrica (considerou-se $6 \%$ de perda no processo de transformação do milho em farinha). Neste modelo, a autora considerou as economias de escala no transporte e no processamento.

Canziani (1991) adotou a programação linear inteira-mista para estudar a localização ótima de fábricas de suco de laranja concentrado no norte e noroeste do Estado do Paraná, visando a minimização dos custos de coleta da produção, de processamento da matéria-prima e de distribuição do produto final. No modelo, o autor considerou a economia de escala no transporte e no processamento, projetando várias situações de oferta de matéria-prima.

Visando uma distribuição mais eficiente de granjas suinícolas, Lopes (1997) determinou o número e o tamanho ótimo destas empresas no Estado de Goiás, de modo que sua distribuição proporcionasse a minimização dos custos de transporte de matéria-prima e do produto final, assim como os custos de implantação das granjas. Para isso, o autor utilizou um modelo baseado na teoria de localização de Weber, o qual envolveu uma estrutura de programação inteira-mista.

Lopes (1997) salienta que nas especificações de modelos de Stollsteimer, King \& Logan, Almeida e Canziani, procurou-se eliminar, principalmente, a pressuposição de inexistência de economias de escala no processamento, por meio da utilização de variáveis binárias no processo de modelagem. Para melhor representar a realidade, outras variáveis foram incluídas nos modelos, tais como o preço da matériaprima e custo de transporte do produto final.

Com relação a aplicações de modelos de localização ótima, com o auxílio de programação inteira-mista, em contextos internacionais, podem ser destacados os trabalhos de Kilmer et al. (1983), Babcock et al. (1985), Brown et al. (1996), Durham et al. (1996) e Snyder et al. (1999).

Kilmer et al. (1983) utilizaram a programação dinâmica para avaliar a abertura de novos packing-houses de laranja na Flórida, Estados Unidos, uma vez que o deslocamento da produção estava fazendo com que muitos deles ficassem distantes da área de produção. Nesta análise os autores buscaram traçar uma programação para a abertura e fechamento dos packing-houses. Como a abertura de novos barracões resulta em custos adicionais, os autores objetivaram minimizar estes custos dentro do horizonte de estudo. Além disso, procuraram apresentar como seriam os ajustamentos de curto-prazo na localização. Os autores utilizaram a programação 
dinâmica com o intuito de analisar os ajustamentos no curto-prazo, os quais constituem uma das limitações dos modelos estáticos de localização, que apresentam uma solução ótima somente para um equilibrio de longo-prazo.

Babcock et al. (1985) avaliaram os efeitos de taxas diferenciadas de transporte ferroviário na localização dos moinhos de farinha de trigo nos Estados Unidos. No estudo, os autores empregaram o modelo de transporte para analisar a localização de plantas na região leste do país e, para a região oeste, aplicaram um modelo de programação linear. De acordo com os resultados, os autores concluíram que as altas tarifas adotadas para o transporte da farinha, em relação às impostas ao trigo, provavelmente causavam o deslocamento dos moinhos, das áreas de produção para as de consumo.

Brown et al. (1996) determinaram o número e a localização ótima de mercados de tabaco para as regiões da Virgínia, Carolina do Norte e Carolina do Sul (E.U.A), sendo a decisão baseada na localização atual dos mercados e na produção dos municípios. Para tanto, adotaram o algoritmo desenvolvido por Erlenkotter $(1978)^{12}$, o qual fornece soluções inteiras por meio de procedimentos de ajuste na forma dual da programação linear. Neste estudo, os autores concluíram que 21 dos 53 mercados existentes deveriam ser fechados.

Durham et al. (1996) desenvolveram um modelo de programação nãolinear para examinar a influência dos preços na alocação ótima de tomates, das fazendas para as indústrias, no centro e no norte do estado da Califórnia (E.U.A). A principal conclusão deste estudo foi a de que a política de preços uniformes encoraja a sobreposição dos mercados das processadoras.

Snyder et al. (1999) utilizaram um modelo de programação inteira para selecionar um conjunto de Áreas de Pesquisa Natural, as quais tinham como objetivo proteger e manter a diversidade biológica de ecossistemas. Neste trabalho, os autores buscaram maximizar o número de ecossistemas regionais, bem como de comunidades naturais no estado de Minnesota (E.U.A).

${ }^{12}$ ERLENKOTTER, D. A dual-based procedure for uncapacitated facility location. Operations Research, v. 26, p.992-1009, 1978 


\subsection{MODELO PROPOSTO}

\subsubsection{Desenvolvimento do modelo}

O objetivo central do modelo de localização a ser desenvolvido neste estudo refere-se à determinação dos locais ótimos para a instalação de packinghouses, de maneira que os custos de transporte e processamento da laranja, bem como os custos de implantação de novas plantas sejam minimizados. Para uma visualização mais clara do processo de formulação do modelo matemático, a descrição do contexto no qual se insere este problema de localização torna-se necessária.

De acordo com a divisão realizada pela Secretaria da Agricultura e do Abastecimento, o Estado de São Paulo está dividido em 40 regiões agrícolas (EDRs) que, a princípio, não apresentam nenhuma restrição quanto à instalação de packinghouses, sendo que em todas elas ocorre produção de laranja, ainda que em volumes bastante distintos. Assim, a primeira parte do problema consiste em se determinar a melhor forma de distribuição física da fruta, através do transporte da matéria-prima das regiões que apresentam excesso de oferta (centros de produção) para as que possuem excesso de demanda (centros de processamento). Cabe ressaltar que este fluxo de matéria-prima deve possibilitar a minimização dos custos de transporte. Além disso, no caso dos centros de produção, a quantidade exportada somada à consumida internamente não pode ser superior à sua capacidade de oferta. Já nos centros de processamento, o total de laranjas importadas, aliadas ao montante produzido pela região, deve ser limitada pela demanda por laranja dos packing-houses.

A segunda parte do problema em questão trata da minimização dos custos associados ao processamento da laranja, em função da demanda dos centros processadores. Para o dimensionamento desta demanda serão considerados 7 tamanhos de packing-houses, em relação à capacidade de processamento anual de cada um deles. Estas unidades processadoras podem ser ou não implantadas numa dada região, de forma que a possibilidade de instalação de uma planta, implica custos de implantação da mesma, que também serão minimizados por meio do modelo de localização ótima. Dessa forma, será possível determinar o número de packing-houses que deve existir em cada região, assim como a capacidade de processamento dessas plantas, tudo isso em função da proximidade do centro de processamento em relação 
aos centros de produção e de consumo. Vale salientar que, ao se instalar um packinghouse numa região, cria-se, além da demanda por laranja, um determinado nível de oferta da fruta para o mercado consumidor final.

Uma vez definida a capacidade de oferta de laranja processada para cada região, parte-se para a terceira e última etapa do problema: o transporte das laranjas até os centros de consumo final, representados pelos 40 EDRs. Como no caso do transporte dos centros de produção aos de processamento, objetiva-se, aqui, minimizar os custos de transporte envolvidos nesta fase, lembrando sempre que o volume de laranja que permanece na região, somada ao montante que será transportado, não deve superar a capacidade de oferta dos centros processadores. Concomitantemente, a quantidade que permanece na região, aliada ao volume proveniente de outras regiões, não deve ser inferior à sua demanda. É importante observar que a determinação da demanda por laranja in natura foi obtida a partir da ponderação da população residente em cada centro consumidor pelo consumo per capita estadual.

Pelo exposto, fica claro que o objetivo do modelo proposto para a localização de packing-houses será o de determinar os locais mais adequados para a instalação dessas unidades de beneficiamento, de modo que se atenda às diversas demandas e se respeite as várias ofertas. Espera-se, ao final, obter-se, de forma agregada, a minimização dos custos de transporte, processamento e implantação de packing-houses, bem como as capacidades de processamento ótimas para cada região. 


\subsubsection{Especificação do modelo}

\subsubsection{Representação Diagramática}

A Figura 30 representa, de forma esquemática, o modelo em questão no qual existem $n$ centros produtores $\left(\mathrm{R}_{\mathrm{i}}\right), p$ centros de processamento $\left(\mathrm{CAP}_{\mathrm{j}}^{\prime}\right)$ com $q$ packing-houses de diferentes capacidades e $r$ centros de consumo $\left(C_{m}\right)$.

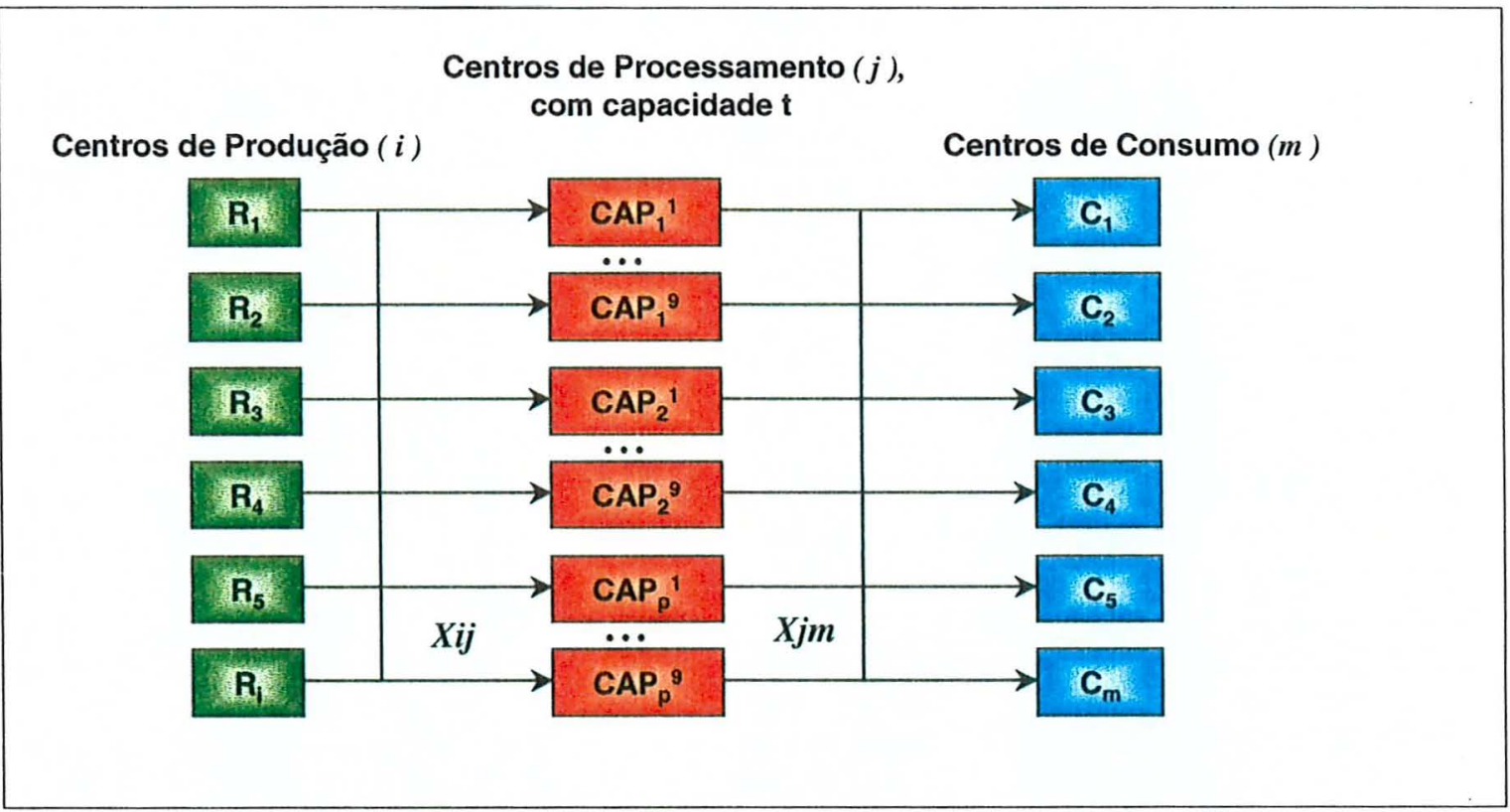

Figura 30 - Representação diagramática do modelo de localização ótima.

\subsubsection{Representação Matemática}

O modelo a ser adotado para este estudo refere-se à minimização de uma função objetivo, que representa os custos considerados para a obtenção da localização ótima de packing-houses, sujeita a várias restrições de ordem física e comportamental.

Apresenta-se, a seguir, a especificação das equações e inequações relativas ao modelo proposto. 
Função objetivo:

$$
\text { Min } C=\sum_{i=1}^{40} \sum_{j=1}^{40} X_{i j} C_{i j}+\sum_{j=1}^{40} C O_{j}+\sum_{j=1}^{40} \sum_{m=1}^{40} Y_{j m} C_{j m}
$$

onde:

$X_{i j}=$ quantidade de matéria-prima transportada da região produtora $\mathrm{i}$ ao packing-house de tamanho $t$, localizado no centro processador $\mathrm{j}$;

$\mathrm{C}_{i j}=$ custo de transporte da matéria-prima da região produtora $\mathrm{i}$ ao packing-house de tamanho $t$ localizado no centro processador $\mathrm{j}$;

$\mathrm{CO}_{\mathrm{j}}=$ custo operacional (implantação e processamento) de um packing-house de tamanho t na região processadora j;

$\mathrm{C}_{\mathrm{jm}}=$ custo de transporte da laranja in natura do packing-house de tamanho $\mathrm{t}$, localizado no centro j, ao mercado consumidor situado na região $m$;

$Y_{\mathrm{jm}}=$ quantidade de laranja in natura transportada do packing-house de tamanho $\mathrm{t}$, localizado no centro processador j, para o mercado consumidor situado na região $\mathrm{m}$.

Desmembrando a função objetivo, obtém-se as seguintes parcelas:

$$
\begin{aligned}
& \sum_{j=1}^{40} \sum_{j=1}^{40} x_{i j} C_{i j} \\
& \sum_{j=1}^{40} \sum_{t=1}^{7} \mathrm{Co}_{j} \\
& \sum_{j=1}^{40} \sum_{m=1}^{40} x_{j m} c_{j m}
\end{aligned}
$$

Note-se que as expressões $(6 a),(6 b)$ e $(6 c)$ representam, respectivamente, o custo de transporte da matéria-prima da região produtora i para o packing-house localizado na região j, o custo operacional de um packing-house de tamanho t situado na região j e o custo de transporte da laranja in natura para o mercado consumidor da região $\mathrm{m}$. Vale ressaltar que foram considerados 7 tamanhos prováveis de packing- 
houses, 40 regiões produtoras, as quais são também regiões de consumo e de possivel instalação de plantas processadoras de laranja.

Restrições:

a) A capacidade de oferta de laranja da região $i$, não deve exceder a capacidade de produção da própria região.

$$
\sum_{j=1}^{40} \sum_{t=1}^{7} X_{i j}-S_{i} \leq 0, \text { para todo } i
$$

onde:

$\sum_{j=1}^{40} \sum_{t=1}^{7} x_{i j}=$ quantidade total de laranja transportada da região de produção $i$ para os packing-houses de tamanho $t$ instalados nas diversas regióes $\mathrm{j}$;

$\mathrm{S}_{\mathrm{i}}=$ quantidade total de laranja disponivel na região produtora $\mathrm{i}$.

Essa restrição significa que a soma das quantidades de laranja que permanecem na região de produção $i$, somadas ao volume exportado para outras áreas de processamento, não deve ser superior à capacidade de produção da própria região.

b) Demanda por laranja pelos centros de processamento.

$$
\sum_{i=1}^{40} X_{i j}-\sum_{t=1}^{7} C A P^{t} F_{j}^{t}=0, \text { para todo } j
$$

onde:

$\sum_{i=1}^{40} X_{i j}=$ quantidade de laranja recebida de todas as regiões produtoras $i$ para atender a demanda total dos packing-houses de tamanho $t$, instalados no centro de processamento j; 
$\sum_{t=1}^{7} \operatorname{CAP}^{t} F_{j}^{t}=$ quantidade total de laranja demandada por todos os packing-houses de tamanho t instalados no centro processador $\mathrm{j}$;

$F_{\mathrm{j}}^{\dagger}=$ variável binária (zero-um) associada à instalação ou não de um packing-house de tamanho t no centro de processamento $\mathrm{j}$.

Conforme a inequação (8), tem-se que a soma das quantidades de laranja produzidas e consumidas na própria região de processamento $j$, adicionadas às quantidades provenientes de outras regiões, não deve ser superior à capacidade de processamento (demanda por laranja) desta região, representada pelos packinghouses instalados na mesma.

c) Oferta de laranja dos packing-houses.

$$
\sum_{m=1}^{40} Y_{j m}-\sum_{j=1}^{40} X_{i j}=0, \text { para todo } j
$$

$\sum_{m=1}^{40} Y_{j m}=$ quantidade de laranja transportada, dos diversos packing-houses de tamanho $t$ instalados nos centros de processamento $j$, que irá abastecer o mercado localizado na região $\mathrm{m}$;

$\sum_{m=1}^{40} X_{i j}=$ quantidade de laranja recebida de todas as regiões produtoras i para atender à demanda total dos packing-houses de tamanho $t$, instalados no centro de processamento j.

Na equação (9), tem-se que a quantidade de laranja recebida e processada pelo packing-house de tamanho $t$ instalado na região $j$ deve ser igual ao volume ofertado por esta unidade de processamento para atender à demanda do mercado consumidor situado na região $\mathrm{m}$. 
d) Demanda de laranja in natura pelo mercado consumidor.

$$
\sum_{j=1}^{40} Y_{j m}-D_{m} \geq 0, \text { para todo } m
$$

onde:

$\sum_{m=1}^{40} Y_{j m}=$ quantidade de laranja transportada, dos diversos packing-houses de tamanho $t$ instalados nos centros de processamento j, que irá abastecer o mercado localizado na região $m$;

$D_{m}=$ demanda por laranja in natura no mercado consumidor situado na região $\mathrm{m}$.

$\mathrm{Na}$ inequação (10), representa-se o volume necessário para abastecer o mercado consumidor situado na região $m$, onde o total de laranjas que chega a este mercado não deve ser inferior à sua demanda.

e) Balanço entre a demanda dos centros de consumo e a oferta dos centros de processamento.

$$
\sum_{m=1}^{40} D_{m} \leq \sum_{j=1}^{40} \sum_{t=1}^{7} C A P^{t} F_{j}^{t}
$$

onde:

$\sum_{m=1}^{40} D_{m}=$ demanda total dos diversos centros de consumo localizados nas regiöes $m$; $\sum_{j=1}^{40} \sum_{t=1}^{7} C A P^{t} F_{j}^{t}=$ quantidade total de laranja ofertada por todos os packing-houses de tamanho t instalados no centro processador $\mathrm{j}$.

Conforme a inequação (11), as demandas dos diversos centros de consumo localizados nas regiōes $m$ não podem ser superiores às ofertas dos diversos packinghouses de tamanho $t$, instalados nas diversas regiões j. 
Para contabilizar o custo total de implantação e processamento dos packing-houses a serem instalados em cada centro processador $j$, foi inserida no modelo a seguinte equação:

$$
H_{j}=\sum_{t=1}^{7} \operatorname{Co}_{j} F_{j}^{t}
$$

onde:

$\mathrm{H}_{\mathrm{j}}=$ custo total de implantaçăo e processamento dos packing-houses instalados na região processadora j.

A equação (12), informa que, caso ocorra a instalação de packing-houses na região de processamento j, a empresa incorrerá num custo total de implantação e de processamento igual a $\mathrm{Hj}$.

A estrutura matemática apresentada (expressões 6 a 11) foi codificada e processada através da linguagem de otimização GAMS (Brooke et all., 1982). Os dados utilizados no processamento do modelo, bem como os cenários adotados, estão especificados nas próximas seções.

\subsubsection{Cenários}

Serão analisados quatro cenários, os quais considerarão variações na oferta e na demanda dos EDRs, bem como restrições em relação ao número de packing-houses instalados por região.

No cenário 1, considerou-se a não existência (prévia) de packing-houses no Estado de São Paulo, uma vez que o intuito desta análise é o de obter, para posterior comparação com a situação atual, o número, a localização destas unidades de beneficiamento e as capacidades ótimas de processamento de cada região. Neste cenário, a oferta de cada Escritório de Desenvolvimento Rural (EDR) será dada pela parcela da produção destinada ao mercado interno, a qual representa, aproximadamente $22 \%$ do total produzido. A demanda de cada região será definida 
como sendo o consumo per capita médio do Estado de São Paulo ponderado pela população residente em cada EDR.

As considerações adotadas para o segundo, terceiro e quarto cenários são semelhantes às definidas para o primeiro, porém com alterações nas definições das variáveis relacionadas ao número de plantas instaladas por região, oferta e demanda por laranja. No cenário 2 admite-se apenas a possibilidade de implantação de um packing-house por EDR. No cenário 3, considera-se que a demanda por laranja, em cada EDR, seja equivalente à sua oferta. Por fim, no cenário 4, admite-se, para cada EDR, a igualdade entre as ofertas e demandas por laranja, bem como a possibilidade de instalação de apenas uma planta beneficiadora por região.

\subsubsection{Especificação dos dados}

\subsubsection{Sub-divisão da área de estudo}

O Estado de São Paulo foi escolhido para a realização deste estudo por ser o principal produtor nacional de laranja (83\%). Aliado a isso, o Estado é, também, o maior centro consumidor do país, o que faz com que seja alvo de grande interesse por parte das empresas ligadas ao sistema agroindustrial citrícola.

A partir de 1997, a Secretaria da Agricultura e do Abastecimento do Estado de São Paulo adotou uma nova divisão administrativa para o Estado, denominada Escritório de Desenvolvimento Rural (EDR). Ao todo, existem 40 EDRs, havendo produção de laranja em todos eles. No entanto, a produção paulista concentra-se no denominado "cinturão citrícola", como pode ser observado na Figura 4. A concentração da produção nessa área pode ser um indicativo de que esta seja a região que apresenta maiores probabilidades para a instalação de packing-houses. Soma-se a isto o fato de alguns dos EDRs pertencentes ao cinturão situarem-se próximos aos grandes mercados consumidores de laranja. A proximidade, tanto em relação aos centros produtores quanto em relação aos centros consumidores, pode ser a alternativa logística mais viável para o problema em estudo, de modo que a redução de custos de coleta, processamento e distribuição poderão ser minimizados se as plantas processadoras estiverem localizadas nesta área intermediária. 
Com a finalidade de simplificar as análises relativas aos fluxos de oferta e de demanda de laranja, adotar-se-á, para fins do presente estudo, a divisão administrativa estabelecida pela Secretaria da Agricultura e do Abastecimento do Estado de São Paulo, de forma que os 40 EDRs do existentes serão considerados como centros de oferta, de consumo e como possíveis centros de processamento. Cada EDR será representado por um único centróide, associado ao principal município da região, o qual servirá como referencial para a obtenção dos custos de transporte. $O$ centróide será utilizado, ainda, como referência para a implantação das plantas processadoras, não significando, contudo, que estas plantas sejam necessariamente instaladas no centróide propriamente dito, mas sim distribuídas dentro do EDR em questão. Lista-se, a seguir, os EDRs existentes no Estado de São Paulo (vide Tabela 16).

Tabela 16. Escritórios de Desenvolvimento Rural, São Paulo, 1997.

\begin{tabular}{ccc}
\hline Número do EDR & EDR & Centróide \\
\hline 1 & Andradina & Andradina \\
2 & Araçatuba & Araçatuba \\
3 & Araraquara & Araraquara \\
4 & Assis & Assis \\
5 & Avaré & Avaré \\
6 & Barretos & Barretos \\
7 & Bauru & Bauru \\
8 & Botucatu & Botucatu \\
9 & Bragança Paulista & Bragança Paulista \\
10 & Campinas & Campinas \\
11 & Catanduva & Catanduva \\
12 & Dracena & Dracena \\
13 & Fernandópolis & Fernandópolis \\
14 & Franca & Franca \\
15 & General Salgado & General Salgado \\
16 & Guaratinguetá & Guaratinguetá \\
17 & Itapetininga & Itapetininga \\
18 & Itapeva & Itapeva \\
19 & Jaboticabal & Jaboticabal \\
20 & Jales & Jales \\
21 & Jaú & Jaú \\
22 & Limeira & Limeira \\
23 & Lins & Lins \\
24 & Marilia & Marilia \\
25 & Mogi das Cruzes & Mogi das Cruzes \\
26 & Mogi Mirim & Mogi Mirim \\
27 & Ourindia & Orlândia \\
28 & Pindamosinhangaba & Ourinhos \\
29 & Piracicaba & Pindamonhangaba \\
30 & & Piracicaba \\
& & \\
& &
\end{tabular}


Tabela 16. Escritórios de Desenvolvimento Rural, São Paulo, 1997.

\begin{tabular}{ccc}
\hline Número do EDR & EDR & Centróide \\
\hline 31 & Presidente Prudente & Presidente Prudente \\
32 & Presidente Venceslau & Presidente Venceslau \\
33 & Registro & Registro \\
34 & Ribeirão Preto & Ribeirão Preto \\
35 & São João da Boa Vista & São João da Boa Vista \\
36 & São José do Rio Preto & São José do Rio Preto \\
37 & São Paulo & São Paulo \\
38 & Sorocaba & Sorocaba \\
39 & Tupã & Tupã \\
40 & Votuporanga & Votuporanga \\
\hline
\end{tabular}

Fonte: Secretaria da Agricultura e do Abastecimento.

\subsubsection{Oferta de Laranja}

Considerou-se, para fins de oferta de laranja, as produções de cada EDR do Estado, como pode ser observado na Tabela 17. Estima-se que nos anos safra 1998/99 e 1999/00 somente $22 \%$ da produção destinou-se ao consumo in natura. Assim, adotou-se como oferta o valor da produção de cada EDR, ponderado pela parcela destinada ao mercado interno. Cabe destacar que o procedimento mais adequado para estimar a oferta de laranja seria o de considerar as curvas de oferta de cada EDR, principalmente porque a disponibilidade desta fruta para o mercado interno oscila em função da demanda da indústria de sucos. No entanto, a indisponibilidade de informações relativas às curvas de oferta para cada EDR fez com que se adotasse um valor constante para esse parâmetro, representado pela parcela da produção destinada ao mercado interno, no ano de 1999. 
Tabela 17. Produção e oferta de laranja para o mercado de frutas frescas, por EDR, São Paulo, 1999.

\begin{tabular}{|c|c|c|}
\hline EDR & $\begin{array}{c}\text { Produção } \\
\text { (em toneladas) }\end{array}$ & $\begin{array}{c}\text { Oferta para Mercado Interno } \\
\text { (em toneladas) }\end{array}$ \\
\hline Andradina & 56.508 & 12.432 \\
\hline Araçatuba & 3.189 & 834 \\
\hline Araraquara & 1.747 .945 & 384.548 \\
\hline Assis & 4.961 & 1.091 \\
\hline Avaré & 130.810 & 28.778 \\
\hline Barretos & 2.657 .533 & 584.657 \\
\hline Bauru & 263.099 & 57.882 \\
\hline Botucatu & 117.180 & 25.780 \\
\hline Bragança Paulista & 47.865 & 10.530 \\
\hline Campinas & 21.270 & 4.679 \\
\hline Catanduva & 1.165 .551 & 256.421 \\
\hline Dracena & 9.096 & 2.001 \\
\hline Fernandópolis & 312.173 & 68.678 \\
\hline Franca & 85.456 & 18.800 \\
\hline General Salgado & 192.849 & 42.427 \\
\hline Guaratinguetá & 6.667 & 1.467 \\
\hline Itapetininga & 416.654 & 91.664 \\
\hline Itapeva & 59.754 & 13.146 \\
\hline Jaboticabal & 2.019 .860 & 444.369 \\
\hline Jales & 345.986 & 76.117 \\
\hline Jaú & 532.274 & 117.100 \\
\hline Limeira & 1.484 .911 & 326.680 \\
\hline Lins & 227.051 & 49.951 \\
\hline Marília & 17.025 & 3.746 \\
\hline Mogi das Cruzes & 2.003 & 441 \\
\hline Mogi Mirim & 1.250 .834 & 275.183 \\
\hline Orlầndia & 612 & 135 \\
\hline Ourinhos & 110.773 & 24.370 \\
\hline Pindamonhangaba & 7.637 & 1.680 \\
\hline Piracicaba & 74.976 & 16.495 \\
\hline Presidente Prudente & 3.496 & 769 \\
\hline Presidente Venceslau & 1.108 & 244 \\
\hline Registro & 27 & 6 \\
\hline Ribeirão Preto & 248.232 & 54.611 \\
\hline São João da Boa Vista & 1.039 .286 & 228.643 \\
\hline São José do Rio Preto & 1.317 .349 & 289.817 \\
\hline São Paulo & 3.432 & 755 \\
\hline Sorocaba & 115.072 & 25.316 \\
\hline Tupã & 9.879 & 2.173 \\
\hline Votuporanga & 211.287 & 46.483 \\
\hline Total & 16.322 .513 & 3.590 .953 \\
\hline
\end{tabular}

Fonte: Instituto de Economia Agrícola (2000). 


\subsubsection{Demanda por laranja}

A laranja, conforme a Pesquisa de Orçamentos Familiares (POF/IBGE), é a fruta mais consumida na maior parte dos domicilios das regiões metropolitanas do Brasil. Contudo, seu consumo, comparando-se os levantamentos de 1987/88 e 1995/96, tem se reduzido, em virtude da maior sofisticação dos hábitos alimentares. Em 1996, o consumo per capita de laranja, no Estado de São Paulo, estava em torno de $12,8 \mathrm{~kg} / \mathrm{ano}$. Para fins do presente estudo, a demanda por laranja in natura, em cada EDR, foi obtida ponderando-se esse nível de consumo per capita médio pela população residente em cada região agrícola, conforme mostra a Tabela 18.

É importante mencionar que, da mesma forma que a oferta, o modo mais correto para se estimar a demanda de cada EDR seria a utilização de curvas de demanda, que poderiam fornecer uma aproximação mais próxima da realidade. Entretanto, a indisponibilidade desta informação fez com que se utilizasse, neste estudo, um valor constante para esse parâmetro do modelo.

Tabela 18. População e demanda por laranja de mesa, por EDR, São Paulo, 1999.

\begin{tabular}{lcc}
\hline \multicolumn{1}{c}{ EDR } & População & $\begin{array}{c}\text { Demanda por laranja } \\
\text { (em toneladas) }\end{array}$ \\
\hline Andradina & 186.364 & 2.385 \\
Araçatuba & 398.627 & 5.102 \\
Araraquara & 582.524 & 7.456 \\
Assis & 242.351 & 3.102 \\
Avaré & 182.616 & 2.337 \\
Barretos & 410.887 & 5.259 \\
Bauru & 435.456 & 5.574 \\
Botucatu & 224.148 & 2.869 \\
Bragança Paulista & 463.235 & 5.929 \\
Campinas & 2.150 .294 & 27.524 \\
Catanduva & 264.622 & 3.387 \\
Dracena & 174.662 & 2.236 \\
Fernandópolis & 101.812 & 1.303 \\
Franca & 410.587 & 5.256 \\
General Salgado & 104.735 & 1.341 \\
Guaratinguetá & 413.734 & 5.296 \\
Itapetininga & 352.483 & 4.512 \\
Itapeva & 258.739 & 3.312 \\
Jaboticabal & 320.146 & 4.098 \\
Jales & 142.563 & 1.825 \\
Jaú & 346.932 & 4.441 \\
Limeira & 761.448 & 9.747 \\
& &
\end{tabular}


Tabela 18. População e demanda por laranja de mesa, por EDR, São Paulo, 1999.

\begin{tabular}{lcc}
\hline \multicolumn{1}{c}{ EDR } & População & $\begin{array}{c}\text { Demanda por laranja } \\
\text { (em toneladas) }\end{array}$ \\
\hline Lins & 168.696 & 2.159 \\
Marília & 289.449 & 3.705 \\
Mogi das Cruzes & 1.282 .015 & 16.410 \\
Mogi Mirim & 460.573 & 5.895 \\
Orlândia & 233.563 & 2.990 \\
Ourinhos & 250.733 & 3.209 \\
Pindamonhangaba & 1.432 .989 & 18.342 \\
Piracicaba & 874.011 & 11.187 \\
Presidente Prudente & 359.926 & 4.607 \\
Presidente Venceslau & 189.604 & 2.427 \\
Registro & 236.225 & 3.024 \\
Ribeirão Preto & 825.312 & 10.564 \\
São João da Boa Vista & 397.160 & 5.084 \\
São José do Rio Preto & 578.994 & 7.411 \\
São Paulo & 17.190 .416 & 220.037 \\
Sorocaba & 1.125 .738 & 14.409 \\
Tupã & 170.007 & 2.176 \\
Votuporanga & 131.143 & 1.679 \\
Total & 35.125 .519 & 449.606 \\
Fonte: Fundação SEADE e IBGE & \multicolumn{2}{|}{}
\end{tabular}

\subsubsection{Localizações potenciais}

Neste estudo, poderia ter-se considerado que todos os 624 municípios do Estado de São Paulo fossem locais candidatos à instalação de packing-houses. Porém, esta consideração aumentaria excessivamente o número de variáveis, elevando consideravelmente o tempo de processamento, sem mencionar a necessidade de se levantar dados muito mais detalhados. Dessa forma, optou-se por uma análise baseada nas localizações associadas às regiões referentes aos Escritórios de Desenvolvimento Rural (EDRs). 


\subsubsection{Capacidade de processamento dos packing-houses}

Quanto ao tamanho das plantas processadores de laranja, adotou-se, para este estudo, 7 diferentes capacidades de processamento: 50 mil, 100 mil, 250 mil, 500 mil, 1 milhão, 2 milhões e 3 milhões de caixas por ano. Verificou-se, por meio de levantamentos realizados junto a proprietários de packing-houses, que a maior parte das plantas existentes no Estado de São Paulo (71\%) apresenta uma capacidade de processamento que varia de 100 a 500 mil caixas por ano.

\subsubsection{Custos}

\subsection{Custos de processamento e de implantação.}

Os custos variáveis de um packing-house compreendem, principalmente, gastos com a matéria-prima, além de outras despesas importantes, tais como energia elétrica, produtos utilizados no beneficiamento da fruta (ceras, fungicidas, detergentes etc.), mão-de-obra, manutenção de equipamentos e embalagens. Os custos de processamento e de equipamentos de beneficiamento foram obtidos a partir de entrevistas com empresas e agentes do setor (vide Tabela 19).

O custo de implantação foi calculado adicionando-se aos valores dos equipamentos o valor da construção civil. Segundo o levantamento de campo realizado, packing-houses que processam até 250 mil caixas por ano ocupam uma área de, aproximadamente, mil metros quadrados. Já as plantas com capacidades superiores utilizam cerca de dois mil metros quadrados. Para o cálculo do valor da construção civil, adotou-se, como referência, o valor de $R \$ 150,00$ por metro quadrado construído. É importante mencionar que os valores obtidos para os equipamentos apresentaram grandes oscilações, de modo que optou-se por empregar valores médios, calculados a partir das informações obtidas no levantamento de campo.

Um outro ponto que merece destaque refere-se às economias de escala no processamento. Conforme os valores apresentados na Tabela 19, observa-se que, a partir de 500 mil caixas processadas por ano, passa a haver uma deseconomia de escala. No entanto, essa informação pode estar equivocada, em virtude da falta de precisão dos dados coletados, que oscilaram muito, especialmente em função do grau 
de tecnologia empregada nos packing-houses, o que levou à adoção de valores médios.

Tabela 19. Custos de implantação e de processamento de packing-houses, São Paulo, 2001.

\begin{tabular}{lccc}
\hline $\begin{array}{c}\text { Capacidade do } \\
\text { packing-house }\end{array}$ & $\begin{array}{c}\text { Custo de Implantação } \\
\text { (em R } \$ \text { ) }\end{array}$ & $\begin{array}{c}\text { Custo de Processamento } \\
\text { (R\$/caixa) }\end{array}$ & $\begin{array}{c}\text { Total } \\
\text { (em R\$/ano) }\end{array}$ \\
\hline 50 mil caixas/ano & 188.000 & 0.60 & 218.000 \\
100 mil caixas/ano & 193.000 & 0,70 & 263.000 \\
250 mil caixas/ano & 200.000 & 0,65 & 362.500 \\
500 mil caixas/ano & 450.000 & 0,60 & 750.000 \\
1 milhão de caixas/ano & 565.000 & 0,70 & 1.265 .000 \\
2 milhöes de caixas/ano & 2.000 .000 & 0,80 & 3.600 .000 \\
3 milhöes de caixas/ano & 2.500 .000 & 0,90 & 5.200 .000 \\
\hline Fonte: Empresas do setor & & &
\end{tabular}

\subsection{Custos de transporte}

Normalmente, os custos relativos ao transporte de produtos são determinados em função do tipo de carga transportada, da distância a ser percorrida e da modalidade de transporte empregada.

Neste estudo, os valores de custo de transporte adotados entre as diversas origens e destinos foram baseados em tabela de fretes rodoviários, em função de distância, fornecida por empresas do setor (vide Tabelas 20, 21, 22). 


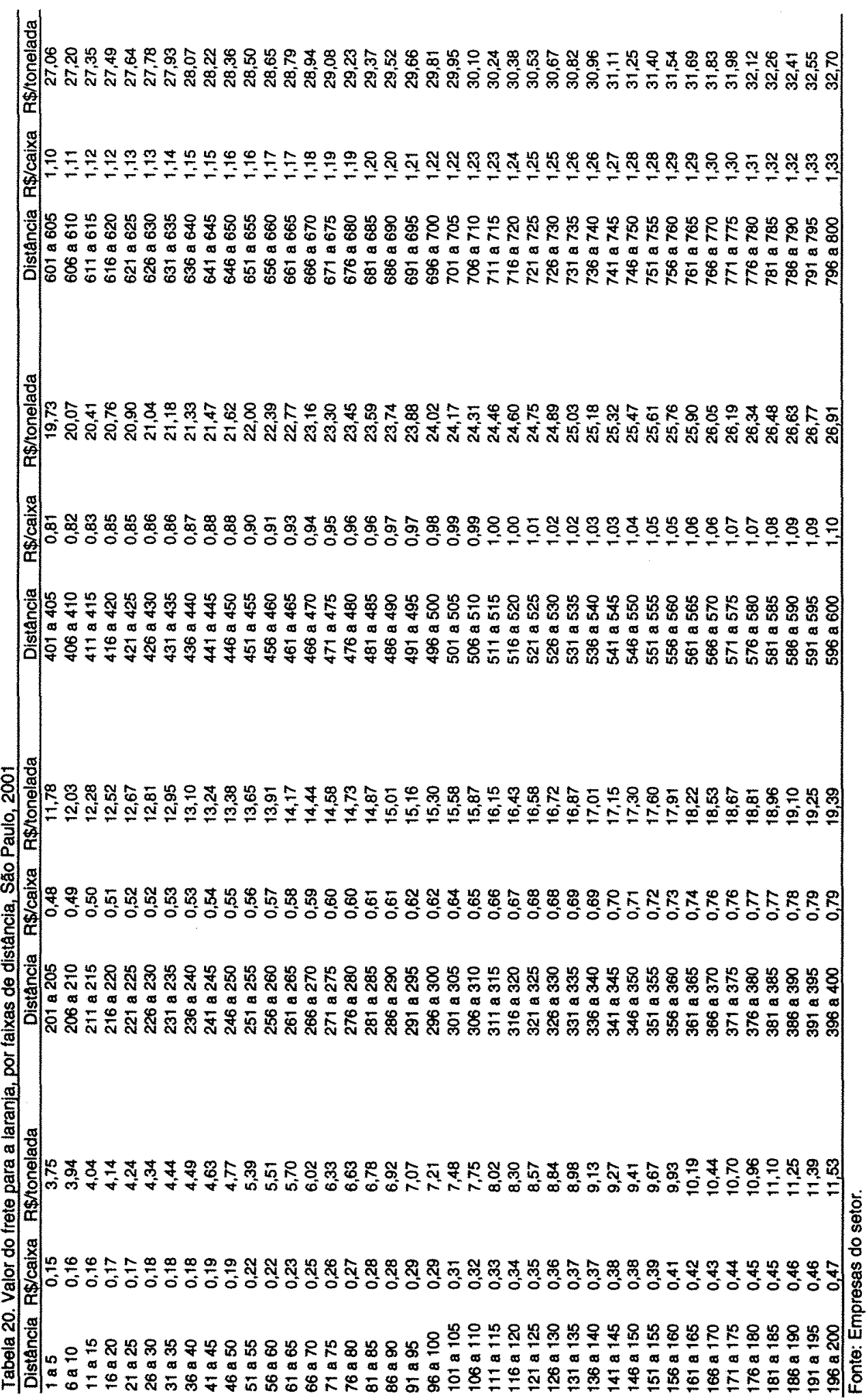




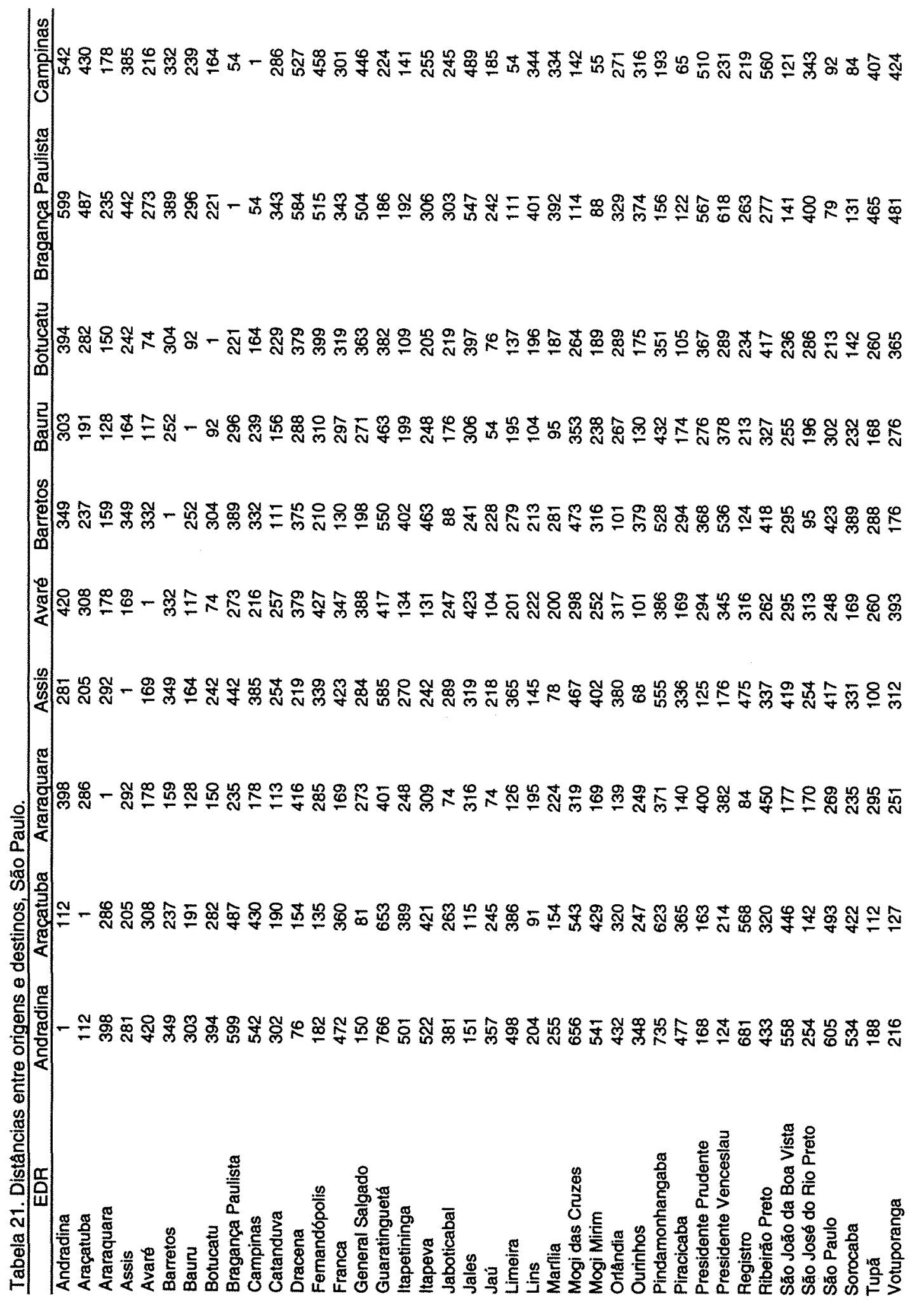




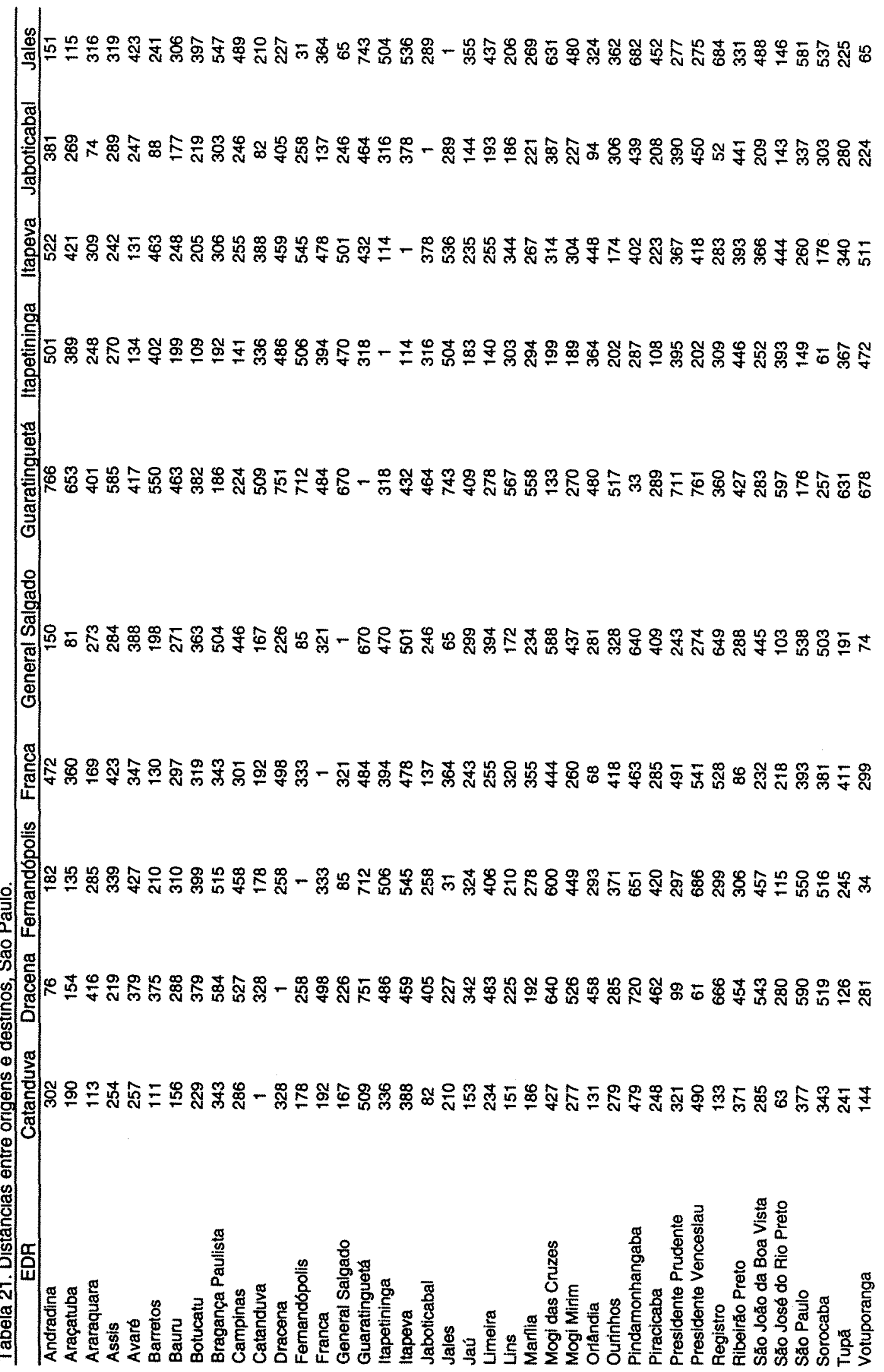




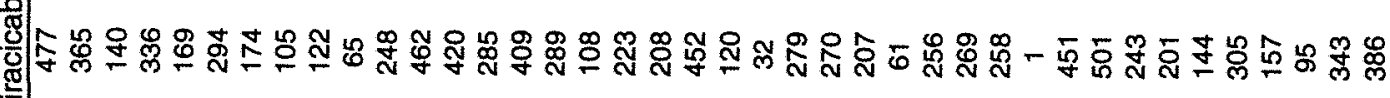

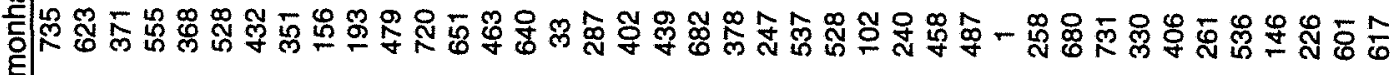

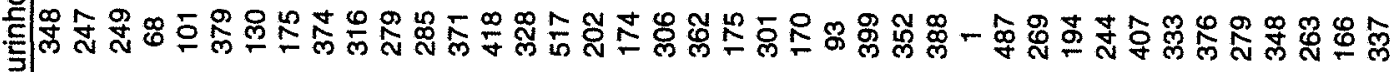

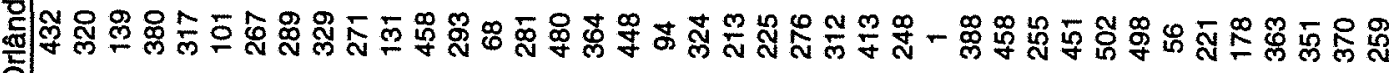

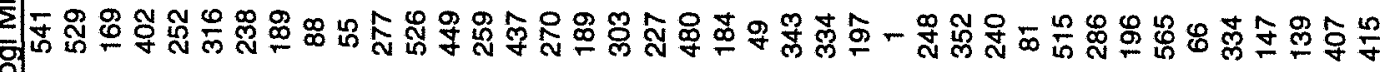

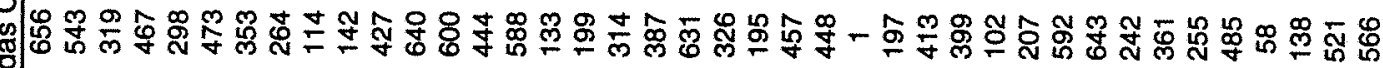

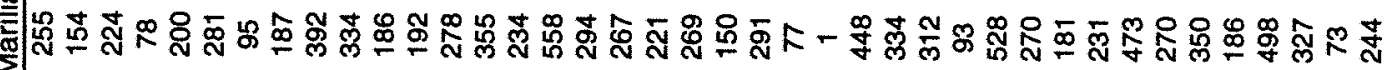

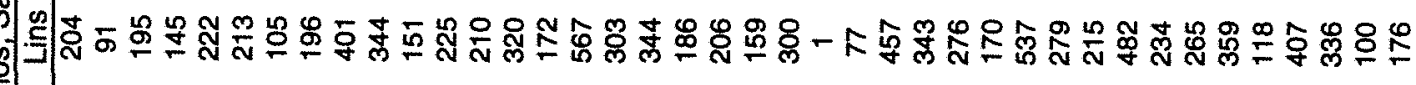

品品品

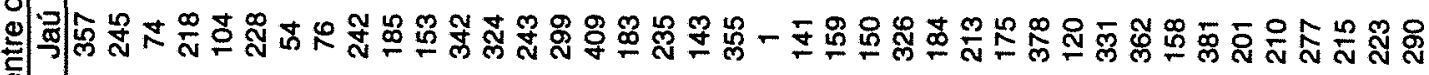


Tabela 21. Distáncias entre origens e destinos, Săo Paulo.

\begin{tabular}{|c|c|c|c|c|c|c|c|c|c|c|}
\hline EDR & Pres. Prudente & Pres. Venceslau & Registro & Ribeirăo Preto & S. João da Boa Vista & S. José do Rio Preto & São Paulo & Sorocaba & Tupã & Votuporanga \\
\hline Andradina & 168 & 124 & 681 & 433 & 558 & 254 & 605 & 534 & 188 & 216 \\
\hline Araçatuba & 163 & 214 & 568 & 320 & 446 & 142 & 493 & 422 & 112 & 127 \\
\hline Araraquara & 400 & 382 & 84 & 450 & 177 & 170 & 269 & 235 & 295 & 251 \\
\hline Assis & 125 & 176 & 475 & 337 & 419 & 254 & 417 & 331 & 100 & 312 \\
\hline Avaré & 294 & 345 & 316 & 262 & 295 & 313 & 248 & 169 & 260 & 393 \\
\hline Barretos & 368 & 536 & 124 & 418 & 295 & 95 & 423 & 389 & 288 & 176 \\
\hline Baturu & 276 & 378 & 213 & 327 & 255 & 196 & 302 & 232 & 168 & 276 \\
\hline Botucatu & 367 & 289 & 234 & 417 & 236 & 286 & 213 & 142 & 260 & 366 \\
\hline Bragança Paulista & 567 & 618 & 263 & 277 & 141 & 400 & 79 & 131 & 465 & 481 \\
\hline Campinas & 510 & 231 & 219 & 560 & 121 & 343 & 92 & 84 & 407 & 424 \\
\hline Catanduva & 321 & 490 & 133 & 371 & 285 & 63 & 377 & 343 & 241 & 144 \\
\hline Dracena & 99 & 61 & 666 & 454 & 543 & 280 & 590 & 519 & 126 & 281 \\
\hline Fernandópolis & 297 & 686 & 299 & 306 & 457 & 115 & 550 & 516 & 245 & 34 \\
\hline Franca & 491 & 541 & 528 & 86 & 232 & 218 & 393 & 381 & 411 & 299 \\
\hline General Salgado & 243 & 274 & 649 & 288 & 445 & 103 & 538 & 503 & 191 & 74 \\
\hline Guaratinguetá & 711 & 761 & 360 & 427 & 283 & 597 & 176 & 257 & 631 & 678 \\
\hline Itapetininga & 395 & 202 & 309 & 446 & 252 & 393 & 149 & 61 & 367 & 473 \\
\hline Itapeva & 367 & 418 & 283 & 393 & 366 & 444 & 260 & 176 & 340 & 511 \\
\hline Jaboticabal & 390 & 450 & 52 & 441 & 209 & 143 & 337 & 303 & 280 & 224 \\
\hline Jales & 277 & 275 & 684 & 331 & 488 & 146 & 581 & 537 & 225 & 65 \\
\hline Jaú & 331 & 362 & 158 & 381 & 201 & 210 & 277 & 215 & 223 & 290 \\
\hline Limeira & 471 & 274 & 173 & 522 & 112 & 291 & 146 & 127 & 364 & 372 \\
\hline Lins & 215 & 482 & 234 & 265 & 359 & 118 & 407 & 336 & 100 & 176 \\
\hline Marfia & 181 & 231 & 473 & 270 & 350 & 186 & 498 & 327 & 73 & 244 \\
\hline Mogi das Cruzes & 592 & 643 & 242 & 361 & 255 & 485 & 58 & 138 & 521 & 566 \\
\hline Mogi Mirim & 515 & 286 & 196 & 565 & 66 & 334 & 147 & 139 & 407 & 415 \\
\hline Orlândia & 451 & 502 & 498 & 56 & 221 & 178 & 363 & 351 & 370 & 259 \\
\hline Ourinhos & 194 & 244 & 407 & 333 & 376 & 279 & 348 & 263 & 166 & 337 \\
\hline PIndamonhangaba & 680 & 731 & 330 & 406 & 261 & 536 & 146 & 226 & 601 & 617 \\
\hline Piracicaba & 451 & 501 & 243 & 201 & 144 & 305 & 157 & 95 & 243 & 386 \\
\hline Presidente Prudente & 1 & 60 & 600 & 439 & 531 & 273 & 542 & 456 & 115 & 275 \\
\hline Presidente Venceslau & 60 & 1 & 651 & 531 & 273 & 323 & 592 & 147 & 165 & 326 \\
\hline Reglstro & 600 & 651 & 1 & 443 & 353 & 548 & 184 & 296 & 546 & 652 \\
\hline Ribeiráo Preto & 439 & 489 & 443 & 1 & 172 & 184 & 311 & 507 & 329 & 265 \\
\hline Săo Joăo da Boa Vista & 531 & 582 & 353 & 172 & 1 & 342 & 213 & 205 & 423 & 423 \\
\hline São Jose do Rio Preto & 273 & 323 & 548 & 184 & 342 & 1 & 435 & 401 & 193 & 81 \\
\hline São Pauło & 542 & 592 & 184 & 311 & 213 & 435 & 1 & 88 & 471 & 516 \\
\hline Sorocaba & 456 & 147 & 296 & 507 & 205 & 401 & 88 & 1 & 400 & 482 \\
\hline Tupå & 115 & 165 & 546 & 329 & 423 & 193 & 471 & 400 & 1 & 224 \\
\hline Votuporanga & 275 & 326 & 652 & 265 & 423 & 81 & 516 & 482 & 224 & 1 \\
\hline
\end{tabular}

Fonte: SIFRECAVSALQ/USP, 2001 
Tabela 22. Custo de transporte entre origens e destinos, Estado de São Paulo, 2001,

\begin{tabular}{|c|c|c|c|c|c|c|c|c|c|c|}
\hline EDR & Andradina & Araçatuba & Araraquara & Assis & Avaré & Barretos & Bauru & Botucatu & Bragança Paulista & Campinas \\
\hline Andradina & 3,75 & 8,03 & 19,39 & 14,87 & 20,76 & 17,30 & 15,58 & 19,25 & 26,91 & 25,32 \\
\hline Araçatuba & 8,03 & 3,75 & 15,01 & 11,78 & 15,87 & 13,10 & 11,39 & 14,87 & 23,74 & 21,04 \\
\hline Araraquara & 19,39 & 15,01 & 3,75 & 15,16 & 10,96 & 9,93 & 8,84 & 9,41 & 12,95 & 10,96 \\
\hline Assis & 14,87 & 11,78 & 15,16 & 3,75 & 10,44 & 17,30 & 10,19 & 13,24 & 21,47 & 18,96 \\
\hline Avaré & 20,76 & 15,87 & 10,96 & 10,44 & 3,75 & 16,87 & 8,30 & 6,33 & 14,58 & 12,52 \\
\hline Barretos & 17,30 & 13,10 & 9,93 & 17,30 & 16,87 & 3,75 & 13,65 & 15,58 & 19,10 & 16,87 \\
\hline Bauru & 15,58 & 11,39 & 8,84 & 10,19 & 8,30 & 13,65 & 3,75 & 7,07 & 15,30 & 13,10 \\
\hline Botucatu & 19,25 & 14,87 & 9,41 & 13,24 & 6,33 & 15,58 & 7,07 & 3,75 & 12,67 & 10,19 \\
\hline Bragança Paulista & 26,77 & 23,74 & 12,95 & 21,40 & 14,58 & 19,10 & 15,30 & 12,67 & 3,75 & 5,39 \\
\hline Campinas & 25,32 & 21,04 & 10,96 & 18,96 & 12,52 & 16,87 & 13,10 & 10,19 & 5,39 & 3,75 \\
\hline Catanduva & 15,58 & 11,25 & 8,02 & 13,65 & 13,91 & 8,02 & 9,93 & 12,81 & 17,15 & 15,01 \\
\hline Dracena & 6,63 & 9,67 & 20,76 & 12,52 & 18,81 & 18,67 & 15,01 & 18,81 & 26,48 & 24,89 \\
\hline Femand6polis & 11,10 & 8,98 & 14,87 & 17,01 & 21,04 & 12,03 & 15,87 & 19,39 & 24,46 & 22,39 \\
\hline Franca & 23,30 & 17,91 & 10,44 & 20,90 & 17,30 & 8,84 & 15,30 & 16,43 & 17,15 & 15,58 \\
\hline General Salgado & 9,41 & 6,78 & 14,58 & 14,87 & 19,10 & 11,53 & 14,58 & 18,22 & 24,17 & 21,62 \\
\hline Guaratinguetá & 31,83 & 28,50 & 19,73 & 26,48 & 20,76 & 25,47 & 22,77 & 18,96 & 11,25 & 12,67 \\
\hline Itapetininga & 24,17 & 19,10 & 13,38 & 14,44 & 8,98 & 19,73 & 11,53 & 7,75 & 11,39 & 9,27 \\
\hline Itapeva & 24,76 & 20,90 & 15,87 & 13,24 & 8,98 & 27,77 & 13,38 & 11,78 & 15,87 & 13,65 \\
\hline Jaboticabal & 18,96 & 14,43 & 6,33 & 15,01 & 13,38 & 6,92 & 10,96 & 12,52 & 15,58 & 13,24 \\
\hline Jales & 9,67 & 8,02 & 16,43 & 16,43 & 20,90 & 13,24 & 15,87 & 19,39 & 25,47 & 23,74 \\
\hline Jaú & 17,91 & 13,24 & 6,33 & 12,52 & 7,48 & 18,81 & 5,39 & 6,63 & 13,24 & 11,10 \\
\hline Limeira & 24,02 & 19,10 & 8,84 & 18,22 & 11,78 & 14,73 & 11,39 & 9,13 & 8,02 & 5,39 \\
\hline Lins & 11,78 & 7,07 & 11,39 & 9,27 & 12,67 & 12,28 & 7,48 & 11,53 & 19,73 & 17,15 \\
\hline Marília & 13,65 & 9,67 & 12,67 & 6,63 & 11,53 & 41,87 & 7,07 & 11,25 & 19,25 & 16,87 \\
\hline Mogi das Cruzes & 28.65 & 25,32 & 16,43 & 23,16 & 15,30 & 23,30 & 17,60 & 14,17 & 8,02 & 9,27 \\
\hline Mogi Mirim & 25,32 & 21,04 & 10,44 & 19,73 & 13,65 & 16,43 & 13,10 & 11,25 & 6,92 & 5,39 \\
\hline Orlândia & 21,18 & 16,43 & 9,13 & 18,81 & 16,43 & 7,48 & 14,44 & 15,01 & 16,72 & 14,58 \\
\hline Ourinhos & 17,30 & 13,38 & 13,38 & 6,02 & 7,48 & 18,81 & 8,84 & 10,70 & 18,67 & 16,43 \\
\hline Pindamonhangaba & 30,82 & 27,64 & 18,67 & 25,61 & 18,53 & 24,89 & 21,18 & 17,60 & 9,93 & 11,39 \\
\hline Piracicaba & 23,45 & 18,22 & 9,13 & 17,01 & 10,44 & 15,16 & 10,70 & 7,48 & 8,57 & 5,70 \\
\hline Presidente Prudente & 10.44 & 10,19 & 19,39 & 8,57 & 15,16 & 18,53 & 14,73 & 18,53 & 26,04 & 24,31 \\
\hline Presidente Venceslau & 8,57 & 12,28 & 18,96 & 10,96 & 17,15 & 25,18 & 18,81 & 15,01 & 27,49 & 2,95 \\
\hline Registro & 29,37 & 26,05 & 6,78 & 23,30 & 16,43 & 8,57 & 12,28 & 12,95 & 14,17 & 12,52 \\
\hline Ribeirão Preto & 21,18 & 16,43 & 21,62 & 17,01 & 14,17 & 20,75 & 16,72 & 20,75 & 14,73 & 25,75 \\
\hline Săo Joāo da Boa Vista & 25,75 & 21,62 & 10,96 & 20,76 & 15,16 & 15,16 & 13,65 & 13,10 & 9,27 & 8,57 \\
\hline Săo José do Rio Preto & 13,65 & 9,27 & 10,44 & 13,65 & 16,15 & 7,07 & 11,53 & 15,01 & 19,39 & 17,15 \\
\hline São Paulo & 27,06 & 23,88 & 14,44 & 20,76 & 13,38 & 20,90 & 15,58 & 12,28 & 6,63 & 7,07 \\
\hline Sorocaba & 25,03 & 20,90 & 12,95 & 16,87 & 10,44 & 19,10 & 12,95 & 9,27 & 8,98 & 6,78 \\
\hline Tupã & 11,25 & 8,02 & 15,16 & 7,21 & 13,91 & 15,01 & 10,44 & 13,91 & 22,77 & 20,07 \\
\hline Votuporanga & 12,52 & 8,84 & 13,65 & 16,15 & 19,25 & 10,96 & 14,73 & 18,22 & 23,59 & 20,90 \\
\hline
\end{tabular}


Tabela 22. Custo de transporte entre origens e destinos, Estado de Săo Paulo, 2001

\begin{tabular}{|c|c|c|c|c|c|c|c|c|c|c|}
\hline EDA & Catanduva & Dracena & Fernandópolis & Franca & General Salgado & Guaratinguetá & Itapetininga & Itapeva & Jaboticabal & Jales \\
\hline Andradina & 15,58 & 6,63 & 11,10 & 23,30 & 9,41 & 31,83 & 24,17 & 24,76 & 18,96 & 9,67 \\
\hline Araçatuba & 11,25 & 9,67 & 8,98 & 17,91 & 6,78 & 28,50 & 19,10 & 20,90 & 14,43 & 8,02 \\
\hline Araraquara & 8,02 & 20,76 & 15,01 & 10,44 & 14,58 & 19,73 & 13,38 & 15,87 & 6,33 & 16.43 \\
\hline Assis & 13,65 & 12,52 & 17,01 & 20,90 & 14,87 & 26,48 & 14,44 & 13,24 & 15,01 & 16,43 \\
\hline Avaré & 13,91 & 18,81 & 21,04 & 17,30 & 19,10 & 20,76 & 8,98 & 8,98 & 13,38 & 20,90 \\
\hline Barretos & 8,02 & 18,67 & 12,03 & 8,84 & 11,53 & 25,47 & 19,73 & 22,77 & 6,92 & 13,24 \\
\hline Bauru & 9,93 & 15,01 & 15,87 & 15,30 & 14,58 & 22,77 & 11,53 & 13,38 & 10,96 & 15,87 \\
\hline Botucatu & 12,81 & 18,81 & 19,39 & 16,43 & 18,22 & 18,96 & 7,75 & 11,78 & 12,52 & 19,39 \\
\hline Bragança Paulista & 17,15 & 26,48 & 24,46 & 17,15 & 24,17 & 11,25 & 11,39 & 15,87 & 15,58 & 25,47 \\
\hline Campinas & 15,01 & 24,89 & 22,39 & 15,58 & 21,62 & 12,67 & 9,27 & 13,65 & 13,24 & 23,74 \\
\hline Catanduva & 3,75 & 16,72 & 10,96 & 11,39 & 10,44 & 24,31 & 17,01 & 19,10 & 6,78 & 12,03 \\
\hline Dracena & 16,72 & 3,75 & 13,91 & 24,02 & 12,81 & 31,40 & 23,74 & 22,39 & 19,73 & 12,81 \\
\hline Fernandópolis & 10,96 & 13,91 & 3,75 & 16,87 & 6,76 & 30,24 & 24,31 & 25,32 & 13,91 & 4,44 \\
\hline Franca & 13,39 & 24,02 & 16,87 & 3,75 & 16,58 & 23,59 & 19,25 & 23.45 & 9,13 & 18,22 \\
\hline General Salgado & 10,44 & 12,81 & 6,78 & 15,58 & 3,75 & 28,94 & 23,16 & 24,17 & 13,38 & 5,70 \\
\hline Guaratinguetá & 24,31 & 31,40 & 30,24 & 23,59 & 28,94 & 3,75 & 16,43 & 21,18 & 22,77 & 31,11 \\
\hline Itapetininga & 17,01 & 23,74 & 24,31 & 19,25 & 23,16 & 16,43 & 3,75 & 8,02 & 16,43 & 24,17 \\
\hline Itapeva & 19,10 & 22,39 & 25,32 & 23,45 & 24,17 & 21,18 & 8,02 & 3,75 & 18,81 & 25,18 \\
\hline Jaboticabal & 6,78 & 19,73 & 13,91 & 9,13 & 13,38 & 22,77 & 16,43 & 18,81 & 3,75 & 15,01 \\
\hline Jales & 12,03 & 12,81 & 4,44 & 18,22 & 5,70 & 31,11 & 24,17 & 25,18 & 15,01 & 3,75 \\
\hline Jaú & 9,67 & 17,15 & 16,58 & 13,24 & 15,30 & 20,07 & 11,10 & 12,95 & 9,27 & 17,60 \\
\hline Limeira & 12,95 & 23,59 & 20,07 & 13,65 & 19,25 & 14,73 & 9,13 & 13,65 & $\$ 1,39$ & 21,33 \\
\hline Lins & 9,67 & 12,67 & 12,03 & 16,43 & 10,70 & 26,05 & 15,58 & 17,15 & 11,25 & 12,03 \\
\hline Marfia & 11,25 & 11,39 & 14,73 & 17,60 & 12,95 & 25,76 & 15,16 & 14,44 & 12,67 & 14,44 \\
\hline Mogl das Cruzes & 21,04 & 28,07 & 26,91 & 21,47 & 26,63 & 8,98 & $\$ 1,53$ & 16,15 & 19,10 & 27,93 \\
\hline Mogi Mirim & 17,73 & 24,89 & 25,62 & 13,91 & 21,33 & 14,44 & 11,25 & 15,58 & 12,81 & 23,45 \\
\hline Ortandia & 8,98 & 22,39 & 15,16 & 6,02 & 14,87 & 23,45 & 18,22 & 21,62 & 7,07 & 16,58 \\
\hline Ourinhos & 14,73 & 14,87 & 18,67 & 20,76 & 16,72 & 24,60 & 11,78 & 10,70 & 15,87 & 18,22 \\
\hline Pindamonhangaba & 23,45 & 30,38 & 28,50 & 22,77 & 28,07 & 4,44 & 15,01 & 19,73 & 21,33 & 29,37 \\
\hline Piracicaba & 13,38 & 22,77 & 20,76 & 14,87 & 20,07 & 15,01 & 7,75 & 12,67 & 12,03 & 22,00 \\
\hline Presidente Prudente & 16,58 & 7,21 & 15,30 & 23,88 & 13,24 & 30,24 & 19,25 & 18,53 & 19,10 & 14,58 \\
\hline Presidente Venceslau & 23,74 & 5,70 & 29,51 & 25,32 & 14,58 & 31,69 & 11,78 & 20,76 & 21,62 & 14,58 \\
\hline Registro & 8,98 & 28,94 & 15,30 & 24,89 & 28,36 & 17,91 & 15,87 & 14,87 & 5,39 & 29,37 \\
\hline Ribelráo Preto & 18,67 & 22,00 & 15,87 & 6,92 & 15,01 & 21,04 & 21,62 & 19,25 & 21,47 & 16,87 \\
\hline Săo Joăo da Boa Vista & 14,87 & 25,32 & 22,39 & 12,95 & 21,47 & 14,87 & 13,65 & 18,53 & 12,03 & 23,74 \\
\hline São José do Rio Preto & 5,70 & 14,73 & 8,02 & 12,52 & 7,48 & 26,91 & 19,25 & 21,47 & 9,27 & 9,41 \\
\hline Săo Paulo & 18,81 & 26,63 & 25,47 & 19,25 & 25,18 & 10,96 & 9,41 & 13,91 & 17,01 & 26.48 \\
\hline Sorocaba & 17,15 & 24,60 & 24,60 & 18,96 & 24,17 & 13,91 & 5,70 & 10,96 & 15,58 & 25,18 \\
\hline Tupa & 13,24 & 8,84 & 13,24 & 20,41 & 11,39 & 27,93 & 18,53 & 17,01 & 14,73 & 12,67 \\
\hline Votuporanga & 9,27 & 14,87 & 4,44 & 15,30 & 6,33 & 29,23 & 23,30 & 24,46 & 12,67 & 5,70 \\
\hline
\end{tabular}


Tabela 22. Custo de transporte entre origens e destinos, Estado de São Paulo, 2001.

\begin{tabular}{|c|c|c|c|c|c|c|c|c|c|c|}
\hline EDR & Jaú & Limeira & Lins & Marília & Mogi das Cruzes & Mogi Mirim & Orlândia & Ourinhos & Pindamonhangaba & Piracicaba \\
\hline Andradina & 17,91 & 24,02 & 11,78 & 13,65 & 28,65 & 25,32 & 21,18 & 17,30 & 30,82 & 23,45 \\
\hline Araçatuba & 13,24 & 19,10 & 7,07 & 9,67 & 25,32 & 21,04 & 16,43 & 13,38 & 27,64 & 18,22 \\
\hline Araraquara & 6,33 & 8,84 & 11,39 & 12,67 & 16,43 & 10,44 & 9,13 & 13,38 & 18,67 & 9,13 \\
\hline Assis & 12,52 & 18,22 & 9,27 & 6,63 & 23,16 & 19,73 & 18,81 & 6,02 & 25,61 & 17,01 \\
\hline Avaré & 7,48 & 11,78 & 12,67 & 11,53 & 15,30 & 13,65 & 16,43 & 7,48 & 18,53 & 10,44 \\
\hline Barretos & 12,81 & 14,73 & 12,28 & 14,87 & 23,30 & 16,43 & 7,48 & 18,81 & 24,89 & 15,16 \\
\hline Bauru & 5,39 & 11,39 & 7,48 & 7,07 & 17,60 & 13,10 & 14,44 & 8,84 & 21,18 & 10,70 \\
\hline Botucatu & 6,63 & 9,13 & 11,53 & 11,25 & 14,17 & 11,25 & 15,01 & 10,70 & 17,60 & 7,48 \\
\hline Bragança Paulista & 13,24 & 8,02 & 19,73 & 19,25 & 8,02 & 6,92 & 16,72 & 18,67 & 9,93 & 8,57 \\
\hline Campinas & 11,10 & 5,39 & 17,15 & 16,87 & 9,27 & 5,39 & 14,58 & 16,43 & 11,39 & 5,70 \\
\hline Catanduva & 9,67 & 12,95 & 9,67 & 11,25 & 21,04 & 14,73 & 8,98 & 14,73 & 23,45 & 13,38 \\
\hline Dracena & 17,15 & 23,59 & 12,67 & 11,39 & 28,07 & 24,89 & 22,39 & 14,87 & 30,38 & 22,77 \\
\hline Femandopolis & 16,58 & 20,07 & 12,03 & 14,73 & 26,91 & 21,62 & 15,16 & 18,67 & 28,50 & 20,76 \\
\hline Franca & 13,24 & 13,65 & 16,43 & 17,60 & 21,47 & 13,91 & 6,02 & 20,76 & 22,77 & 14,87 \\
\hline General Salgado & 15,30 & 19,25 & 10,70 & 12,95 & 26,63 & 21,33 & 14,87 & 16,72 & 28,07 & 20,07 \\
\hline Guaratinguetá & 20,07 & 14,73 & 26,05 & 25,76 & 8,98 & 14,44 & 23,45 & 24,60 & 4,44 & 15,01 \\
\hline Itapetininga & 11,10 & 9,13 & 15,58 & 15,16 & 11,53 & 11,25 & 18,22 & 11,78 & 15,01 & 7,75 \\
\hline Itapeva & 12,95 & 13,65 & 17,15 & 14,44 & 16,15 & 15,58 & 21,62 & 10,70 & 19,73 & 12,67 \\
\hline Jaboticabal & 9,27 & 11,39 & 11,25 & 12,67 & 19,10 & 12,81 & 7,07 & 15,87 & 21,33 & 12,03 \\
\hline Jales & 17,60 & 21,33 & 12,03 & 14,44 & 27,93 & 23,45 & 16,58 & 18,22 & 29,37 & 22,00 \\
\hline Jaú & 3,75 & 9,27 & 9,93 & 9,41 & 16,72 & 11,10 & 12,28 & 10,70 & 18,81 & 8,30 \\
\hline Limeira & 9,27 & 3,75 & 15,30 & 15,16 & 11,39 & 4,77 & 12,67 & 15,58 & 13,38 & 4,44 \\
\hline Lins & 9,93 & 15,30 & 3,75 & 6,63 & 22,39 & 17,15 & 14,73 & 10,44 & 25,18 & 17,73 \\
\hline Marnia & 9,41 & 15,16 & 6,63 & 3,75 & 21,62 & 16,87 & 16,15 & 7,07 & 24,89 & 14,44 \\
\hline Mogi das Cruzes & 16,72 & 11,39 & 22,39 & 21,62 & 3,75 & 11,53 & 20,41 & 19,39 & 7,48 & 12,03 \\
\hline Mogi Mirim & 11,10 & 4,77 & 17,15 & 16,87 & 11,53 & 3,75 & 13,38 & 17,60 & 13,10 & 6,78 \\
\hline Orlândia & 12,28 & 12,67 & 14,73 & 16,15 & 20,41 & 13,38 & 3,75 & 19,10 & 22,39 & 13,65 \\
\hline Ourinhos & 10,70 & 15,58 & 10,44 & 7,07 & 19,39 & 17,60 & 19,10 & 3,75 & 23,74 & 14,44 \\
\hline Pindamonhangaba & 18,81 & 13,38 & 25,18 & 24,89 & 7,48 & 13,10 & 22,39 & 23,74 & 3,75 & 13,91 \\
\hline Piracicaba & 8,30 & 4,44 & 17,73 & 14,44 & 12,03 & 6,78 & 13,65 & 14,44 & 13,91 & 3,75 \\
\hline Presidente Prudente & 16,87 & 23,30 & 12,28 & 11,10 & 23,77 & 24,46 & 22,00 & 11,39 & 29,23 & 22,00 \\
\hline Presidente Venceslau & 18,22 & 14,58 & 23,59 & 12,95 & 28,22 & 15,01 & 24,17 & 13,24 & 30,82 & 24,17 \\
\hline Registro & 9,93 & 10,70 & 12,25 & 23,30 & 13,24 & 11,53 & 24,02 & 20,07 & 16,72 & 13,24 \\
\hline Pibeirăo Preto & 18,96 & 24,75 & 14,17 & 14,44 & 18,22 & 25,90 & 5,51 & 16,87 & 20,07 & 11,78 \\
\hline Săo Jođ̃o da Boa Vista & 11,78 & 8,02 & 17,91 & 17,30 & 13,65 & 6,02 & 12,67 & 18,81 & 14,17 & 9,27 \\
\hline Săo José do Rio Preto & 13,03 & 15,16 & 8,30 & 11,25 & 23,59 & 16,87 & 10,96 & 14,73 & 25,18 & 15,58 \\
\hline Săo Paulo & 14,73 & 9,41 & 20,07 & 24,02 & 5,51 & 9,41 & 18,22 & 17,30 & 9,41 & 9,93 \\
\hline Sorocaba & 12,28 & 8,84 & 17,01 & 16,72 & 9,13 & 9,13 & 17,60 & 14,17 & 12,81 & 7,07 \\
\hline Tupå & 12,67 & 18,22 & 7,21 & 6,33 & 24,75 & 20,70 & 18,53 & 10,44 & 27,06 & 17,15 \\
\hline Votuporanga & 15,01 & 18,67 & 10,56 & 13,24 & 26,05 & 20,41 & 13,91 & 17,01 & 27,49 & 19,10 \\
\hline
\end{tabular}


Tabela 22. Custo de transporte entre origens e destinos, Estado de Săo Paulo.

\begin{tabular}{|c|c|c|c|c|c|c|c|c|c|c|}
\hline EDR & Pres. Prudente & Pres. Venceslau & Registro & Ribeirăo Preto & S. Joăo da Boa Vista & S. Josś do Rio Preto & Săo Paulo & Sorocaba & Tupăă & Votuporanga \\
\hline Andradina & 10,44 & 8,57 & 29,37 & 21,18 & 25,75 & 13,65 & 27,06 & 25,03 & 11,25 & 12,52 \\
\hline Araçatuba & 10,19 & 12,28 & 26,05 & 16,43 & 21,62 & 9,27 & 23,88 & 20,90 & 8,02 & 8,82 \\
\hline Araraquara & 19,39 & 18,96 & 6,78 & 21,62 & 10,96 & 10,44 & 14,44 & 12,95 & 15,16 & 13,65 \\
\hline Assis & 8,57 & 10,96 & 23,30 & 17,01 & 20,76 & 13,65 & 20,76 & 16,87 & 7,21 & 16,15 \\
\hline Avaré & 15,16 & 17,15 & 16,43 & 14,17 & 15,16 & 16,15 & 13,38 & 10,44 & 13,91 & 19,25 \\
\hline Barretos & 18,53 & 25,18 & 8,57 & 20,75 & 15,16 & 7,07 & 20,90 & 19,10 & 15,01 & 10,96 \\
\hline Bauru & 14,73 & 18,81 & 12,28 & 16,72 & 13,65 & 11,53 & 15,58 & 12,95 & 10,44 & 14,73 \\
\hline Botucatu & 18,53 & 15,01 & 12,95 & 20,75 & 13,10 & 15,01 & 12,28 & 9,27 & 13,91 & 18,22 \\
\hline Bragança Paulista & 26,04 & 27,49 & 14,17 & 14,73 & 9,27 & 19,39 & 6,63 & 8,98 & 22,77 & 23,59 \\
\hline Campinas & 24,31 & 12,95 & 12,52 & 25,75 & 8,57 & 17,15 & 7,07 & 6,78 & 20,07 & 20,90 \\
\hline Catanduva & 16,58 & 23,74 & 8,98 & 18,67 & 14,87 & 5.70 & 18,81 & 17,15 & 13,24 & 9,27 \\
\hline Dracena & 7,21 & 5,70 & 28,94 & 22,00 & 25,32 & 14,73 & 26,63 & 24,60 & 8,84 & 14,87 \\
\hline Femandopolis & 15,30 & 29,51 & 15,30 & 15,87 & 22,39 & 8,02 & 25,47 & 24,60 & 13,24 & 4,44 \\
\hline Franca & 23,88 & 25,32 & 24,89 & 6,92 & 12,95 & 12,52 & 19,25 & 18,96 & 20,41 & 15,30 \\
\hline General Salgado & 13,24 & 14,58 & 28,36 & 15,01 & 21,47 & 7,48 & 25,18 & 24,17 & 11,39 & 6,33 \\
\hline Guaratinguetá & 30,24 & 31,69 & 17,91 & 21,04 & 14,87 & 26,91 & 10,96 & 13,91 & 27,93 & 29,23 \\
\hline Itapetininga & 19,25 & 11,78 & 15,87 & 21,62 & 13,65 & 19,25 & 9,45 & 5,70 & 18,53 & 23,30 \\
\hline Itapeva & 18,53 & 20,76 & 14,87 & 19,25 & 18,53 & 21,47 & 13,91 & 10,96 & 17,01 & 24,46 \\
\hline Jaboticabal & 19,10 & 21,62 & 5,39 & 21,47 & 12,03 & 9,27 & 17,01 & 15,58 & 14,73 & 12,67 \\
\hline Jales & 14,58 & 14,58 & 29,37 & 16,87 & 23,74 & 9,41 & 26,48 & 25,18 & 12,67 & 5,70 \\
\hline Jaú & 16,87 & 18,22 & 9,93 & 18,96 & 11,78 & 12,03 & 14,73 & 12,28 & 12,67 & 15,01 \\
\hline Limeira & 23,30 & 14,58 & 10,70 & 24,75 & 8,02 & 15,16 & 9,41 & 8,84 & 18,22 & 18,67 \\
\hline Lins & 12,28 & 23,59 & 12,95 & 14,17 & 17,91 & 8,30 & 20,07 & $\$ 7,01$ & 7,21 & 10,96 \\
\hline Marilia & 11,10 & 12,95 & 23,30 & 14,44 & 17,30 & 11,25 & 24,02 & 16,72 & 6,33 & 13,24 \\
\hline Mogi das Cruzes & 26,77 & 28,22 & 13,24 & 18,22 & 13,65 & 23,59 & 5,51 & 9,13 & 24,74 & 26,05 \\
\hline Mogl Mirim & 24,46 & 15,01 & 11,53 & 25,90 & 6,02 & 16,87 & 9,41 & 9,13 & 20,07 & 20,41 \\
\hline Orlandla & 22,00 & 24,17 & 24,02 & 5,51 & 12,67 & 10,96 & 18,22 & 17,60 & 18,53 & 13,91 \\
\hline Ourinhos & 11,39 & 13,24 & 20.07 & 18,87 & 18,81 & 14,73 & 17,30 & 14,17 & 10,44 & 17,01 \\
\hline Pindamonhangaba & 29,23 & 30,82 & 16,72 & 20,07 & 14,17 & 25,17 & 9,41 & 12,81 & 27,06 & 27,49 \\
\hline Piracicaba & 22,00 & 24,17 & 13,24 & 11,78 & 9,27 & 15,58 & 9,93 & 7,07 & 17,15 & 19,10 \\
\hline Presidente Prudente & 3,75 & 5,51 & 26,91 & 21,33 & 25,03 & 14,58 & 25,32 & 22,39 & 8,02 & 14,58 \\
\hline Presidente Venceslau & 5,51 & 3,75 & 28,50 & 23,74 & 26,48 & 16,58 & 26,77 & 9,41 & 10,19 & 16,72 \\
\hline Registro & 26,91 & 28,50 & 3,75 & 21,47 & 17,60 & 25,47 & 11,10 & 15,30 & 25,47 & 28,50 \\
\hline Ribeirăo Preto & 21,33 & 23,74 & 21,47 & 3,75 & 10,70 & 11,10 & 16,15 & 24,31 & 16,72 & 14,17 \\
\hline Sẽo Joâo da Boa Vista & 25,03 & 26,48 & 17,60 & 10,70 & 3,75 & 17,15 & 12,28 & 11,78 & 20,90 & 20,90 \\
\hline Sáo José do Rio Preto & 14.58 & 16,58 & 25,47 & 11,10 & 17,15 & 3,75 & 21,18 & 19,73 & 11,39 & 6,78 \\
\hline São Paulo & 25,32 & 27,77 & 11,10 & 16,15 & 12,28 & 21,18 & 3,75 & 6,92 & 23,30 & 24,60 \\
\hline Sorocaba & 22,39 & 9,41 & 15,30 & 24,31 & 11,78 & 19,73 & 6,92 & 3,75 & 19,39 & 23,59 \\
\hline Tupă & 8,02 & 10,19 & 25,47 & 16,72 & 20,90 & 11,39 & 23,30 & 19,39 & 3,75 & 12,67 \\
\hline Votuporanga & 14,58 & 16,72 & 28,50 & 14,17 & 20,90 & 6,78 & 24,60 & 23,59 & 12,67 & 3,75 \\
\hline
\end{tabular}

Fonte: Empresas do setor e SIFRECA 


\section{Resultados e Discussão}

São apresentados, neste capítulo, os resultados obtidos para cada cenário considerado no presente estudo. Analisa-se o fluxo de laranja no Estado de São Paulo, a escala ótima de processamento para cada região, bem como questões ligadas às áreas mais adequadas para a instalação de packing-houses, quando o objetivo é a redução dos custos de transporte, implantação e processamento.

\subsection{Cenário 1}

Neste primeiro cenário, considerou-se a não existência de packing-houses no Estado de São Paulo, uma vez que o intuito desta análise é o de obter, para posterior comparação com a situação atual, o número, a localização destas unidades de beneficiamento e capacidades ótimas de processamento de cada região. Para tanto, não se restringiu o número de plantas instaladas por região e considerou-se a oferta e a demanda correntes de cada EDR.

Tomando-se por base os resultados fornecidos pelo modelo de localização ótima, observa-se que a solução para o problema em questão, ou seja, a minimização dos custos de transporte, processamento e implantação de packing-houses, dadas as condições anteriormente estipuladas, equivale a $R$ \$ 14.372.200. A determinação dos locais para a instalação das unidades processadoras de laranja e as respectivas quantidades a serem transportadas dos centros de produção aos centros de processamento podem ser visualizados no Quadro 1. 


\begin{tabular}{|c|c|c|c|c|}
\hline $\begin{array}{l}\text { Centros de Processamento } \\
\text { Centros de Produção }\end{array}$ & Araraquara & Campinas & Dracena & Itapetininga \\
\hline $\begin{array}{l}\text { Araraquara } \\
\text { Campinas } \\
\text { Dracena } \\
\text { Itapetininga } \\
\text { Limeira } \\
\text { Presidente Venceslau } \\
\end{array}$ & $\begin{array}{c}39.566 \\
- \\
- \\
- \\
- \\
- \\
\end{array}$ & $\begin{array}{c}921 \\
- \\
- \\
203.079 \\
- \\
\end{array}$ & 2.001 & $\begin{array}{c}- \\
- \\
40.800 \\
- \\
\end{array}$ \\
\hline Total & 39.566 & 204.000 & 2040 & 40.800 \\
\hline $\begin{array}{l}\text { Centro de Processamento } \\
\text { Centros de Producăa }\end{array}$ & Limeira & Piracicaba & $\begin{array}{l}\text { S. José do } \\
\text { Rio Preto }\end{array}$ & São Paulo \\
\hline $\begin{array}{l}\text { Bragança Paulista } \\
\text { Campinas } \\
\text { Limeira } \\
\text { Mogi das Cruzes } \\
\text { Piracicaba } \\
\text { São José do Rio Preto } \\
\text { São Paulo } \\
\text { Sorocaba } \\
\end{array}$ & $\begin{array}{c}- \\
40.800 \\
- \\
- \\
- \\
- \\
\end{array}$ & $\begin{array}{c}- \\
24.305 \\
- \\
16.495 \\
- \\
- \\
- \\
\end{array}$ & $\begin{array}{c}- \\
- \\
- \\
- \\
- \\
40.800 \\
- \\
-\end{array}$ & $\begin{array}{c}10.530 \\
3.758 \\
- \\
441 \\
- \\
- \\
755 \\
25.316 \\
\end{array}$ \\
\hline Total & 40.800 & 40.800 & 40.800 & 40.800 \\
\hline
\end{tabular}

Quadro 1 - Volume transportado de laranja dos centros de produção para os centros de processamento, em toneladas, cenário 1.

Fonte: Dados da pesquisa.

A partir destes resultados verifica-se que, neste cenário, o abastecimento dos packing-houses foi obtido por meio da produção de 12 EDRs. As regiões fornecedoras de matéria-prima para as plantas instaladas em Campinas foram Limeira $(99,5 \%)$ e a própria Campinas $(0,5 \%)$. A unidade processadora de Dracena foi abastecida pelas produções da própria região (98\%) e de Presidente Venceslau (2\%). Já os packing-houses implantados em Piracicaba foram abastecidos pelos municípios pertencentes aos EDRs de Limeira (60\%) e Piracicaba (40\%). São Paulo teve como centros fornecedores de matéria-prima os EDRs de Bragança Paulista (26\%), Campinas (9\%), Mogi das Cruzes (1\%), São Paulo $(2 \%)$ e Sorocaba $(62 \%)$. A demanda da unidade instalada em Araraquara foi totalmente suprida pela produção da própria região, o mesmo ocorrendo em Itapetininga, Limeira e São José do Rio Preto.

No que se refere ao tamanho das plantas, o modelo determinou que deveriam ser instaladas plantas com capacidade de processamento igual a 40.800 toneladas por ano em todas as regiōes, com exceção de. Dracena (2.040 toneladas/ano). O número de unidades de beneficiamento a ser implantado em cada uma das regiões é mostrado no Quadro 2. 


\begin{tabular}{|l|c|c|}
\hline \multicolumn{1}{|c|}{ EDR } & $\begin{array}{c}\text { Número de packing-houses } \\
\text { (2040 toneladas/ano) }\end{array}$ & $\begin{array}{c}\text { Número de packing-houses } \\
\text { (40.800 toneladas/ano) }\end{array}$ \\
\hline Araraquara & - & 1 \\
Campinas & - & 5 \\
Dracena & - & - \\
Itapetininga & - & 1 \\
Limeira & - & 1 \\
Piracicaba & - & 1 \\
São José do Rio Preto & - & 1 \\
São Paulo & 1 & 11 \\
\hline Total & & 1. \\
\hline
\end{tabular}

Quadro 2 - Número de packing-houses instalados, por EDR, cenário 1.

Fonte: Dados da pesquisa

Comparando-se estes valores com os do levantamento realizado pelo FUNDECITRUS em 1998, constata-se que a quantidade de plantas existentes, cerca de 400 , é muito superior ao número necessário para satisfazer a demanda interna do Estado. Entretanto, há que se considerar que São Paulo, além de ser um grande produtor de suco de laranja concentrado, é um exportador da fruta in natura para os demais estados da federação, fatores que não foram considerados no modelo proposto e que podem justificar este excesso de unidades de beneficiamento.

Analisando somente o mercado interno paulista de laranja para consumo in natura, conclui-se que o número de unidades localizadas nas regiões de Araraquara, Campinas, Itapetininga, Limeira e São José do Rio Preto deveria ser reduzido em 8 , $12,22,40$ e 6 , respectivamente. Por outro lado, para atender ao objetivo de minimização dos custos de transporte, processamento e implantação no Estado de São Paulo, deveriam ser instaladas, também, unidades de beneficiamento nos EDRs de Dracena, Piracicaba e São Paulo.

No que tange à distribuição espacial das plantas processadoras, observouse que a tendência foi a instalação de unidades em áreas mais próximas aos mercados consumidores, sobretudo no caso dos EDRs de Campinas e São Paulo, que segundo a distribuição proposta passam a suprir cerca de $54 \%$ da demanda estadual. Tal comportamento difere significativamente da distribuição atual, mais voltada para a proximidade em relação aos principais centros produtores. Apesar disso, duas unidades (Araraquara e São José do Rio Preto) foram implantadas próximas a estas áreas. Verificou-se, ainda, que regiões que apresentam proximidade tanto em relação aos centros produtores quanto aos consumidores emergem como áreas potencias para a instalação de packing-houses, como é o caso dos EDRs de Itapetininga, Limeira e 
Piracicaba. Por fim, a implantação da unidade situada em Dracena pode ser explicada pelo fato do extremo noroeste do Estado ser carente em plantas que possam abastecê-lo diretamente.

Em relação ao fluxo de laranja dos centros processadores aos consumidores, pode-se observar, no Quadro 3 , os resultados obtidos para as quantidades a serem transportadas, bem como o mercado consumidor atendido por cada região processadora.

\begin{tabular}{|c|c|c|c|c|}
\hline $\begin{array}{l}\text { Centro de Processamento } \\
\text { Centros de Consumo }\end{array}$ & Araraquara & Campinas & Dracena & Itapetininga \\
\hline Araraquara & 7.456 & - & - & - \\
\hline Assis & 3.022 & - & - & - \\
\hline Avaré & - & - & - & 2.337 \\
\hline Bauru & 5.574 & - & - & - \\
\hline Bragança Paulista & - & 5.929 & - & - \\
\hline Dracena & - & - & 2.040 & - \\
\hline Franca & 5.256 & - & - & - \\
\hline Guaratinguetá & - & 5.296 & - & - \\
\hline Itapetininga & - & - & - & 4.512 \\
\hline Itapeva & - & - & - & 3.312 \\
\hline Jaboticabal & 4.098 & - & - & - \\
\hline Jaú & 4.441 & - & - & - \\
\hline Marilia & 3.705 & - & - & - \\
\hline Orlândia & 2.990 & - & - & - \\
\hline Ourinhos & - & - & - & 3.209 \\
\hline Pindamonhangaba & - & 7.722 & - & - \\
\hline Presidente Venceslau & - & - & - & 2.427 \\
\hline Registro & 3.024 & - & - & - \\
\hline São Paulo & - & 185.053 & - & 10.594 \\
\hline Sorocaba & - & - & - & 14.409 \\
\hline Total & 39.566 & 204.000 & 2.040 & 40.800 \\
\hline $\begin{array}{l}\text { Centro de Processamento } \\
\text { Centros de Consumo }\end{array}$ & Limeira & Piracicaba & $\begin{array}{l}\text { S. José do } \\
\text { Rio Preto }\end{array}$ & São Paulo \\
\hline Andradina & - & - & 2.385 & - \\
\hline Araçatuba & - & - & 5.102 & - \\
\hline Assis & - & - & 80 & - \\
\hline Barretos & - & - & 5.259 & - \\
\hline Botucatu & - & 2.869 & - & - \\
\hline Campinas & 9.454 & 18.070 & - & - \\
\hline Catanduva & - & - & 3.387 & - \\
\hline Dracena & - & - & 196 & - \\
\hline Fernandópolis & - & - & 1.303 & - \\
\hline General Salgado & - & - & 1.341 & - \\
\hline Jales & - & - & 1.825 & - \\
\hline Limeira & 9.747 & - & - & - \\
\hline Lins & - & - & 2.159 & - \\
\hline Mogi das Cruzes & - & - & - & 16.410 \\
\hline Mogi Mirim & 5.895 & - & - & - \\
\hline Pindamonhangaba & 10.620 & - & - & - \\
\hline Piracicaba & & 11.187 & - & $=$ \\
\hline
\end{tabular}




\begin{tabular}{|l|c|c|c|c|}
\hline \multicolumn{1}{|c|}{ Centro de Processamento } & Limeira & Piracicaba & $\begin{array}{c}\text { S. José do Rio } \\
\text { Preto }\end{array}$ & São Paulo \\
\hline Centros de Consumo & - & - & 4.607 & - \\
\hline Presidente Prudente & - & 8.674 & 1.890 & - \\
Ribeirão Preto & 5.084 & - & - & - \\
São João da Boa Vista & - & - & 7.411 & - \\
São José do Rio Preto & - & - & - & 24.390 \\
São Paulo & - & - & 2.176 & - \\
Tupã & - & - & 1679 & - \\
Votuporanga & 40.800 & 40.800 & 40.800 & $40.800-$ \\
\hline Total & & & \\
\hline
\end{tabular}

Quadro 3 - Volume transportado de laranja dos centros de processamento para os centros de consumo final, em toneladas, cenário 1.

Fonte: Dados da pesquisa.

Os resultados apresentados no Quadro 3 permitem concluir que os oito centros de processamento satisfazem totalmente as demandas de todos os EDRs do Estado de São Paulo. Cabe salientar que as demandas dos EDRs foram satisfeitas, em sua maioria, pelo fornecimento a partir de somente um centro processador, exceção feita às regiões de Assis, Pindamonhangaba, Dracena, São Paulo, Campinas e Ribeirão Preto.

A análise dos custos marginais de transporte reflete as alterações que podem vir a ocorrer nos custos associados ao transporte de uma tonelada de matériaprima da região de produção para a de processamento, caso haja a necessidade de alteração de alguma rota. De maneira geral, o acréscimo que uma mudança de rota devida, por exemplo, a uma quebra de safra ou à impossibilidade de utilização de determinada rota, acarretaria em termos de despesa com transporte, é representado pela diferença entre o custo de transporte que se terá com a nova rota e o custo de transporte da rota que se encontra impossibilitada.

Discernindo melhor os aspectos de fornecimento de laranja dos centros de produção para os de processamento, observou-se, por meio dos resultados obtidos a partir do modelo de localização proposto, que a principal região que poderia suprir a demanda dos EDRs de Campinas e Piracicaba, no caso de alguma eventualidade, seria a região de Limeira, já que o acréscimo no valor do custo de transporte, neste caso, seria nulo. Isso se explica pelo fato de Limeira estar sob o mesmo raio de influência de Campinas e Piracicaba. No caso de São Paulo, as principais regiões fornecedoras seriam as de Bragança Paulista, Campinas e Mogi das Cruzes. O Quadro 
4 mostra a análise dos custos marginais de transporte, considerando as rotas que proporcionam menores acréscimos por tonelada de laranja transportada para a região de processamento.

\begin{tabular}{|c|c|c|c|c|}
\hline \multirow{2}{*}{ Centro Produtor Alternativo } & \multicolumn{4}{|c|}{ Centro Processador } \\
\hline & Araraquara & Campinas & Dracena & Itapetininga \\
\hline $\begin{array}{l}\text { Catanduva } \\
\text { Jaboticabal } \\
\text { Jaú } \\
\end{array}$ & $\begin{array}{l}4,27 \\
2,58 \\
2,58 \\
\end{array}$ & $\begin{array}{l}- \\
- \\
\end{array}$ & $\begin{array}{l}- \\
- \\
\end{array}$ & $\begin{array}{l}- \\
- \\
-\end{array}$ \\
\hline $\begin{array}{l}\text { Bragança Paulista } \\
\text { Piracicaba } \\
\text { Sorocaba }\end{array}$ & $\begin{array}{l}- \\
- \\
-\end{array}$ & $\begin{array}{l}2,08 \\
1,00 \\
3,18\end{array}$ & 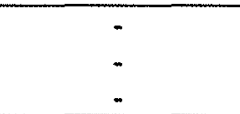 & - \\
\hline $\begin{array}{l}\text { Andradina } \\
\text { Presidente Prudente } \\
\text { Tupã }\end{array}$ & $\begin{array}{l}- \\
- \\
\end{array}$ & $\begin{array}{l}- \\
- \\
\end{array}$ & $\begin{array}{l}0,93 \\
1,51 \\
3,14 \\
\end{array}$ & $\begin{array}{l}- \\
- \\
\end{array}$ \\
\hline $\begin{array}{l}\text { Botucatu } \\
\text { Itapeva } \\
\text { Sorocaba } \\
\end{array}$ & - & $\begin{array}{l}- \\
- \\
\end{array}$ & $\begin{array}{l}- \\
- \\
- \\
\end{array}$ & $\begin{array}{l}, 00 \\
4,27 \\
3,74 \\
\end{array}$ \\
\hline \multirow{2}{*}{ Centro Produtor Alternativo } & \multicolumn{4}{|c|}{ Centro Processador } \\
\hline & Limeira & Piracicaba & $\begin{array}{c}\text { S. José do Rio } \\
\text { Preto }\end{array}$ & São Paulo \\
\hline $\begin{array}{l}\text { Campinas } \\
\text { Mogi Mirim } \\
\text { Piracicaba }\end{array}$ & $\begin{array}{l}3,28 \\
1,02 \\
1,38\end{array}$ & $\begin{array}{l}- \\
- \\
-\end{array}$ & $\begin{array}{l}- \\
- \\
-\end{array}$ & $\begin{array}{l}- \\
- \\
-\end{array}$ \\
\hline $\begin{array}{l}\text { Botucatu } \\
\text { Campinas } \\
\text { Mogi Mirim }\end{array}$ & $\begin{array}{l}- \\
-\end{array}$ & $\begin{array}{l}3,04 \\
2,90 \\
2,34 \\
\end{array}$ & $\begin{array}{l}- \\
- \\
-\end{array}$ & - \\
\hline $\begin{array}{l}\text { Barretos } \\
\text { Catanduva } \\
\text { Votuporanga }\end{array}$ & $\begin{array}{l}- \\
- \\
-\end{array}$ & - & $\begin{array}{l}3,32 \\
1,95 \\
3,03\end{array}$ & $\begin{array}{l}- \\
- \\
-\end{array}$ \\
\hline $\begin{array}{l}\text { Itapetininga } \\
\text { Limeira } \\
\text { Mogi Mirim } \\
\text { Pindamonhangaba }\end{array}$ & $\begin{array}{l}- \\
- \\
-\end{array}$ & $\begin{array}{l}- \\
- \\
- \\
\end{array}$ & $\begin{array}{l}- \\
- \\
- \\
\end{array}$ & $\begin{array}{l}0,70 \\
0,70 \\
0,70 \\
0,70 \\
\end{array}$ \\
\hline
\end{tabular}

Quadro 4 - Custos marginais de transporte, em Reais por tonelada transportada, cenário 1.

Fonte: Dados da pesquisa. 


\subsection{Cenário 2}

Este cenário, assim como o anterior, considera que não existem packinghouses no Estado de São Paulo. Para verificar se a distribuição espacial das plantas processadoras sofrerá alterações significativas, em relação à distribuição obtida no cenário 1, admitiu-se a possibilidade de instalação de apenas uma unidade de beneficiamento por EDR. Neste caso, verificou-se que o custo total de transporte, processamento e implantação de plantas processadoras é o mesmo obtido para o cenário 1. O Quadro 5 fornece informações relativas ao fluxo de laranja e ao volume transportado, das regiões de produção para as de processamento.

\begin{tabular}{|c|c|c|c|c|}
\hline $\begin{array}{l}\text { Centro de Processamento } \\
\text { Centros de Produção }\end{array}$ & $\begin{array}{l}\text { Bragança } \\
\text { Paulista }\end{array}$ & Campinas & Guaratinguetá & Itapetininga \\
\hline $\begin{array}{l}\text { Bragança Paulista } \\
\text { Guaratinguetá } \\
\text { Itapetininga } \\
\text { Limeira } \\
\text { Mogi Mirim } \\
\text { Pindamonhangaba }\end{array}$ & $\begin{array}{c}10.530 \\
- \\
- \\
30.270 \\
-\end{array}$ & $\begin{array}{c}- \\
- \\
- \\
40.800 \\
-\end{array}$ & $\begin{array}{c}- \\
1.467 \\
- \\
- \\
573\end{array}$ & $\begin{array}{c}- \\
40.800 \\
- \\
- \\
-\end{array}$ \\
\hline Total & 40.800 & 40.800 & 2.040 & 40.800 \\
\hline $\begin{array}{l}\text { Centro de Processamento } \\
\text { Centros de Produção }\end{array}$ & Jaboticabal & Limeira & Lins & Mogi Mirim \\
\hline $\begin{array}{l}\text { Jaboticabal } \\
\text { Limeira } \\
\text { Lins } \\
\text { Mogi Mirim }\end{array}$ & $\begin{array}{c}40.800 \\
- \\
- \\
-\end{array}$ & $\begin{array}{c}- \\
40.800 \\
- \\
-\end{array}$ & 40.800 & $\begin{array}{c}- \\
- \\
40.800\end{array}$ \\
\hline Total & 40.800 & 40.800 & 40.800 & 40.800 \\
\hline $\begin{array}{ll} & \text { Centro de Processamento } \\
\text { Centros de Produção }\end{array}$ & Piracicaba & São Paulo & $\begin{array}{l}\text { S. João da Boa } \\
\text { Vista }\end{array}$ & Sorocaba \\
\hline $\begin{array}{l}\text { Campinas } \\
\text { Itapetininga } \\
\text { Limeira } \\
\text { Mogi das Cruzes } \\
\text { Pindamonhangaba } \\
\text { Piracicaba } \\
\text { São João da Boa Vista } \\
\end{array}$ & $\begin{array}{c}- \\
24.305 \\
- \\
- \\
16.495 \\
- \\
\end{array}$ & $\begin{array}{c}4.679 \\
- \\
8.502 \\
441 \\
1.107 \\
- \\
- \\
\end{array}$ & $\begin{array}{c}- \\
- \\
- \\
- \\
- \\
39.566\end{array}$ & $\begin{array}{c}- \\
40.800 \\
- \\
- \\
- \\
- \\
\end{array}$ \\
\hline Total & 40.800 & 40.800 & 39.566 & 40.800 \\
\hline
\end{tabular}

Quadro 5 - Volume transportado de laranja dos centros de produção para os centros de processamento, em toneladas, cenário 2.

Fonte: Dados da pesquisa.

Analisando-se os resultados apresentados no Quadro 6, constata-se que a matéria-prima tem como origem apenas 12 EDRs, sendo que o número de plantas 
instaladas (12) permaneceu inalterado em relação ao cenário anterior. Contudo, devido à restrição de que cada região pode abrigar somente uma unidade de beneficiamento, nota-se que foram implantados packing-houses em regiões próximas a Campinas (Bragança Paulista, Mogi Mirim, Sorocaba), com a finalidade de suprir as áreas anteriormente cobertas pelo volume das 5 plantas existentes neste EDR. Observa-se, ainda, que há pouco transporte inter-regional, especialmente nas áreas de Itapetininga, Jaboticabal, Limeira, Lins, Mogi Mirim e São João da Boa Vista, onde a produção regional é suficiente para prover as necessidades das plantas.

Dentre as regiões fornecedoras de matéria-prima, destacaram-se Itapetininga, Limeira e Mogi Mirim que, juntas, responderam por $57 \%$ do total de laranja absorvido pelos packing-houses instalados no Estado. É importante salientar que a economia de escala no processamento também é observada neste cenário, já que predominou a utilização de plantas de maior porte (vide Quadro 6).

\begin{tabular}{|l|c|c|}
\hline \multicolumn{1}{|c|}{ EDR } & $\begin{array}{c}\text { Número de packing-houses } \\
\text { (2.040 toneladas/ano) }\end{array}$ & $\begin{array}{c}\text { Número de packing-houses } \\
\text { (40.800 toneladas/ano) }\end{array}$ \\
\hline Bragança Paulista & - & 1 \\
Campinas & - & 1 \\
Guaratinguetá & 1 & - \\
ltapetininga & - & 1 \\
Jaboticabal & - & 1 \\
Limeira & - & 1 \\
Lins & - & 1 \\
Mogi Mirim & - & 1 \\
Piracicaba & - & 1 \\
São Paulo & - & 1 \\
São João da Boa Vista & - & 1 \\
Sorocaba & 1 & 11 \\
\hline Total & - & 1 \\
\hline
\end{tabular}

Quadro 6 - Número de packing-houses instalados, por EDR, cenário 2.

Fonte: Dados da pesquisa.

No cenário em questão, verificou-se que prevaleceu a localização de unidades de beneficiamento em áreas que apresentam proximidade tanto em relação aos centros produtores quanto em relação aos centros consumidores, como é o caso de Bragança Paulista, Campinas, Itapetininga, Limeira, Mogi Mirim, Piracicaba e Sorocaba. Os packing-houses implantados em Jaboticabal, São João da Boa Vista e Lins situam-se próximos aos grandes centros de produção, ao contrário das unidades 
localizadas em São Paulo e Guaratinguetá, que estão mais próximas aos maiores centros consumidores. O fluxo de laranja dos centros processadores aos consumidores pode ser observado no Quadro 7, assim como os resultados obtidos para as quantidades a serem transportadas das áreas de processamento às de consumo.

\begin{tabular}{|c|c|c|c|c|}
\hline Centro de Processamento & $\begin{array}{l}\text { Bragança } \\
\text { Paulista }\end{array}$ & Campinas & Guaratinguetá & Itapetininga \\
\hline Avaré & - & - & - & 2.337 \\
\hline Bragança Paulista & 5.929 & - & - & - \\
\hline Guaratinguetá & - & - & 2.040 & - \\
\hline Itapetininga & - & - & - & 4.512 \\
\hline Itapeva & - & - & - & 3.312 \\
\hline Mogi das Cruzes & 16.410 & - & - & - \\
\hline Presidente Venceslau & - & - & - & 2.427 \\
\hline São Paulo & 18.461 & 40.800 & - & 13.803 \\
\hline Sorocaba & - & - & - & 14.409 \\
\hline Total & 40.800 & 40.800 & 2.040 & 40.800 \\
\hline Centro de Processamento & Jaboticabal & Limeira & Lins & Mogi Mirim \\
\hline \multicolumn{5}{|l|}{ Centros de Consumo } \\
\hline Andradina & - & - & 2.385 & - \\
\hline Araçatuba & - & - & 5.102 & - \\
\hline Araraquara & 7.456 & - & - & - \\
\hline Assis & - & - & 3.102 & - \\
\hline Barretos & 5.259 & - & - & - \\
\hline Bauru & - & - & 5.574 & - \\
\hline Campinas & - & 2.905 & - & - \\
\hline Catanduva & 3.387 & - & - & \\
\hline Dracena & - & - & 2.236 & - \\
\hline Fernandópolis & - & - & 1.303 & - \\
\hline Franca & 5.256 & - & - & - \\
\hline General Salgado & - & - & 1.341 & - \\
\hline Jaboticabal & 4.098 & - & - & - \\
\hline Jales & - & - & 1.825 & - \\
\hline Jaú & 2.316 & - & - & - \\
\hline Limeira & - & 9.747 & - & - \\
\hline Lins & - & - & 2.159 & - \\
\hline Marilia & - & - & 3.705 & - \\
\hline Mogi Mirim & - & - & - & 3.575 \\
\hline Orlẩndia & 2.990 & - & - & - \\
\hline Ourinhos & - & - & 3.209 & - \\
\hline Presidente Prudente & - & - & 4.607 & - \\
\hline Registro & 3.024 & - & - & - \\
\hline São José do Rio Preto & 7.014 & - & 397 & - \\
\hline São Paulo & - & 28.148 & - & 37.225 \\
\hline Tupã & - & - & 2.176 & - \\
\hline Votuporanga & - & - & 1.679 & - \\
\hline Total & 40.800 & 40.800 & 40.800 & 40.800 \\
\hline
\end{tabular}




\begin{tabular}{|c|c|c|c|c|}
\hline $\begin{array}{ll}\text { Centros de Consumo } & \text { Centro de Processamento } \\
\text { Cento }\end{array}$ & Piracicaba & $\begin{array}{l}\text { S. João da } \\
\text { Boa Vista }\end{array}$ & São Paulo & Sorocaba \\
\hline Botucatu & 2.869 & - & $=$ & - \\
\hline Campinas & 24.619 & 3.256 & - & - \\
\hline Jaú & 2.125 & - & - & - \\
\hline Mogi Mirim & - & 2.320 & - & - \\
\hline Pindamonhangaba & - & 18.342 & - & - \\
\hline Piracicaba & 11.187 & - & - & - \\
\hline Ribeirão Preto & - & 10.564 & - & - \\
\hline São João da Boa Vista & - & 5.084 & - & - \\
\hline São Paulo & - & - & 40.800 & - \\
\hline Sorocaba & - & - & - & 40.800 \\
\hline Total & 40.800 & 40.800 & 40.800 & 40.800 \\
\hline
\end{tabular}

Quadro 7 - Volume transportado de laranja dos centros de processamento para os centros de consumo final, em toneladas, cenário 2.

Fonte: Dados da pesquisa

Os resultados mostram que os 12 centros de processamento, recomendados pelo modelo de otimização, atendem totalmente às demandas de todos os EDRs do Estado de São Paulo. Cabe ressaltar que as demandas dos EDRs foram satisfeitas pelo fornecimento a partir de somente um centro processador, exceção feita às regiōes de Jaú, Mogi Mirim, São José do Rio Preto, São Paulo e Campinas e Sorocaba.

O Quadro 8 fornece informações relativas à análise dos custos marginais de transporte. Como salientado anteriormente, esta análise permite conhecer quais serão as alterações, em termos de custo de transporte por tonelada de matéria-prima, caso haja a necessidade de se modificar alguma rota, dentre aquelas apontadas como ótimas pelo modelo de localização. É importante mencionar que foram consideradas apenas as três rotas que proporcionam menores acréscimos por tonelada de laranja transportada para a região de processamento. 


\begin{tabular}{|c|c|c|c|c|}
\hline \multirow[b]{2}{*}{ Centro Produtor Alternativo } & \multicolumn{4}{|c|}{ Centro Processador } \\
\hline & $\begin{array}{c}\text { Bragança } \\
\text { Paulista }\end{array}$ & Campinas & Guaratinguetá & Itapetininga \\
\hline $\begin{array}{l}\text { Campinas } \\
\text { Limeira } \\
\text { Piracicaba } \\
\end{array}$ & $\begin{array}{l}0,81 \\
1,10 \\
2,34 \\
\end{array}$ & $\begin{array}{l}- \\
- \\
-\end{array}$ & $\begin{array}{l}- \\
- \\
\end{array}$ & - \\
\hline $\begin{array}{l}\text { Bragança Paulista } \\
\text { Campinas } \\
\text { Limeira }\end{array}$ & - & $\begin{array}{l}3,17 \\
0,70 \\
1,10 \\
\end{array}$ & $\begin{array}{l}- \\
- \\
-\end{array}$ & - \\
\hline $\begin{array}{l}\text { Bragança Paulista } \\
\text { Mogi das Cruzes } \\
\text { Mogi Mirim }\end{array}$ & - & $\begin{array}{l}- \\
- \\
\end{array}$ & $\begin{array}{c}9,98 \\
8,44 \\
10,00 \\
\end{array}$ & $\begin{array}{l}- \\
- \\
-\end{array}$ \\
\hline $\begin{array}{l}\text { Botucatu } \\
\text { Itapeva } \\
\text { Sorocaba }\end{array}$ & 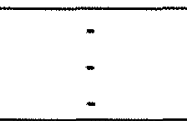 & $\begin{array}{l}- \\
- \\
-\end{array}$ & $\begin{array}{r}- \\
- \\
- \\
\end{array}$ & $\begin{array}{l}4,00 \\
4,27 \\
4,44\end{array}$ \\
\hline \multirow{2}{*}{ Centro Produtor Alternativo } & \multicolumn{4}{|c|}{ Centro Processador } \\
\hline & Jaboticabal & Limeira & Lins & Mogi Mirim \\
\hline $\begin{array}{l}\text { Araraquara } \\
\text { Catanduva } \\
\text { Registro }\end{array}$ & $\begin{array}{l}2,58 \\
3,03 \\
1,64 \\
\end{array}$ & $\begin{array}{l}- \\
- \\
\end{array}$ & $\begin{array}{l}- \\
- \\
-\end{array}$ & $\begin{array}{l}- \\
- \\
-\end{array}$ \\
\hline $\begin{array}{l}\text { Campinas } \\
\text { Mogi Mirim } \\
\text { Piracicaba }\end{array}$ & $\begin{array}{l}- \\
- \\
-\end{array}$ & $\begin{array}{l}3,98 \\
1,02 \\
1,38 \\
\end{array}$ & $\begin{array}{l}- \\
- \\
\end{array}$ & - \\
\hline $\begin{array}{l}\text { Araçatuba } \\
\text { Marília } \\
\text { Tupã } \\
\end{array}$ & $\begin{array}{l}- \\
- \\
\end{array}$ & $\begin{array}{l}- \\
- \\
\end{array}$ & $\begin{array}{l}3,32 \\
2,88 \\
3,46 \\
\end{array}$ & $\begin{array}{l}- \\
- \\
\end{array}$ \\
\hline $\begin{array}{l}\text { Limeira } \\
\text { Piracicaba } \\
\text { S. João da Boa Vista }\end{array}$ & - & $\begin{array}{l}- \\
- \\
- \\
\end{array}$ & $\begin{array}{r}- \\
- \\
- \\
\end{array}$ & $\begin{array}{l}1,02 \\
3,72 \\
2,27 \\
\end{array}$ \\
\hline \multirow[b]{2}{*}{ Centro Produtor Alternativo } & \multicolumn{4}{|c|}{ Centro Processador } \\
\hline & Piracicaba & São Paulo & S. João da Boa Vista & Sorocaba \\
\hline $\begin{array}{l}\text { Bragança Paulista } \\
\text { Itapetininga } \\
\text { Mogi Mirim }\end{array}$ & $\begin{array}{l}3,04 \\
3,31 \\
2,34 \\
\end{array}$ & $\begin{array}{l}- \\
- \\
-\end{array}$ & $\begin{array}{l}- \\
- \\
- \\
\end{array}$ & $\begin{array}{l}- \\
- \\
-\end{array}$ \\
\hline $\begin{array}{l}\text { Bragança Paulista } \\
\text { Piracicaba } \\
\text { Registro } \\
\end{array}$ & $\begin{array}{l}- \\
- \\
\end{array}$ & $\begin{array}{l}0,39 \\
1,21 \\
1,69 \\
\end{array}$ & $\begin{array}{l}- \\
- \\
\end{array}$ & $\begin{array}{l}- \\
- \\
-\end{array}$ \\
\hline $\begin{array}{l}\text { Limeira } \\
\text { Mogi Mirim } \\
\text { Ribeirão Preto }\end{array}$ & - & - & $\begin{array}{l}4,27 \\
2,27 \\
6,95\end{array}$ & $\begin{array}{l}- \\
- \\
-\end{array}$ \\
\hline $\begin{array}{l}\text { Limeira } \\
\text { Piracicaba } \\
\text { Sorocaba } \\
\end{array}$ & $\begin{array}{l}- \\
- \\
\end{array}$ & $\dot{-}$ & $\begin{array}{l}- \\
-\end{array}$ & $\begin{array}{l}3,14 \\
2,06 \\
0,54 \\
\end{array}$ \\
\hline
\end{tabular}

Quadro 8 - Custos marginais de transporte, em Reais por tonelada transportada, cenário 2.

Fonte: Dados da pesquisa.

No que tange ao suprimento da demanda dos centros processadores, os resultados obtidos permitem constatar que a principal região fornecedora de matériaprima para o EDR de Bragança Paulista seria a região de Mogi Mirim, caso ocorresse 
alguma eventualidade, pois esta nova rota não implicaria nenhum acréscimo no custo de transporte. Isso se explica pelo fato de Mogi Mirim estar sob o mesmo raio de influência de Bragança Paulista. Para o EDR de Campinas, a principal região fornecedora seria a região de Limeira. Já para a região de Guaratinguetá, Pindamonhangaba é a região mais importante no fornecimento de laranja, caso haja alguma alteração de rota. Finalmente, no que se refere ao suprimento da demanda da região de Piracicaba, Limeira é o principal EDR, quando se trata de modificação de rota.

\subsection{CENÁRIO 3}

Neste cenário admite-se, também, que não existem packing-houses no Estado de São Paulo e que a demanda por laranja se iguala à oferta estadual de laranja in natura. Com o intuito de verificar qual seria a distribuição espacial, o número ótimo de plantas processadoras e a capacidade de processamento de cada EDR numa situação em que ocorrem variações na oferta e na demanda de laranja, admitiu-se, para cada região, a igualdade entre a oferta da fruta e sua demanda. Dadas essas considerações, verificou-se que o custo total de transporte, processamento e instalação dessas unidades de beneficiamento equivale a $R \$ 111.157 .300$. No Quadro 9 , estão dispostos os valores referentes ao volume de laranja transportado dos centros produtores aos processadores.

\begin{tabular}{|c|c|c|c|c|c|}
\hline $\begin{array}{l}\text { Centro de Processamento } \\
\text { Centros de Produçăo }\end{array}$ & Araraquara & Barretos & Bauru & $\begin{array}{l}\text { Bragança } \\
\text { Paulista }\end{array}$ & Campinas \\
\hline Araraquara & 81.600 & - & - & - & 12.617 \\
\hline Barretos & - & 81.600 & - & - & - \\
\hline Bauru & - & - & 57.882 & - & - \\
\hline Bragança Paulista & - & - & - & 10.530 & - \\
\hline Catanduva & - & - & 9.205 & - & - \\
\hline Jaú & - & - & 55.313 & - & - \\
\hline Limeira & - & - & - & - & 326.680 \\
\hline Mogi Mirim & - & - & - & 71.070 & 191.103 \\
\hline Total & 81.600 & 81.600 & 122.400 & 81.600 & 530.400 \\
\hline
\end{tabular}




\begin{tabular}{|c|c|c|c|c|c|}
\hline $\begin{array}{l}\text { Centro de Processamento } \\
\text { Centros de Produção }\end{array}$ & Catanduva & Dracena & $\begin{array}{l}\text { General } \\
\text { Salgado }\end{array}$ & Itapetininga & Jaboticabal \\
\hline Andradina & - & 12.432 & - & - & - \\
\hline Catanduva & 40.800 & - & - & - & 40.800 \\
\hline Dracena & - & 2.001 & - & - & - \\
\hline General Salgado & - & - & 40.800 & - & - \\
\hline Itapetininga & - & - & - & 27.654 & -. \\
\hline Itapeva & - & - & - & 13.146 & - \\
\hline Jales & - & 26.367 & - & - & - \\
\hline Total & 40.800 & 40.800 & 40.800 & 40.800 & 40.800 \\
\hline Total & 40.800 & 244.800 & 40.800 & 40.800 & 40.800 \\
\hline $\begin{array}{ll} & \text { Centro de Processamento } \\
\text { Centros de Produção } & \end{array}$ & Orlândia & Ourinhos & Pinda & amonhangaba & Piracicaba \\
\hline Araraquara & - & - & & $=$ & 3.318 \\
\hline Assis & - & 1.091 & & - & - \\
\hline Avaré & - & 28.778 & & - & - \\
\hline Barretos & 8.054 & - & & - & - \\
\hline Franca & 18.800 & - & & - & - \\
\hline Guaratinguetá & - & - & & 1.467 & - \\
\hline Jaú & - & - & & - & 61.787 \\
\hline Lins & - & 9.151 & & - & - \\
\hline Marília & - & 3.746 & & - & - \\
\hline Orlândia & 135 & - & & - & - \\
\hline Ourinhos & - & 24.370 & & - & - \\
\hline Pindamonhangaba & - & 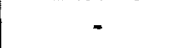 & & 1.680 & - \\
\hline Piracicaba & - & - & & - & 16.495 \\
\hline Ribeirão Preto & 13.811 & - & & - & - \\
\hline São João da Boa Vista & - & - & & 37.653 & - \\
\hline São José do Rio Preto & - & 4.720 & & - & - \\
\hline Total & 40.800 & 71.855 & & 40.800 & 81.600 \\
\hline $\begin{array}{ll} & \text { Centro de Processamento } \\
\text { Centros de Produçăo }\end{array}$ & $\begin{array}{c}\text { Presidente } \\
\text { Prudente }\end{array}$ & Registro & & beirão Preto & $\begin{array}{l}\text { S. João da } \\
\text { Boa Vista }\end{array}$ \\
\hline Araçatuba & 834 & - & & - & - \\
\hline Barretos & - & 495.003 & & - & - \\
\hline Catanduva & - & 162.228 & & - & - \\
\hline General Salgado & 1.627 & - & & $=$ & $=$ \\
\hline Jaboticabal & - & 444.369 & & - & - \\
\hline Jales & 8.950 & - & & - & - \\
\hline Presidente Prudente & 769 & - & & - & - \\
\hline Presidente Venceslau & 244 & - & & 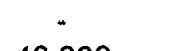 & - \\
\hline Ribeirão Preto & - & - & & 40.800 & - \\
\hline São João da Boa Vista & - & - & & - & $163.200-$ \\
\hline Tupã & 2.173 & - & & - & - \\
\hline Votuporanga & 26.203 & - & & - & $\frac{-}{4000}$ \\
\hline Total & 40.800 & 1.101 .600 & & 40.800 & 163.200 \\
\hline
\end{tabular}




\begin{tabular}{|l|c|c|c|}
\hline \multicolumn{1}{|c|}{ Centro de Processamento } & S. José do Rio Preto & São Paulo & Sorocaba \\
\hline Centros de Produção & - & 28.389 & - \\
\hline Araraquara & - & 4.679 & - \\
Campinas & - & - & 64.010 \\
Registringa & - & - & - \\
São José do Rio Preto & 51.000 & 7.726 & - \\
Sorocaba & 51.000 & 40.800 & 81.600 \\
\hline Total & & & \\
\hline
\end{tabular}

Quadro 9 - Volume transportado de laranja dos centros de produção para os centros de processamento, em toneladas, cenário 3.

Fonte: Dados da pesquisa.

Pela análise das informações contidas no Quadro 9, verifica-se que a laranja processada pelas 81 plantas instaladas no Estado é oriunda de 39 dos 40 EDR existentes em São Paulo e que o transporte inter-regional é pequeno, principalmente nas regiões de Araraquara, Barretos, Catanduva, General Salgado, Jales, Lins, Ribeirão Preto, São João da Boa Vista e São José do Rio Preto, onde a produção regional é suficiente para prover as necessidades dos packing-houses implantados.

Dentre as regiōes fornecedoras de matéria-prima, destacaram-se Araraquara, Limeira, Mogi Mirim, Barretos, Catanduva, Jaboticabal e São João da Boa Vista que, juntas, responderam por $70 \%$ do total de laranja absorvido pelos packinghouses instalados no Estado. Neste cenário, observou-se a predominância de unidades de beneficiamento com capacidades de processamento mais elevadas, o que pode resultar em economias de escala no processamento (vide Quadro 10) 


\begin{tabular}{|c|c|c|}
\hline EDR & $\begin{array}{c}\text { Número de packing-houses } \\
(10.200 \text { toneladas/ano })\end{array}$ & $\begin{array}{c}\text { Número de packing-houses } \\
(40.800 \text { toneladas/ano })\end{array}$ \\
\hline Araraquara & - & 2 \\
\hline Barretos & - & 2 \\
\hline Bauru & - & 3 \\
\hline Bragança Paulista & - & 2 \\
\hline Campinas & - & 13 \\
\hline Catanduva & - & 1 \\
\hline Dracena & - & 1 \\
\hline General Salgado & - & 1 \\
\hline Itapetininga & - & 1 \\
\hline Jaboticabal & - & 1 \\
\hline Jales & - & 1 \\
\hline Limeira & - & 6 \\
\hline Lins & - & 1 \\
\hline Mogi das Cruzes & - & 1 \\
\hline Mogi Mirim & - & 1 \\
\hline Orlầndia & - & 1 \\
\hline Ourinhos & - & 2 \\
\hline Pindamonhangaba & - & 1 \\
\hline Piracicaba & - & 2 \\
\hline Presidente Prudente & - & 1 \\
\hline Registro & - & 27 \\
\hline Ribeiräo Preto & - & 1 \\
\hline São João da Boa Vista & - & 4 \\
\hline São José do Rio Preto & 1 & 1 \\
\hline São Paulo & - & 1 \\
\hline Sorocaba & - & 2 \\
\hline Total & 1 & 80 \\
\hline
\end{tabular}

Quadro 10 - Número de packing-houses instalados, por EDR, cenário 3.

Fonte: Dados da pesquisa.

No presente cenário, verificou-se que $40 \%$ das plantas foram instaladas em regiões mais próximas aos centros consumidores, $32 \%$ em áreas intermediárias e $28 \%$ em áreas próximas aos maiores centros de produção, como é o caso de Araraquara, Catanduva e Jaboticabal. Observou-se, ainda, que foram implantadas unidades na maior parte dos EDRs produtores de laranja, porém em menor número em relação à quantidade instalada nas proximidades dos maiores centros de consumo, tais como os EDRs de São Paulo e Campinas.

Considerando-se que o objetivo do presente estudo é a obtençăo da localização de plantas processadoras de laranja que minimizam os custos de transporte, processamento e implantação, verificou-se que a recomendação dada pelo modelo difere sensivelmente da localizaçăo atual dessas plantas. Observou-se, inicialmente, que as regiōes de São José do Rio Preto, Barretos, Catanduva, Jaboticabal, Lins, Araraquara, Bauru, Limeira, Campinas, Sorocaba, Itapetininga e 
Mogi Mirim são áreas aptas para a instalação de packing-houses. No entanto, o número de unidades existentes nestas regiões deveria ser reduzido. Outra importante observação é que muitas áreas com potencial para a instalação de plantas, como é o caso de Bragança Paulista, Dracena, General Salgado, Jales, Mogi das Cruzes, Orlândia, Ourinhos, Pindamonhangaba, Piracicaba, Registro, Ribeirão Preto, São João da Boa Vista e São Paulo, não estão sendo aproveitadas, de modo que sua utilização seria positiva no que tange à redução de custos. Finalmente, o modelo considerou as regiões de Votuporanga, Jaú, Botucatu e Fernandópolis como áreas inaptas para a implantação de packing-houses.

O Quadro 11 mostra o fluxo de laranja dos centros processadores aos consumidores, bem como as quantidades a serem transportadas.

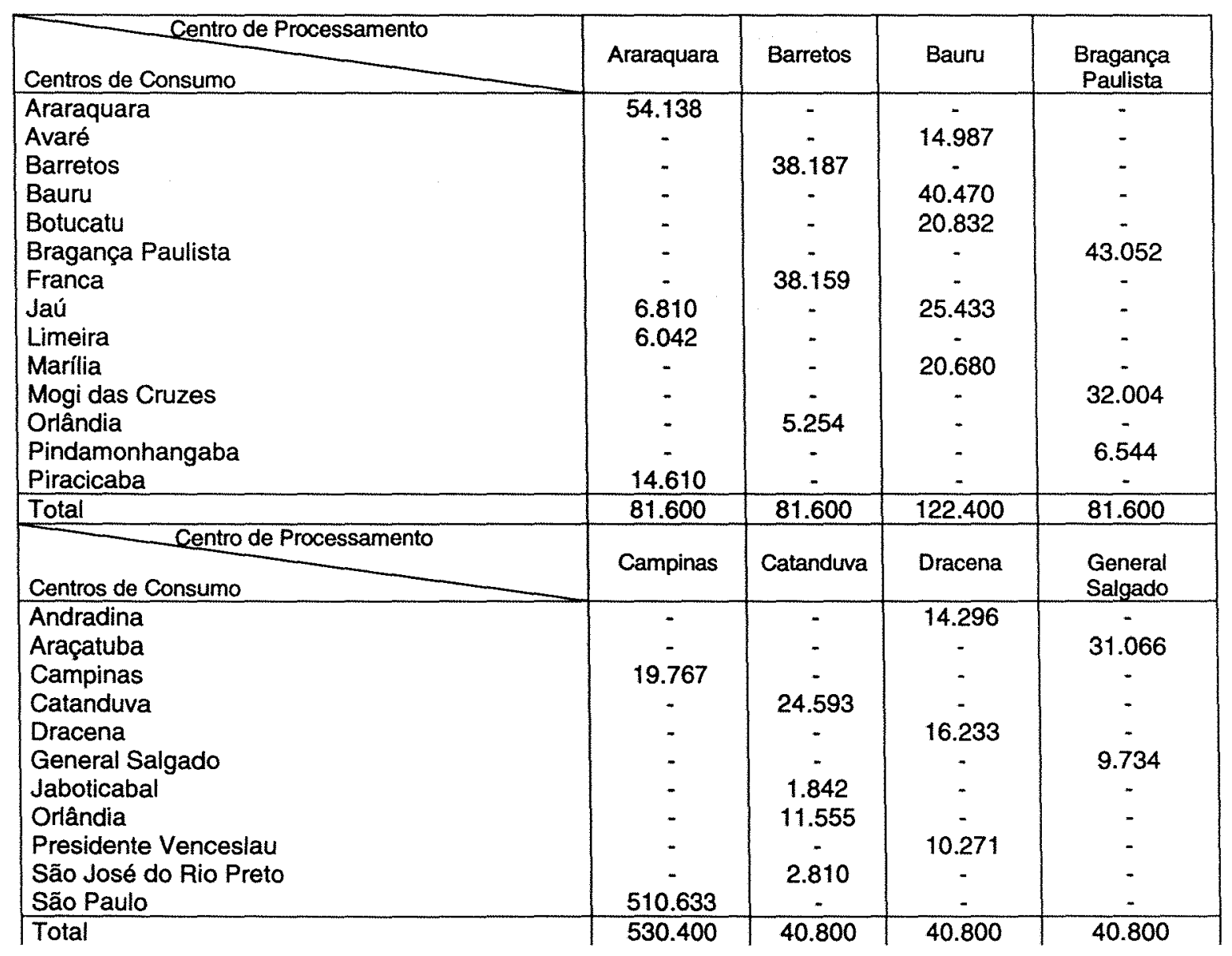




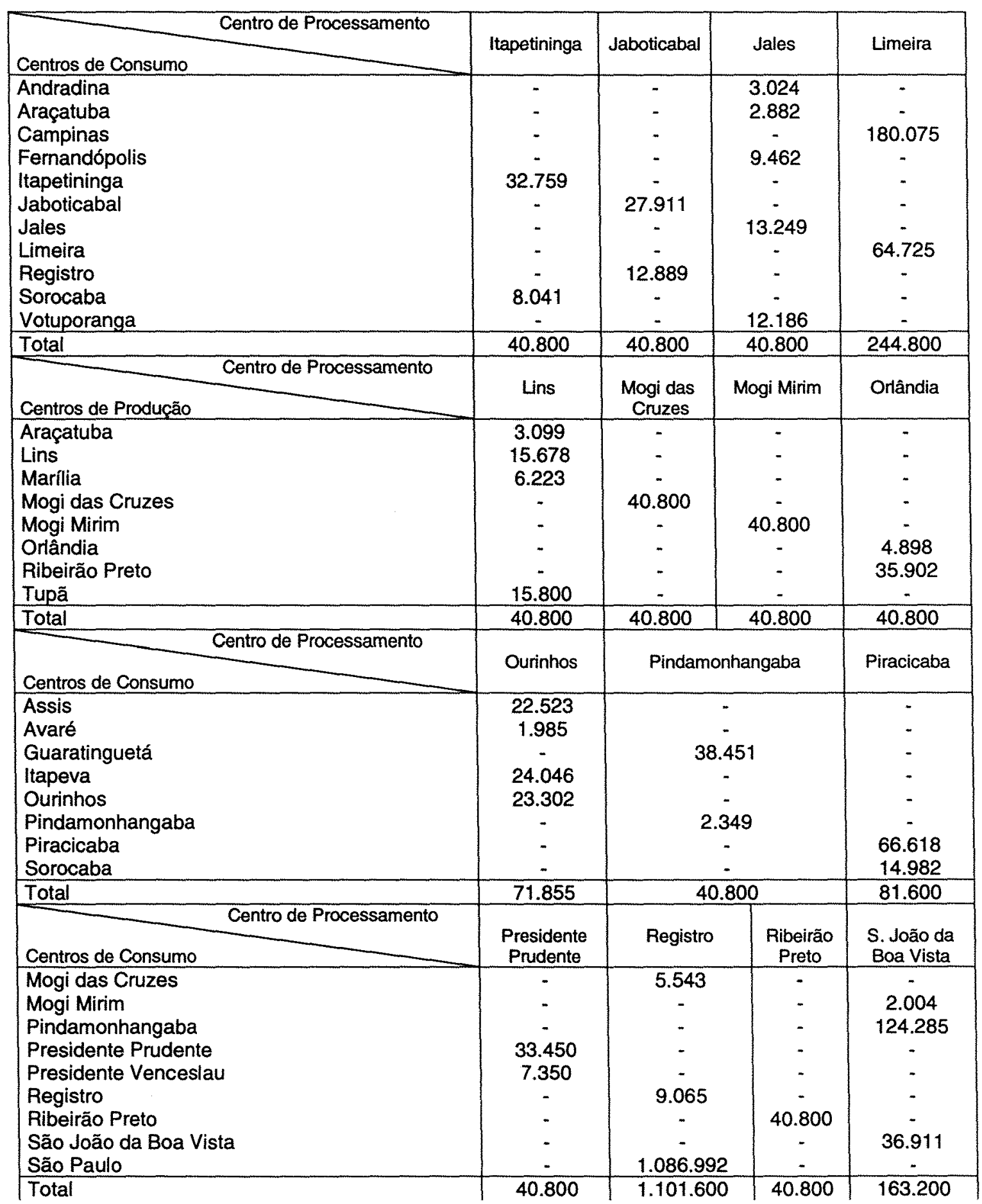




\begin{tabular}{|l|c|c|c|}
\hline \multicolumn{1}{|c|}{ Centro de Processamento } & $\begin{array}{c}\text { S. José do } \\
\text { Rio Preto }\end{array}$ & São Paulo & Sorocaba \\
\hline Centros de Consumo & 51.000 & 40.800 & \\
\hline $\begin{array}{l}\text { Mogi das Cruzes } \\
\text { São José do Rio Preto }\end{array}$ & 51.000 & 40.800 & 81.600 \\
Sorocaba & & 81.600 \\
\hline
\end{tabular}

Quadro 11 - Volume transportado de laranja dos centros de processamento para os centros de consumo final, em toneladas, cenário 3.

Fonte: Dados da pesquisa.

Os resultados mostram que 26 centros de processamento satisfazem totalmente as demandas de todos os EDRs do Estado de São Paulo. O Quadro 12 fornece a análise dos custos marginais de transporte, considerando as rotas que proporcionam menores acréscimos por tonelada de laranja transportada para a região de processamento.

\begin{tabular}{|l|c|c|c|c|c|}
\hline \multirow{2}{*}{ Centro Produtor Alternativo } & \multicolumn{5}{|c|}{ Centro Processador } \\
\cline { 2 - 6 } & Araraquara & Barretos & Bauru & $\begin{array}{c}\text { Bragança } \\
\text { Paulista }\end{array}$ & Campinas \\
\hline Barretos & 2,88 & - & - & - & - \\
Catanduva & 0,56 & - & - & - & - \\
Jaboticabal & 2,46 & - & - & - & - \\
\hline Catanduva & - & 3,86 & - & - & - \\
Jaboticabal & - & 6,35 & - & - & - \\
S. José do Rio Preto & - & 2,91 & - & - & - \\
\hline Araraquara & - & - & 2,62 & - & - \\
Lins & - & - & 1,84 & - & - \\
S. José do Rio Preto & - & - & 1,60 & - & - \\
\hline Araraquara & - & - & - & 0,46 & - \\
Campinas & - & - & - & 0,27 & - \\
Catanduva & - & - & - & 0,95 & - \\
\hline Campinas & - & - & - & - & 0,16 \\
Catanduva & - & - & - & - & 0,34 \\
Piracicaba & - & - & - & - & 0,12 \\
\hline
\end{tabular}




\begin{tabular}{|c|c|c|c|c|c|}
\hline \multirow[b]{2}{*}{ Centro Produtor Alternativo } & \multicolumn{5}{|c|}{ Centro Processador } \\
\hline & Catanduva & Dracena & $\begin{array}{l}\text { General } \\
\text { Salgado }\end{array}$ & Itapetininga & Jaboticabal \\
\hline $\begin{array}{l}\text { Barretos } \\
\text { Lins } \\
\text { S. José do Rio Preto }\end{array}$ & $\begin{array}{l}4,68 \\
1,84 \\
1,60 \\
\end{array}$ & $\begin{array}{l}- \\
- \\
-\end{array}$ & $\begin{array}{l}- \\
- \\
- \\
\end{array}$ & $\begin{array}{l}- \\
- \\
\end{array}$ & $\begin{array}{l}- \\
- \\
\end{array}$ \\
\hline $\begin{array}{l}\text { Araçatuba } \\
\text { Fernandópolis } \\
\text { General Salgado }\end{array}$ & $\begin{array}{l}- \\
- \\
\end{array}$ & $\begin{array}{l}1,25 \\
1,10 \\
1,34 \\
\end{array}$ & $\begin{array}{l}- \\
- \\
-\end{array}$ & - & - \\
\hline $\begin{array}{l}\text { Fernandópolis } \\
\text { Jales } \\
\text { Votuporanga }\end{array}$ & $\begin{array}{l}- \\
-\end{array}$ & $\begin{array}{l}- \\
- \\
\end{array}$ & $\begin{array}{l}1,69 \\
0,61 \\
1,20 \\
\end{array}$ & $\begin{array}{l}- \\
- \\
\end{array}$ & $\begin{array}{l}- \\
- \\
\end{array}$ \\
\hline $\begin{array}{l}\text { Avaré } \\
\text { Botucatu } \\
\text { Jaú }\end{array}$ & $\begin{array}{l}- \\
- \\
\end{array}$ & - & $\begin{array}{l}- \\
- \\
-\end{array}$ & $\begin{array}{l}3,20 \\
0,69 \\
2,61 \\
\end{array}$ & $\begin{array}{l}- \\
- \\
\end{array}$ \\
\hline $\begin{array}{l}\text { Barretos } \\
\text { Jaboticabal } \\
\text { S. José do Rio Preto }\end{array}$ & - & $\begin{array}{l}- \\
- \\
- \\
\end{array}$ & $\begin{array}{l}- \\
- \\
-\end{array}$ & $\begin{array}{l}- \\
- \\
-\end{array}$ & $\begin{array}{l}0,55 \\
0,56 \\
2,49 \\
\end{array}$ \\
\hline \multirow[b]{2}{*}{ Centro Produtor Alternativo } & \multicolumn{5}{|c|}{ Centro Processador } \\
\hline & Jales & Limeira & Lins & $\begin{array}{c}\text { Mogi das } \\
\text { Cruzes }\end{array}$ & Mogi Mirim \\
\hline $\begin{array}{l}\text { Fernandópolis } \\
\text { Jaboticabal } \\
\text { S. José do Rio Preto }\end{array}$ & $\begin{array}{l}0,69 \\
0,56 \\
2,49 \\
\end{array}$ & $\begin{array}{l}- \\
- \\
-\end{array}$ & $\begin{array}{l}- \\
- \\
\end{array}$ & $\begin{array}{l}- \\
- \\
\end{array}$ & $\begin{array}{l}- \\
- \\
\end{array}$ \\
\hline $\begin{array}{l}\text { Catanduva } \\
\text { Limeira } \\
\text { Piracicaba } \\
\end{array}$ & - & $\begin{array}{l}0,40 \\
0,48 \\
0,98 \\
\end{array}$ & $\begin{array}{l}- \\
- \\
-\end{array}$ & 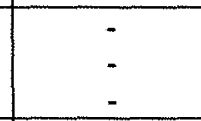 & $\begin{array}{l}- \\
- \\
-\end{array}$ \\
\hline $\begin{array}{l}\text { Catanduva } \\
\text { S. José do Rio Preto } \\
\text { Votuporanga }\end{array}$ & $\begin{array}{l}- \\
- \\
\end{array}$ & $\begin{array}{l}- \\
- \\
-\end{array}$ & $\begin{array}{l}1,63 \\
0,26 \\
2,92 \\
\end{array}$ & $\begin{array}{l}- \\
- \\
-\end{array}$ & $\begin{array}{l}- \\
- \\
\end{array}$ \\
\hline $\begin{array}{l}\text { Campinas } \\
\text { Registro } \\
\text { Sorocaba } \\
\end{array}$ & - & - & $\begin{array}{l}- \\
- \\
-\end{array}$ & $\begin{array}{l}0,21 \\
0,15 \\
0,22 \\
\end{array}$ & $\begin{array}{l}- \\
- \\
\end{array}$ \\
\hline $\begin{array}{l}\text { Araraquara } \\
\text { Catanduva } \\
\text { Limeira } \\
\end{array}$ & - & $\begin{array}{l}- \\
- \\
- \\
\end{array}$ & $\begin{array}{l}- \\
- \\
- \\
\end{array}$ & $\begin{array}{l}- \\
- \\
\end{array}$ & $\begin{array}{l}1,12 \\
1,70 \\
1,02 \\
\end{array}$ \\
\hline \multirow[b]{2}{*}{ Centro Produtor Alternativo } & \multicolumn{5}{|c|}{ Centro Processador } \\
\hline & Orlândia & Ourinhos & Pindam & onhangaba & Piracicaba \\
\hline $\begin{array}{l}\text { Catanduva } \\
\text { Jaboticabal } \\
\text { S. José do Rio Preto }\end{array}$ & $\begin{array}{l}1,09 \\
2,77 \\
3,07 \\
\end{array}$ & $\begin{array}{l}- \\
- \\
-\end{array}$ & & - & - \\
\hline $\begin{array}{l}\text { Bauru } \\
\text { Itapeva } \\
\text { Jaú }\end{array}$ & $\begin{array}{l}- \\
- \\
\end{array}$ & $\begin{array}{l}0,29 \\
0,98 \\
0,51 \\
\end{array}$ & & $\begin{array}{l}- \\
- \\
-\end{array}$ & - \\
\hline $\begin{array}{l}\text { Araraquara } \\
\text { Bragança Paulista } \\
\text { Mogi Mirim } \\
\end{array}$ & $\begin{array}{l}- \\
- \\
\end{array}$ & $\begin{array}{l}- \\
- \\
\end{array}$ & & $\begin{array}{l}1,20 \\
1,20 \\
1,20\end{array}$ & $\begin{array}{l}- \\
- \\
-\end{array}$ \\
\hline $\begin{array}{l}\text { Botucatu } \\
\text { Catanduva } \\
\text { Limeira }\end{array}$ & - & $\begin{array}{l}- \\
-\end{array}$ & & - & $\begin{array}{l}0,61 \\
0,54 \\
0,88\end{array}$ \\
\hline
\end{tabular}




\begin{tabular}{|c|c|c|c|c|}
\hline \multirow[b]{2}{*}{ Centro Produtor Alternativo } & \multicolumn{4}{|c|}{ Centro Processador } \\
\hline & $\begin{array}{l}\text { Presidente } \\
\text { Prudente }\end{array}$ & Registro & $\begin{array}{c}\text { Ribeirão } \\
\text { Preto }\end{array}$ & $\begin{array}{l}\text { S. João da } \\
\text { Boa Vista }\end{array}$ \\
\hline $\begin{array}{l}\text { Catanduva } \\
\text { Dracena } \\
\text { Fernandópolis }\end{array}$ & $\begin{array}{l}2,00 \\
1,69 \\
0,72\end{array}$ & $\begin{array}{l}- \\
-\end{array}$ & $\begin{array}{l}- \\
- \\
-\end{array}$ & - \\
\hline $\begin{array}{l}\text { Araraquara } \\
\text { Fernandópolis } \\
\text { Jaú }\end{array}$ & - & $\begin{array}{l}1,51 \\
6,32 \\
5,49\end{array}$ & $\begin{array}{l}- \\
-\end{array}$ & 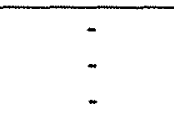 \\
\hline $\begin{array}{l}\text { Fernandópolis } \\
\text { Franca } \\
\text { Orlândia }\end{array}$ & 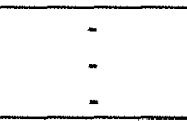 & $\begin{array}{l}- \\
- \\
\end{array}$ & $\begin{array}{l}9,74 \\
2,66 \\
3,52 \\
\end{array}$ & 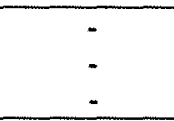 \\
\hline $\begin{array}{l}\text { Araraquara } \\
\text { Catanduva } \\
\text { Franca }\end{array}$ & 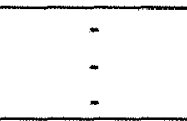 & $\begin{array}{l}- \\
- \\
-\end{array}$ & $\begin{array}{l}- \\
- \\
-\end{array}$ & $\begin{array}{l}3,91 \\
4,11 \\
4,06 \\
\end{array}$ \\
\hline \multirow[b]{2}{*}{ Centro Produtor Alternativo } & \multicolumn{4}{|c|}{ Centro Processador } \\
\hline & S. José c & Rio Preto & São Paulo & Sorocaba \\
\hline $\begin{array}{l}\text { Barretos } \\
\text { Catanduva } \\
\text { Votuporanga }\end{array}$ & & & - & $\begin{array}{l}- \\
- \\
-\end{array}$ \\
\hline $\begin{array}{l}\text { Botucatu } \\
\text { Itapetininga } \\
\text { Limeira } \\
\text { Mogi Mirim }\end{array}$ & & & $\begin{array}{l}0,10 \\
0,54 \\
0,54 \\
0,54 \\
\end{array}$ & $\overline{-}$ \\
\hline $\begin{array}{l}\text { Botucatu } \\
\text { Itapeva } \\
\text { Piracicaba }\end{array}$ & & & 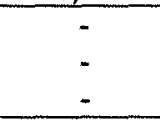 & $\begin{array}{l}0,26 \\
0,99 \\
1,18 \\
\end{array}$ \\
\hline
\end{tabular}

Quadro 12 - Custos marginais de transporte, em Reais por tonelada transportada, cenário 3.

Fonte: Dados da pesquisa.

\subsection{Cenário 4}

Com o intuito de verificar qual seria a distribuição espacial, o número ótimo de plantas processadoras e a capacidade de processamento de cada EDR numa situação em que ocorre variações na oferta e na demanda de laranja, considerou-se, assim como no cenário 3 , que a demanda por laranja de cada EDR se iguala à sua oferta. Para verificar se a distribuição espacial das plantas processadoras sofrerá alterações significativas, em relação à distribuição obtida no cenário 3 , admitiu-se a possibilidade de instalação de no máximo uma unidade de beneficiamento, de cada tamanho, por EDR. De acordo com os resultados fornecidos pelo modelo proposto, 0 valor do custo total de transporte, processamento e instalação dessas plantas equivale a $R \$ 140.182 .800$, valor superior ao observado para o cenário 3. Pode-se verificar, no 
Quadro 13, as quantidades transportadas de laranja, assim como os fluxos de matériaprima, dos centros produtores aos processadores.

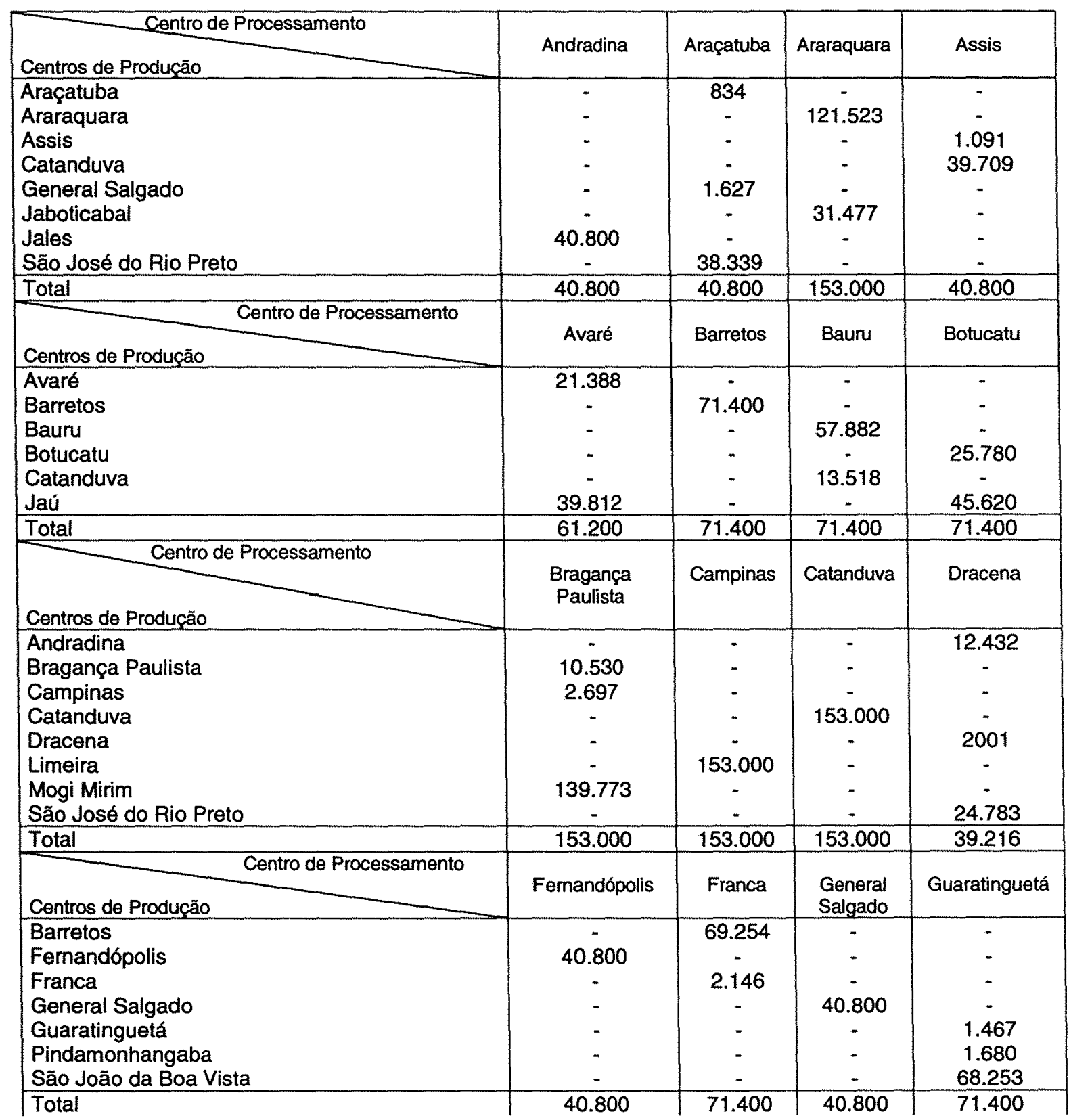




\begin{tabular}{|c|c|c|c|c|}
\hline $\begin{array}{ll} & \text { Centro de Processamento } \\
\text { Centros de Produçăo }\end{array}$ & Itapetininga & Itapeva & Jaboticabal & Jales \\
\hline $\begin{array}{l}\text { Avaré } \\
\text { Barretos } \\
\text { Fernandópolis } \\
\text { Itapetininga } \\
\text { itapeva } \\
\text { Jaboticabal } \\
\text { Jales }\end{array}$ & $\begin{array}{c}- \\
- \\
71.400 \\
- \\
- \\
\end{array}$ & $\begin{array}{c}7.390 \\
- \\
- \\
20.264 \\
13.146 \\
- \\
- \\
\end{array}$ & $\begin{array}{c}- \\
46.160 \\
- \\
- \\
106.840 \\
- \\
\end{array}$ & $\begin{array}{c}\cdot \\
- \\
13.161 \\
- \\
- \\
- \\
27.639\end{array}$ \\
\hline Total & 71.400 & 40.800 & 153.000 & 40.800 \\
\hline $\begin{array}{ll} & \text { Centro de Processamento } \\
\text { Centros de Producão }\end{array}$ & Jaú & Limeira & Lins & Marilia \\
\hline $\begin{array}{l}\text { Araraquara } \\
\text { Catanduva } \\
\text { Jales } \\
\text { Jaú } \\
\text { Limeira } \\
\text { Lins } \\
\text { São José do Rio Preto } \\
\end{array}$ & $\begin{array}{c}30.912 \\
8.820 \\
31.668 \\
- \\
- \\
- \\
\end{array}$ & $\begin{array}{c}- \\
- \\
- \\
153.000 \\
- \\
-\end{array}$ & $\begin{array}{c}- \\
- \\
- \\
- \\
37.841 \\
23.359 \\
\end{array}$ & $\begin{array}{c}- \\
28.690 \\
- \\
- \\
- \\
12.110 \\
- \\
\end{array}$ \\
\hline Total & 71.400 & 153.000 & 61.200 & 40.800 \\
\hline $\begin{array}{l}\text { Centro de Processamento } \\
\text { Centros de Produção }\end{array}$ & $\begin{array}{c}\text { Mogi das } \\
\text { Cruzes }\end{array}$ & $\begin{array}{l}\text { Mogi } \\
\text { Mirim }\end{array}$ & Orlândia & Ourinhos \\
\hline $\begin{array}{l}\text { Araraquara } \\
\text { Catanduva } \\
\text { Limeira } \\
\text { Marilia } \\
\text { Mogi das Cruzes } \\
\text { Mogi Mirim } \\
\text { Orlândia } \\
\text { Ourinhos } \\
\text { São João da Boa Vista } \\
\text { São Paulo } \\
\end{array}$ & $\begin{array}{c}49.524 \\
- \\
20.680 \\
- \\
441 \\
- \\
- \\
- \\
- \\
755 \\
\end{array}$ & $\begin{array}{c}- \\
- \\
- \\
- \\
135.410 \\
- \\
- \\
17.590 \\
\end{array}$ & $\begin{array}{c}- \\
- \\
- \\
- \\
- \\
71.400 \\
- \\
- \\
-\end{array}$ & $\begin{array}{c}- \\
12.684 \\
- \\
3 . \overline{7} 46 \\
- \\
- \\
- \\
24.370 \\
- \\
-\end{array}$ \\
\hline Total & 71.400 & 153.000 & 71.400 & 40.800 \\
\hline $\begin{array}{ll} & \text { Centro de Processamento } \\
\text { Centros de Producão }\end{array}$ & \multicolumn{2}{|c|}{ Pindamonhangaba } & Piracicaba & $\begin{array}{c}\text { Presidente } \\
\text { Prudente }\end{array}$ \\
\hline $\begin{array}{l}\text { Araraquara } \\
\text { São João da Boa Vista } \\
\text { São José do Rio Preto } \\
\end{array}$ & \multicolumn{2}{|c|}{$\begin{array}{c}- \\
71.400 \\
- \\
\end{array}$} & $\begin{array}{c}153.000 \\
- \\
- \\
\end{array}$ & 40.800 \\
\hline Total & \multicolumn{2}{|c|}{71.400} & 153.000 & 40.800 \\
\hline $\begin{array}{l}\text { Centro de Processamento } \\
\text { Centros de Produção }\end{array}$ & $\begin{array}{l}\text { Presidente } \\
\text { Venceslau }\end{array}$ & Registro & $\begin{array}{c}\text { Ribeirão } \\
\text { Preto }\end{array}$ & $\begin{array}{c}\text { São João da } \\
\text { Boa Vista } \\
\end{array}$ \\
\hline $\begin{array}{l}\text { Franca } \\
\text { Jaboticabal } \\
\text { Jales } \\
\text { Orlândia } \\
\text { Presidente Prudente } \\
\text { Presidente Venceslau } \\
\text { Ribeirão Preto } \\
\text { São João da Boa Vista } \\
\text { São José do Rio Preto } \\
\end{array}$ & $\begin{array}{c}- \\
- \\
7.678 \\
- \\
769 \\
244 \\
- \\
- \\
52.509 \\
\end{array}$ & $\begin{array}{c}- \\
155.040 \\
- \\
- \\
- \\
- \\
- \\
- \\
\end{array}$ & $\begin{array}{c}16.654 \\
- \\
- \\
135 \\
- \\
54.611 \\
- \\
-\end{array}$ & $\begin{array}{c}- \\
- \\
- \\
- \\
- \\
- \\
- \\
71.400 \\
- \\
\end{array}$ \\
\hline Total & 61.200 & 155.040 & 71.400 & 71.400 \\
\hline
\end{tabular}




\begin{tabular}{|c|c|c|c|c|}
\hline $\begin{array}{ll} & \text { Centro de Processamento } \\
\text { Centros de Producão }\end{array}$ & $\begin{array}{l}\text { São José do } \\
\text { Rio Preto }\end{array}$ & São Paulo & Sorocaba & Tupā \\
\hline $\begin{array}{l}\text { Araraquara } \\
\text { Campinas } \\
\text { Jaboticabal } \\
\text { Piracicaba } \\
\text { Registro } \\
\text { São José do Rio Preto } \\
\text { Sorocaba } \\
\text { Tupã } \\
\end{array}$ & $\begin{array}{c}- \\
- \\
- \\
- \\
71.400 \\
- \\
- \\
\end{array}$ & $\begin{array}{c}1.982 \\
151.012 \\
- \\
6 \\
- \\
- \\
\end{array}$ & $\begin{array}{c}29.589 \\
- \\
- \\
16.495 \\
- \\
- \\
25.316 \\
- \\
\end{array}$ & $\begin{array}{c}- \\
- \\
- \\
- \\
38.627 \\
2.173 \\
\end{array}$ \\
\hline Total & 71.400 & 153.000 & 71.400 & 40.800 \\
\hline $\begin{array}{ll} & \text { Centro de Processamento } \\
\text { Centros de Producão }\end{array}$ & \multicolumn{4}{|c|}{ Votuporanga } \\
\hline $\begin{array}{l}\text { Fernandópolis } \\
\text { Votuporanga }\end{array}$ & \multicolumn{4}{|c|}{$\begin{array}{l}14.717 \\
46.483 \\
\end{array}$} \\
\hline Total & \multicolumn{4}{|c|}{61.200} \\
\hline
\end{tabular}

Quadro 13 - Volume transportado de laranja dos centros de produção para os centros de processamento, em toneladas, cenário 4.

Fonte: Dados da pesquisa.

Neste cenário, a minimização de custos é obtida a partir da instalação de uma unidade beneficiadora em cada uma das 40 regiões do Estado de São Paulo. Observa-se, também, que existe uma pequena quantidade de transporte inter-regional, de modo que a demanda dos centros processadores é suprida, no máximo, a partir de quatro regiōes produtoras, como é o caso dos EDRs de Mogi das Cruzes e Presidente Venceslau. Já as plantas localizadas nas regiões de Barretos, Catanduva, Fernandópolis, General Salgado, Itapetininga, Limeira, Orlândia, São João da Boa Vista e São José do Rio Preto têm suas necessidades satisfeitas pela produção local.

O Quadro 14 fornece o número de packing-houses e a capacidade ótima de processamento de cada região do Estado. 


\begin{tabular}{|c|c|c|c|c|c|}
\hline EDR & $\begin{array}{l}\mathrm{N}^{2} \text { de plantas } \\
\text { (2.040 Vano) }\end{array}$ & $\begin{array}{l}\mathrm{N}^{0} \text { de plantas } \\
(10.200 \text { tano }\end{array}$ & $\begin{array}{l}\mathrm{N}^{0} \text { de plantas } \\
(20.400 \text { tano) }\end{array}$ & $\begin{array}{l}N^{0} \text { de plantas } \\
(40.800 \text { tano) }\end{array}$ & $\begin{array}{l}N^{0} \text { de plantas } \\
(81.600 \text { tano) }\end{array}$ \\
\hline Andradina & - & - & - & 1 & - \\
\hline Araçatuba & - & - & - & 1 & - \\
\hline Araraquara & - & 1 & 1 & 1 & 1 \\
\hline Assis & - & - & - & 1 & - \\
\hline Avaré & - & - & 1 & 1 & - \\
\hline Barretos & - & 1 & 1 & 1 & - \\
\hline Bauru & - & 1 & 1 & 1 & - \\
\hline Botucatu & - & 1 & 1 & 1 & - \\
\hline Bragança Paulista & - & 1 & 1 & 1 & 1 \\
\hline Campinas & - & 1 & 1 & 1 & 1 \\
\hline Catanduva & - & 1 & 1 & 1 & 1 \\
\hline Dracena & - & - & - & 1 & - \\
\hline Fernandópolis & - & - & - & 1 & - \\
\hline Franca & - & 1 & 1 & 1 & - \\
\hline General Salgado & - & - & - & 1 & - \\
\hline Guaratinguetá & - & 1 & 1 & 1 & - \\
\hline Itapetininga & - & 1 & 1 & 1 & - \\
\hline Itapeva & - & - & - & 1 & - \\
\hline Jaboticabal & - & 1 & 1 & 1 & 1 \\
\hline Jales & - & - & - & 1 & - \\
\hline Jaú & - & 1 & 1 & 1 & - \\
\hline Limeira & - & 1 & 1 & 1 & 1 \\
\hline Lins & - & - & 1 & 1 & - \\
\hline Marília & - & - & - & 1 & - \\
\hline Mogi das Cruzes & - & 1 & 1 & 1 & - \\
\hline Mogi Mirim & - & 1 & 1 & 1 & 1 \\
\hline Orlândia & - & 1 & 1 & 1 & - \\
\hline Ourinhos & - & - & - & 1 & - \\
\hline Pindamonhangaba & - & 1 & 1 & 1 & - \\
\hline Piracicaba & - & 1 & 1 & 1 & 1 \\
\hline Presidente Prudente & - & - & - & 1 & - \\
\hline Presidente Venceslau & - & - & 1 & 1 & - \\
\hline Registro & 1 & 1 & 1 & 1 & 1 \\
\hline Ribeirão Preto & - & 1 & 1 & 1 & - \\
\hline São João da Boa Vista & - & 1 & 1 & 1 & - \\
\hline São José do Rio Preto & . & 1 & 1 & 1 & - \\
\hline São Paulo & - & 1 & 1 & 1 & 1 \\
\hline Sorocaba & - & 1 & 1 & 1 & - \\
\hline Tupã & - & - & - & 1 & - \\
\hline Votuporanga & - & - & 1 & 1 & - \\
\hline Total & 01 & 24 & 28 & 40 & 10 \\
\hline
\end{tabular}

Quadro 14 - Número de packing-houses instalados, por EDR, cenário 4.

Fonte: Dados da pesquisa.

É importante destacar a economia de escala no processamento, também verificada neste cenário. Dentre as possibilidades de instalação de packing-houses propostas pelo modelo, observa-se a tendência de implantação de plantas com maiores capacidades de processamento, visto que $39 \%$ das plantas são capazes de processar 40.800 t/ano, $27 \%$ processam 20.400 tano, $23 \%$ processam 10.200 t/ano, 
$10 \%$ beneficiam 81.600 t/ano e $1 \%$ possui capacidade de processamento igual a 2.040 tano.

Pode-se observar, no Quadro 15, os fluxos de laranja dos centros processadores aos consumidores, assim como as quantidades de laranja a serem transportadas entre essas regiōes.

\begin{tabular}{|c|c|c|c|c|}
\hline $\begin{array}{l}\text { Centro de Processamento } \\
\text { Centros de Consumo }\end{array}$ & Andradina & Araçatuba & Araraquara & Assis \\
\hline Andradina & 17.320 & - & - & - \\
\hline Araçatuba & - & 37.047 & - & - \\
\hline Assis & - & - & - & 17.498 \\
\hline Lins & - & 3.753 & - & - \\
\hline Ourinhos & - & - & - & 23.302 \\
\hline São Paulo & 23.480 & - & 153.000 & - \\
\hline Total & 40.800 & 40.800 & 153.000 & 40.800 \\
\hline $\begin{array}{ll} & \text { Centro de Processamento } \\
\text { Centros de Consumo }\end{array}$ & Avaré & Barretos & Bauru & Botucatu \\
\hline Barretos & - & 38.187 & - & - \\
\hline Jaboticabal & - & 29.753 & - & - \\
\hline Registro & - & 3.460 & - & - \\
\hline São Paulo & 61.200 & - & 71.400 & 71.400 \\
\hline Total & 61.200 & 71.400 & 71.400 & 71.400 \\
\hline $\begin{array}{l}\text { Centro de Processamento } \\
\text { Centros de Consumo }\end{array}$ & $\begin{array}{l}\text { Bragança } \\
\text { Paulista } \\
\end{array}$ & Campinas & Catanduva & Dracena \\
\hline Araraquara & $-i$ & - & 39.642 & - \\
\hline Bragança Paulista & 43.052 & - & - & - \\
\hline Dracena & - & - & - & 16.233 \\
\hline Mogi das Cruzes & 47.747 & - & - & - \\
\hline Presidente Venceslau & - & - & - & 17.621 \\
\hline São Paulo & 62.201 & 153.000 & 113.358 & 5.362 \\
\hline Total & 153.000 & 153.00 & 153.000 & 39.216 \\
\hline $\begin{array}{ll}\text { Centros de Consumo } & \text { Centro de Processamento } \\
\end{array}$ & Fernandópolis & Franca & $\begin{array}{l}\text { General } \\
\text { Salgado }\end{array}$ & Guaratinguetá \\
\hline Franca & - & 38.159 & - & - \\
\hline General Salgado & - & - & 9.734 & - \\
\hline Guaratinguetá & - & - & i. & 38.451 \\
\hline Limeira & - & - & 23.960 & - \\
\hline Pindamonhangaba & - & - & - & 32.949 \\
\hline São José do Rio Preto & - & - & 7.106 & - \\
\hline $\begin{array}{l}\text { São Paulo } \\
\text { Votuporanga }\end{array}$ & $\begin{array}{l}28.617 \\
12.183\end{array}$ & 33.241 & - & - \\
\hline$\frac{\text { Votuporanga }}{\text { Total }}$ & $\frac{12.183}{40.800}$ & 71.400 & 40.800 & 71.400 \\
\hline
\end{tabular}




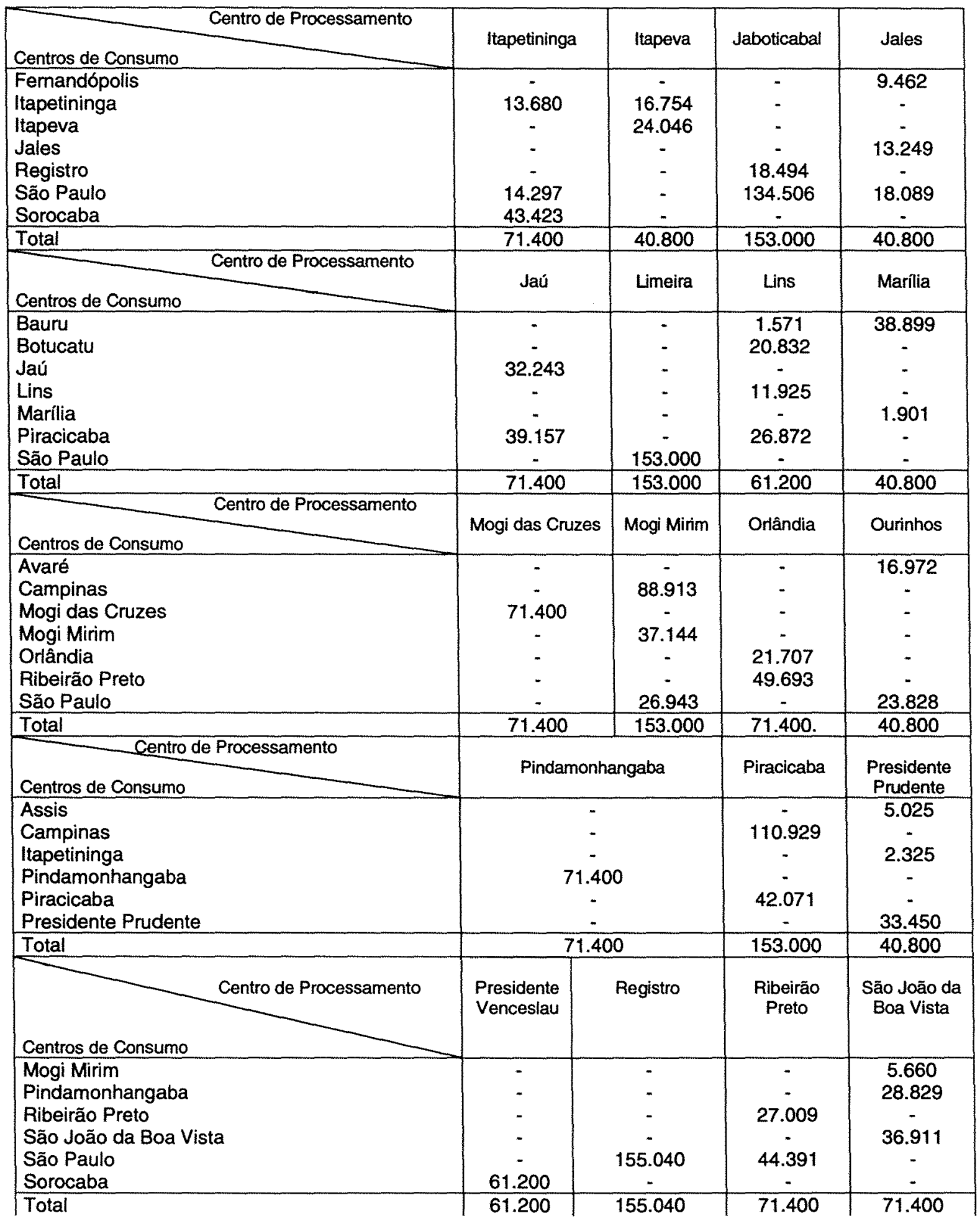




\begin{tabular}{|c|c|c|c|c|}
\hline $\begin{array}{ll} & \text { Centro de Processamento } \\
\text { Centros de Consumo }\end{array}$ & $\begin{array}{c}\text { São José do Rio } \\
\text { Preto } \\
\end{array}$ & São Paulo & Sorocaba & Tupã \\
\hline Catanduva & 24.593 & - & - & - \\
\hline Limeira & 46.807 & - & - & - \\
\hline Marilia & - & - & - & 25.000 \\
\hline São Paulo & - & 153.000 & 71.400 & - \\
\hline Tupã & - & - & - & 15.800 \\
\hline Votuporanga & - & - & - & - \\
\hline Total & 71.400 & 153.000 & 71.400 & 40.800 \\
\hline $\begin{array}{ll} & \text { Centro de Processamento } \\
\text { Centros de Consumo } & \end{array}$ & \multicolumn{4}{|c|}{ Votuporanga } \\
\hline $\begin{array}{l}\text { Araraquara. } \\
\text { São José do Rio Preto }\end{array}$ & \multicolumn{4}{|c|}{$\begin{array}{l}14.496 \\
46.704 \\
\end{array}$} \\
\hline Total & \multicolumn{4}{|c|}{61.200} \\
\hline
\end{tabular}

Quadro 15 - Volume transportado de laranja dos centros de processamento para os centros de consumo final, em toneladas, cenário 4.

Fonte: Dados da pesquisa.

Os resultados apresentados no Quadro 15 permitem concluir que os quarenta centros de processamento satisfazem totalmente as demandas de todos os EDRs do Estado de São Paulo. A análise dos custos marginais de transporte, considerando as rotas que proporcionam menores acréscimos por tonelada de laranja transportada para a região de processamento, pode ser visualizada no Quadro 16.

\begin{tabular}{|l|c|c|c|c|c|}
\hline \multirow{2}{*}{ Centro Produtor Alternativo } & \multicolumn{5}{|c|}{ Centro Processador } \\
\cline { 2 - 6 } & $\begin{array}{c}\text { Andradi } \\
\text { na }\end{array}$ & Araçatuba & Araraquara & Assis & Avaré \\
\hline Andradina & 0,18 & - & - & - & - \\
Fernandópolis & 0,74 & - & - & - & - \\
General Salgado & 0,23 & - & - & - & - \\
\hline Barretos & - & 1,35 & - & - & - \\
Fernandópolis & - & 1,02 & - & - & - \\
Jales & - & 0,75 & - & - & - \\
\hline Barretos & - & - & 0,43 & - & - \\
Catanduva & - & - & 0,93 & - & - \\
S. José do Rio Preto & - & 3,42 & - & - \\
& - & - & - & 0,24 & - \\
\hline Lins & - & - & - & 0,64 & - \\
Marília & - & - & - & 0,07 & - \\
S. José do Rio Preto & - & - & - & - & 0,90 \\
\hline Araraquara & - & - & - & - & 0,74 \\
Catanduva & - & - & - & & \\
Jaboticabal & & & & & - \\
\hline
\end{tabular}




\begin{tabular}{|c|c|c|c|c|c|c|c|}
\hline \multirow[b]{2}{*}{ Centro Produtor Alternativo } & \multicolumn{7}{|c|}{ Centro Processador } \\
\hline & Barretos & & Bauru & & otucatu & $\begin{array}{c}\text { Bragança } \\
\text { Paulista }\end{array}$ & Campinas \\
\hline $\begin{array}{l}\text { Catanduva } \\
\text { Jaboticabal } \\
\text { S. José do Rio Preto }\end{array}$ & $\begin{array}{l}6,68 \\
6,34 \\
5,80 \\
\end{array}$ & & $\begin{array}{l}- \\
- \\
\end{array}$ & & $\begin{array}{l}- \\
- \\
-\end{array}$ & $\begin{array}{l}- \\
- \\
- \\
\end{array}$ & - \\
\hline $\begin{array}{l}\text { Barretos } \\
\text { Jaboticabal } \\
\text { S. José do Rio Preto }\end{array}$ & $\begin{array}{l}- \\
- \\
-\end{array}$ & & $\begin{array}{l}1,31 \\
1,79 \\
1,67 \\
\end{array}$ & & 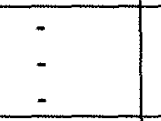 & $\begin{array}{l}- \\
- \\
\end{array}$ & $\begin{array}{l}- \\
- \\
\end{array}$ \\
\hline $\begin{array}{l}\text { Araraquara } \\
\text { Barretos } \\
\text { Catanduva } \\
\end{array}$ & $\begin{array}{l}- \\
- \\
\end{array}$ & & $\begin{array}{l}- \\
- \\
\end{array}$ & & $\begin{array}{l}0,20 \\
0,62 \\
0,26\end{array}$ & $\begin{array}{l}- \\
- \\
\end{array}$ & $\begin{array}{l}- \\
- \\
\end{array}$ \\
\hline $\begin{array}{l}\text { Araraquara } \\
\text { Jaboticabal } \\
\text { S. João da Boa Vista }\end{array}$ & - & & - & & $\begin{array}{l}- \\
- \\
\end{array}$ & $\begin{array}{l}0,20 \\
0,25 \\
0,08 \\
\end{array}$ & $\begin{array}{l}- \\
- \\
\end{array}$ \\
\hline $\begin{array}{l}\text { Araraquara } \\
\text { Campinas } \\
\text { Jaboticabal }\end{array}$ & $\begin{array}{l}- \\
- \\
\end{array}$ & & $\begin{array}{l}- \\
- \\
-\end{array}$ & & $\begin{array}{l}- \\
- \\
- \\
\end{array}$ & $\begin{array}{l}- \\
- \\
\end{array}$ & $\begin{array}{l}0,53 \\
0,68 \\
0,23 \\
\end{array}$ \\
\hline \multirow[b]{2}{*}{ Centro Produtor Alternativo } & \multicolumn{7}{|c|}{ Centro Processador } \\
\hline & $\begin{array}{c}\text { Catanduv } \\
a \\
\end{array}$ & & acena & Ferr & רandópolis & Franca & $\begin{array}{l}\text { General } \\
\text { Salgado }\end{array}$ \\
\hline $\begin{array}{l}\text { Barretos } \\
\text { Jaboticabal } \\
\text { S. José do Rio Preto }\end{array}$ & $\begin{array}{l}1,86 \\
3,79 \\
2,02 \\
\end{array}$ & & $\begin{array}{l}- \\
- \\
-\end{array}$ & & $\begin{array}{l}- \\
- \\
-\end{array}$ & $\begin{array}{l}- \\
- \\
\end{array}$ & $\begin{array}{l}- \\
- \\
- \\
\end{array}$ \\
\hline $\begin{array}{l}\text { Araçatuba } \\
\text { Fernandópolis } \\
\text { Jales }\end{array}$ & $\begin{array}{l}- \\
- \\
\end{array}$ & & $\begin{array}{l}0,46 \\
0,49 \\
0,08\end{array}$ & & $\begin{array}{l}- \\
- \\
-\end{array}$ & $\begin{array}{l}- \\
- \\
\end{array}$ & 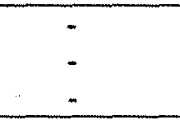 \\
\hline $\begin{array}{l}\text { Jales } \\
\text { S. José do Rio Preto } \\
\text { Votuporanga }\end{array}$ & $\overline{-}$ & & $\begin{array}{l}- \\
- \\
\end{array}$ & & $\begin{array}{l}1,38 \\
2,96 \\
1,38 \\
\end{array}$ & $\begin{array}{l}- \\
- \\
\end{array}$ & $\begin{array}{l}- \\
- \\
\end{array}$ \\
\hline $\begin{array}{l}\text { Catanduva } \\
\text { Jaboticabal } \\
\text { Orlândia } \\
\end{array}$ & $\begin{array}{l}- \\
-\end{array}$ & & $\begin{array}{l}- \\
- \\
\end{array}$ & & $\begin{array}{l}- \\
- \\
\end{array}$ & $\begin{array}{l}4,96 \\
3,46 \\
3,68 \\
\end{array}$ & $\begin{array}{l}- \\
- \\
-\end{array}$ \\
\hline $\begin{array}{l}\text { Fernandópolis } \\
\text { Jales } \\
\text { S. José do Rio Preto }\end{array}$ & $\begin{array}{l}- \\
-\end{array}$ & & - & & $\begin{array}{l}- \\
- \\
\end{array}$ & $\begin{array}{l}- \\
- \\
-\end{array}$ & $\begin{array}{l}1,85 \\
1,46 \\
1,24 \\
\end{array}$ \\
\hline \multirow[b]{2}{*}{ Centro Produtor Alternativo } & \multicolumn{7}{|c|}{ Centro Processador } \\
\hline & Guaratingu & & Itapeti & nga & Itapeva & Jaboticabal & Jales \\
\hline $\begin{array}{l}\text { Araraquara } \\
\text { Barretos } \\
\text { Limeira } \\
\end{array}$ & $\begin{array}{r}1,30 \\
1,29 \\
1,34 \\
\end{array}$ & & - & & $\begin{array}{l}- \\
- \\
\end{array}$ & 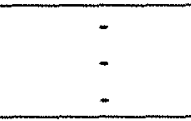 & $\begin{array}{l}- \\
- \\
-\end{array}$ \\
\hline $\begin{array}{l}\text { Araraquara } \\
\text { Botucatu } \\
\text { Presidente Prudente }\end{array}$ & $\begin{array}{l}- \\
- \\
- \\
\end{array}$ & & $\begin{array}{l}2, \\
2, \\
2,6\end{array}$ & & $\begin{array}{l}- \\
- \\
-\end{array}$ & $\dot{-}$ & $\begin{array}{l}- \\
- \\
-\end{array}$ \\
\hline $\begin{array}{l}\text { Araraquara } \\
\text { Catanduva } \\
\text { Jaú }\end{array}$ & - & & 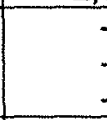 & & $\begin{array}{l}0,58 \\
0,47 \\
0,24\end{array}$ & $\begin{array}{l}- \\
- \\
\end{array}$ & - \\
\hline $\begin{array}{l}\text { Araraquara } \\
\text { Catanduva } \\
\text { S. José do Rio Preto }\end{array}$ & $\begin{array}{l}- \\
-\end{array}$ & & . & & 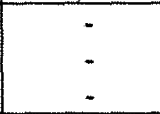 & $\begin{array}{l}5,16 \\
2,27 \\
4,83 \\
\end{array}$ & $\begin{array}{l}- \\
- \\
-\end{array}$ \\
\hline $\begin{array}{l}\text { General Salgado } \\
\text { S. José do Rio Preto } \\
\text { Votuporanga }\end{array}$ & - & & & & $\begin{array}{l}- \\
-\end{array}$ & $\begin{array}{l}- \\
-\end{array}$ & $\begin{array}{l}2,44 \\
3,66 \\
1,95\end{array}$ \\
\hline
\end{tabular}




\begin{tabular}{|c|c|c|c|c|c|}
\hline \multirow[b]{2}{*}{ Centro Produtor Alternativo } & \multicolumn{5}{|c|}{ Centro Processador } \\
\hline & Jaú & Limeira & Lins & Marília & $\begin{array}{c}\text { Mogi das } \\
\text { Cruzes }\end{array}$ \\
\hline $\begin{array}{l}\text { Barretos } \\
\text { Bauru } \\
\text { Jaboticabal }\end{array}$ & $\begin{array}{l}0,73 \\
1,90 \\
0,36 \\
\end{array}$ & $\begin{array}{l}- \\
- \\
-\end{array}$ & $\dot{-}$ & $\begin{array}{l}- \\
- \\
\end{array}$ & 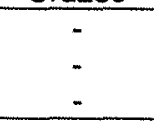 \\
\hline $\begin{array}{l}\text { Araraquara } \\
\text { Barretos } \\
\text { Jaboticabal }\end{array}$ & $\begin{array}{l}- \\
- \\
-\end{array}$ & $\begin{array}{l}0,05 \\
0,19 \\
0,02\end{array}$ & $\begin{array}{l}- \\
-\end{array}$ & $\begin{array}{l}- \\
- \\
-\end{array}$ & - \\
\hline $\begin{array}{l}\text { Barretos } \\
\text { Catanduva } \\
\text { Jaboticabal }\end{array}$ & - & $\begin{array}{l}- \\
- \\
-\end{array}$ & $\begin{array}{l}1,50 \\
1,30 \\
3,64\end{array}$ & 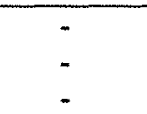 & - \\
\hline $\begin{array}{l}\text { Barretos } \\
\text { Marília } \\
\text { S. José do Rio Preto }\end{array}$ & - & $\begin{array}{l}- \\
- \\
\end{array}$ & $\begin{array}{l}- \\
- \\
\end{array}$ & $\begin{array}{l}1,21 \\
0,16 \\
0,07 \\
\end{array}$ & $\begin{array}{l}- \\
- \\
\end{array}$ \\
\hline $\begin{array}{l}\text { Campinas } \\
\text { Jaboticabal } \\
\text { Registro }\end{array}$ & - & - & $\begin{array}{l}- \\
- \\
-\end{array}$ & $=$ & $\begin{array}{l}0,20 \\
0,09 \\
0,14\end{array}$ \\
\hline \multirow[b]{2}{*}{ Centro Produtor Alternativo } & \multicolumn{5}{|c|}{ Centro Processador } \\
\hline & $\begin{array}{l}\text { Mogi } \\
\text { Mirim }\end{array}$ & Orlândia & Ourinhos & \multicolumn{2}{|c|}{ Pindamonhangaba } \\
\hline $\begin{array}{l}\text { Araraquara } \\
\text { Jaboticabal } \\
\text { Limeira }\end{array}$ & $\begin{array}{l}0,86 \\
0,65 \\
0,23 \\
\end{array}$ & $\begin{array}{l}- \\
- \\
\end{array}$ & $\begin{array}{l}- \\
- \\
\end{array}$ & \multicolumn{2}{|c|}{$\begin{array}{l}- \\
- \\
-\end{array}$} \\
\hline $\begin{array}{l}\text { Franca } \\
\text { Jaboticabal } \\
\text { Orlândia }\end{array}$ & - & $\begin{array}{l}3,63 \\
2,76 \\
2,77\end{array}$ & $\begin{array}{l}- \\
- \\
\end{array}$ & \multicolumn{2}{|c|}{$\begin{array}{l}- \\
-\end{array}$} \\
\hline $\begin{array}{l}\text { Botucatu } \\
\text { Lins } \\
\text { S. José Rio Preto }\end{array}$ & - & - & $\begin{array}{l}0,29 \\
0,33 \\
0,07\end{array}$ & \multicolumn{2}{|c|}{-} \\
\hline $\begin{array}{l}\text { Araraquara } \\
\text { Limeira } \\
\text { Pindamonhangaba }\end{array}$ & - & $\begin{array}{l}- \\
- \\
-\end{array}$ & $\begin{array}{l}- \\
- \\
- \\
\end{array}$ & \multicolumn{2}{|c|}{$\begin{array}{l}0,94 \\
0,69 \\
0,01 \\
\end{array}$} \\
\hline \multirow[b]{2}{*}{ Centro Produtor Alternativo } & \multicolumn{5}{|c|}{ Centro Processador } \\
\hline & Piracicaba & $\begin{array}{l}\text { Presidente } \\
\text { Prudente }\end{array}$ & $\begin{array}{l}\text { Presidente } \\
\text { Venceslau }\end{array}$ & Registro & $\begin{array}{c}\text { Ribeirão } \\
\text { Preto }\end{array}$ \\
\hline $\begin{array}{l}\text { Barretos } \\
\text { Jaboticabal } \\
\text { Limeira }\end{array}$ & $\begin{array}{l}0,28 \\
0,32 \\
0,35\end{array}$ & $\begin{array}{l}- \\
- \\
-\end{array}$ & 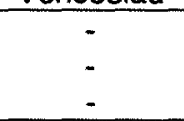 & - & $\begin{array}{l}- \\
- \\
-\end{array}$ \\
\hline $\begin{array}{l}\text { Araçatuba } \\
\text { Presidente Prudente } \\
\text { Tupã }\end{array}$ & $\begin{array}{l}- \\
- \\
\end{array}$ & $\begin{array}{l}1,13 \\
0,24 \\
1,08 \\
\end{array}$ & 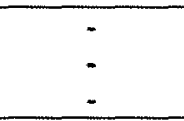 & - & - \\
\hline $\begin{array}{l}\text { Andradina } \\
\text { Dracena } \\
\text { General Salgado }\end{array}$ & - & - & $\begin{array}{l}0,09 \\
0,10 \\
0,49\end{array}$ & $\begin{array}{l}- \\
- \\
-\end{array}$ & $\begin{array}{l}- \\
-\end{array}$ \\
\hline $\begin{array}{l}\text { Araraquara } \\
\text { Barretos } \\
\text { Catanduva }\end{array}$ & - & - & $\dot{-}$ & $\begin{array}{l}3,97 \\
0,01 \\
2,83\end{array}$ & $\begin{array}{l}- \\
-\end{array}$ \\
\hline $\begin{array}{l}\text { Fernandópolis } \\
\text { General Salgado } \\
\text { S. José do Rio Preto }\end{array}$ & - & - & - & - & $\begin{array}{l}7,65 \\
7,97 \\
1,57\end{array}$ \\
\hline
\end{tabular}




\begin{tabular}{|c|c|c|c|c|}
\hline \multirow[b]{2}{*}{ Centro Produtor Alternativo } & \multicolumn{4}{|c|}{ Centro Processador } \\
\hline & $\begin{array}{c}\text { S. João da Boa } \\
\text { Vista }\end{array}$ & $\begin{array}{l}\text { S. José do Rio } \\
\text { Preto }\end{array}$ & São Paulo & Sorocaba \\
\hline $\begin{array}{l}\text { Araraquara } \\
\text { Barretos } \\
\text { Jales } \\
\end{array}$ & $\begin{array}{l}3,65 \\
2,10 \\
2,14 \\
\end{array}$ & $\begin{array}{l}- \\
- \\
- \\
\end{array}$ & 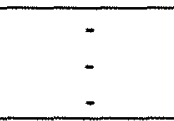 & :- \\
\hline $\begin{array}{l}\text { Barretos } \\
\text { Catanduva } \\
\text { Votuporanga }\end{array}$ & $\begin{array}{l}- \\
- \\
\end{array}$ & $\begin{array}{l}0,84 \\
1,88 \\
5,03 \\
\end{array}$ & $\begin{array}{l}- \\
- \\
-\end{array}$ & $\begin{array}{l}- \\
- \\
\end{array}$ \\
\hline $\begin{array}{l}\text { Araraquara } \\
\text { Barretos } \\
\text { Mogi Mirim } \\
\end{array}$ & - & $\div$ & $\begin{array}{l}0,01 \\
0,02 \\
0,81\end{array}$ & $\begin{array}{l}- \\
- \\
-\end{array}$ \\
\hline $\begin{array}{l}\text { Barretos } \\
\text { Catanduva } \\
\text { Itapetininga }\end{array}$ & & & & $\begin{array}{l}0,40 \\
0,86 \\
0,02 \\
\end{array}$ \\
\hline \multirow[b]{2}{*}{ Centro Produtor Alternativo } & \multicolumn{4}{|c|}{ Centro Processador } \\
\hline & \multicolumn{2}{|c|}{ Tupã } & \multicolumn{2}{|c|}{ Votuporanga } \\
\hline $\begin{array}{l}\text { Barretos } \\
\text { Catanduva } \\
\text { Lins } \\
\end{array}$ & \multicolumn{2}{|c|}{$\begin{array}{l}1,14 \\
1,78 \\
0,37 \\
\end{array}$} & \multicolumn{2}{|c|}{$\begin{array}{l}- \\
- \\
\end{array}$} \\
\hline $\begin{array}{l}\text { Barretos } \\
\text { Jales } \\
\text { S. José do Rio Preto }\end{array}$ & \multicolumn{2}{|c|}{ 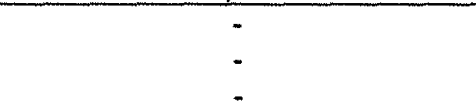 } & \multicolumn{2}{|c|}{$\begin{array}{l}2,73 \\
1,95 \\
1,03\end{array}$} \\
\hline
\end{tabular}

Quadro 16 - Custos marginais de transporte, em Reais por tonelada transportada, cenário 4.

Fonte: Dados da pesquisa. 


\section{Conclusões}

Com a implantação da indústria de suco concentrado no Estado de São Paulo, iniciada em meados da década de 60 , ocorreu uma profunda alteração na estrutura de comercialização de laranja. A indústria processadora transformou-se no pólo dinâmico do setor, subordinando a produção paulista à sua demanda. Ademais, a indústria passou a ser, também, a fonte indutora da evolução da citricultura no Estado, uma vez que sua expansão se fez, principalmente, por meio de variedades apropriadas ao processamento, tais como Pera, Natal e Valência. Dessa forma, a disponibilidade interna de laranja passou a ser direcionada, primordialmente, pelas necessidades e demandas da indústria.

De acordo com Neves et al. (1995), no período compreendido entre 1973 e 1982, o continente europeu destacou-se como o maior importador (54\%) de suco de laranja concentrado, sendo seguido pelos Estados Unidos (32\%). No entanto, na década de 80 , os Estados Unidos, em virtude das freqüentes geadas na Flórida e da elevada demanda interna, transformaram-se no maior importador de suco de laranja concentrado brasileiro (47\%). Nesta época, as altas cotações do suco de laranja no mercado internacional estimularam os citricultores brasileiros a realizar novos plantios, que ocorreram de forma acelerada e desordenada.

A recuperação dos pomares da Flórida, baseada no deslocamento da produção para áreas menos sujeitas a geadas e no adensamento do plantio, aliada ao crescimento da produção brasileira, gerou um grande aumento na oferta internacional de laranja, levando a uma queda nas cotações internacionais do produto. Conseqüentemente, na década de 90 , houve uma forte redução nos preços pagos aos produtores, em relação aos elevados valores observados no final da década de 80 .

Dessa forma, um dos maiores problemas com o qual os citricultores passaram a se deparar na década de 90 foi, justamente, o excesso de oferta de laranja 
para o processamento. Estatísticas da ABECITRUS mostram que durante essa década houve um crescimento de $2,62 \%$ na produção paulista, enquanto o processamento industrial cresceu a uma taxa de $2,14 \%$ ao ano. Esta situação tem despertado o interesse do governo e do setor no sentido de buscar alternativas para contornar este problema, o que pode ser alcançado por meio da redução do crescimento da produção, do desenvolvimento e fortalecimento do mercado interno de laranjas e do aumento das exportações de suco concentrado.

O mercado interno de laranja in natura pagou um alto preço nas últimas décadas, em face do privilégio dado às exportações de suco concentrado. Para grande parte dos citricultores, o mercado de laranja in natura passou a ser considerado residual, ou seja, visto como uma alternativa nos momentos em que o preço do suco concentrado no mercado internacional sofria reduções significativas. Trata-se, portanto, de um setor que observa aumentos esporádicos, apresenta baixa profissionalização e cujo desenvolvimento tecnológico é bastante lento. Este fato pode ser constatado, por exemplo, no acondicionamento da fruta para a comercialização, que ainda é feita em caixas de madeira - técnica utilizada desde a década de 50 . Outro exemplo é a padronização da fruta que, quando feita, é realizada com critérios bastante subjetivos.

Devido a essas razões expostas, este início de novo século não parece ser um momento muito favorável aos agentes envolvidos com o sistema agroindustrial citricola. No entanto, a despeito da situação problemática em que a citricultura paulista está inserida, o mercado interno de laranja in natura emerge como a grande oportunidade para que o setor consiga superar as dificuldades com as quais se depara neste momento, pois trata-se de um amplo mercado a ser explorado, capaz de consumir boa parcela da produção. Para tanto, o setor necessita de uma melhor estrutura, profissional e moderna, de forma que as deficiências relacionadas, principalmente, à padronização da fruta, à logística de distribuição, à falta de união e profissionalismo dos produtores, à ausência de marketing e à falta de foco nas vendas para o mercado interno sejam superadas.

Neste sentido, a avaliação da localização de packing-houses de laranja torna-se interessante, uma vez que um dos principais gargalos do setor refere-se aos custos associados à movimentação do produto, que têm consumido cerca de $4 \%$ do faturamento total deste sistema agroindustrial e de 8 a $16 \%$ do valor do produto final. 
A presente pesquisa teve como objetivo analisar a distribuição espacial dos packing-houses no Estado de São Paulo, de modo a se obter a minimização dos custos de transporte, processamento e implantação de plantas processadoras de laranja, bem como o porte ideal dessas plantas e a capacidade de processamento ótima em cada região do Estado. Para tanto, utilizou-se, como referencial teórico, a teoria da localização, desenvolvida inicialmente por Weber e aprimorada através da evolução da programação matemática e dos avanços computacionais. Cabe destacar que o modelo proposto restringiu-se apenas ao mercado de laranja in natura, desconsiderando, portanto, a capacidade instalada das indústrias e o volume de laranja exportado, tanto para os demais estados brasileiros quanto para outros países.

O estudo desenvolvido considerou quatro cenários, relacionados ao número de plantas instaladas numa dada região do Estado de São Paulo. De acordo com resultados obtidos, observou-se uma tendência à implantação de packing-houses de grande porte (de 500 mil a 1 milhão de caixas/ano), o que possibilita uma razoável economia de escala no processamento. A localização dessas unidades priorizou áreas intermediárias, ou seja, aquelas que apresentam proximidade em relação aos centros produtores e aos mercados consumidores ao mesmo tempo. Contudo, verificou-se que as regiões que apresentam essa característica não fazem parte do "cinturão citrícola", área que abriga os maiores centros produtores. Além disso, essas áreas intermediárias são bem próximas aos centros de consumo mais expressivos do Estado, o que permite concluir que a solução sugerida pelo modelo de otimização enfatizou a proximidade em relação aos centros demandantes.

Um ponto importante refere-se ao transporte inter-regional, que é observado principalmente em centros de processamento que se localizam em áreas que não são consideradas como grandes centros de produção. Nos cenários 1 e 2 , que consideraram a demanda atual do Estado de São Paulo, observou-se que apenas 12 plantas seriam suficientes para processar o volume total de laranja demandado pelo Estado. Nos cenários 3 e 4, em que se adotou a hipótese de que a demanda interna de São Paulo seria equivalente à oferta estadual de laranja para mercado interno, verificou-se que haveria a necessidade de se instalar 81 e 103 packing-houses, respectivamente. Dessa forma, pode-se concluir que o número de unidades beneficiadoras existentes atualmente no Estado (cerca de 400) é muito superior à sua real necessidade. 
Este estudo apresenta algumas limitações, as quais derivam de algumas pressuposições básicas, características de modelos de localização. A primeira delas diz respeito à oferta e à demanda, que foram consideradas como parâmetros fixos, ou seja, inelásticos em relação à variações de preços. Isso fez com que a análise realizada apresentasse um caráter estático, não fornecendo nenhum elemento acerca do comportamento da oferta e da demanda ao longo do tempo. Indubitavelmente, o procedimento mais adequado seria a utilização de curvas de oferta e de demanda para cada região do Estado de São Paulo, principalmente porque os padrões de oferta de laranja estão sempre sofrendo alterações em função da demanda da indústria. Além disso, a adoção de curvas de oferta e de demanda poderia captar mais facilmente as alterações nos padrões de produção e de consumo, o que tornaria a análise mais dinâmica. No entanto, a indisponibilidade de informações, relativas a curvas de oferta e demanda para cada uma das regiōes consideradas, fez com que se optasse por definir a oferta e a demanda de cada uma delas como fixas. Dessa forma, é interessante incluir, em análises futuras, estimativas referentes às curvas de demanda e de oferta de cada região considerada.

Outra limitação refere-se ao fato do modelo proposto ter considerado apenas o mercado de laranja in natura, desconsiderando, portanto, a capacidade instalada das plantas industriais e o volume de laranja destinado à exportação, tanto para os demais estados brasileiros quanto para outros países. A exclusão da indústria deve-se à dificuldade de obtenção de dados relativos a custos, uma vez que o segmento considera este tipo de informação como sigilosa. Da mesma forma, a não inclusão do volume de laranja destinado à exportação para os demais estados da federação justifica-se em função da dificuldade de obtenção destes dados, que poderiam ser estimados a partir da quantidade de laranja recebida pelas Centrais de Abastecimento. Contudo, grande parte destas centrais armazenam estas informações por um período de tempo muito curto, tornando-as indisponiveis. A exclusão destas duas variáveis pode ter subestimado os resultados relativos ao número de plantas instaladas no Estado, à capacidade de processamento das regiões, ao porte das plantas e à distribuição espacial dos packing-houses, que poderiam estar mais próximos à indústria - grande centro de demanda. Assim, é importante considerar, em estudos futuros, a influência das exportações e da indústria processadora na localização dos packing-houses. 
A falta de precisão das informações relativas ao custo de implantação de packing-houses constituiu-se em outra limitação deste estudo, uma vez que a tecnologia adotada pelas empresas fabricantes de equipamentos, bem como 0 segmento de mercado que desejam atingir, fazem com que o custo de aquisição do maquinário empregado no beneficiamento da laranja oscile muito de uma empresa para outra. Sugere-se, portanto, que em trabalhos futuros caracterize-se melhor o custo de implantação, padronizando uma tecnologia e realizando levantamentos junto a empresas que se encaixem no perfil adotado. Tal recomendação também é válida para os custos de processamento, cujos valores apresentaram pouca precisão em virtude da avaliação desses custos, num packing-house, ser pouco praticada e difícil de ser contabilizada.

Vale ressaltar que os modelos de localização não consideram a importância de fatores exógenos, sendo que a localização ótima da firma é obtida apenas para o local de mínimo custo. Portanto, sugere-se, em estudos futuros, a inclusão de outras variáveis relevantes na localização das plantas, tais como privilégios fiscais e serviços adicionais.

Finalmente, apesar das limitações mencionadas, é importante frisar que os modelos de localização podem ser considerados como um importante instrumento de política pública, bem como um ferramental para a decisão empresarial, já que os resultados obtidos podem orientar os agentes em relação à instalação de futuras unidades de beneficiamento. Além disso, podem auxiliar na identificação de áreas potenciais para o estabelecimento de firmas, assim como o porte e capacidade ótima de processamento de tais plantas. Em suma, os modelos de localização são capazes de sugerir a maneira mais eficaz de se estruturar as atividades econômicas, fornecendo o número, o porte, a capacidade produtiva e a localização ótima das empresas, conferindo-Ihes maior competitividade. 


\section{REFERÊNCIAS BIBLIOGRÁFICAS}

AGROANALYSIS. Citricultura: estatísticas da atividade. São Paulo, v.19, n.3, p. 2832, maio 1999.

ALMEIDA, L. A. S. B. Viabilidade econômica e localização de unidades produtoras de farinha de milho para utilização em mistura com o no estado de São Paulo. Piracicaba, 1981. 159p. Dissertação (M.S.) - Escola Superior de Agricultura "Luiz de Queiroz", Universidade de São Paulo.

AMARO, A. A.; SILVA, J. F. G.; PERES, M. C.; LARSON, D. W. Desenvolvimento da citricultura e localização de novas indústrias para o processamento no estado de São Paulo. Piracicaba: ESALQ, Departamento de Economia e Administração e Sociologia, 1973. 78p. (Série Pesquisa, 22)

AMARO, A. A. Comercialização de citros. In: RODRGUEZ, O.; VIÉGAS, F.; POMPEU JÚNIOR, J.; AMARO, A. A. Citricultura brasileira. Campinas: Fundação Cargill, 1991. v.1, p. 55-81.

AMARO, A. A.; MAIA, M. L. Produção e comércio de laranja e de suco no Brasil. Informações Econômicas, v.27, n.7, p.11-23, jul. 1997.

AMARO, A. A.; MAIA, M. L.; RAGA, A et al. Repensando a agricultura paulista: cadeia produtiva das frutas. São Paulo: Secretaria da Agricultura e Abastecimento, 1997. 70p. 
ASSOCIAÇÃO BRASILEIRA DOS EXPORTADORES DE CÍTRICOS - ABECITRUS. http://www.abecitrus.com.br. (2000-2001)

AZZONI, C.R. Teoria da localização: uma análise crítica. São Paulo: IPE/USP, 1982. 200p.

BABCOCK, M. W.; CRAMER, G. L; NELSON, W. A. The impact of transportation rates on the location of the wheat flour milling industry. Agribusiness: an International Journal, v.1, n.1, p.61-71, Spring 1985.

BERGER, R. Minimização do custo de transporte de madeira de eucalipto no estado de São Paulo. Piracicaba, 1975. 122p. Dissertação (M.S.) - Escola Superior de Agricultura "Luiz de Queiroz", Universidade de São Paulo.

BOTEON, M. Mercado interno de frutas cítricas. Piracicaba, 1999. 80p. Dissertação (M. S.) - Escola Superior de Agricultura "Luiz de Queiroz", Universidade de São Paulo.

BROWN, E.; FATHI, Y.; SOWELL, R. Linear programming applied to a facility location problem. Applied Engineering in Agriculture, v.12, n.1, p.105-110, jan. 1996.

CANZIANI, J. R. F. Simulação sobre a implantação da indústria de suco concentrado de laranja no estado do Paraná. Piracicaba, 1991. 111p. Dissertação (M. S.) Escola Superior de Agricultura "Luiz de Queiroz", Universidade de São Paulo.

COMPANHIA DE ENTREPOSTOS E ARMAZÉNS GERAIS DO ESTADO DE SÃO PAULO. Centro de Qualidade em Horticultura $(\mathrm{CQH})$ : Programa automatizado contendo informações referentes a volume comercializado, origem e preços de laranja no ano de 1998. São Paulo: CEAGESP, 2000. 1 disquete.

COMPANHIA DE ENTREPOSTOS E ARMAZÉNS GERAIS DO ESTADO DE SÃO PAULO - CEAGESP. http://www.ceagesp.com.br. (abril/2000) 
COORDENADORIA DE ASSISTÊNCIA TÉCNICA INTEGRAL - CATI. http://www.cati.sp.gov.br. (abril/2000).

DURHAM, C. A.; SEXTON, R.J.; SONG, J.H. Spatial competition, uniform pricing and transportation efficiency in the California processing tomato industry. American Journal of Agricultural Economics, v.78, n.1, p.115-125, Feb. 1996.

FOOD AND AGRICULTURE ORGANIZATION - FAO. http://www.fao.org. (2001).

FUNDAÇÃO SISTEMA ESTADUAL DE ANÁLISE DE DADOS - FUNDAÇÃO SEADE. http://www.seade.gov.br. (abril/2000)

GENERAL ALGEBRAIC MODELING SYSTEM - GAMS, versão 2.25: programa de otimização (software). Washington DC, 1992.

HARDER, W.C. Normas de classificação e seus impactos na coordenação do sistema agroindustrial da laranja de nessa. Piracicaba, 1998 . 75p. Monografia (Graduação) - Escola Superior de Agricultura "Luiz de Queiroz", Universidade de São Paulo.

IANNINI, P. L. Mercado interno de frutas frescas. Laranja, v.10, n.1, p. 71-81, 1989.

INSTITUTO BRASILEIRO DE GEOGRAFIA E ESTATISTIICA - IBGE. Pesquisa de Orçamentos Familiares 1987/88. Rio de Janeiro: IBGE, 1991. 564p.

INSTITUTO BRASILEIRO DE GEOGRAFIA E ESTATISTTICA - IBGE. Pesquisa de Orçamentos Familiares 1995/96. Rio de Janeiro: IBGE, 1999. 3v.

INSTITUTO DE ECONOMIA AGRÍCOLA. Informações estatísticas da agricultura: Anuário IEA. São Paulo: IEA, 2000. 222p.

INSTITUTO DE ECONOMIA AGRÍCOLA - IEA. http://www.iea.sp.gov.br. (2000-2001) 
KELLERMAN, A. Agricultural location theory 1: basic models. International Journal of Urban and Regional Research, v.21, n.10, p.1381-1896, 1989.

KILMER, R. L.; SPREEN, T.; TILLEY, D.S. A dynamic plant location model: the east Florida fresh citrus packing industry. American Journal of Agricultural Economics, v.46, n.1, p.94-108, 1964.

KING, G. A.; LOGAN, S. H. Optimum location, number and size of processing plants with raw product and final product shipments. Journal of Farm Economics, v.65, n. 4, p.730-737, 1976.

KOTLER, P. Administração de marketing: análise, planejamento, implementação e controle. 4 ed. São Paulo: Atlas, 1994. 676p.

LOPES, R. L. Suinocultura no estado de Goiás: aplicação de um modelo de localização. Piracicaba, 1997. 95p. Dissertação (M.S.) - Escola Superior de Agricultura "Luiz de Queiroz", Universidade de São Paulo.

MAIA, M. L. Citricultura paulista: evolução, estrutura a acordos de preços. São Paulo: Instituto de Economia Agrícola, 1996. 157p. (Coleção Estudos Agrícolas, 4)

MARTINELLI JÚNIOR, O. O complexo agroindustrial no Brasil: um estudo sobre a agroindústria citrícola no estado de São Paulo. São Paulo, 1987. 275p. Dissertação (M.S) - Faculdade de Economia e Administração, Universidade de São Paulo.

NEVES, E. M.; POMPEU, R. B.; NEVES, M. F.; POMPEU JÚNIOR, J. A laranja no estado de São Paulo: produção regional, destino e mercados. Laranja, v.16, n.2, p.37-85, 1995.

NEVES, E.M. Economia citrícola: você a conhece? Notesalq, v.9, n.1, p.3, mar. 2000. 
NEVES, E. M.; DRAGONE, D.; NEVES, M.F.; BOTEON, M. Conhecendo a citricultura: impactos alocativos, mercado, preços. Piracicaba: ESALQ - Departamento de Economia Administração e Sociologia, 2001. 1 disquete.

NEVES, M. F. Um modelo para planejamento de canais de distribuição no setor de alimentos. São Paulo, 1999. 297p. Tese (Doutorado) - Faculdade de Economia, Administração e Contabilidade, Universidade de São Paulo.

PETTO NETO, A.; POMPEU JÚNIOR, J. Colheita, beneficiamento e transporte. In: RODRGUEZ, O.; VIÉGAS, F.; POMPEU JÚNIOR, J.; AMARO, A. A. Citricultura brasileira. Campinas: Fundação Cargill, 1991. v.2, p.892-897.

SABOYA, L. V. A dinâmica locacional da avicultura e suinocultura no Centro-Oeste brasileiro. Piracicaba, 2001. 146p. Dissertação (M. S.) - Escola Superior de Agricultura "Luiz de Queiroz", Universidade de São Paulo.

SÃO PAULO (Estado). Secretaria de Agricultura e Abastecimento. Instituto de Economia Agrícola. Escritórios de Desenvolvimento Rural e Regionais Agrícolas. São Paulo, 2000. 16p.

SISTEMA DE INFORMAÇÕES DE FRETES E CARGAS AGRICOLAS - SIFRECA. Infoguia 2.0. Programa automatizado para o gerenciamento de rotas rodoviárias (software). São Paulo: CEPEA/ESALQ/USP, 2000.

SNYDER, S. A.; TYRRELL, L. E.; HAIGHT, R. G. An optimization approach to selecting research natural areas in national forests. Forest Science, v.45, n.3, p.458-468, 1999.

STEMBERGER, A. P. Evaluating the competitive position of North Caroline eggs by use of the transportation model. Journal of Farm Economics, v.41, n.4, p.790-798, Nov. 1959. 
STOLLSTEIMER, J. F. A working model for plant numbers and location. Journal of Farm Economics, v.45, n.3, p.631-645, Aug. 1963.

WEST, D. A.; BRADOW, G. E. Space product equilibrium in the dairy industry of Northeastern and North central region. Journal of Farm Economics, v.45, n.4, p.719-731, Nov. 1964.

ZYLBERSZTAJN, D. Estruturas de governança e coordenação do agribusiness: uma aplicação da nova economia das instituições. São Paulo, 1995. 238p. Tese (LivreDocência) - Faculdade de Economia e Administração, Universidade de São Paulo. 


\section{APÊNDICES}




\section{APÊNDICE 1 : Questionário aplicado junto a atacadistas da CEAGESP.}

Data:

Empresa:

Box:

Tel:

Fax:

1) Informações Gerais

1. Em que município se localiza o packing-house?

2. Qual a sua capacidade?

( ) até 50 mil caixas/ano

( ) de 50 a 100 mil caixas/ano

( ) de 100 a 250 mil caixas/ano

( ) de 250 a 500 mil caixas/ano

( ) de 500 a 1.000 mil caixas/ano

( ) de 1.000 a 2.000 mil caixas/ano

( ) de 2.000 a 3.000 mil caixas/ano

( ) de 3.000 a 4.000 mil caixas/ano

( ) de 4.000 a 5.000 mil caixas/ano

( ) mais de 5.000 mil caixas/ano

3. Em que época a laranja é processada?

4. Quanto se perde no processamento?

5. Processa algum outro produto além da laranja?

( ) Não

( ) Sim

Quais?

6. Seu produto apresenta algum diferencial?

( ) Não

( ) Sim

Qual?

7. O packing-house fica na área de produção?

( ) Sim

( ) Não Onde?

8. Qual o motivo que o levou a esta escolha?

( ) Proximidade da produção

( ) Proximidade do mercado consumidor

( ) Outros

9. Compra de terceiros?

( ) Sim

( ) Não

10. Os fornecedores são fixos?

( ) $\operatorname{Sim}$

( ) Não

11. Como os fornecedores de matéria-prima são selecionados?

( ) Distância ( ) Preço ( ) Qualidade do produto

( ) Outros 
12. Quais os principais mercados consumidores e sua localização geográfica?
( ) Supermercado
( ) Cozinha industrial
( ) Restaurante
( ) Quitanda
( ) Rede de distribuição
() Outros CEASAS
( ) Varejão
() Ambulante
( ) Feira
( ) Outros:
( ) Estados:

13. Tipo de contrato com o produtor e com o comprador:
( ) verbal
( ) formal

14. Estrutura de comercialização

( ) Verticalizado (produção, processamento e venda)

( ) Processamento e venda

( ) Produção e processamento

( ) Outros

II) Custos

1. Custos de transporte (por km, caixa ou peso?).

a) Da fazenda ao packing-house: $R \$$

b) Do packing-house ao mercado consumidor: $R \$$

2. Custos Operacionais (Tabela em anexo).

a) Instalação (orçamento): $\mathrm{R} \$$

b) Processamento: $R \$$

III) Embalagem

1. Qual o tipo de embalagem utilizada?
( ) Caixa "M"
( ) Bin
( ) Saco plástico
( ) Outras:

2. Custo da embalagem: $R \$$
3. Existe retorno de embalagens?
( ) Não
( ) Sim

4. De quem é a responsabilidade pelo frete de devolução?

( ) Do vendedor

5. Quantas caixas são perdidas por mês?

6. Qual a despesa mensal com reparos? R\$

IV) Máquinário de beneficiamento

1. Como é feita a classificação?

( ) máquina de classificação

( ) manualmente

2. Valor da máquina classificadora : $R \$$ 
3. Tipo:

( ) Eletrônica

( ) Mecânica

( ) Outros

4. Critério de classificação:

() Cor () Tamanho ( ) Diâmetro ( )Peso ( )
Outros

5. Tempo de utilização: anos.

6. A manutenção é periódica?

( ) Não

( ) Sim Qual a freqüência? 


\section{APÊNDICE 2: Comandos utilizados no software GAMS para a formulação do cenário 1.}

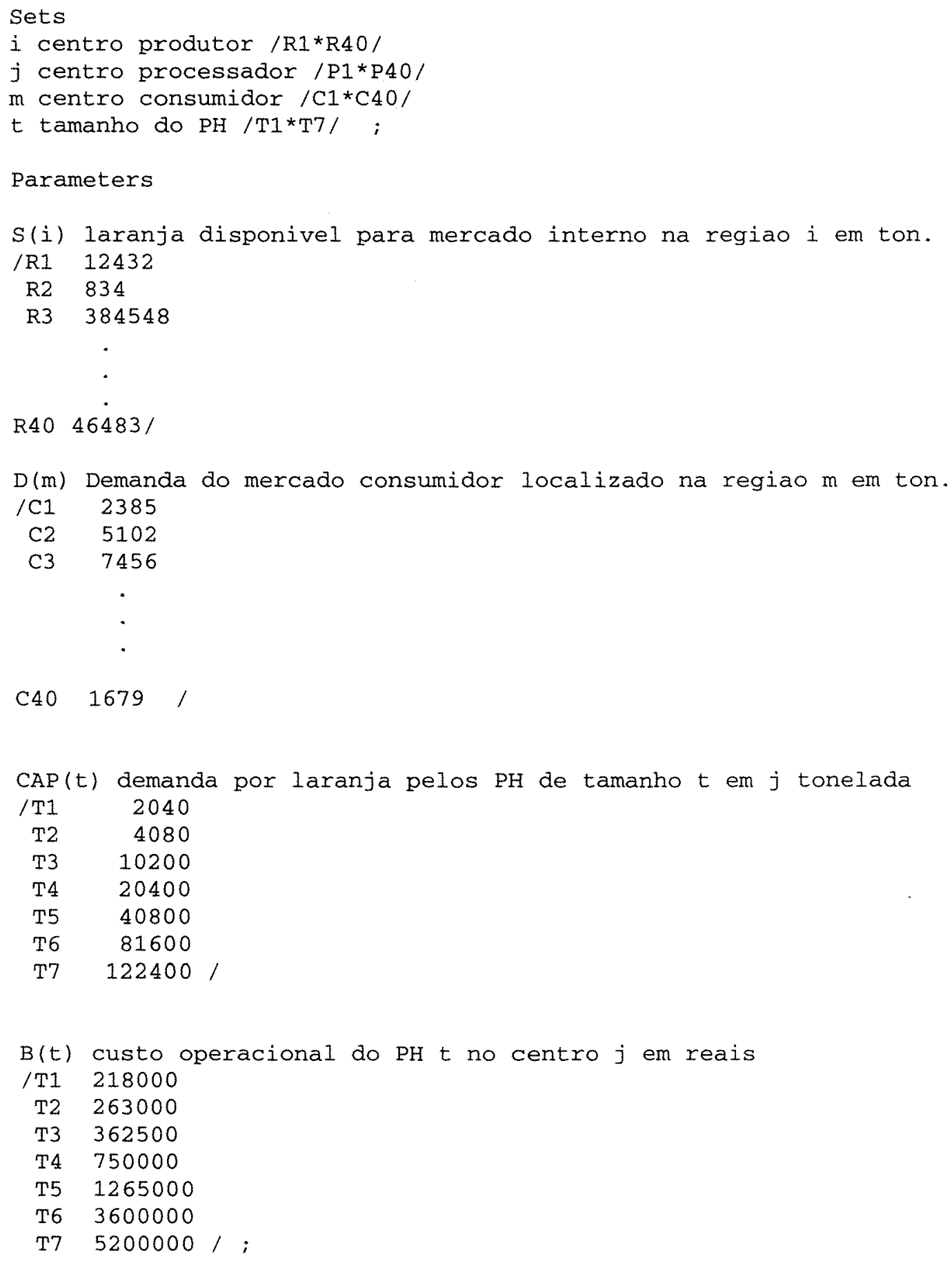


Table $A(i, j)$ custo de transporte de $i$ a $j$ em reais por ton.

$\begin{array}{lccccc} & \text { P1 } & \text { P2 } & \text { P3 } & \ldots & \text { P10 } \\ \text { R1 } & 3.75 & 8.03 & 19.39 & \ldots & 25.32 \\ \text { R2 } & 8.03 & 3.75 & 15.01 & \ldots & 21.04 \\ \text { R3 } & 19.39 & 15.01 & 3.75 & \ldots & 10.96 \\ . & . & . & . & . & . \\ . & . & . & . & . & . \\ . & . & . & . & . & . \\ \text { R40 } & 12.52 & 8.84 & 13.65 & \ldots & 20.90\end{array}$

\begin{tabular}{|c|c|c|c|c|c|}
\hline & P11 & P12 & P13 & $\ldots$ & P20 \\
\hline R1 & 15.58 & 6.63 & 11.10 & $\ldots$ & 9.67 \\
\hline R2 & 11.25 & 9.67 & 8.98 & $\ldots$ & 8.02 \\
\hline R3 & 8.02 & 20.76 & 15.01 & $\cdots$ & 16.43 \\
\hline - & - & - & - & • & - \\
\hline$\cdot$ & - & - & . & - & . \\
\hline R40 & 9.27 & 14.87 & 4.44 & $\cdots$ & 5.70 \\
\hline \multicolumn{6}{|l|}{+} \\
\hline & P21 & P22 & P23 & $\ldots$ & P30 \\
\hline RI & $17: 91$ & 24.02 & 11.78 & $\ldots$ & 23.45 \\
\hline R2 & 13.24 & 19.10 & 7.07 & $\cdots$ & 18.22 \\
\hline \multirow[t]{3}{*}{ R3 } & 6.33 & 8.84 & 11.39. & $\cdots$ & 9.13 \\
\hline & - & $\cdot$ & $\cdot$ & $\cdot$ & $\cdot$ \\
\hline & - & - & $\cdot$ & - & - \\
\hline \multirow[t]{3}{*}{$\mathrm{R} 40$} & 15.01 & 18.67 & 10.96 & $\cdots$ & 19.10 \\
\hline & + & & & & \\
\hline & P31 & P32 & P33 & $\cdots$ & P40 \\
\hline R1 & 10.44 & 8.57 & 29.37 & $\cdots$ & 12.52 \\
\hline R2 & 10.19 & 12.28 & 26.05 & $\cdots$ & 8.82 \\
\hline R3 & 19.39 & 18.96 & 6.78 & $\ldots$ & 13.65 \\
\hline • & · & $\cdot$ & • & $\cdot$ & - \\
\hline - & . & . & . & . & - \\
\hline R40 & 14.58 & 16.72 & 28.50 & $\ldots$ & 3.75 \\
\hline
\end{tabular}


Table $E(j, m)$ custo de transporte de $j$ a $m$ em reais por ton.

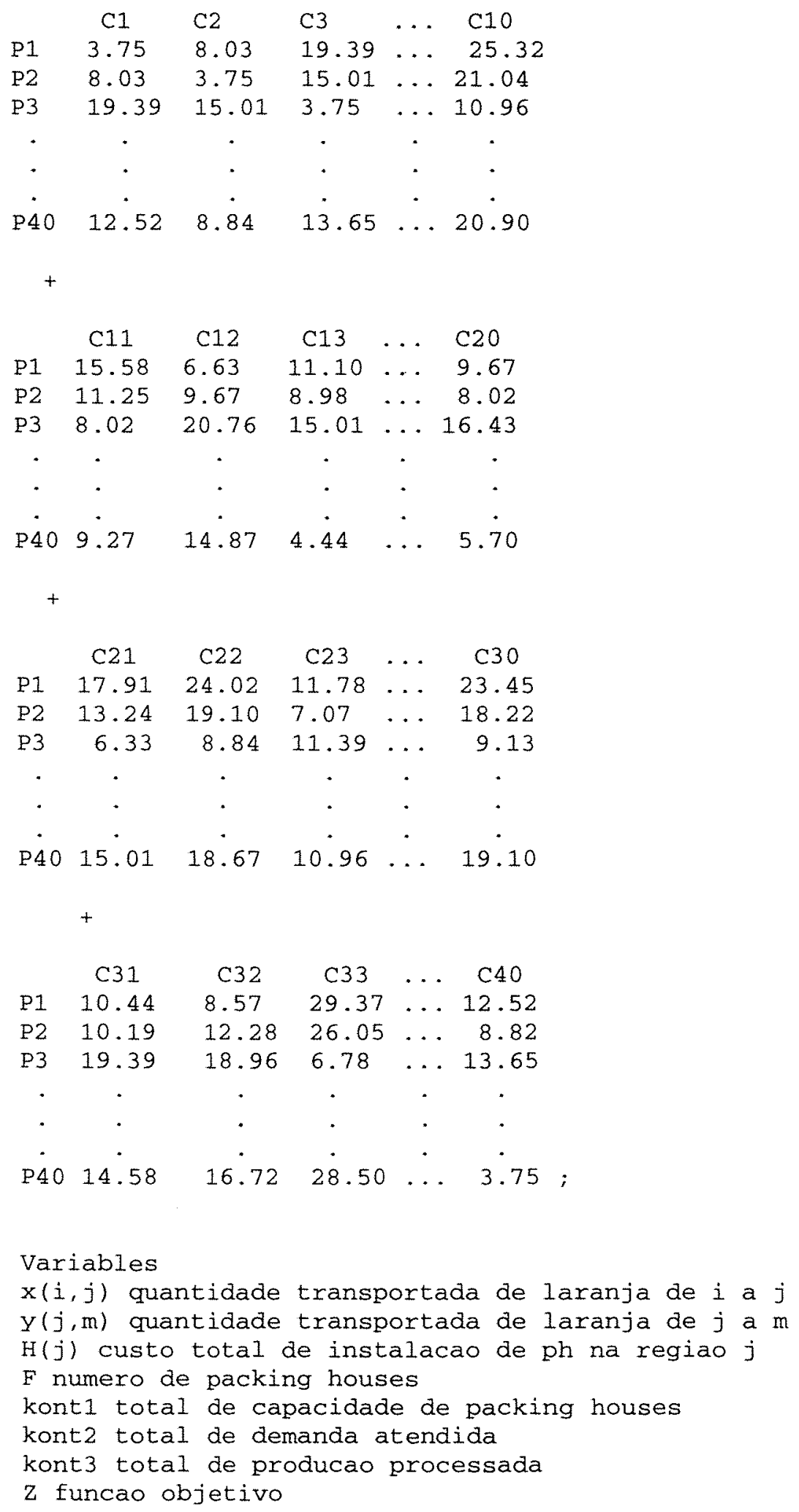




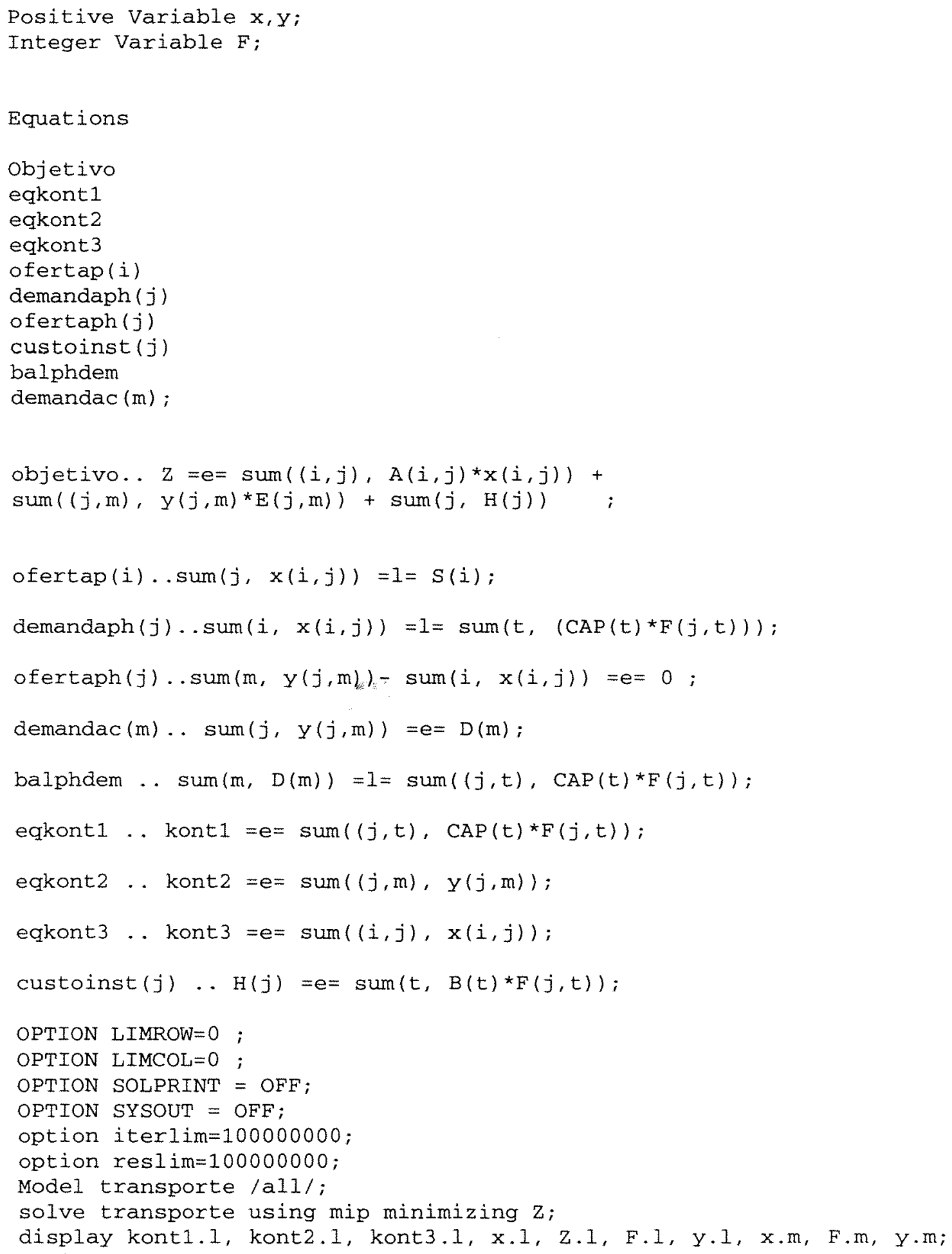

